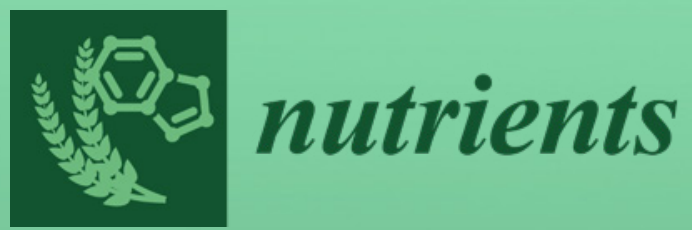


Effects of Iodine Intake on Human Health 



\section{Effects of Iodine Intake on Human Health}

Editors

Daniela Bonofiglio

Stefania Catalano

MDPI • Basel • Beijing • Wuhan • Barcelona $\bullet$ Belgrade $\bullet$ Manchester $\bullet$ Tokyo $\bullet$ Cluj $\bullet$ Tianjin 


\section{Editors}

Daniela Bonofiglio

University of Calabria

Italy
Stefania Catalano

University of Calabria

Italy

\section{Editorial Office}

MDPI

St. Alban-Anlage 66

4052 Basel, Switzerland

This is a reprint of articles from the Special Issue published online in the open access journal Nutrients (ISSN 2072-6643) (available at: https:/ /www.mdpi.com/journal/nutrients/special_issues/ Iodine_Intake_Human).

For citation purposes, cite each article independently as indicated on the article page online and as indicated below:

LastName, A.A.; LastName, B.B.; LastName, C.C. Article Title. Journal Name Year, Article Number, Page Range.

ISBN 978-3-03936-906-5 (Hbk)

ISBN 978-3-03936-907-2 (PDF)

Cover image courtesy of Daniela Bonofiglio.

(C) 2020 by the authors. Articles in this book are Open Access and distributed under the Creative Commons Attribution (CC BY) license, which allows users to download, copy and build upon published articles, as long as the author and publisher are properly credited, which ensures maximum dissemination and a wider impact of our publications.

The book as a whole is distributed by MDPI under the terms and conditions of the Creative Commons license CC BY-NC-ND. 


\section{Contents}

About the Editors $\ldots \ldots \ldots \ldots \ldots \ldots \ldots \ldots \ldots \ldots \ldots \ldots$

Daniela Bonofiglio and Stefania Catalano

Effects of Iodine Intake and Nutraceuticals in Thyroidology: Update and Prospects

Reprinted from: Nutrients 2020, 12, 1491, doi:10.3390/nu12051491 . . . . . . . . . . . . . 1

Renuka Jayatissa, Jonathan Gorstein, Onyebuchi E. Okosieme, John H. Lazarus and Lakdasa D. Premawardhana

Stable Iodine Nutrition During Two Decades of Continuous Universal Salt Iodisation in Sri Lanka

Reprinted from: Nutrients 2020, 12, 1109, doi:10.3390/nu12041109 _ . . . . . . . . . . . . 5

Demetre E. Gostas, D. Enette Larson-Meyer, Hillary A. Yoder, Ainsley E. Huffman and Evan C. Johnson

Dietary Relationship with $24 \mathrm{~h}$ Urinary Iodine Concentrations of Young Adults in the Mountain West Region of the United States

Reprinted from: Nutrients 2020, 12, 121, doi:10.3390/nu12010121 . . . . . . . . . . . . . .

Sohye Kim, Yong Seok Kwon, Ju Young Kim, Kyung Hee Hong and Yoo Kyoung Park

Association between Iodine Nutrition Status and Thyroid Disease-Related Hormone in Korean Adults: Korean National Health and Nutrition Examination Survey VI (2013-2015)

Reprinted from: Nutrients 2019, 11, 2757, doi:10.3390/nu11112757 . . . . . . . . . . . . . . 33

Cinzia Giordano, Ines Barone, Stefania Marsico, Rosalinda Bruno, Daniela Bonofiglio, Stefania Catalano and Sebastiano Andò

Endemic Goiter and Iodine Prophylaxis in Calabria, a Region of Southern Italy: Past and Present Reprinted from: Nutrients 2019, 11, 2428, doi:10.3390/nu11102428 . . . . . . . . . . . . . . 49

Enke Baldini, Camilla Virili, Eleonora D'Armiento, Marco Centanni and Salvatore Ulisse Iodine Status in Schoolchildren and Pregnant Women of Lazio, a Central Region of Italy Reprinted from: Nutrients 2019, 11, 1647, doi:10.3390/nu11071647 . . . . . . . . . . . . .

Lanfranco D'Elia, Galina Obreja, Angela Ciobanu, Joao Breda, Jo Jewell,

Francesco P. Cappuccio and on behalf of the Salt Consumption Survey in the Republic of Moldova Study Group

Sodium, Potassium and Iodine Intake, in a National Adult Population Sample of the Republic of Moldova

Reprinted from: Nutrients 2019, 11, 2896, doi:10.3390/nu11122896 . . . . . . . . . . . . .

Lindsay Ellsworth, Harlan McCaffery, Emma Harman, Jillian Abbott and Brigid Gregg

Breast Milk Iodine Concentration Is Associated with Infant Growth, Independent of Maternal Weight

Reprinted from: Nutrients 2020, 12,358, doi:10.3390/nu12020358 . . . . . . . . . . . . 8

Alexandra C. Purdue-Smithe, Tuija Männistö, Griffith A. Bell, Sunni L. Mumford, Aiyi Liu, Kurunthachalam Kannan, Un-Jung Kim, Eila Suvanto, Heljä-Marja Surcel, Mika Gissler and James L. Mills

The Joint Role of Thyroid Function and Iodine Status on Risk of Preterm Birth and Small for Gestational Age: A Population-Based Nested Case-Control Study of Finnish Women Reprinted from: Nutrients 2019, 11, 2573, doi:10.3390/nu11112573 . . . . . . . . . . . . . . . 
Giuseppe Lisco, Anna De Tullio, Vito Angelo Giagulli, Giovanni De Pergola and Vincenzo Triggiani

Interference on Iodine Uptake and Human Thyroid Function by Perchlorate-Contaminated Water and Food

Reprinted from: Nutrients 2020, 12,1669, doi:10.3390/nu12061669 . . . . . . . . . . . . . . 107

Salvatore Benvenga, Herbert R. Marini, Antonio Micali, Jose Freni, Giovanni Pallio, Natasha Irrera, Francesco Squadrito, Domenica Altavilla, Alessandro Antonelli, Silvia Martina Ferrari, Poupak Fallahi, Domenico Puzzolo and Letteria Minutoli

Protective Effects of Myo-Inositol and Selenium on Cadmium-Induced Thyroid Toxicity in Mice Reprinted from: Nutrients 2020, 12, 1222, doi:10.3390/nu12051222 . . . . . . . . . . . . . . . . . 125

Salvatore Benvenga, Silvia Martina Ferrari, Giusy Elia, Francesca Ragusa, Armando Patrizio, Sabrina Rosaria Paparo, Stefania Camastra, Daniela Bonofiglio, Alessandro Antonelli and Poupak Fallahi

Nutraceuticals in Thyroidology: A Review of in Vitro, and in Vivo Animal Studies

Reprinted from: Nutrients 2020, 12, 1337, doi:10.3390/nu12051337 . . . . . . . . . . . . . . . 141

Salvatore Benvenga, Ulla Feldt-Rasmussen, Daniela Bonofiglio and Ernest Asamoah

Nutraceutical Supplements in the Thyroid Setting: Health Benefits beyond Basic Nutrition

Reprinted from: Nutrients 2019, 11, 2214, doi:10.3390/nu11092214 163 


\section{About the Editors}

Daniela Bonofiglio, an MD endocrinologist, is currently a Full Professor of Biotechnology and Methods in Laboratory Medicine at the Department of Pharmacy, Health and Nutritional Sciences, University of Calabria, Italy. Her scientific interests are devoted to dissecting the molecular mechanisms involved in the initiation and progression of endocrine-related cancers with the main goal to identify novel markers and potential therapeutic targets for these diseases. Her achievements contributed to advancing scientific knowledge on peroxisome proliferator-activated receptor gamma $(\operatorname{PPAR} \gamma)$ biology, focusing on the inhibiting role of natural and synthetic ligands of PPAR $\gamma$ in cancer growth and progression. In the context of the natural products field, her research activity has been also focused on the beneficial role of different food compounds on human health. Specifically, in the last two decades, she investigated the iodine status of young and adult populations living in sufficient and deficient iodine areas. She is the author of more than 80 peer-review papers and 6 book chapters related to the subjects of endocrinology, metabolism, and cancer.

Stefania Catalano, an MD endocrinologist, is currently a Full Professor of Clinical Pathology at the Department of Pharmacy, Health and Nutritional Sciences, University of Calabria, Italy. Her research efforts, which have led to several seminal scientific discoveries, have been mainly dedicated to disclosing the clinically relevant vicious molecular relationship linking obesity and cancer, by deeply investigating the role of adipokines in sustaining tumor growth and progression. Alongside these research activities, her scientific interests have been also devoted to examining different endocrine disorders related to environmental deficiencies, with special attention to the role of iodine on human health. Dr. Catalano has authored more than 100 peer-review papers and 6 book chapters focusing on these specific topics. 

Dedicated to Professor Andò, our brilliant mentor who catalyzes for greatness,

for constantly providing his guidance and support in setting up our own professional and research path.

With warm hearts and sincere gratitude

Daniela \& Stefania 



\title{
Editorial \\ Effects of Iodine Intake and Nutraceuticals in Thyroidology: Update and Prospects
}

\author{
Daniela Bonofiglio ${ }^{1,2, *, \dagger}$ and Stefania Catalano ${ }^{1,2, *, \dagger}$ \\ 1 Department of Pharmacy, Health and Nutritional Sciences, University of Calabria, 87036 Rende (CS), Italy \\ 2 Centro Sanitario, University of Calabria, 87036 Rende (CS), Italy \\ * Correspondence: daniela.bonofiglio@unical.it (D.B.); stefcatalano@libero.it (S.C.); \\ Tel.: +39-0984-496208 (D.B.); Fax: +39-0984-496203 (D.B.) \\ + The Authors contributed equally to the work.
}

Received: 10 May 2020; Accepted: 12 May 2020; Published: 20 May 2020

Iodine is a microelement that is naturally present in some foods, added to others, and available as a dietary supplement. Iodine from the diet is converted into the iodide ion before it is absorbed throughout the gastrointestinal tract $[1,2]$. When iodide enters the circulation, the thyroid gland selectively concentrates it in the appropriate amounts required for thyroid hormone synthesis, and most of the remaining amount is excreted in the urine [3]. The iodine-replete healthy adult has about $15-20 \mathrm{mg}$ of iodine, $70-80 \%$ of which is contained in the thyroid [4]. The estimated average requirement of iodine can be extrapolated from a median urinary iodine concentration of $100 \mu \mathrm{g} / \mathrm{L}$, which corresponds roughly to $150 \mu \mathrm{g}$ daily iodine intake [5]. Median urinary iodine concentrations of $100-199 \mu \mathrm{g} / \mathrm{L}$ in children and adults, $150-249 \mu \mathrm{g} / \mathrm{L}$ in pregnant women and $>100 \mu \mathrm{g} / \mathrm{L}$ in lactating women indicate iodine intakes are adequate [6,7]. Values lower than $100 \mu \mathrm{g} / \mathrm{L}$ in children and non-pregnant adults indicate insufficient iodine intake, although iodine deficiency is not classified as severe until urinary iodine levels are lower than $20 \mu \mathrm{g} / \mathrm{L}$. Seaweed (kelp, nori, kombu, and wakame) is one of the best food sources of iodine, although it is highly variable in its content [8]. Other dietary sources of iodine are seafood, dairy products (partly due to the use of iodine feed supplements and iodophor sanitizing agents in the dairy industry), milk, green beans and eggs [9]. Iodine is also present in human breast milk, in infant formulas and in many multivitamin/mineral supplements, which contain iodine in the forms of potassium iodide or sodium iodide $[7,10,11]$. Over the last years, there has been a growing interest in some nutraceuticals, including selenium, carnitine, myo-inositol, flavonoids, omega-3 polyunsaturated fatty acids, resveratrol and vitamins, for their potential role in thyroid function [12-14]. Nutraceuticals could represent an opportunity in the prevention and treatment of some thyroid diseases, even though their effective action and high safety level should need to be supported by large clinical outcome trials. However, iodine remains the essential element for the thyroid gland being the key component of the thyroid hormones thyroxine (T4) and triiodothyronine (T3), which regulate a wide variety of physiological processes, such as protein synthesis and enzymatic activity, and are critical determinants of metabolic activity. They are also required for proper skeletal and central nervous system development in fetuses and infants [15].

Thyroid function is primarily regulated by the thyroid-stimulating hormone (TSH), secreted by the pituitary gland, which increases thyroidal uptake of iodine and stimulates the synthesis and release of T3 and T4. In the presence of inadequate iodine intake, TSH levels remain elevated, leading to goiter, an enlargement of the thyroid gland that reflects the body's attempt to trap more iodine from the circulation and produce thyroid hormones. 
Iodine deficiency impairs thyroid hormone production and has many adverse effects during the course of the life, collectively termed the iodine deficiency disorders (IDDs), which depend on its severity and the age of the affected subjects. Although goiter is the classic sign of iodine deficiency, and can take place at any age, the most serious adverse effect of iodine deficiency is damage to the fetus during pregnancy, since the absence or inadequate level of thyroid hormones cause significant clinical manifestations such as increased risk of stillbirths, abortions, perinatal mortality, congenital abnormalities, cretinism, impaired growth $[9,16]$. Nowadays, IDDs are still a public health problem in most countries, including industrialized and developing regions of the world, in which all groups of people are affected, even though pregnant women are the most susceptible group to insufficient iodine intake [17-20].

Over the last few decades, intensive efforts have been made by the governments of IDD-affected countries to implement and control salt iodization program, since the most cost-effective strategy for IDD is universal salt iodization with the recommended iodine concentration of $20-40 \mathrm{mg}$ iodine per kg salt [5]. Despite a significant improvement in iodine nutrition being observed over the years, some countries still remain at risk of deficiency, implying that further strategies should be designed to achieve iodine sufficiency worldwide.

In this issue, we provide an update on the iodine status of the general population in different countries of the world, including Moldovia [21], Korea [22], the United States [23,24], Sri Lanka [25], Finland [26] and Italy [27,28], with a special focus on newborns [24] and pregnant women [24,26], which are the most vulnerable categories. Importantly, we have invited an international panel of endocrinologists to review the literature and to comment upon the effects of the most common nutraceuticals on thyroid function, based on the most recent in vitro and in vivo [29,30], as well as human, studies [31]. We believe that this collection represents a useful summary of iodine intake on human health, and provides a critical opinion on the benefits of some popular nutraceuticals that may play a role in clinical thyroidology.

Author Contributions: The Authors contributed equally to the development and finalization of this Editorial. All authors have read and agreed to the published version of the manuscript.

Funding: This research received no external funding.

Conflicts of Interest: The authors declare no conflict of interest.

\section{References}

1. Haldimann, M.; Alt, A.; Blanc, A.; Blondeau, K. Iodine content of food groups. J. Food Comp. Anal. 2005, 18, 461-471. [CrossRef]

2. Alexander, W.D.; Harden, R.M.; Harrison, M.T.; Shimmins, J. Some aspects of the absorption and concentration of iodide by the alimentary tract in man. Proc. Nutr. Soc. 1967, 26, 62-66. [CrossRef] [PubMed]

3. Vought, R.L.; London, W.T. Iodine intake, excretion and thyroidal accumulation in healthy subjects. J. Clin. Endocrinol. Metab. 1967, 27, 913-919. [CrossRef] [PubMed]

4. Fisher, D.A.; Oddie, T.H. Thyroid iodine content and turnover in euthyroid subjects: Validity of estimation of thyroid iodine accumulation from short-term clearance studies. J. Clin. Endocrinol. Metab. 1969, 29, 721-727. [CrossRef] [PubMed]

5. Institute of Medicine. Academy of Sciences 2001 Dietary Reference Intakes for Vitamin A, Vitamin K, Arsenic, Boron, Chromium, Copper, Iodine, Iron, Manganese, Molybdenum, Nickel, Silicon, Vanadium, and Zinc; National Academy Press: Washington, DC, USA, 2001.

6. World Health Organization; United Nations Children's Fund; International Council for the Control of Iodine Deficiency Disorders. Assessment of Iodine Deficiency Disorders and Monitoring Their Elimination, 3rd ed.; World Health Organization: Geneva, Switzerland, 2007.

7. Semba, R.D.; Delange, F. Iodine in human milk: Perspectives for human health. Nutr. Rev. 2001, 59, $269-278$. [CrossRef]

8. Nagataki, S. The average of dietary iodine intake due to the ingestion of seaweeds is $1.2 \mathrm{mg} /$ day in Japan. Thyroid 2008, 18, 667-668. [CrossRef] [PubMed] 
9. Hernando, V.U.; Anilza, B.P.; Hernan, S.T.C. Iodine deficiency disorders. Thyroid Disord. Ther. 2015, 4, 172.

10. Azizi, F.; Smyth, P. Breastfeeding and maternal and infant iodine nutrition. Clin. Endocrinol. 2009, 70, 803-809. [CrossRef]

11. Pearce, E.N.; Pino, S.; He, X.; Bazrafshan, H.R.; Lee, S.L.; Braverman, L.E. Sources of dietary iodine: Bread, cows' milk, and infant formula in the Boston area. J. Clin. Endocrinol. Metab. 2004, 89, 3421-3424. [CrossRef]

12. Montanelli, L.; Benvenga, S.; Vitti, P.; Latrofa, F.; Duntas, L.H. Drugs and other substances interfering with thyroid function. In Thyroid Diseases; Vitti, P., Hegedus, L., Eds.; Springer: Cham, Switzerland, 2018; pp. 733-761.

13. Sharma, R.; Bharti, S.; Kumar, K.V.S.H. Diet and thyroid: Myths and facts. J. Med. Nutr. Nutraceuticals 2014, 3, 60-65.

14. Das, L.; Bhaumik, E.; Raychaudhuri, U.; Chakraborty, R. Role of nutraceuticals in human health. J. Food Sci. Technol. 2012, 49, 173-183. [CrossRef] [PubMed]

15. Zimmermann, M.B. The role of iodine in human growth and development. Semin. Cell Dev. Biol. 2011, 22, 645-652. [CrossRef]

16. Eastman, C.J.; Zimmermann, M.B. The Iodine Deficiency Disorders. In Endotext; Feingold, K.R., Anawalt, B., Boyce, A., Chrousos, G., Dungan, K., Grossman, A., Hershman, J.M., Kaltsas, G., Koch, C., Kopp, P., et al., Eds.; MDText.com, Inc.: South Dartmouth, MA, USA, 2000.

17. Li, M.; Eastman, C.J. The changing epidemiology of iodine deficiency. Nat. Rev. Endocrinol. 2012, 8, 434-440. [CrossRef]

18. Mohammadi, M.; Azizi, F.; Hedayati, M. Iodine deficiency status in the WHO Eastern Mediterranean Region: A systematic review. Environ. Geochem. Health 2018, 40, 87-97. [CrossRef]

19. The Iodine Global Network: 2018 Annual Report. Available online: https://www.ign.org/cm_data/IGN_ 2018_Annual_Report_5_web.pdf (accessed on 19 March 2020).

20. Candido, A.C.; Morais, N.S.; Dutra, L.V.; Pinto, C.A.; Franceschini, S.D.C.C.; Alfenas, R.C.G. Insufficient iodine intake in pregnant women in different regions of the world: A systematic review. Arch. Endocrinol. Metab. 2019, 63, 306-311. [CrossRef] [PubMed]

21. D'Elia, L.; Obreja, G.; Ciobanu, A.; Breda, J.; Jewell, J.; Cappuccio, F.P. The Salt Consumption Survey in the Republic of Moldova Study Group; Sodium, Potassium and Iodine Intake, in a National Adult Population Sample of the Republic of Moldova. Nutrients 2019, 11, 2896. [CrossRef]

22. Kim, S.; Kwon, Y.S.; Kim, J.Y.; Hong, K.H.; Park, Y.K. Association between Iodine Nutrition Status and Thyroid Disease-Related Hormone in Korean Adults: Korean National Health and Nutrition Examination Survey VI (2013-2015). Nutrients 2019, 11, 2757. [CrossRef] [PubMed]

23. Gostas, D.E.; Larson-Meyer, D.E.; Yoder, H.A.; Huffman, A.E.; Johnson, E.C. Dietary Relationship with $24 \mathrm{~h}$ Urinary Iodine Concentrations of Young Adults in the Mountain West Region of the United States. Nutrients 2020, 12, 121. [CrossRef]

24. Ellsworth, L.; McCaffery, H.; Harman, E.; Abbott, J.; Gregg, B. Breast Milk Iodine Concentration Is Associated with Infant Growth, Independent of Maternal Weight. Nutrients 2020, 12, 358. [CrossRef]

25. Jayatissa, R.; Gorstein, J.; Okosieme, O.E.; Lazarus, J.H.; Premawardhana, L.D. Stable Iodine Nutrition During Two Decades of Continuous Universal Salt Iodisation in Sri Lanka. Nutrients 2020, 12, 1109. [CrossRef]

26. Purdue-Smithe, A.C.; Männistö, T.; Bell, G.A.; Mumford, S.L.; Liu, A.; Kannan, K.; Kim, U.-J.; Suvanto, E.; Surcel, H.-M.; Gissler, M.; et al. The Joint Role of Thyroid Function and Iodine Status on Risk of Preterm Birth and Small for Gestational Age: A Population-Based Nested Case-Control Study of Finnish Women. Nutrients 2019, 11, 2573. [CrossRef] [PubMed]

27. Giordano, C.; Barone, I.; Marsico, S.; Bruno, R.; Bonofiglio, D.; Catalano, S.; Andò, S. Endemic Goiter and Iodine Prophylaxis in Calabria, a Region of Southern Italy: Past and Present. Nutrients 2019, 11, 2428. [CrossRef] [PubMed]

28. Baldini, E.; Virili, C.; D’Armiento, E.; Centanni, M.; Ulisse, S. Iodine Status in Schoolchildren and Pregnant Women of Lazio, a Central Region of Italy. Nutrients 2019, 11, 1647. [CrossRef] [PubMed]

29. Benvenga, S.; Marini, H.R.; Micali, A.; Freni, J.; Pallio, G.; Irrera, N.; Squadrito, F.; Altavilla, D.; Antonelli, A.; Ferrari, S.M.; et al. Protective Effects of Myo-Inositol and Selenium on Cadmium-Induced Thyroid Toxicity in Mice. Nutrients 2020, 12, 1222. [CrossRef] [PubMed] 
30. Benvenga, S.; Ferrari, S.M.; Elia, G.; Ragusa, F.; Patrizio, A.; Paparo, S.R.; Camastra, S.; Bonofiglio, D.; Antonelli, A.; Fallahi, P. Nutraceuticals in Thyroidology: A Review of in Vitro, and in Vivo Animal Studies. Nutrients 2020, 12, 1337. [CrossRef]

31. Benvenga, S.; Feldt-Rasmussen, U.; Bonofiglio, D.; Asamoah, E. Nutraceutical Supplements in the Thyroid Setting: Health Benefits beyond Basic Nutrition. Nutrients 2019, 11, 2214. [CrossRef]

(C) 2020 by the authors. Licensee MDPI, Basel, Switzerland. This article is an open access article distributed under the terms and conditions of the Creative Commons Attribution (CC BY) license (http://creativecommons.org/licenses/by/4.0/). 


\title{
Stable Iodine Nutrition During Two Decades of Continuous Universal Salt Iodisation in Sri Lanka
}

\author{
Renuka Jayatissa ${ }^{1, *}$, Jonathan Gorstein ${ }^{2}$, Onyebuchi E. Okosieme ${ }^{3}$, John H. Lazarus ${ }^{3}$ and \\ Lakdasa D. Premawardhana ${ }^{3}$ \\ 1 Department of Nutrition, Medical Research Institute, Danister De Silva Mawatha, Colombo 8, Sri Lanka \\ 2 University of Washington, Department of Global Health, Seattle, WA 98195, USA; jgorstein@ign.org \\ 3 Centre for Endocrine and Diabetes Sciences and Thyroid Research Group, C2 Link Corridor, \\ University Hospital of Wales, Heath Park, Cardiff CF14 4XN, UK; Okosiemeoe@cardiff.ac.uk (O.E.O.); \\ Lazarus@cardiff.ac.uk (J.H.L.); PremawadhanaLD@cardiff.ac.uk (L.D.P.) \\ * Correspondence: renukajayatissa@ymail.com; Tel.: +94-777-788-444
}

Received: 23 March 2020; Accepted: 9 April 2020; Published: 16 April 2020

\begin{abstract}
Universal salt iodisation (USI) was introduced in Sri Lanka in 1995. Since then, four national iodine surveys have assessed the iodine nutrition status of the population. We retrospectively reviewed median urine iodine concentration (mUIC) and goitre prevalence in 16,910 schoolchildren (6-12 years) in all nine provinces of Sri Lanka, the mUIC of pregnant women, drinking-water iodine level, and the percentage of households consuming adequately $(15 \mathrm{mg} / \mathrm{kg})$ iodised salt (household salt iodine, HHIS). The mUIC of schoolchildren increased from $145.3 \mu \mathrm{g} / \mathrm{L}$ (interquartile range (IQR) $=84.6-240.4$ ) in 2000 to $232.5 \mu \mathrm{g} / \mathrm{L}(\mathrm{IQR}=159.3-315.8)$ in 2016, but stayed within recommended levels. Some regional variability in mUIC was observed (178.8 and $297.3 \mu \mathrm{g} / \mathrm{L}$ in 2016). There was positive association between mUIC in schoolchildren and water iodine concentration. Goitre prevalence to palpation was a significantly reduced from $18.6 \%$ to $2.1 \%(\mathrm{p}<0.05)$. In pregnant women, median UIC increased in each trimester (102.3 (61.7-147.1); 217.5 (115.6-313.0); 273.1 (228.9-337.6) $\mu \mathrm{g} / \mathrm{L}(\mathrm{p}=0.000))$. We conclude that the introduction and maintenance of a continuous and consistent USI programme has been a success in Sri Lanka. In order to sustain the programme, it is important to retain monitoring of iodine status while tracking salt-consumption patterns to adjust the recommended iodine content of edible salt.
\end{abstract}

Keywords: iodine schoolchildren; urine iodine; goitre; iodised salt; water iodine; iodine pregnant women

\section{Introduction}

Iodine is a micronutrient that primarily acts through the thyroid gland and its two hormones (thyroxine and triiodothyronine), and it is vital to the integrity of many physiological functions in the human body [1,2]. Iodine deficiency may affect multiple aspects of human development (including intrauterine physical and neurological development), linear growth, and physiological organ function. Organs such as the brain and nervous system are particularly vulnerable in their formative stages during intrauterine life [1,2]. Fortunately, iodine deficiency is relatively easy and inexpensive to prevent through universal iodisation of all edible salt. This is a pure food-chain effect, beginning with soil erosion and leading to environmental iodine deficiency, and a lack of iodine sources in our typical diet. Iodised salt was first introduced in Switzerland in 1922 [2,3] and has been used in many previously iodine-deficient countries with good results [4]. The restoration of iodine sufficiency in many of these countries has been a major public-health triumph facilitated by the United Nations Children's Fund (UNICEF), World Health Organisation (WHO), and International Council of Control Iodine Deficiency Disorders (ICCIDD, now named Iodine Global Network (IGN)). Statutory regulations 
enforcing universal salt iodisation (USI) were implemented by regulatory authorities in each country [5]. Sri Lanka is one such country that has successfully adopted a USI programme since 1995.

\section{History of Iodine Deficiency and Its Management in Sri Lanka}

Bennet and Pridham first referred to the existence of endemic goitre along the coast of Galle in the southern province of Sri Lanka in 1849 [6]. However, the link between poor iodine consumption and endemic goitre was first recognised only in the 20th century in a WHO study that confirmed high goitre rates, an iodine-poor diet, and low iodine concentrations in drinking water in 1950 [7]. Mahadeva and his group in 1960 identified a "goitre belt" extending across the western, central, southern, sabaragamuwa, and uva provinces in Sri Lanka [8]. The high annual rainfall in these regions led experts to believe that iodine was "leeched" from the soil, leading to iodine deficiency. At that stage, almost no goitre had been identified in the northern, eastern, and north-western provinces [9]. However, in 1986, Fernando et al. described a high goitre rate of $18.8 \%$ in schoolchildren in 17 of 24 districts in Sri Lanka-a variable prevalence of 6.5\% in the Matale district and 30.2\% in the Kalutara district [10]. This study used palpation as the method of goitre assessment, and was the first to recognise iodine deficiency as a major public-health problem.

USI was introduced nationwide by the government in 1995 by statutory regulation [11]. This legislation banned the sale of non-iodised salt for human consumption, thus ensuring access to iodised salt to all consumers in the country. Potassium iodate was used as the vehicle of iodine supplementation, and added to salt at an optimal concentration of $50 \mathrm{ppm}$ at producer level and 25 ppm at consumer level. The national reference laboratory for monitoring USI was established at the Medical Research Institute (MRI) in 2000 with the aid of UNICEF. This laboratory has the dual role of monitoring USI and of assessing its clinical impact by performing periodic national iodine surveys (NISs). External quality control is linked to the EQUIP programme of the Centers for Disease Control (CDC), Atlanta, Georgia, USA [12].

We review and describe the iodine-nutrition status in Sri Lanka by utilising serial datasets from the four national iodine surveys carried out by the MRI between 2000 and 2016. We assessed the success of USI in Sri Lanka in relation to global indicators of population iodine status, i.e., median urine iodine concentration (mUIC), total goitre prevalence rates (TGRs), and household salt iodine (HHIS) consumption.

\section{Methods}

\subsection{Available Data Sources for Analysis}

mUIC, TGRs, and HHIS were available for analysis from 4 national iodine surveys (NISs) between 2000 and 2016-NIS2000, NIS2005, NIS2010, and NIS2016 [13-16]. These NIS used a two-stage stratified cluster-sampling technique as specified by the WHO, UNICEF, and IGN $[17,18]$. During each NIS, the same team of field investigators visited all nine administrative provinces of the country to detect goitres by palpation, and collected urine from 6-12-year-old schoolchildren, and salt from their households and drinking-water samples from the household or school locality. Figure 1 illustrates the map of Sri Lanka demarcating 9 provinces. All four national studies were carried out to ascertain provincial variation. A total of 16,910 schoolchildren of 6-12 years of age were studied in the four surveys and included in the final analysis (Table 1). Furthermore, we had available data for analysis from the national micronutrient study in pregnant women in 2015 (MNSPM2015) (Table 2) [19]. 


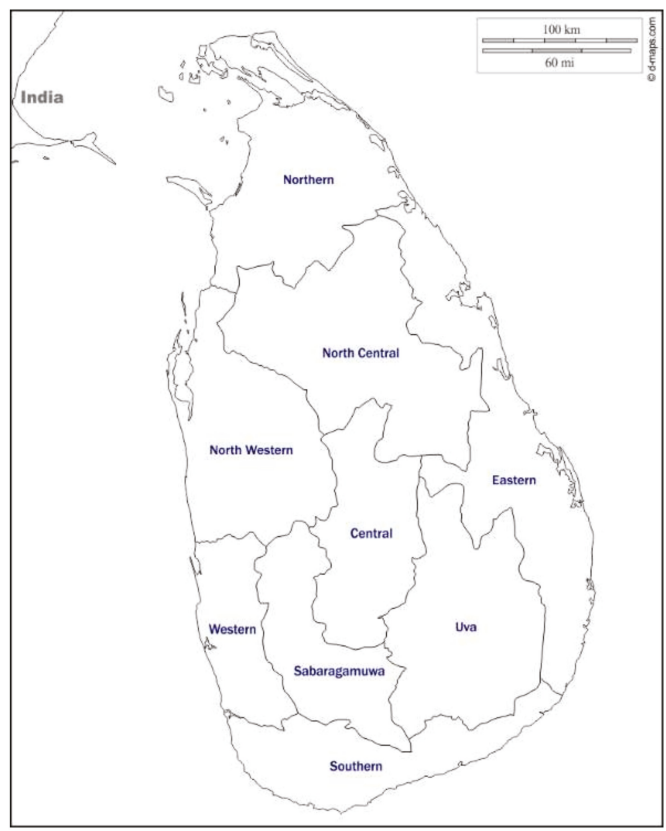

Figure 1. Map of Sri Lanka demarcating nine provinces.

Table 1. Median urine iodine concentration (mUIC), goitre prevalence, and household salt iodine consumption in schoolchildren aged 6-12 years in 2000-2016. TGR, total goitre prevalence rate; HHIS, household salt iodine; IQR, interquartile range.

\begin{tabular}{|c|c|c|c|c|c|c|c|}
\hline \multirow[t]{2}{*}{ Surveys } & \multicolumn{2}{|c|}{ UIC $(\mu \mathrm{g} / \mathrm{L})$} & \multirow{2}{*}{$\begin{array}{c}\text { TGR }^{3} \\
\%\end{array}$} & \multicolumn{4}{|c|}{ HHIS (\%) ${ }^{4}$} \\
\hline & $\%<50^{1}$ & Median (IQR) $^{2}$ & & $<5$ & 5-14.9 & $15-30$ & $>30$ \\
\hline $\begin{array}{l}\text { NIS-2016 } \\
(\mathrm{n}=5000)\end{array}$ & 1.6 & $\begin{array}{c}232.5 \\
(159.3-315.8)\end{array}$ & 1.9 & 3.1 & 18.4 & 63.5 & 15.0 \\
\hline $\begin{array}{l}\text { NIS-2010 } \\
(\mathrm{n}=7401)\end{array}$ & 6.7 & $\begin{array}{c}163.4 \\
(99.1-245.1)\end{array}$ & 4.4 & 4.6 & 27.1 & 52.5 & 16.1 \\
\hline $\begin{array}{l}\text { NIS-2005 } \\
(\mathrm{n}=1879)\end{array}$ & 7.4 & $\begin{array}{c}154.4 \\
(90.3-252.6)\end{array}$ & 3.8 & 0.0 & 8.7 & 47.7 & 43.5 \\
\hline $\begin{array}{l}\text { NIS-2000 } \\
(\mathrm{n}=2628)\end{array}$ & 2.7 & $\begin{array}{c}145.3 \\
(84.6-315.8)\end{array}$ & 18.0 & - & - & - & - \\
\hline
\end{tabular}

Table 2. Median UIC in pregnant women in three trimesters (national micronutrient study in pregnant women in 2015, NNMSPM2015).

\begin{tabular}{|c|c|c|c|}
\hline \multirow{2}{*}{$\frac{\text { Trimesters }}{\text { Period of Amenorrhea (POA) }}$} & \multicolumn{2}{|c|}{ UIC $(\mu \mathrm{g} / \mathrm{L})$} & \multirow[t]{2}{*}{ No } \\
\hline & $\%<50^{1}$ & Median (IQR) $^{2}$ & \\
\hline $\begin{array}{c}\text { First trimester } \\
(\leq 12 \text { weeks of } \mathrm{POA})\end{array}$ & 17.0 & $102.3(61.7-147.1)$ & 447 \\
\hline $\begin{array}{c}\text { Second trimester } \\
(13-28 \text { weeks of POA) }\end{array}$ & 6.2 & $\begin{array}{c}217.5 \\
(115.6-313.0)\end{array}$ & 339 \\
\hline $\begin{array}{c}\text { Third trimester } \\
(>28 \text { weeks of POA) }\end{array}$ & 0.0 & $\begin{array}{c}273.1 \\
(228.9-337.6)\end{array}$ & 176 \\
\hline Overall & 10.1 & $157.7(91.2-256.4)$ & 962 \\
\hline
\end{tabular}




\subsection{Indicators of Population Iodine Status}

Three primary indicators of population iodine status were considered, and we used the methodology described below to assess the outcomes of the USI programme: (i) mUIC was measured by ammonium persulfate digestion with spectrophotometric detection of the Sandell-Kolthoff reaction in a laboratory certified by the EQUIP programme [20-22]; (ii) TGR-the grading of goitres was done by palpation by the same team utilising the classification recommended by the WHO, UNICEF, and IGN [3,18]: (a) "no goitre" — thyroid not palpable or visible; (b) "goitre present" — thyroid palpable not visible or palpable and visible; and (iii) iodine content in salt: titration method to measure the iodine content of salt certified by a regional iodine laboratory [3,18]. Geographical location (province), iodine in drinking water, and household salt were measured to estimate their influence on optimal iodine consumption. Iodine levels in drinking water at the household level and school localities were tested using ammonium persulfate oxidation [20].

\section{Data Analysis}

The following definitions were used for classifying population iodine nutrition status [22]. (i) Median UIC: (a) adequate mUIC - 150-299 $\mu \mathrm{g} / \mathrm{L}$ (pregnant women) and 100-299 $\mu \mathrm{g} / \mathrm{L}$ (schoolchildren); (b) excessive mUIC $-\geq 300 \mu \mathrm{g} / \mathrm{L}$; and (c) iodine sufficiency $-<20 \%$ samples should have mUIC of $<50 \mu \mathrm{g} / \mathrm{L}$. (ii) Household salt iodine (HHIS) content: we classified salt iodine content as follows. (a) $<5 \mathrm{mg} / \mathrm{kg}$ —non-iodised; (b) 5-14.9 mg/kg—inadequately iodised; (c) 15-30 mg/kg-adequately iodised; and (d) $>30 \mathrm{mg} / \mathrm{kg}$-over-iodised. (iii) Iodine content in drinking water: iodine in drinking water was classified as follows. (a) $<5 \mathrm{mg} / \mathrm{kg}$ - no iodine; (b) 5-14.9 mg/kg-low iodine; (c) $15-30 \mathrm{mg} / \mathrm{kg}$ - moderate iodine; and (d) $>30 \mathrm{mg} / \mathrm{kg}$ - high iodine $[23,24]$.

Statistical analysis was performed using SPSS (IBM version 24). Data that were not normally distributed were expressed as median and interquartile range (IQR) unless otherwise stated. The Mann-Whitney U-test was used to compare data between the two groups. The Kruskal-Wallis test (nonparametric analysis of variance (ANOVA)) was used to assess the significance of differences between more than two groups. Categorical variables were analysed using the chi-squared test for trend; a p-value of $<0.05$ was considered statistically significant.

\section{Results}

(i) mUIC was consistently in the adequate or iodine-sufficient range in all four national iodine surveys of 2000-2016. There has been a significant increase in mUIC, but still within the adequate range in surveys between 2000 (145.3 (84.6-240.4)) and 2016 (232.5 (159.3-315.8)); $p=0.000)$. There has also been a significant reduction in the percentage of schoolchildren with $\mathrm{mUIC}<50 \mu \mathrm{g} / \mathrm{L}(2.7 \%$ in 2000 vs $1.6 \%$ in 2016; $p=0.000$ ). As shown in Table 2 , the mUIC of pregnant women was also in the adequate or iodine-sufficient range (157.7 (228.9-337.6) $\mu \mathrm{g} / \mathrm{L})$ at the national level, and in the second and third trimesters 217.5 (115.6-313.0), and 273.1 (228.9-337.6) $\mu \mathrm{g} / \mathrm{L} ; \mathrm{p}<0.000)$. Table 3 shows there is regional variability in mUIC levels in children of 6-12 years of age (297.3 vs. $178.8 \mu \mathrm{g} / \mathrm{L}$ in 2016; $p=0.000$ ). It was significantly higher in the northern and north-central provinces when compared to the rest of the country since 2005 . 
Table 3. Regional variations of key indicators of population iodine nutrition in 2000-2016.

\begin{tabular}{|c|c|c|c|c|c|c|c|c|c|c|}
\hline \multirow[t]{2}{*}{ Province } & \multicolumn{3}{|c|}{$\begin{array}{l}\text { Median Iodine Content in Salt } \\
\text { (IQR; } \mathrm{mg} / \mathrm{kg} \text { ) }\end{array}$} & \multicolumn{3}{|c|}{$\begin{array}{l}\text { Adequately Iodised } \\
\text { HHIS (\%) }\end{array}$} & \multicolumn{4}{|c|}{$\begin{array}{l}\text { Median UIC (IQR) } \\
(\mu \mathrm{g} / \mathrm{dL})\end{array}$} \\
\hline & $2005^{1}$ & $2010^{2}$ & $2016^{3}$ & $2005^{4}$ & $2010^{5}$ & $2016^{6}$ & $2000^{7}$ & $2005^{8}$ & $2010^{9}$ & $2016^{10}$ \\
\hline Western & $\begin{array}{c}28.5 \\
(22.3-37.9)\end{array}$ & $\begin{array}{c}21.2 \\
(13.2-27.5)\end{array}$ & $\begin{array}{c}19.0 \\
(14.8-25.4)\end{array}$ & 96.1 & 70.0 & 71.6 & $\begin{array}{c}151.4 \\
(92.8-238.1)\end{array}$ & $\begin{array}{c}142.2 \\
(96.7-197.7)\end{array}$ & $\begin{array}{c}168.4 \\
(11.7-231.5)\end{array}$ & $\begin{array}{c}233.1 \\
(166.7-313.3)\end{array}$ \\
\hline Southern & $\begin{array}{c}32.7 \\
(23.2-41.7)\end{array}$ & $\begin{array}{c}21.2 \\
(11.6-27.5)\end{array}$ & $\begin{array}{c}21.2 \\
(13.8-25.4)\end{array}$ & 94.4 & 66.7 & 70.2 & $\begin{array}{c}122.4 \\
(74.2-178.9)\end{array}$ & $\begin{array}{c}111.0 \\
(69.9-189.5)\end{array}$ & $\begin{array}{c}123.3 \\
(74.3-203.0)\end{array}$ & $\begin{array}{c}201.3 \\
(121.5-289.9)\end{array}$ \\
\hline Central & $\begin{array}{c}27.5 \\
(20.6-34.9)\end{array}$ & $\begin{array}{c}22.2 \\
(14.8-27.5)\end{array}$ & $\begin{array}{c}27.5 \\
(21.2-34.9)\end{array}$ & 97.4 & 74.0 & 91.0 & $\begin{array}{c}96.2 \\
(61.6-149.1)\end{array}$ & $\begin{array}{c}144.7 \\
(83.8-211.9)\end{array}$ & $\begin{array}{c}168.2 \\
(104.1-247.4)\end{array}$ & $\begin{array}{c}220.7 \\
(168.3-286.4)\end{array}$ \\
\hline Northern & $\begin{array}{c}19.0 \\
(14.8-26.9)\end{array}$ & $\begin{array}{c}14.8 \\
(7.4-23.3)\end{array}$ & $\begin{array}{c}22.2 \\
(18.0-26.5)\end{array}$ & 74.3 & 48.3 & 83.6 & $\begin{array}{c}139.5 \\
(74.1-247.4)\end{array}$ & $\begin{array}{c}283.4 \\
(182.8-403.1)\end{array}$ & $\begin{array}{c}203.8 \\
(124.6-292.1)\end{array}$ & $\begin{array}{c}297.3 \\
(230.4-355.4)\end{array}$ \\
\hline Eastern & $\begin{array}{c}29.0 \\
(21.6-45.9)\end{array}$ & $\begin{array}{c}23.3 \\
(16.9-28.6)\end{array}$ & $\begin{array}{c}23.3 \\
(20.1-26.5)\end{array}$ & 90.6 & 78.5 & 91.2 & $\begin{array}{c}231.3 \\
(152.9-328.3)\end{array}$ & $\begin{array}{c}160.4 \\
(94.5-250.9)\end{array}$ & $\begin{array}{c}173.2 \\
(110.9-241.7)\end{array}$ & $\begin{array}{c}233.8 \\
(159.5-323.5)\end{array}$ \\
\hline North Western & $\begin{array}{c}28.0 \\
(22.7-35.8)\end{array}$ & $\begin{array}{c}19.0 \\
(9.4-25.4)\end{array}$ & $\begin{array}{c}19.3 \\
(12.7-24.3)\end{array}$ & 93.6 & 60.6 & 68.1 & $\begin{array}{c}122.5 \\
(76.6-190.9)\end{array}$ & $\begin{array}{c}152.8 \\
(98.7-221.3)\end{array}$ & $\begin{array}{c}151.7 \\
(93.4-228.1)\end{array}$ & $\begin{array}{c}229.4 \\
(155.9-318.6)\end{array}$ \\
\hline North Central & $\begin{array}{c}28.6 \\
(20.4-40.7)\end{array}$ & $\begin{array}{c}21.2 \\
(12.7-27.5)\end{array}$ & $\begin{array}{c}18.0 \\
(12.2-24.3)\end{array}$ & 90.1 & 67.7 & 64.1 & $\begin{array}{c}135.9 \\
(76.9-204.9)\end{array}$ & $\begin{array}{c}229.9 \\
(135.2-332.0)\end{array}$ & $\begin{array}{c}237.9 \\
(164.6-328.7)\end{array}$ & $\begin{array}{c}278.0 \\
(186.3-327.2)\end{array}$ \\
\hline Uva & $\begin{array}{c}28.5 \\
(23.8-30.1)\end{array}$ & $\begin{array}{c}23.3 \\
(13.8-28.6)\end{array}$ & $\begin{array}{c}21.2 \\
(16.9-25.4)\end{array}$ & 94.6 & 72.9 & 81.5 & $\begin{array}{c}181.1 \\
(106.0-320.1)\end{array}$ & $\begin{array}{c}108.5 \\
(68.4-186.4)\end{array}$ & $\begin{array}{c}129.3 \\
(78.9-198.1)\end{array}$ & $\begin{array}{c}178.8 \\
(126.5-259.1)\end{array}$ \\
\hline Sabaragamuwa & $\begin{array}{c}32.0 \\
(22.7-41.2)\end{array}$ & $\begin{array}{c}22.2 \\
(12.7-29.6)\end{array}$ & $\begin{array}{c}22.2 \\
(18.0-27.5)\end{array}$ & 92.4 & 70.7 & 82.0 & $\begin{array}{c}194.4 \\
(117.6-304.0)\end{array}$ & $\begin{array}{c}109.0 \\
(69.3-205.8)\end{array}$ & $\begin{array}{c}121.1 \\
(69.7-187.0)\end{array}$ & $\begin{array}{c}217.5 \\
(148.7-305.0)\end{array}$ \\
\hline Sri Lanka & $\begin{array}{c}28.0 \\
(20.6-38.6)\end{array}$ & $\begin{array}{c}21.2 \\
(11.6-27.5)\end{array}$ & $\begin{array}{c}21.2 \\
(15.9-26.5)\end{array}$ & 91.4 & 67.6 & 78.0 & $\begin{array}{c}145.3 \\
(84.6-240.4)\end{array}$ & $\begin{array}{c}154.4 \\
(90.3-252.6)\end{array}$ & $\begin{array}{c}163.5 \\
(99.1-245.1)\end{array}$ & $\begin{array}{c}232.5 \\
(159.3-315.8)\end{array}$ \\
\hline
\end{tabular}

(ii) There was significant reduction in TGR by palpation between surveys done in $2000(18.0 \%)$ and $2016(1.9 \% ; p=0.000$; Table 1$)$.

(iii) The iodine content of HHIS was only measured since 2005, and since that time, over $95 \%$ of all HHIS has contained at least some iodine $(>5 \mathrm{mg} / \mathrm{kg}$ ). The percentage of HHIS with adequate iodine concentrations (defined as $15-30 \mathrm{mg} / \mathrm{kg}$ ) showed a significant increase- $47.7 \%$ in NIS2005 vs. $63.5 \%$ in NIS2016 $(p=0.000)$. Furthermore, only $3.1 \%$ had a salt content of $<5 \mathrm{mg} / \mathrm{kg}$ (non-iodised) in the last survey in 2016. The prevalence of over-iodised salt $(>30 \mathrm{mg} / \mathrm{kg}$ ) significantly fell from $43.5 \%$ in 2005 to $15.0 \%$ in 2016 ( $p=0.000$; Table 1). HHIS was less than $90 \%$ at the national level, and in all provinces in 2010 and 2016 except for the central and eastern provinces. In 2016, the interprovincial difference of median iodine content in HHIS was between 18.0 and $27.5 \mathrm{mg} / \mathrm{kg}$ (Table 3).

(iv) Median iodine content of drinking water was $33.4(12.3-66.8) \mu \mathrm{g} / \mathrm{L}$. Wide variation was observed between provinces $(8.3(4.6-29.0)$ vs $75.5(48.4-102.5) \mu \mathrm{g} / \mathrm{L} ; p=0.000)$ in the uva and north-central provinces, respectively (Table 4 ).

Table 4. Regional variations of median iodine content of drinking water in 2016.

\begin{tabular}{ccc}
\hline Province & No & Median (IQR) $\mu \mathrm{g} / \mathrm{L}$ \\
\hline Western & 67 & $15.6(4.1-29.1)$ \\
Southern & 70 & $19.1(15.3-29.9)$ \\
Central & 68 & $18.0(5.7-44.6)$ \\
Northern & 78 & $53.4(28.9-79.4)$ \\
Eastern & 189 & $33.3(17.0-69.6)$ \\
North Western & 122 & $39.9(9.4-61.4)$ \\
North Central & 170 & $75.5(48.4-102.5)$ \\
Uva & 62 & $8.3(4.6-50.4)$ \\
Sabaragamuwa & 108 & $31.3(15.1-50.4)$ \\
Sri Lanka & 934 & $33.4(12.3-66.8)$ \\
\hline \multicolumn{3}{c}{ Note: $p=0.000}$.
\end{tabular}

Figure 2 provides a graphical representation of the data on median UIC of children aged 6-12 years in 2016, stratified by the iodine content in HHIS and in drinking water. These data are noteworthy since the mUIC was within the optimal range in all subgroups, including those households of which the iodine content in HHIS was $<5 \mathrm{ppm}$ or in the range of 5-14.9 ppm, suggesting that the consumed 
iodine in HHIS is not the exclusive diet source of iodine. There was a significant increase in median UIC with increasing iodine concentrations in drinking water $(p=0.000)$.

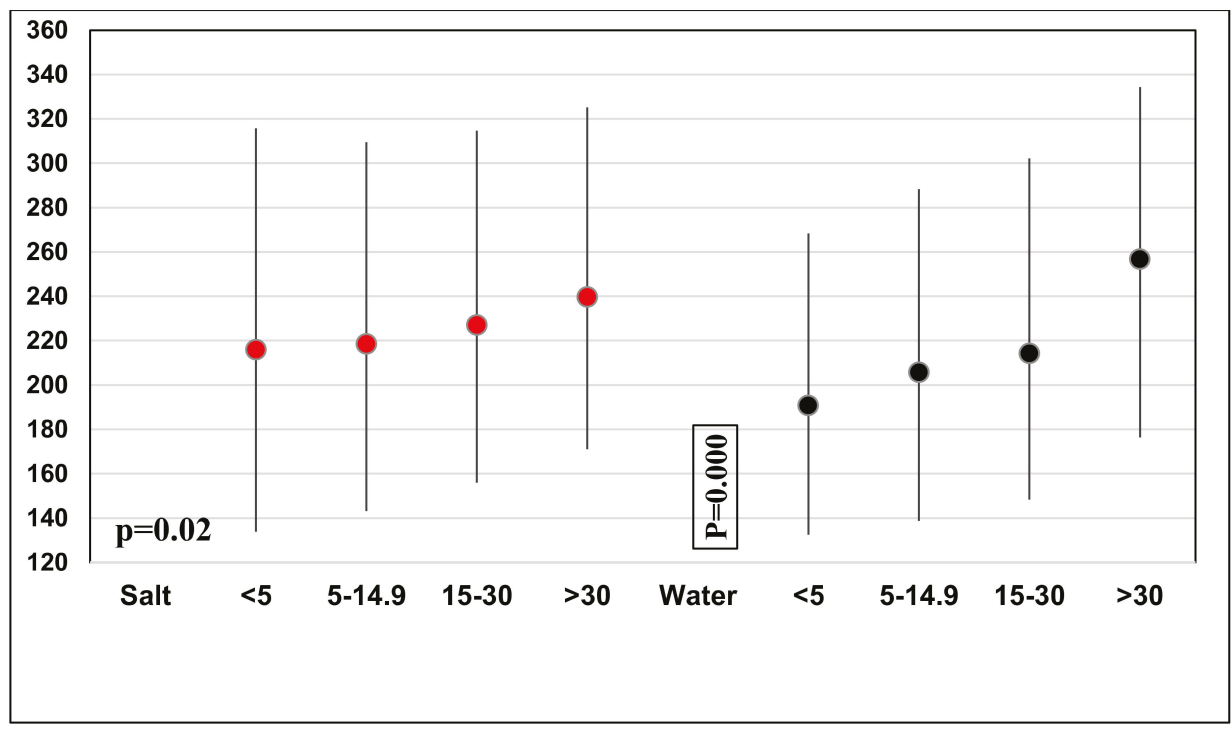

Figure 2. Median urine iodine concentration (IQR) and its relationship with iodine concentrations in household salt and drinking water in school children aged 6-12 years in 2016.

\section{Discussion}

USI was first implemented in Sri Lanka in 1995. We demonstrated in this retrospective review of data from four national iodine surveys of over more than two decades of continuous salt iodisation that (i) mUIC has consistently been in the adequate range with a sequential increase within safe and recommended limits; (ii) the goitre-prevalence rate to palpation in children between 6-12 years significantly decreased between 2000 and $2016(18.0 \%$ to $1.9 \% ; p=0.000)$; and (iii) the percentage of adequately iodised household salt samples significantly increased during this period (47.7\% in 2005 vs. $63.3 \%$ in 2016; $p=0.000$ ), and its household consumption remains satisfactory (Tables 1 and 3 ).

These indices of population iodine nutrition favourably reflect the success of the USI programme enforced by successive governments of Sri Lanka, having adequate iodine status at the national level and in most provinces (Tables 1 and 3). Furthermore, there has been a recurrence of iodine deficiency in several countries where iodine-deficiency disorders (IDDs) were eliminated with USI because of inadequate monitoring of their USI programmes [25-29]. Strict monitoring is essential in sustaining proper iodine nutrition in countries that adopt USI [28].

However, there is a need for caution. (a) The median UIC of pregnant women is only marginally above the recommended cut off of $150 \mu \mathrm{g} / \mathrm{L}$, and iodine-insufficient in the first trimester (102.3 (61.7-147.1) $\mu \mathrm{g} / \mathrm{L}$ (Table 2)). There was a remarkable improvement in the iodine status of pregnant women compared to $2011(113.7 \mu \mathrm{g} / \mathrm{L})$ [30]. There was also a significant minority of pregnant women (nearly $10 \%$ ) who had a median UIC of $<50 \mu \mathrm{g} / \mathrm{L}$. This is an important population group, and inadequate iodine delivery to this group may have important long-term consequences, particularly regarding the intrauterine development of the brain, central nervous system, and physical growth [29]. (b) The median UIC of schoolchildren in the northern and north-central provinces in 2016 approached $300 \mu \mathrm{g} / \mathrm{L}$. In these two areas at risk of iodine excess, iodine content in drinking water was the highest among those provinces (Table 4). Other countries' experience with high iodine content in drinking water should be reviewed [31,32]. (c) Some regional variability in mUIC was observed over the course 
of the programme, but in the most recent survey, the range was between 178.8 and $297.3 \mu \mathrm{g} / \mathrm{L}$, all within the optimal range. The reasons for regional variability of median UIC have not been investigated in detail, but need to be noted (Table 2). There is a clear need, therefore, to closely monitor these groups in the future, with periodic well-designed and more elaborate studies. However, we acknowledge that these UIC assessments were done on single "spot" samples of urine and may not be truly representative of the iodine-nutrition status of each individual in these communities [28].

We also showed that the supervision and monitoring of salt iodisation has improved over two decades of USI. The percentage of samples delivering adequate levels of salt at the consumer level (i.e., $15-30 \mathrm{mg} / \mathrm{kg})$ increased from $47.5 \%$ in NIS2005 to $63.3 \%$ in NIS2016 $(p=0.000)$, while at the same time, the percentage of over-iodised salt samples has significantly decreased ( $p=0.000$; Table 1$)$. The percentage of households using adequately iodised salt was less than $90 \%$ (the WHO goal for USI) at the national level and in seven out of nine provinces (Table 3). However, it showed that the median HHIS content in provinces was between 18.0 and $27.5 \mathrm{mg} / \mathrm{kg}$, confirming that household iodised salt was providing a significant amount of iodine to the diet [33].

Despite a $<90 \%$ of households consuming adequately iodised salt, there has been an increase in mUIC, and some provinces in the country consistently showed a high level of mUIC. Daily mean per capita salt intake of Sri Lankans was reported as $8.3 \mathrm{~g}$ (CI: 7.9, 8.8) in 2012 [34]. We also need to be aware of the contribution of other sources of iodine contributing to population iodine nutrition, e.g., drinking water, processed foods, or condiments, which are being manufactured with iodised salt, as well as some iodine in foods. Our results indicated a positive association between iodine status in schoolchildren and water iodine concentration, although the major contributor to iodine intake is iodised salt in the diet (Figure 2). In fact, over $95 \%$ of households have consistently had access to iodised salt since 2005. A similar contribution was observed in other countries [24,32]. There is a need to adjust the recommended level of HHIS, and to explore the iodine supply through different dietary sources and the geological assessment of soil iodine content for future monitoring.

IGN/UNICEF recommends that the optimal iodine intake, as measured by the median UIC for school-age children, should be $<300 \mu \mathrm{g} / \mathrm{L}$, while the mUIC among pregnant women should be $<500 \mu \mathrm{g} / \mathrm{L}$ [22]. Thus, the current salt-iodisation programme is having its desired impact and not placing the Sri Lankan population at risk for iodine excess, as described in the previous study [33]. The salt-iodisation programme needs to be consistently monitored so that the level of iodine in all edible salt, including that used at the household level as well as in processed foods and condiments, leads to an optimal intake. As salt-reduction efforts are implemented, there may be a decline in overall salt consumption, in which case the government may need to accordingly adjust the recommended salt iodine level to ensure that public-health strategies of iodine-deficiency prevention, salt reduction, and reduction in NCDs are realised.

Despite adequate iodine nutrition among schoolchildren, iodine nutrition among pregnant women remains just above the cut-off levels in the country. There is a need to focus on pregnant women for continuous monitoring while sustaining the iodised-salt programme.

This study has several strengths. (a) Data availability from a large number of 6-12-year-old schoolchildren (16,910 in total); (b) uniform methodology for UIC assessments over the period of review in a single laboratory with stringent external quality control; (c) permanent health staff used as a single team in all four studies and goitre palpation; (d) minimising variability in urine- and salt-assay methodology using the same protocols developed by the UNICEF, WHO, and IGN. However, the unavailability of pre-USI data for comparison was an inherent shortcoming of this study.

\section{Conclusions}

The iodine nutrition of the population has remained optimal and stable in Sri Lanka during more than two decades of continuous salt iodisation after its introduction in 1995 . However, we recommend the close and careful monitoring of pregnant women and schoolchildren in view of the data we presented. 
The delivery of salt to consumers has improved and is adequate in the majority. The contribution of dietary sources other than salt needs to be assessed in well-planned studies.

Author Contributions: R.J. analysed datasets; R.J., J.G., L.D.P., J.H.L., and O.E.O. conceptualised, designed, and wrote the paper. All authors read the manuscript, made a substantial contribution to the revision, and approved the final manuscript. All authors have read and agreed to the published version of the manuscript.

Acknowledgments: We thank the staff of the Department of Nutrition, Medical Research Institute, Ministry of Health, Sri Lanka for conducting the national survey, and all the participants of the study. We would like to thank Dulitha Fernando, Pierre Boudex, and the late Meliyanthi Gunathilaka for supporting us in every step. Adikari, Morina Hossein, Aberra Bekele, Moazzem Hossaine from UNICEF, Colombo and Chandrakant Pandav for all their support from the beginning. This research received no specific grant from any funding agency in the public, commercial, or not-for-profit sectors.

Conflicts of Interest: The opinions expressed are those of the authors and do not necessarily reflect the views of the institutions with which they are affiliated. The authors declare that there is no conflict of interest.

\section{References}

1. Stanbury, J.B.; Hetzel, B.S. Endemic Goitre and Endemic Cretinism, Iodine Nutrition in Health and Disease; John Wiley and Sons: New York, NY, USA, 1980.

2. World Health Organization. Iodine and Health-Eliminating Iodine Deficiency Disorders Safely through Salt Iodisation; A statement by the WHO; WHO: Geneva, Switzerland, 1994.

3. World Health Organization. Assessment of Iodine Deficiency Disorders and Monitoring Their Elimination: A Guide for Programme Managers, 3rd ed.; WHO: Geneva, Switzerland, 2007.

4. Iodine Global Network (IGN). Global Scorecard of Iodine Nutrition in 2019. Available online: https: //www.ign.org/cm_data/Global_Scorecard_2019_SAC.pdf (accessed on 14 March 2020).

5. World Health Organization. Recommended Iodine Levels in Salt and Guidelines for Monitoring their Adequacy and Effectiveness. Based on a Joint WHO/UNICEF/ICCIDD Consultation. World Health Organization: Geneva, Switzerland, 8-9 July 1996. Available online: https://apps.who.int/iris/bitstream/ handle/10665/63322/WHO_NUT_96.13.pdf (accessed on 14 March 2020).

6. Greenwald, I. Some notes on the history of goitre in Ceylon. Ceylon Med J. 1953, 2, 140. [PubMed]

7. Wilson, D.C. Goitre in Ceylon and Nigeria. Br. J. Nutr. 1954, 8, 90-99. [CrossRef] [PubMed]

8. Mahadeva, K.; Seneviratne, D.A.; Jayatilleke, D.B.; Shanmuganathan, S.S.; Premachandra, P.; Nagarajah, M. Further studies on the problem of goitre in Ceylon. Br. J. Nutr. 1968, 22, 527-534. [CrossRef] [PubMed]

9. Deo, M.G.; Subramanian, T.A.V. Iodine metabolism in children and women with goitre in Ceylon. Br. J. Nutr. 1971, 25, 97-105. [CrossRef] [PubMed]

10. Fernando, M.A.; Balsuriya, S.; Herath, K.B.; Katugampola, S. Endemic Goitre in Sri Lanka. Asia Pac. J. Public Health 1989, 3, 11-18. [CrossRef] [PubMed]

11. Government of Sri Lanka. Food (Iodization of Salt) Regulations under Section 32 of the Food Act, No. 26 of 1980 ; Department of Government Printing: Colombo, Sri Lanka, 1995.

12. Centers for Diseases Control and Prevention (CDC). The Challenge of Iodine Deficiency Disorders. EQIP 10 Years Anniversary. Atlanta, USA. 2011. Available online: https://www.cdc.gov/labstandards/pdf/equip/ EQUIP_Booklet.pdf (accessed on 14 March 2020).

13. Jayatissa, R.; Gunathilaka, M.; Fernando, D. Iodine nutrition status among schoolchildren after salt iodisation. Ceylon Med. J. 2005, 50, 144-148. [CrossRef] [PubMed]

14. Jayatissa, R.; Gunathilaka, M.; Fernando, D. Second National Iodine Survey; Medical Research Institute: Colombo, Sri Lanka, 2006. Available online: http://www.mri.gov.lk/assets/Nutrition/2005-Second-NationalIDD-Survey-.pdf (accessed on 21 March 2020).

15. Jayatissa, R.; Gunathilaka, M.; Fernando, D. Third National Iodine Survey; Medical Research Institute: Colombo, Sri Lanka, 2010. Available online: https://www.ign.org/cm_data/2017_Sri_Lanka.pdf (accessed on 21 March 2020).

16. Jayatissa, R.; Fernando, D.; De Silva, H. Fourth National Iodine Survey; Medical Research Institute: Colombo, Sri Lanka, 2016. Available online: http://www.mri.gov.lk/assets/Nutrition/2016-Fourth-National-IDD-survey.pdf (accessed on 21 March 2020). 
17. Gorstein, J.S.K.; Parvanta, I.; Begin, I. Indicators and Methods for Cross-Sectional Surveys of Vitamin and Mineral Status of Populations; The Micronutrient Initiative: Ottawa, ON, Canada; Center of Disease Surveillance: Atlanta, GA, USA, 2007.

18. World Health Organisation. Indicators for Assessing Iodine Deficiency Disorders and their Control through Salt Iodizaton; WHO/NUT/94.6; WHO; UNICEF; ICCIDD: Geneva, Switzerland, 1994; pp. 1-55.

19. Jayatissa, R.; Fernando, D.; De Silva, H. National Nutrition and Micronutrient Survey of Pregnant Women in Sri Lanka: 2015; Medical Research Institute/UNICEF/WFP: Colombo, Sri Lanka, 2017. Available online: https://www.wfp.org/publications/national-nutrition-and-micronutrient-survey-pregnant-womensri-lanka (accessed on 21 March 2020).

20. Ohashi, T.; Yamaki, M.; Pandav, C.S.; Karmarkar, M.G.; Irie, M. Simple microplate method for determination of urinary iodine. Clin. Chem. 2000, 46, 529-536. [CrossRef] [PubMed]

21. Delange, F.; de Benoist, B.; Burgi, H.; ICCIDD Working Group. At what median urinary iodine concentration is a population iodine suffcient? IDD News Lett. 2001, 17, 10-11.

22. United Nation of Independent Children's Fund (UNICEF). Guidance on the Monitoring of Salt Iodization Programmes and Determination of Population Iodine Status; UNICEF: New York, NY, USA, 2019.

23. World Health Organization. Iodine in Drinking Water; WHO: Geneva, Switzerland, 2003.

24. Lv, S.; Wang, Y.; Xu, D.; Rutherford, S.; Chong, Z.; Du, Y.; Jia, L.; Zhao, J. Drinking water contributes to excessive iodine intake among children in Hebei, China. Eur. J. Clin. Nutr. 2013, 67, 961-965. [CrossRef] [PubMed]

25. Markou, K.B.; Georgopoulos, A.; Makri, M.; Anastasiou, E.; Vlasopoulou, B.; Lazarou, N.; Veizis, A.; Sakellaropoulos, G.; Vagenakis, A.G. Iodine deficiency in Azerbaijan after the discontinuation of an iodine prophylaxis program: Reassessment of iodine intake and goiter prevalence in schoolchildren. Thyroid 2001, 11, 1141-1146. [CrossRef] [PubMed]

26. Li, M.; Ma, G.; Boyages, S.C.; Eastman, C.J. Re-emergence of iodine deficiency in Australia. Asia Pac. J. Clin. Nutr. 2001, 10, 200-203. [CrossRef] [PubMed]

27. Zimmermann, M.B.; Wegmüller, R.; Zeder, C.; Torresani, T.; Chaouki, N. Rapid relapse of thyroid dysfunction and goiter in school age children after withdrawal of salt iodization. Am. J. Clin. Nutr. 2004, 79, 642-645. [CrossRef] [PubMed]

28. Zimmermann, M.B. Assessing iodine status and monitoring progress of iodised salt programs. J. Nutr. 2004, 134, 1673-1677. [CrossRef] [PubMed]

29. Lazarus, J.H.; Bestwick, J.P.; Channon, S.; Paradice, R.; Maina, A.; Rees, R.; Chiusano, E.; John, R.; Guaraldo, V.; George, L.M. Antenatal thyroid screening and childhood cognitive function. N. Engl. J. Med. 2012, 366, 493-501. [CrossRef]

30. Jayatissa, R.; Gunathilaka, M.M.; Ranbanda, J.M.; Peiris, P.; Jayasingha, J.; Ekanayaka, P.; Kulathunga, H. Iodine status of pregnant women in Sri Lanka. Sri Lanka J. Diabetes Endocrinol. Metab. 2013, 3, 4-7. [CrossRef]

31. Zimmermann, M.B.; Ito, Y.; Hess, S.Y.; Fujieda, K.; Molinari, L. High thyroid volume in children with excess dietary iodine intakes. Am. J. Clin. Nutr. 2005, 81, 840-844. [CrossRef]

32. Shen, H.; Liu, S.; Sun, D.; Zhang, S.; Su, X.; Shen, Y.; Han, H. Geographical distribution of drinking water with high iodine level and association between high iodine level in drinking water and goitre: A Chines national investigation. Br. J. Nutr. 2011, 106, 243-247. [CrossRef] [PubMed]

33. Jayatissa, R.; Fernando, D.N. Supplementation of micronutrients in children and food fortification initiatives in Sri Lanka: Benefits versus risks. Ann. N. Y. Acad. Sci. 2018, 1-14. [CrossRef] [PubMed]

34. Jayatissa, R.; Yamori, Y.; De Silva, A.H.; Mori, M.; De Silva, P.C. Estimation of salt intake, potassium intake and sodium-to-potassium ratio by 24-hour urinary excretion: An urban rural study in Sri Lanka. 2012, in press. [CrossRef]

(C) 2020 by the authors. Licensee MDPI, Basel, Switzerland. This article is an open access article distributed under the terms and conditions of the Creative Commons Attribution (CC BY) license (http://creativecommons.org/licenses/by/4.0/). 

Article

\title{
Dietary Relationship with 24 h Urinary Iodine Concentrations of Young Adults in the Mountain West Region of the United States
}

\author{
Demetre E. Gostas ${ }^{1}$, D. Enette Larson-Meyer ${ }^{1, *}$, Hillary A. Yoder ${ }^{2}$, Ainsley E. Huffman ${ }^{3}$ and \\ Evan C. Johnson ${ }^{4}$ \\ 1 Department of Family and Consumer Sciences, University of Wyoming, Laramie, WY 82071, USA; \\ gostas1@uwyo.edu \\ 2 Division of Kinesiology, University of Alabama, Tuscaloosa, AL 35487, USA; hayoder@crimson.ua.edu \\ 3 University of Utah School of Medicine; Salt Lake City, UT 84108, USA; ainsley.huffman@hsc.utah.edu \\ 4 Division of Kinesiology \& Health, University of Wyoming; Laramie, WY 82070, USA; ejohns54@uwyo.edu \\ * Correspondence: enette@uwyo.edu
}

Received: 20 November 2019; Accepted: 19 December 2019; Published: 1 January 2020

\begin{abstract}
Background: Iodine deficiency is not seen as a public health concern in the US. However certain subpopulations may be vulnerable due to inadequate dietary sources. The purpose of the present study was to determine the dietary habits that influence iodine status in young adult men and women, and to evaluate the relationship between iodine status and thyroid function. Methods: 111 participants $(31.6 \pm 0.8$ years, $173.2 \pm 1.0 \mathrm{~cm}, 74.9 \pm 1.7 \mathrm{~kg}$ ) provided $24 \mathrm{~h}$ urine samples and completed an iodine-specific Food Frequency Questionnaire (FFQ) for assessment of urinary iodine content (UIC) as a marker of iodine status and habitual iodine intake, respectively. Serum Thyroid Stimulating Hormone (TSH) concentration was evaluated as a marker of thyroid function. Spearman correlational and regression analysis were performed to analyze the associations between iodine intake and iodine status, and iodine status and thyroid function. Results: $50.4 \%$ of participants had a $24 \mathrm{~h}$ UIC $<100 \mu \mathrm{g} / \mathrm{L})$. Dairy $(r=0.391, p<0.000)$ and egg intake $(r=0.192, p=0.044)$ were the best predictors of UIC, accounting for $19.7 \%$ of the variance $(p \leq 0.0001)$. There was a significant correlation between UIC and serum TSH $(\mathrm{r}=0.194, p<0.05)$ but TSH did not vary by iodine status category $(\mathrm{F}=1.087, p=0.372)$. Discussion: Total dairy and egg intake were the primary predictors of estimated iodine intake, as well as UIC. Iodized salt use was not a significant predictor, raising questions about the reliability of iodized salt recall. These data will be useful in directing public health and clinical assessment efforts in the US and other countries.
\end{abstract}

Keywords: Iodine Status; Food Frequency Questionnaire; iodized salt; iodine intake; dairy intake; adults

\section{Introduction}

Iodine is an essential trace mineral that forms the building blocks of the thyroid hormones thyroxine and triiodothyronine, which are critical regulators of metabolic activity [1]. Iodine's major environmental source is the ocean [2], with seafood and seaweed providing significant dietary sources. The iodine content of most other foods, however, is low and dependent on soil content and agriculture practices [3]. Exceptions include dairy products, which may be richer sources due to livestock iodine supplementation and use of iodophors for cleaning milk udders [4-6]. Insufficient iodine intake leads to iodine deficiency, which can manifest as hypothyroidism and endemic goiter in adults [3,7]. Iodine deficiency is of particular concern in women of reproductive age, as many pregnancies are unplanned [8], and deficiency can impair fetal cognitive and physical development [3,7]. 
Although iodine deficiency is a worldwide concern, with nearly one-third of the global population thought to be deficient [9], the iodine status of the US population has been viewed as adequate since the widespread iodization of salt in the late 1920s [10]. Urinary iodine concentration (UIC) measured over $24 \mathrm{~h}$ is a commonly used biomarker to assess iodine status in populations [3,11]. The most recent data from the National Health and Nutrition Examination Survey (NHANES 2005-2006 and 2007-2008) [12] show median UIC as adequate at $164 \mu \mathrm{g} / \mathrm{L}$, with just under $10 \%$ of the population categorized as severely deficient [12]. Still, some subpopulations of the US may be vulnerable to deficiency due to food selection patterns or avoidance of iodized salt. These at-risk subpopulations include vegans/vegetarians [13], those who avoid seafood and/or dairy [14], and those follow a sodium restricted diet [15-17] or eat local foods in regions with iodine-depleted soils [2,3]. The Institute of Medicine [18] and the American Heart Association [19] have advocated for decreasing sodium intake to less than $2300 \mathrm{mg}$ per day [18] and, more prudently, to less than $1500 \mathrm{mg}$ per day [19], which could be reducing Americans' intake of iodized salt. Additionally, apparent trends toward local and plant-based diets may negatively influence iodine status depending on food selection patterns and habits (e.g., avoidance of seafood and dairy) and the content of local soils. Therefore, despite the labeling of the US populations' iodine intake as adequate, certain dietary choices, including strict adherence to dietary recommendations to restrict salt intake [20], may directly influence iodine status and indirectly influence thyroid function.

The present study was a pilot study that aimed to assess iodine intake and status in a sample of young adult men and women and determine the dietary patterns and habits that influence the observed iodine status. Twenty-four hour UIC was used as a reference standard for estimation of iodine status $[7,21]$ although there is no consensus on the biomarker to use for the assessment of individual iodine status $[22,23]$. We hypothesized, based on the above, that we would observe at least some individuals with a low $24 \mathrm{~h}$ UIC $(<100 \mu \mathrm{g} / \mathrm{L})$, and that UIC would be associated with dietary factors such as the frequency of milk, fish and seafood intake, multivitamin and iodized salt use, and vegetarian status. A secondary purpose was to explore the relationship between iodine status and hypothyroidism using the thyroid stimulating hormone (TSH) as a general marker of thyroid function.

\section{Materials and Methods}

This study was conducted concurrently as part of a larger study evaluating urine color as a marker of change in daily water intake [24] conducted over a 13 month period beginning in the spring of 2016. Male and female participants between the age of 18 and 45 years were recruited from the Laramie, Wyoming community. To be eligible, participants had to be in good overall health and not have a health condition that could influence study results (e.g., anemia, diabetes, cystic fibrosis, cancer autoimmune disorders). Exclusionary criteria are previously published [24] and include: inability to understand and write English (for ability to complete written survey instruments); evidence of clinically relevant metabolic, cardiovascular, hematologic, hepatic, gastrointestinal, renal, pulmonary, endocrine or psychiatric history of disease (based on the medical history questionnaire); pregnancy or breast-feeding; regular prescription drug treatment within 15 days prior to start of the study; inability to discontinue use of specific dietary/herbal supplements (calcium, chromium, vitamin C, cat's claw, chaparral, cranberry, creatine, ephedra, germanium, hydrazine, licorice, l-lysine, pennyroyal, thunder god vine, willow bark, wormwood oil, yellow oleander, yohimbe); currently exercising $>4 \mathrm{~h}$ per week; changes in diet or in body mass of $>2.5 \mathrm{~kg}(\sim 5 \mathrm{lbs})$ in the past month; or recent relocation from low altitude to Laramie within the past three months. The study was approved by the Institutional Review Board of the University of Wyoming. Volunteers were informed that the urine samples collected to assess hydration status would also be used to establish the iodine status of a healthy population of individuals through measurement of iodine levels in urine and if these levels are related to specific dietary or lifestyle factors. They were also informed of any possible risks prior to giving written formal consent to participate in the study. 


\subsection{Overview of Testing}

This analysis was performed on 111 of the 125 total participants enrolled in the study, who had complete data on $24 \mathrm{~h}$ urinary iodine concentrations (UIC) and valid responses from a food frequency questionnaire (FFQ). Reasons for exclusion of 14 of the 125 participants included: voluntary withdrawal prior to completion, not following study protocol instructions, not providing adequate urine for analysis or not turning in complete dietary data. At study initiation (baseline), participants completed a dietary habits survey and an iodine-specific food-frequency questionnaire (FFQ). Height and weight were measured on a stadiometer (Health o meter ${ }^{\circledR}$, Model $201 \mathrm{HR}$ ) and digital weight scale (Seca, Model 780 2321138), respectively, with body mass index (BMI) calculated as kg/m². Physical activity was estimated using the International physical Activity Questionnaire (IPAQ) [25].

\subsection{Measurement of Urinary Iodine Concentration and Iodine Status}

As part of an 11 day collection protocol, participants collected a $24 \mathrm{~h}$ urine sample for the purpose of UIC measurement on the morning of day two. Participants were asked to void and discard the first morning urine sample and then collect all subsequent samples for $24 \mathrm{~h}$, ending with the first sample upon waking on day three. Food and fluid intake were ad libitum during this $24 \mathrm{~h}$ urine collection. Iodine in urine was measured by a commercial laboratory (Mayo Clinic, Rochester, MN) using an inductively coupled plasma-mass spectrometry using tellurium as an internal standard and an aqueous acid calibration. The repeated tolerance acceptability was $10 \mathrm{ng} / \mathrm{mL}$ or $10 \%$. Twenty-four hour UIC was defined using the following criteria: $<20 \mu \mathrm{g} / \mathrm{L}$ (severe iodine deficiency), 20-49 $\mu \mathrm{g} / \mathrm{L}$ (moderate iodine deficiency), 50-99 $\mu \mathrm{g} / \mathrm{L}$ (mild iodine deficiency), 100-199 $\mu \mathrm{g} / \mathrm{L}$ (adequate iodine nutrition), 200-299 $\mu \mathrm{g} / \mathrm{L}$ (more than adequate iodine intake), $\geq 300 \mu \mathrm{g} / \mathrm{L}$ (excessive iodine intake) [15]. UIC was also entered into the equation of Zitterman, which incorporates body mass to estimate intake [26,27]. Urinary iodine $(\mu \mathrm{g} / \mathrm{L}) \times 0.0235 \times$ body weight $(\mathrm{kg})=$ Daily Iodine Intake.

\subsection{Iodine Intake, Frequency of Iodine Containing Foods and Dietary Habits}

The iodine-specific FFQ (Appendix A) evaluated the frequency of consumption of 43 food items known to have significant iodine content (e.g., seafood, seaweed, dairy-see Table 1). Frequency was evaluated according to the following responses: (a) never or less than one time per month; (b) one to three times per month; (c) one time per week; (d) two to four times per week; (e) five to six times per week; (f) one time per day; (g) two to three times per day; (h) four to five times per day; (i) or six or more times per day). Daily intake of iodine was estimated by multiplying the frequency midpoint by the average content of each vitamin D-containing food and expressed as IU/day (assuming 30 days per month), as previously outlined by Halliday et al. [28]. As iodine content is not available in food composition tables or databases, iodine content of the food items in the FFQ was derived from several sources (Table 1), with a majority of the data coming from the ongoing Total Diet Study (TDS) [29]. Iodine content in the TDS is listed per $100 \mathrm{~g}$ of the selected food item. Iodine content was recalculated from the TDS to iodine per serving size, to match the household measured listed in the FFQ. The iodine content in other sources was also converted to adjust given units to iodine per serving size. For ease of analysis, iodine intake from specific categories of foods were combined, which included estimates of iodine intake from total dairy (fluid milk plus yogurt), total fish (all types of fish) and total seafood (total fish plus all types of shellfish).

The Dietary Habits Survey (Appendix B) addressed questions regarding the frequency of table salt use in salting and cooking foods, and the type of table salt typically consumed (iodized, non-iodized). It also addressed whether participants followed a vegetarian diet, frequented a farmer's market for local food purchases, were a member of a Community Supported Agriculture program (CSA), or maintained a home garden for growing food, based on Yes, Sometimes, or NO responses (Appendix B). Both instruments were developed for the current study and have not yet been validated. 
Table 1. Iodine content of foods deduced from current available resources.

\begin{tabular}{|c|c|c|}
\hline Food Item & Estimated Iodine Level ( $\mu$ g per Serving) & Serving Size \\
\hline Milk (fluid) & $90.86^{\mathrm{a}}$ & 1 cup \\
\hline Soy Milk & $2.2^{\mathrm{b}}$ & 1 cup \\
\hline Soy Protein Bar & $20^{\mathrm{c}}$ & 1 bar \\
\hline Soy Protein Powder & $0^{\mathrm{d}}$ & 1 scoop \\
\hline Soy Sauce & $0^{\mathrm{d}}$ & $1 \mathrm{Tbsp}$ \\
\hline Non-dairy Milk & $2.2^{b}$ & 1 cup \\
\hline Orange Juice & $0^{\mathrm{a}}$ & 1 cup \\
\hline Cereal & $1.62^{\mathrm{a}}$ & $\frac{3}{4}$ cup \\
\hline Bread & $1.18^{\mathrm{a}}$ & 1 slice $(26 \mathrm{~g})$ \\
\hline Subway Sandwich & $4.14^{\mathrm{a}}$ & 6-inch sandwich \\
\hline Bagel & $4.312^{\mathrm{a}}$ & 1 bagel (95 g) \\
\hline Yogurt & $87^{\text {a }}$ & 1 cup \\
\hline Cheese & $13.33^{\text {a }}$ & $2 \mathrm{oz}$ \\
\hline Egg & $21.42^{\text {a }}$ & 1 egg $(50 \mathrm{~g})$ \\
\hline Margarine & $0^{\mathrm{a}}$ & $1 \mathrm{tsp}$ \\
\hline Liver & $11^{\mathrm{a}}$ & $100 \mathrm{~g}(3.5 \mathrm{oz})$ \\
\hline Cod & $93^{\mathrm{e}}$ & $3.5 \mathrm{oz}$ \\
\hline Grouper & $84^{\mathrm{f}}$ & $3.5 \mathrm{oz}$ \\
\hline Haddock & $224^{\mathrm{e}}$ & $3.5 \mathrm{oz}$ \\
\hline Halibut & $9.9^{\mathrm{e}}$ & $3.5 \mathrm{oz}$ \\
\hline Herring & $84^{\mathrm{f}}$ & $3.5 \mathrm{oz}$ \\
\hline Mackerel & $84^{\mathrm{f}}$ & $3.5 \mathrm{oz}$ \\
\hline Perch & $10.89^{\mathrm{e}}$ & $3.5 \mathrm{oz}$ \\
\hline Salmon & $10.43^{e}$ & $3.5 \mathrm{oz}$ \\
\hline Sardines & $6.69^{g}$ & $3.5 \mathrm{oz}$ \\
\hline Seabass & $84^{\mathrm{f}}$ & $3.5 \mathrm{oz}$ \\
\hline Swordfish & $19.8^{\mathrm{e}}$ & $3.5 \mathrm{oz}$ \\
\hline Tukaoua & $84^{\mathrm{f}}$ & $3.5 \mathrm{oz}$ \\
\hline Tuna Albacore & $6.69^{a}$ & $3.5 \mathrm{oz}$ \\
\hline Tuna Light & $6.69^{\mathrm{a}}$ & $3.5 \mathrm{oz}$ \\
\hline Walleye & $84^{\mathrm{f}}$ & $3.5 \mathrm{oz}$ \\
\hline Other Fish & $22^{\mathrm{h}}$ & $3.5 \mathrm{oz}$ \\
\hline Clams & $74.8^{\mathrm{e}}$ & $4 \mathrm{oz}$ \\
\hline Crabmeat & $42.56^{\mathrm{e}}$ & $4 \mathrm{oz}$ \\
\hline Lobster & $209.67^{\mathrm{e}}$ & $4 \mathrm{oz}$ \\
\hline Mussels & $9.14^{\mathrm{i}}$ & $4 \mathrm{oz}$ \\
\hline Oysters & $135^{\mathrm{e}}$ & $4 \mathrm{oz}$ \\
\hline Scallops & $9.14^{\mathrm{e}}$ & $4 \mathrm{oz}$ \\
\hline Shimp & $8.184^{\mathrm{a}}$ & $4 \mathrm{oz}$ \\
\hline Seaweed & $34.56^{j}$ & $2.6 \mathrm{~g}$ (1 sheet) \\
\hline Iodized Table Salt & $68^{\mathrm{k}}$ & $1.5 \mathrm{~g}(1 / 4 \mathrm{tsp})$ \\
\hline Other Salt & $0^{1}$ & $1.5 \mathrm{~g}$ \\
\hline Multivitamin-(Iodine-Containing) & $150^{\mathrm{m}}$ & 1 tablet \\
\hline Kelp Supplement & $225^{c}$ & 1 capsule \\
\hline
\end{tabular}

Sources: a Total Diet Study 2006-2013 [29], ${ }^{\mathrm{b}}$ Bath et al. [30], ${ }^{\mathrm{c}}$ Popular product nutrient labels, ${ }^{\mathrm{d}}$ American Thyroid Association [31], ${ }^{\text {e }}$ United States Department of Agriculture (USDA) National Food and Nutrient Analysis Program [32], ${ }^{\mathrm{f}}$ Inferred from other fish values from USDA's National Food and Nutrient Analysis Program, $\mathrm{g}$ Inferred from Canned Tuna TDS 2006-2013, h Inferred from the average of multiple fish types from USDA's National Food and Nutrient Analysis Program, ${ }^{\mathrm{I}}$ Inferred from the scallop value from USDA's National Food and

Nutrient Analysis Program, ${ }^{\mathrm{j}}$ Teas et al. 2004 [33], ${ }^{\mathrm{k}}$ Total Diet Study 1982-1991 [34], ' Dasgupta et al. 2008 [35], ${ }^{\mathrm{m}}$ Summation of observation of popular multivitamins available at local grocery stories and pharmacies. 


\subsection{Assessment of Thyroid Function}

A blood sample was obtained on the morning of day three for measurement of TSH via immunometric assay, (Regional West, Scotts Bluff, NE). Daily quality control at different representative levels was evaluated across the measurement range, as precision changed with concentration for 112 replicates. The CV was $3.4 \%$ when the mean was $50 \mu \mathrm{g}$ I per $24 \mathrm{~h}$, and $1.3 \%$ when the mean was $191 \mu \mathrm{g}$ I per $24 \mathrm{~h}$. The presence of hypothyroidism (TSH $>4.68 \mathrm{mIU} / \mathrm{L})$ and hyperthyroidism $(\mathrm{TSH}<$ $0.47 \mathrm{mIU} / \mathrm{L}$ ) was evaluated based on standard laboratory ranges (normal TSH $=0.47$ to $4.68 \mathrm{mIU} / \mathrm{L}$ ) as well as using recent, more conservative criteria for subclinical hypothyroidism (TSH > 2.5) [36].

\subsection{Statistical Analysis}

Data were analyzed using IBM SPSS statistics software (SPSS Inc., Chicago, IL; version 24.0). Analysis of Variance (ANOVA) was used to compare differences in iodine intake, iodine status, thyroid function and other key variables by sex (male vs. female). Correlation coefficients (Pearson or Spearman Rank) were used to evaluate the associations between iodine status (i.e., UIC) and gross iodine intake, or iodine intake from specific foods or supplements (dairy, seafood, seaweed, iodized salt, multivitamin intake, etc.). Pearson correlations were also used for the evaluation of UIC and serum TSH relationships. In most cases, Spearman Rank Coefficients were used instead of Pearson Correlation Coefficients, due to the general non-normal distribution of intake data. Multiple linear Regression Models (Backwards Regression) were created to determine which dietary source(s) were the largest contributors to iodine intake and iodine status. ANOVA was also used to determine whether there were differences in iodine intake and status by the items indicated on the dietary habits survey, which included following a vegetarian diet, frequenting farmer's markets for local food purchases, being CSA members or maintaining a home garden for growing food. Data are expressed as means \pm SEM unless otherwise specified. Significance was set as an alpha $<0.05$.

\section{Results}

\subsection{Subject Characteristics}

The characteristics of the 111 participants are shown in Table 2. BMI and reported physical activity varied widely among participants. Men were taller, heavier, and had a higher BMI than women $(p<0.05)$. The sample size is provided in parenthesis in the case of occasional missing datapoints, attributed to inadequate samples for analysis or missing responses on questionnaires.

Table 2. Descriptive characteristics of Participants and Frequency of Overweight, Smoking and Physical Activity by Sex.

\begin{tabular}{|c|c|c|c|}
\hline & \multicolumn{2}{|c|}{ Mean \pm SEM } & $n$ \\
\hline Age & \multicolumn{2}{|c|}{$31.6 \pm 0.8$} & 111 \\
\hline Height (cm) & \multicolumn{2}{|c|}{$173.2 \pm 1.0$} & 111 \\
\hline Body Mass (kg) & \multicolumn{2}{|c|}{$74.9 \pm 1.7$} & 111 \\
\hline BMI $\left(\mathrm{kg} / \mathrm{M}^{2}\right)$ & \multicolumn{2}{|c|}{$24.8 \pm 0.4$} & 111 \\
\hline Hematocrit (\%) & \multicolumn{2}{|c|}{$45.1 \pm 0.28$} & 110 \\
\hline \multirow[t]{2}{*}{ TSH (mIU/L) } & \multicolumn{2}{|c|}{$2.1 \pm 0.11$} & 107 \\
\hline & Male $(n)$ & Female $(n)$ & \\
\hline Sex & 59 & 52 & 111 \\
\hline BMI Underweight & 1 & 0 & 1 \\
\hline BMI Normal & 25 & 36 & 61 \\
\hline BMI Overweight & 26 & 13 & 39 \\
\hline BMI Obese & 7 & 3 & 10 \\
\hline Smokers & 4 & 0 & 4 \\
\hline IPAQ Low & 10 & 7 & 17 \\
\hline IPAQ Moderate & 21 & 30 & 51 \\
\hline IPAQ High & 22 & 14 & 36 \\
\hline
\end{tabular}




\section{2. $24 \mathrm{~h}$ UIC and Iodine Status}

Twenty-four hour UIC ranged between 15 and $714 \mu \mathrm{g} / \mathrm{L}$. The median value was $98.0 \mu \mathrm{g} / \mathrm{L}$ (interquartile range $=60.0-180.0)$, with no difference by sex $(p=0.36)$. The frequency of the various categories of iodine status based on WHO criteria is shown in Figure 1.

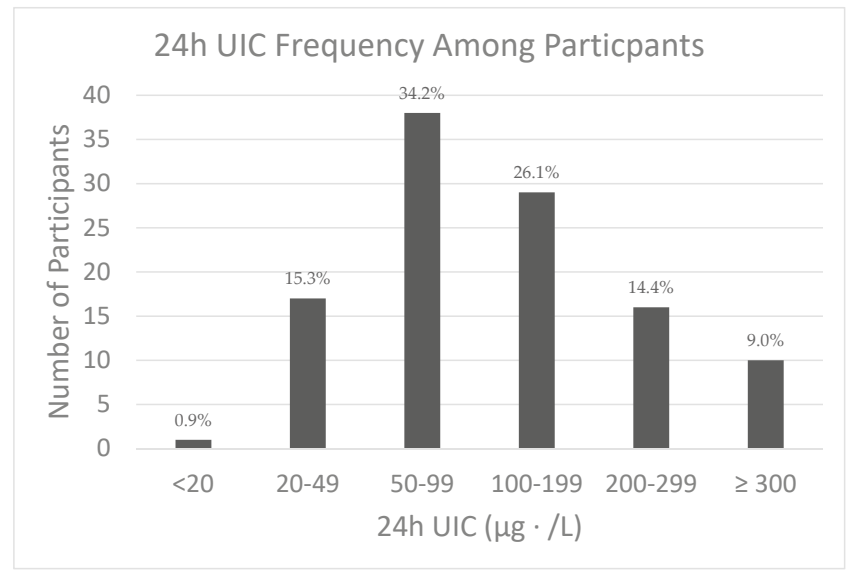

Figure 1. Iodine status based on the World Health Organization (WHO) criteria for urinary iodine concentration (UIC) [15]: <20 $\mu \mathrm{g} / \mathrm{L}$ (Severe Deficiency); 20-49 $\mu \mathrm{g} / \mathrm{L}$ (Moderate Deficiency); 50-99 $\mu \mathrm{g} / \mathrm{L}$

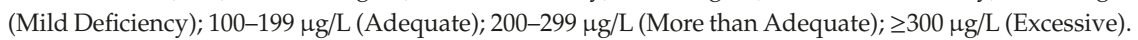

Body Mass Index (BMI) and International Physical Activity Questionnaire (IPAQ) [37] scales were used in classifications. BMI classifications are as follows: Underweight $(<18.5)$, Normal weight (18.5-24.9), Overweight (25.0-29.9), Obese (>30.0). IPAQ classifications are as follows: Low (not meeting criteria for Moderate or High), Moderate (likely doing $30 \mathrm{~min}$ moderate intensity physical activity on most days), High (likely doing at least $1 \mathrm{~h}$ of moderate intensity physical activity per day) [25].

\subsection{Estimated Daily Iodine Intake and Frequency of Intake of Iodine-Containing Foods}

Frequency of consumption of selected iodine-containing foods along with supplements is shown in Table 3. Overall, estimated daily iodine intake ranged from 36.4 to $1113.3 \mu \mathrm{g} /$ day. Daily intake averaged $327.7 \mu \mathrm{g}$ (SD: 21.0; median 291.4) and was not different by sex ( $p=0.49)$. While the mean and median iodine intake was higher than the U.S. Recommended Dietary Allowance (RDA) for adults of $150 \mu \mathrm{g} / \mathrm{day}, 21.6 \%(n=24)$ had estimated intakes less than the RDA, and $1.8 \%(n=2)$ had intakes greater than the Upper Limit of $1100 \mu \mathrm{g} /$ day. The estimated average daily iodine intakes from contributing foods are as follows) total dairy $(100.0 \mu \mathrm{g} \pm 8.6)$, eggs $(18.7 \mu \mathrm{g} \pm 2.3)$, total fish $(4.4 \mu \mathrm{g} \pm 1.3)$, total seafood (includes fish plus shellfish; $8.4 \mu \mathrm{g} \pm 1.7)$, iodized table salt $(33.7 \mu \mathrm{g} \pm$ $5.1)$, multivitamin $(47.61 \mu \mathrm{g} \pm 9.0)$, and seaweed $(0.81 \mu \mathrm{g} \pm 0.25)$. Using Spearman rank correlation coefficients, the total estimated iodine intake from the FFQ was correlated with reported total milk intake ( $\mathrm{r}=0.769, p<0.001)$, dairy intake (milk plus yogurt) $(\mathrm{r}=0.716, p<0.01)$, egg consumption $(\mathrm{r}=$ $0.295, p=0.002)$, total fish intake $(\mathrm{r}=0.191, p=0.044)$ and multivitamin use $(\mathrm{r}=0.460, p<0.01)$ but not with total seafood consumption $(\mathrm{r}=0.169, p=0.08)$, seaweed consumption $(\mathrm{r}=-0.050, p=0.6)$, or iodized salt intake $(\mathrm{r}=0.141, p=0.14)$.

A linear regression model was created to determine which food source was the biggest determinant of estimated iodine intake. Dietary sources that were significantly correlated with total intake by simple correlation analysis (total dairy, egg consumption, total fish and multivitamin use) were entered, along 
with iodized table salt and seaweed. As shown in Table 4, all sources remained significant contributors to estimated iodine intake.

Table 3. Frequency of major sources of reported dietary iodine by serving.

\begin{tabular}{|c|c|c|}
\hline Food Serving Size & Iodine ( $\mu \mathrm{g}$ per Serving) & Frequency \\
\hline Milk ( 1 cup fluid) $\left(n=110^{*}\right)$ & 90.86 & $\begin{array}{c}0 \text { or }<1 \text { times } \cdot \text { month }^{-1}=17 \\
1-3 \text { times } \cdot \text { month }^{-1}=12 \\
1 \text { time } \cdot \text { week }^{-1}=10 \\
2-4 \text { times } \cdot \text { week }^{-1}=26 \\
5-6 \text { times } \cdot \text { week }^{-1}=15 \\
1 \text { time } \cdot \text { day }^{-1}=17 \\
2-3 \text { times } \cdot \text { day }^{-1}=11 \\
4-5 \text { times } \cdot \text { day }^{-1}=2\end{array}$ \\
\hline Yogurt ( 1 cup) $\left(n=111^{*}\right)$ & 87 & $\begin{array}{c}0 \text { or }<1 \text { month }^{-1}=26 \\
1-3 \text { times } \cdot \text { month }^{-1}=17 \\
1 \text { time } \cdot \text { week }^{-1}=15 \\
2-4 \text { times } \cdot \text { week }^{-1}=24 \\
5-6 \text { times } \cdot \text { week }^{-1}=18 \\
1 \text { time } \cdot \text { day }^{-1}=9 \\
2-3 \text { times } \cdot \text { day }^{-1}=2 \\
4-5 \text { times } \cdot \text { day }^{-1}=0\end{array}$ \\
\hline Eggs ( 1 whole) $(n=109 *)$ & 21.42 & 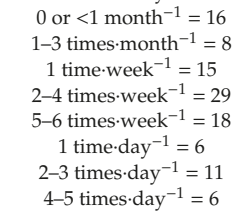 \\
\hline Total Seafood $(3.75 \mathrm{oz})\left(n=110^{*}\right)$ & 61 & $\begin{array}{c}0 \text { or }<1 \text { month }^{-1}=28 \\
1-3 \text { times } \cdot \text { month }^{-1}=48 \\
1 \text { time } \cdot \text { week }^{-1}=22 \\
2-4 \text { times } \cdot \text { week }^{-1}=9 \\
5-6 \text { times } \cdot \text { week }^{-1}=1 \\
1 \text { time } \cdot \text { day }^{-1}=2 \\
2-3 \text { times } \cdot \text { day }^{-1}=0 \\
4-5 \text { times } \cdot \text { day }^{-1}=0\end{array}$ \\
\hline Iodized Table Salt $(1.5 \mathrm{~g})\left(n=108^{*}\right)$ & 68 & $\begin{array}{c}0 \text { or }<1 \text { month }^{-1}=28 \\
1-3 \text { times } \cdot \text { month }^{-1}=18 \\
1 \text { time } \cdot \text { week }^{-1}=12 \\
2-4 \text { times } \cdot \text { week }^{-1}=12 \\
5-6 \text { times } \cdot \text { week }^{-1}=12 \\
1 \text { time } \cdot \text { day }^{-1}=14 \\
2-3 \text { times } \cdot \text { day }^{-1}=10 \\
4-5 \text { times } \cdot \text { day }^{-1}=2\end{array}$ \\
\hline Multivitamin ( 1 tablet) $\left(n=106^{*}\right)$ & 150 & 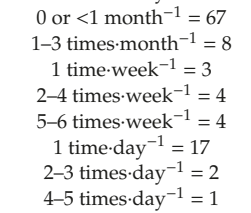 \\
\hline
\end{tabular}

* Number of participants who reported consuming each food source.

Table 4. Backwards Regression Model with Estimated iodine intake from food frequency questionnaire (FFQ) as the dependent variable and estimated iodine intake from various food categories as independent variables.

\begin{tabular}{ccccc}
\hline & $\mathbf{R}^{2}$ & SEE & Beta & Sig. \\
\hline Model & 0.991 & 21.81 & & 0.005 \\
Total Dairy & - & - & 0.066 & $>0.001$ \\
Total Fish & - & - & 0.108 & $>0.001$ \\
Multivitamin & - & - & 0.034 & $>0.001$ \\
Iodized Table Salt & - & - & 0.033 & $>0.001$ \\
Seaweed & - & - & 0.122 & $>0.001$ \\
Egg & - & - & 0.032 & $>0.001$ \\
\hline
\end{tabular}

SEE, standard error of the estimate. 


\subsection{Relationship between Iodine Intake and Iodine Status}

Using Spearman Rank Correlations, the estimated total iodine intake from the FFQ was correlated with UIC ( $\mathrm{r}=0.310, p=0.001)$ (Figure 2a). FFQ-estimated iodine intake was also correlated with predicted iodine intake using the equation of Zimmerman UIC ( $\mathrm{r}=0.327, p=0.001$ ) which incorporates UIC and body mass (Figure 2b) [26,27].

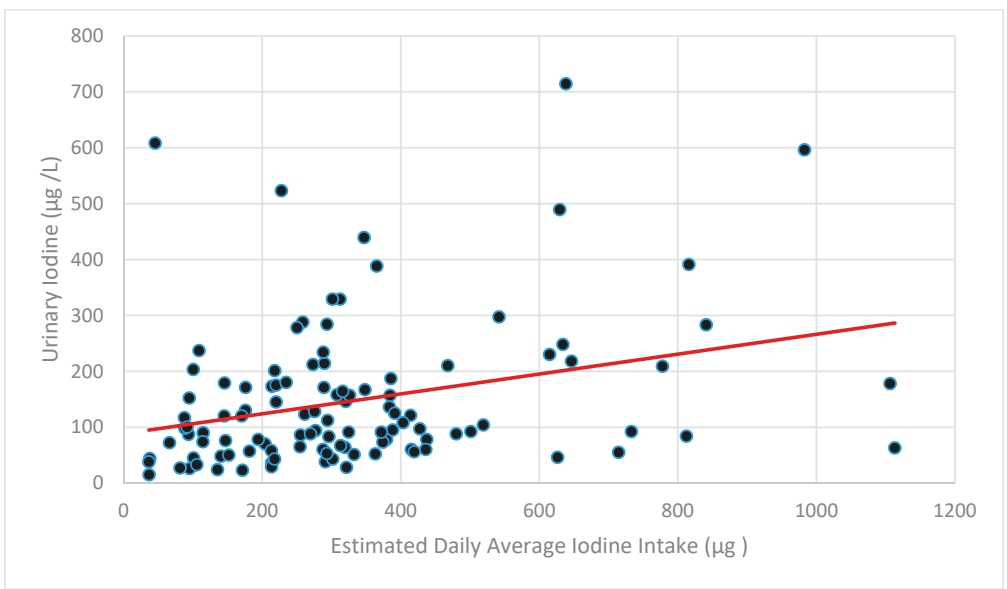

(a)

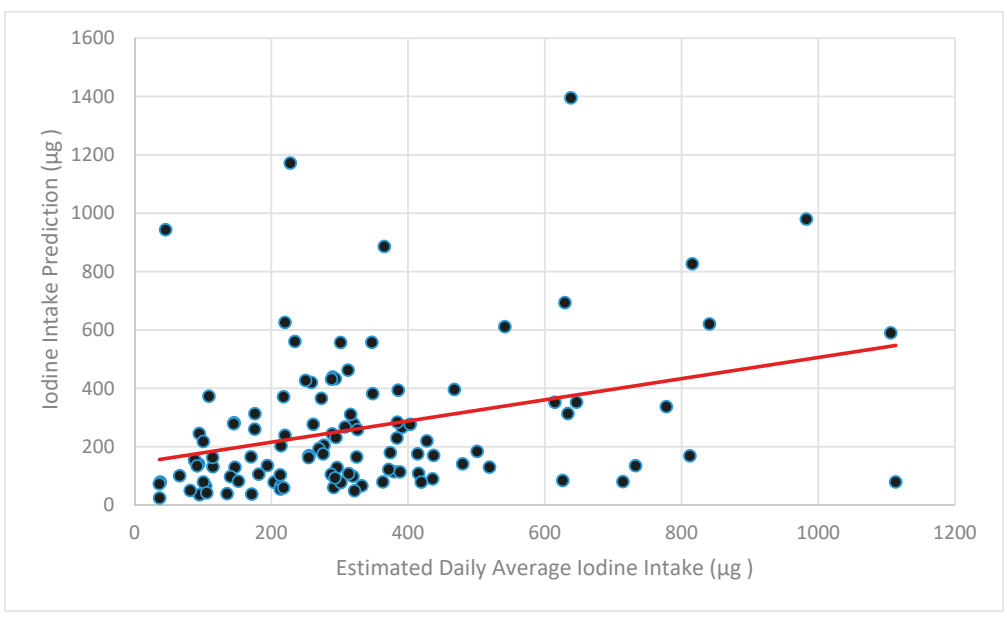

(b)

Figure 2. Estimated iodine intake by Food Frequency Questionnaire versus Urinary Iodine Concentration (a) and Iodine Intake Prediction (using the equation of Zimmerman) [26,27] where Daily Iodine Intake $=$ Urinary iodine $(\mu \mathrm{g} / \mathrm{L}) \times 0.0235 \times$ body weight $(\mathrm{kg})(\mathbf{b})$.

By Spearman Rank Correlation Coefficients, UIC was correlated with reported total dairy intake $(\mathrm{r}=0.391, p<0.01)$, egg consumption $(\mathrm{r}=0.192, p=0.044)$ and seaweed consumption $(\mathrm{r}=-0.239$, $p=0.011)$, but not with total fish intake $(\mathrm{r}=-0.003, p=0.973)$, total seafood consumption $(\mathrm{r}=-0.055$, $p=0.569)$, iodized table salt use $(\mathrm{r}=0.044, p=0.646)$ or multivitamin use $(\mathrm{r}=0.031, p=0.749)$.

A linear regression model was created to determine which food source(s) were the biggest determinant of $24 \mathrm{~h}$ UIC. Intake of iodine from dairy products, eggs, seaweed, fish, iodized salt and 
eggs were entered into the model. As shown in Table 5, only dairy and eggs remained significant contributors to UIC, explaining $19.7 \%$ of the variance $(p \leq 0.0001)$. Total fish, iodized table salt, multivitamin use and seaweed consumption accounted for an additional $3.2 \%$ of the variance, but were not significant contributors $(p>0.10)$.

Table 5. Backwards regression models with urinary iodine concentration (UIC) as the dependent variable and estimated iodine intake from total dairy, total fish, multivitamin, iodized salt, seaweed and egg consumption entered as independent variables.

\begin{tabular}{|c|c|c|c|c|}
\hline & $\mathbf{R}^{2}$ & SEE & Beta & Sig. \\
\hline Model 1 & 0.229 & 118.1 & & 0.001 \\
\hline Total Dairy & - & - & 0.017 & 0.001 \\
\hline Total Fish & - & - & -0.033 & 0.249 \\
\hline Multivitamin & - & - & -0.006 & 0.128 \\
\hline Iodized Table Salt & - & - & 0.003 & 0.704 \\
\hline Seaweed & - & - & 0.111 & 0.455 \\
\hline Egg & - & - & 0.037 & 0.032 \\
\hline Model 2 & 0.228 & 117.6 & & 0.001 \\
\hline Total Dairy & - & - & 0.017 & 0.001 \\
\hline Total Fish & - & - & -0.033 & 0.234 \\
\hline Multivitamin & - & - & -0.006 & 0.118 \\
\hline Seaweed & - & - & 0.105 & 0.474 \\
\hline Egg & - & - & 0.038 & 0.024 \\
\hline Model 3 & 0.224 & 117.3 & & 0.001 \\
\hline Total Dairy & - & - & 0.016 & 0.001 \\
\hline Total Fish & - & - & -0.033 & 0.234 \\
\hline Multivitamin & - & - & -0.006 & 0.125 \\
\hline Egg & - & - & 0.040 & 0.016 \\
\hline Model 4 & 0.213 & 117.5 & & 0.001 \\
\hline Total Dairy & - & - & 0.016 & 0.001 \\
\hline Multivitamin & - & - & -0.006 & 0.136 \\
\hline Egg & - & - & 0.041 & 0.013 \\
\hline Model 5 & 0.197 & 118.2 & & 0.000 \\
\hline Total Dairy & - & - & 0.016 & 0.000 \\
\hline Egg & - & - & 0.039 & 0.018 \\
\hline
\end{tabular}

\subsection{Dietary Habits, Iodine Intakes and Intake Status}

Twenty-one participants neglected to complete all questions on the Dietary Habits Survey. Complete data for those responding to questions addressing vegetarian status $(n=94)$, frequently visiting a farmer's market or food co-op for local food purchases $(n=95)$, having membership in a CSA $(n=94)$, and growing food in a home garden $(n=95)$ are shown in parentheses. Of those who completed the questions, five reported following a vegetarian or vegan diet, 49 reported regularly or sometimes frequenting a farmer's market for local food purchases, with 37 being members of a CSA or maintaining a home garden for growing food. Differences between estimated iodine intake or UIC were not observed according to whether participants reported following a vegetarian diet $(p=0.52$ and 0.91 ), regularly or sometimes frequenting a farmer's market ( $p=0.60$ and 0.49$)$, being a CAS member $(p=0.44$ and 0.38$)$ or maintaining a home garden (0.58 and 0.49$)(p>0.05)$.

\subsection{Relationship between Iodine Status and Thyroid Function}

The mean TSH $(n=107)$ was $2.07 \pm 0.11 \mathrm{mIU} / \mathrm{L}$. Based on standard laboratory criteria, four participants were classified with hypothyroidism $(\mathrm{TSH}>4.68 \mathrm{mIU} / \mathrm{L}$ ) and one was classified with hyperthyroidism (TSH $<0.47 \mathrm{mIU} / \mathrm{L}$ ). Using more conservative criteria $(\mathrm{TSH}>2.5)$, 24 were considered to have an underactive thyroid [36]. By Spearman rank correlation coefficients there was a correlation $(p<0.05)$ between serum TSH concentration and UIC $(\mathrm{r}=0.194, p=0.045)$. TSH concentration, however, did not differ by WHO iodine deficiency categories $(p=0.372)$. Notably, no differences in iodine intake or status were observed in those with TSH indicative of hypo- or hyperthyroid. 


\section{Discussion}

The overall purpose of this pilot study was to evaluate iodine intake and status in a sample of young adult men and women and determine if intake and UIC, as a biomarker of status, are influenced by dietary patterns. Overall, we found that our sample, with a median UIC of $98.0 \mu \mathrm{g} / \mathrm{L}$ and with $16.2 \%$ with a UIC below $<50 \mu \mathrm{g} / \mathrm{L}$, may be borderline deficient. However, there was high intersubjective variability, providing an opportunity to explore dietary relationships with UICs. In contrast, $23.4 \%$ of participants had a $24 \mathrm{~h} \mathrm{UIC} \mathrm{of}>200 \mu \mathrm{g} / \mathrm{L}$. These data suggest that some members of our population may be at risk of compromised or excessive iodine status if such patterns are consistently observed (e.g., are not based on a single $24 \mathrm{~h}$ UIC). Both inadequate and excess iodine intake can be linked to adverse health consequences $[15,38]$. These findings, however, are relevant only to the sample examined and cannot be extrapolated to, and are not necessarily representative of, the young adults in our town, the mountain west region or elsewhere in the US. However, the high intersubjective variability provided the opportunity to explore dietary relationships with UIC to estimate the dietary factors that may place individuals at risk of a single suboptimal $24 \mathrm{~h}$ UIC.

Total dairy and egg intake were the primary predictors of estimated iodine intake as well as UIC. Importantly, these two foods together predicted approximately $20 \%$ of the variance in UIC (Table 5). These results are in agreement with previous research showing a link between dairy and egg consumption and iodine status $[39,40]$. Dairy has been determined to be a reliable source due to iodine-fortified cattle feed [14] (which influences circulating iodine and the uptake of iodine by mammary epithelial cells and secretion into milk) [41] and the use of iodophor disinfecting agents on udders, although this can vary across the seasons and with industry practices [5,14,42]. In agreement with our study, a published review has suggested that milk and dairy contribute $\sim 13 \%$ to $64 \%$ of the recommended daily iodine intake based on country-specific food intake data [6]. Eggs draw their iodine content from the laying hen's feed [43-46], which is increased with iodine supplementation. Dairy and eggs might be easier to recall compared to other sources such as iodized table salt, seafood or fish. Also, dairy is often a habitual food item, with yogurts and milk often complimenting popular breakfast and snacks such as ready-to-eat cereal with milk, yogurt with fruit, coffee with milk or a protein shake mixed with milk. Additionally, since eggs must be cracked or consumed individually, the physical nature of preparation could make serving frequency and size easier to recall.

In contrast, iodine intake from iodized table salt consumption was not found to be a primary predictor of iodine status within the present study. This finding is contrary to our hypothesis, as iodized salt is among the densest iodine sources, with more than threefold the amount of iodine per serving compared to an egg. This may be due to several factors. People may not know what iodized salt is or be aware of which sources of salt are iodized. This includes salt found in the kitchen, used in restaurants or used in processed foods. Iodization of salt, which was initiated in the United States in the late 1920s [10], is not currently mandated by the Food and Drug Administration. It is estimated that only $20 \%$ of the salt consumed in the United States is iodized [35]. Error may have been introduced if participants assumed that salt in processed foods or all salt in the saltshakers at restaurants is iodized. Additionally, it may be objectively difficult for participants to recall iodized salt use over a three month period. Salt is a seasoning that may be used sporadically in cooking and when salting foods to taste and, under these conditions, may contribute little to overall dietary intake. Finally, the amount of iodine found in iodized salt may vary considerably and depend on how long the salt has been on the grocery store shelf and in individual cupboards. One study found that iodine content varied among different brands of salt, and even within a single container [35]. Several others found that the iodine content of foods cooked with iodized salt depends on the food type and cooking method [47,48]. The increased popularity of blended salts (i.e., garlic salt) and artesian salts (i.e., Pink Himalayan, sea salt and Kosher rock salt) add another element of uncertainty as these products are typically not iodized [35], yet often share the same shelf space as iodized salt. As it is likely that habitual use of iodized salt does contribute to iodine status [49], future versions of our FFQ will consider the recall time of our FFQ as well as use 
of a photographic album during FFQ administration, along with more detailed and explicit questions related to salt intake, to help improve the accuracy of subjects' salt use recall.

Similar to table salt, seaweed consumption was also not found to be a positive contributor of iodine status, despite its known influence on status in countries including Korea, Japan and parts of coastal Alaska [50,51]. Our negative correlation between seaweed consumption and iodine status may be due to the low number of participants $(n=26)$ who reported eating seaweed and our use of a single value for seaweed by "serving" (Table 1). As different types of seaweed have different amounts of iodine [33], future versions of the FFQ should consider including better descriptions of the type of seaweed consumed to improve estimated iodine consumption. For example, one analysis of 12 common types of seaweed estimated that nori contained $\sim 16 \mu \mathrm{g}$ while processed kelp contained over $8000 \mu \mathrm{g}$ per serving. Additionally, iodine status was not found to differ according to dietary patterns identified on the Dietary Habits Survey (vegetarian status, CSA membership, regular gardener, etc.). This is likely due to a low sample size of participants who identified with these specific dietary habits. Only about half of the subjects identified with at least one dietary preference $(n=61)$. Further studies could target these groups, as well as those adhering to AHA guidelines regarding reduced salt intake, to better analyze the influence of dietary habits on iodine status.

As both insufficient and excess iodine intake can affect thyroid function, a secondary purpose of this study was to explore the relationship between iodine status and serum TSH concentration as a marker of hypothyroidism and general thyroid function [7]. While we were expecting that participants with $24 \mathrm{~h}$ UICs in the WHO severe-to-moderate deficiency category would have high, normal or slightly elevated TSH concentrations, we instead found no relationship between thyroid function and WHO iodine deficiency category. In the typical hormone feedback scenario, serum TSH concentration should increase as iodine status drops [52], although the thyroid is very efficient at compensating for instances of low and excess iodine intake [53] and $24 \mathrm{~h}$ UIC may be more reflective of acute intake than long-term status (as discussed below). For example, a healthy adult stores $~ 15-20 \mathrm{mg}$ of iodine, with $70-80 \%$ of these stores in the thyroid. These stores are in excess of the daily recommendation of $150 \mu \mathrm{g}$ and can help prevent a drop in the synthesis of thyroid hormone (and subsequent increase in TSH) during periods of low iodine intake. The thyroid can also alter the efficiency of iodine organification or the incorporation of iodine into the thyroglobulin in times of excess iodine intake via 'the Wolff-Chaikoff effect' $[54,55]$. The weak but significant association between TSH and $24 \mathrm{~h}$ UIC $(\mathrm{r}=0.194, p=0.045)$ could be explained by a few participants that shifted the simple correlation in the positive direction in our sample, which had only a few subjects with TSH concentration falling in the hypo- (TSH $>$ $4.68 \mathrm{mIU} / \mathrm{L}$ ) or hyperthyroid (TSH $<0.47 \mathrm{mIU} / \mathrm{L}$ ) ranges, at $3.7 \%$ and $1 \%$, respectively. The data may have also been influenced by the inclusion of participants with autoimmune disorders (as we did not measure thyroid autoantibodies) or the inclusion of four smokers.

The lack of a national database for iodine content in food was a major limitation of this study. The USDA is currently developing an iodine database for commonly consumed food products [56] which should greatly improve the assessment of iodine intake in relation to iodine status. However, the potential variability of the iodine content of foods due to iodine content of the soil in different regions [3] is likely to consistently complicate assessment of iodine intake and status. Further modification of our FFQ may also enhance its future use as a tool to estimate iodine intake and help determine the dietary habits that place an individual at risk of compromised iodine status. These include better clarification of iodized salt and specific fish and seaweed sources. Portion sizes may also be better quantified by allowing participants the opportunity to enter typical portion sizes or by including images and metaphors to visually clarify standard serving sizes (i.e., "3 $\mathrm{oz}^{\prime}$ ). A major strength of our study, however, was the creation of our own aggregated dietary iodine database for items in our FFQ. We combined multiple sources of the recent literature investigating iodine content in various foods (Table 1) and converted the listed units to iodine content per serving for better applicability to our FFQ and, ultimately, increased ease of analysis. The significant association between estimated dietary iodine 
intake from the FFQ and UIC further increased our confidence in our novel database. This database can be built upon for additional research until the USDA completes their official iodine database.

An additional limitation of our study and many others is the use of UIC as the biomarker of iodine status. Twenty-four hour UIC is a widely used biomarker for the assessment of iodine status, as approximately $90 \%$ of dietary iodine is excreted in the urine [57]. However, $24 \mathrm{~h}$ UIC is prone to collection and methodological errors and is thought to be more representative of acute (i.e., days) versus chronic iodine status [15], due to variations in $24 \mathrm{~h}$ UIC samples [58]. Some of this variability may be due to day-to-day differences in dietary iodine intake, but confounders such as circadian [59] and seasonal differences $[60,61]$ also account for individual variability. Currently, there is no consensus on the biomarker to use for assessment of individual iodine status [22,23]. Additionally, in the current study, differences in the period of collection in our comparison of $24 \mathrm{~h}$ UIC and our FFQ, which addressed intake over three months, may have been a further limitation. While other biomarkers for assessment of this status have been suggested, including multiple $24 \mathrm{~h}$ UIC samples [22], age-adjusted iodine-creatine ratio [62], and serum thyroglobulin concentration [63], use of these markers are not without error and come with practical and logistics concerns when testing a large number of participants [64]. Thus, as mentioned previously, the results of the current study, particularly those related to UIC, are relevant only to the sample examined and cannot be extrapolated to, and are not necessarily representative of young adults, in our town, the mountain west region or elsewhere in the US. They do, however, support the need for continuous national iodine monitoring with emphasis on subgroups that may be susceptible to iodine deficiency [21] based on dietary choices.

\section{Conclusions}

The current study found an indication that our sample of healthy young individuals living in the mountain west region of the U.S. may be borderline deficient (based on a median $24 \mathrm{~h} \mathrm{UIC} \mathrm{of} 98 \mu \mathrm{g} / \mathrm{L}$ ), although a high degree of variability in $24 \mathrm{~h}$ UIC was observed. These results, however, are indicative of the status of this sample only, and not of other, similar subsamples. Dairy and egg consumption were found to be significant predicators of $24 \mathrm{~h}$ UIC, whereas reported intake of iodized salt was not. Iodized salt consumption may either be difficult to assess reliably, or not as big a predictor of iodine status in iodine-replete areas. Development of a national dietary iodine database and better biomarkers for the assessment of iodine status in individuals will greatly improve understanding of the relationships between iodine intake, iodine status and thyroid function.

Author Contributions: Conceptualization, D.E.L.-M.; methodology, D.E.G., D.E.L.-M., H.A.Y., A.E.H. and E.C.J.; validation, D.E.G., D.E.L.-M. and E.C.J.; formal analysis, D.E.G. and D.E.L.-M.; investigation, D.E.G., H.A.Y., A.E.H. and E.C.J.; resources, D.E.L.M and E.C.J.; data curation, D.E.G., H.A.Y., A.E.H. and E.C.J.; writing-original draft preparation, D.E.G..; writing — review and editing, D.E.L.-M., H.A.Y. and E.C.J.; visualization, D.E.L.-M.; supervision, D.E.L.-M. and E.C.J.; project administration, E.C.J.; funding acquisition, E.C.J. All authors have read and agreed to the published version of the manuscript.

Funding: This research received no direct funding.

Acknowledgments: The investigators would like to thank, Shane McCullough, Joshua Loseke, and for assistance with data collection, and Sarah R. Rich for assistance with summation of iodine content of foods (Table 1).

Conflicts of Interest: The authors declare no conflict of interest. Data collection, analyses, interpretation of results and the writing of the manuscript occurred independently. 


\section{Appendix A}

Food Frequency Questionnaire (FFQ)

Instructions: For each food listed, check the box indicating how often on average you have used the amount specified during the last three months

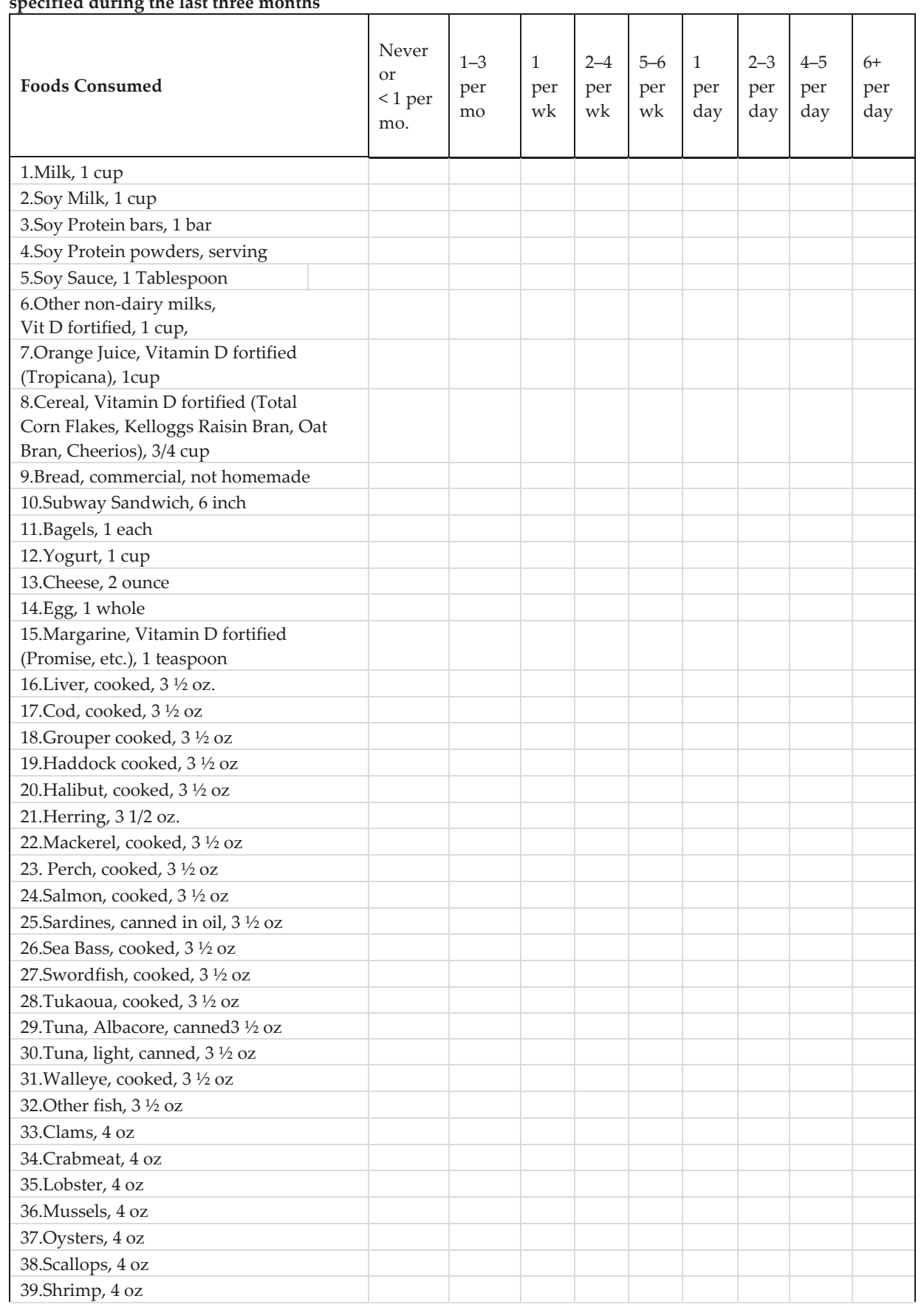




\begin{tabular}{|l|l|l|l|l|l|}
\hline $\begin{array}{l}\text { 40.Sea weed (Nori, Komgu, Dulse, } \\
\text { Wakame, Kelp) }\end{array}$ & & & \\
41.Iodized Table Salt & & & & \\
\hline 42.Other Salt & & & & \\
\hline
\end{tabular}

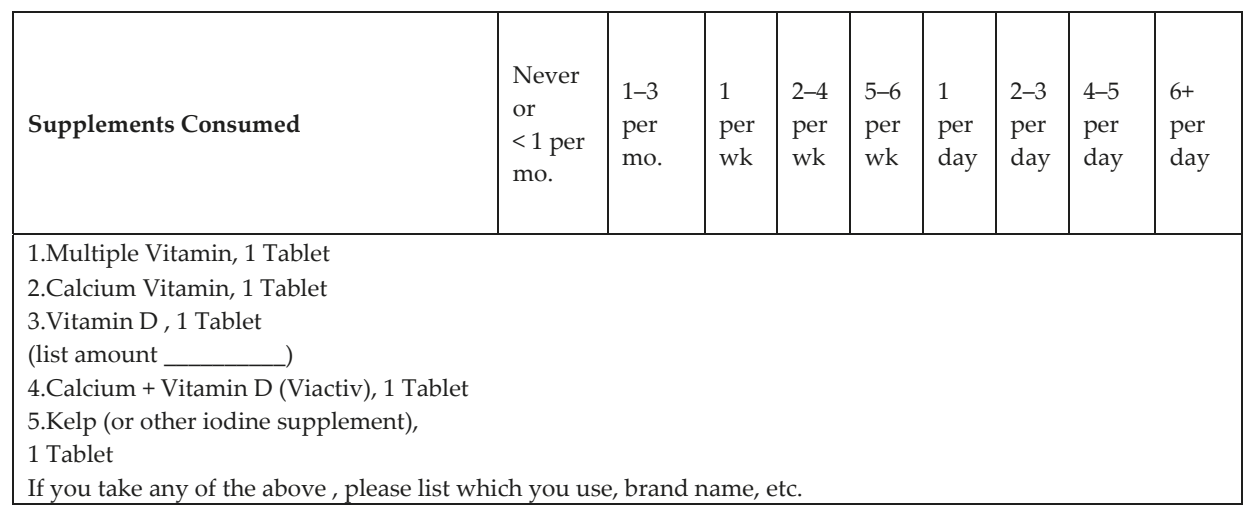

\section{Appendix B}

\section{Dietary Habits Survey}

How frequently do you use the salt shaker to salt your foods?

Never Sometimes Usually

What type of salt do you use?

How frequently do you use salt in your cooking?

Never Sometimes Usually

What type of salt do you use?

\section{Applicable Questions on the Dietary Preferences Survey}

$\begin{array}{llll}\text { Do you follow a vegetarian Diet? } & \text { Yes } & \text { No } & \\ \text { Do you shop at the Farmers Market or Food Coop)? } & \text { Yes } & \text { No } & \text { Sometimes } \\ \text { Do you belong to a CSA (Community Supported Agriculture)? } & \text { Yes } & \text { No } \\ \text { Do you have a garden and grow your own food? } & \text { Yes } & \text { No } & \text { Sometimes }\end{array}$

Comments

\section{References}

1. Mariotti, S.; Beck-Peccoz, P. Physiology of the Hypothalamic-Pituitary-Thyroid Axis. In Endotext; Feingold, K.R., Anawalt, B., Boyce, A., Chrousos, G., Dungan, K., Grossman, A., Hershman, J.M., Kaltsas, G., Koch, C., Kopp, P., et al., Eds.; South Dartmouth, MA, USA, 2000; Available online: https://www.endotext.org/section/thyroiddiseasemanager/ (accessed on 15 July 2019).

2. Fuge, R.; Johnson, C.C. The geochemistry of iodine-A review. Environ. Geochem. Health 1986, 8, 31-54. [CrossRef]

3. Zimmermann, M.B. Iodine Deficiency. Endocr. Rev. 2009, 30, 376-408. [CrossRef]

4. Swanson, E.W.; Miller, J.K.; Mueller, F.J.; Patton, C.S.; Bacon, J.A.; Ramsey, N. Iodine in Milk and Meat of Dairy Cows Fed Different Amounts of Potassium Iodide or Ethylenediamine Dihydroiodide1. J. Dairy Sci. 1990, 73, 398-405. [CrossRef]

5. Galton, D.M.; Petersson, L.G.; Erb, H.N. Milk iodine residues in herds practicing iodophor premilking teat disinfection. J. Dairy Sci. 1986, 69, 267-271. [CrossRef]

6. van der Reijden, O.L.; Zimmermann, M.B.; Galetti, V. Iodine in dairy milk: Sources, concentrations and importance to human health. Best Pract. Res. Clin. Endocrinol. Metab. 2017, 31, 385-395. [CrossRef] [PubMed] 
7. Niwattisaiwong, S. Iodine deficiency: Clinical implications. Cleve Clin. J. Med. 2017, 84, 236-244. [CrossRef] [PubMed]

8. Finer, L.B.; Henshaw, S.K. Disparities in rates of unintended pregnancy in the United States, 1994 and 2001. Perspect. Sex. Reprod. Health 2006, 38, 90-96. [CrossRef] [PubMed]

9. Zimmermann, M.B.; Andersson, M. Update on iodine status worldwide. Curr. Opin. Endocrinol. Diabetes Obes. 2012, 19, 382-387. [CrossRef]

10. Markel, H. "When it rains it pours": Endemic goiter, iodized salt, and David Murray Cowie, MD. Am. J. Public Health 1987, 77, 219-229. [CrossRef]

11. Gibson, R.S. Principles of Nutritional Assessment, 2nd ed.; Oxford University Press: New York, NY, USA, 2005; p. 908.

12. Caldwell, K.L.; Makhmudov, A.; Ely, E.; Jones, R.L.; Wang, R.Y. Iodine status of the US population, National Health and Nutrition Examination Survey, 2005-2006 and 2007-2008. Thyroid 2011, 21, 419-427. [CrossRef]

13. Krajčovičová-Kudláčková, M.; Bučková, K.; Klimeš, I.; Šeboková, E. Iodine Deficiency in Vegetarians and Vegans. Ann. Nutr. Metab. 2003, 47, 183-185. [CrossRef] [PubMed]

14. Pearce, E.N.; Pino, S.; He, X.; Bazrafshan, H.R.; Lee, S.L.; Braverman, L.E. Sources of Dietary Iodine: Bread, Cows' Milk, and Infant Formula in the Boston Area. J. Clin. Endocrinol. Metab. 2004, 89, 3421-3424. [CrossRef] [PubMed]

15. World Health Organization; The United Nations Children's Fund; International Council for Control of Iodine Deficiency Disorders. Assessment of iodine deficiency disorders and monitoring their elimination. In $A$ Guide for Programme Managers; World Health Organization: Geneva, Switzerland, 2007.

16. Alderman, M.H.; Lamport, B. Moderate Sodium RestrictionDo the Benefits Justify the Hazards? Am. J. Hypertens. 1990, 3, 499-504. [CrossRef] [PubMed]

17. Tayie, F.A.K.; Jourdan, K. Hypertension, dietary salt restriction, and iodine deficiency among adults. Am. J. Hypertens. 2010, 23, 1095-1102. [CrossRef] [PubMed]

18. Boon, C.S.; Taylor, C.L.; Henney, J.E. Strategies to Reduce Sodium Intake in the United States; National Academies Press: Washington, DC, USA, 2010.

19. Appel, L.J.; Frohlich, E.D.; Hall, J.E.; Pearson, T.A.; Sacco, R.L.; Seals, D.R.; Sacks, F.M.; Smith, S.C., Jr.; Vafiadis, D.K.; Van Horn, L.V. The importance of population-wide sodium reduction as a means to prevent cardiovascular disease and stroke: A call to action from the American Heart Association. Circulation 2011, 123, 1138-1143. [CrossRef] [PubMed]

20. Dean, S. Medical Nutrition Therapy for Thyroid, Adrenal, and Other Endocrine Disorders. In Krause's Food and the Nutrition Care Process, 14th ed.; Mahn, L.K., Raymond, J.L., Eds.; Elsevier: Saint Louis, MO, USA, 2017; pp. 619-630.

21. National Instituesd of Health Office of Dietary Supplements. Iodine Fact. Sheet for Health Professionals; U.S. Department of Health \& Human Services: Bethesda, MD, USA, 2019. Available online: https: //ods.od.nih.gov/factsheets/Iodine-HealthProfessional/90/history/ (accessed on 2 April 2019).

22. König, F.; Andersson, M.; Hotz, K.; Aeberli, I.; Zimmermann, M.B. Ten repeat collections for urinary iodine from spot samples or 24-hour samples are needed to reliably estimate individual iodine status in women. J. Nutr. 2011, 141, 2049-2054. [CrossRef] [PubMed]

23. Skeaff, S.; Thomson, C.; Eastman, C. Iodine deficiency does exist but is difficult to assess in individuals. N. Z. Med. J. 2009, 122, 101-102.

24. Johnson, E.C.; Huffman, A.E.; Yoder, H.; Dolci, A.; Perrier, E.T.; Larson-Meyer, D.E.; Armstrong, L.E. Urinary Markers of Hydration during 3-day Water Restriction and Graded Rehydration. Eur. J. Nutr. 2019, 1-11. [CrossRef]

25. Forde, C. Exercise Prescription for the Prevention and Treatment of Disease: Scoring the International Physical Activity Questionnaire (IPAQ). Available online: https://ugc.futurelearn.com/uploads/files/bc/c5/ bcc53b14-ec1e-4d90-88e3-1568682f32ae/IPAQ_PDF.pdf (accessed on 2 April 2019).

26. Zimmermann, M.B. Iodine requirements and the risks and benefits of correcting iodine deficiency in populations. J. Trace Elem. Med. Biol. 2008, 22, 81-92. [CrossRef]

27. Trumbo, P.; Yates, A.A.; Schlicker, S.; Poos, M. Dietary reference intakes: Vitamin A, vitamin K, arsenic, boron, chromium, copper, iodine, iron, manganese, molybdenum, nickel, silicon, vanadium, and zinc. J. Acad. Nutr. Diet. 2001, 101, 294. 
28. Halliday, T.M.; Peterson, N.J.; Thomas, J.J.; Kleppinger, K.; Hollis, B.W.; Larson-Meyer, D.E. Vitamin D status relative to diet, lifestyle, injury, and illness in college athletes. Med. Sci. Sports Exerc. 2011, 43, 335-343. [CrossRef] [PubMed]

29. Total Diet Study Elements Results Summary Statistics-Market Baskets 2006 through 2013. Available online: https://www.fda.gov/downloads/food...totaldietstudy/ucm184301.pdf (accessed on 4 March 2019).

30. Bath, S.C.; Hill, S.; Infante, H.G.; Elghul, S.; Nezianya, C.J.; Rayman, M.P. Iodine concentration of milk-alternative drinks available in the UK in comparison with cows' milk. Br. J. Nutr. 2017, 118, 525-532. [CrossRef] [PubMed]

31. Low Iodine Diet. Available online: https://www.thyroid.org/wp-content/uploads/patients/brochures/ LowIodineDietFAQ.pdf (accessed on 4 March 2019).

32. Pehrsson, P.R.; Patterson, K.Y.; Spungen, J.H.; Wirtz, M.S.; Andrews, K.W.; Dwyer, J.T.; Swanson, C.A. Iodine in food-and dietary supplement-composition databases. Am. J. Clin. Nutr. 2016, 104, 868S-876S. [CrossRef] [PubMed]

33. Teas, J.; Pino, S.; Critchley, A.; Braverman, L.E. Variability of iodine content in common commercially available edible seaweeds. Thyroid 2004, 14, 836-841. [CrossRef]

34. Pennington, J.A.; Schoen, S.A. Total diet study: Estimated dietary intakes of nutritional elements, 1982-1991. Int. J. Vitam. Nutr. Res. 1996, 66, 350-362.

35. Dasgupta, P.K.; Liu, Y.; Dyke, J.V. Iodine Nutrition: Iodine Content of Iodized Salt in the United States. Environ. Sci. Technol. 2008, 42, 1315-1323. [CrossRef]

36. Baloch, Z.; Carayon, P.; Conte-Devolx, B.; Demers, L.M.; Feldt-Rasmussen, U.; Henry, J.F.; LiVosli, V.A.; Niccoli-Sire, P.; John, R.; Ruf, J. Laboratory medicine practice guidelines. Laboratory support for the diagnosis and monitoring of thyroid disease. Thyroid Off. J. Am. Thyroid Assoc. 2003, 13, 3.

37. Hagströmer, M.; Oja, P.; Sjöström, M. The International Physical Activity Questionnaire (IPAQ): A study of concurrent and construct validity. Public Health Nutr. 2006, 9, 755-762. [CrossRef]

38. Stanbury, J.B.; Ermans, A.E.; Bourdoux, P.; Todd, C.; Oken, E.; Tonglet, R.; Vidor, G.; Braverman, L.E.; Medeiros-Neto, G. Iodine-induced hyperthyroidism: Occurrence and epidemiology. Thyroid 1998, 8, 83-100. [CrossRef]

39. Hemken, R.W. Milk and meat iodine content: Relation to human health. J. Am. Vet. Med Assoc. 1980, 176, $1119-1121$.

40. Kaufmann, S.; Wolfram, G.; Delange, F.; Rambeck, W.A. Iodine supplementation of laying hen feed: A supplementary measure to eliminate iodine deficiency in humans? Z. Ernährungswiss. 1998, 37, 288-293. [CrossRef] [PubMed]

41. Spitzweg, C.; Joba, W.; Eisenmenger, W.; Heufelder, A.E. Analysis of human sodium iodide symporter gene expression in extrathyroidal tissues and cloning of its complementary deoxyribonucleic acids from salivary gland, mammary gland, and gastric mucosa. J. Clin. Endocrinol. Metab. 1998, 83, 1746-1751. [CrossRef] [PubMed]

42. Hubble, I.B.; Mein, G.A. Effect of pre-milking udder preparation of dairy cows on milk quality. Aust. J. Dairy Technol. (Aust.) 1986, 41, 66-70.

43. Chandler, W.L. Iodine on the Poultry farm. Poult. Sci. 1926, 6, 31-35. [CrossRef]

44. Travnicek, J.; Kroupova, V.; Herzig, I.; Kursa, J. Iodine content in consumer hen eggs. Vet. Med. Praha 2006, 51, 93. [CrossRef]

45. Bourre, J.M.; Galea, F. An important source of omega-3 fatty acids, vitamins D and E, carotenoids, iodine and selenium: A new natural multi-enriched egg. J. Nutr. Health Aging 2006, 10, 371.

46. Michella, S.M.; Slaugh, B.T. Producing and marketing a specialty egg. Poult. Sci. 2000, 79, 975-976. [CrossRef]

47. Liu, L.; Li, X.; Wang, H.; Cao, X.; Ma, W. Reduction of iodate in iodated salt to iodide during cooking with iodine as measured by an improved HPLC/ICP-MS method. J. Nutr. Biochem. 2017, 42, 95-100. [CrossRef]

48. Meinhardt, A.K.; Muller, A.; Burcza, A.; Greiner, R. Influence of cooking on the iodine content in potatoes, pasta and rice using iodized salt. Food Chem. 2019, 301. [CrossRef]

49. Andersson, M.; de Benoist, B.; Rogers, L. Epidemiology of iodine deficiency: Salt iodisation and iodine status. Best Pract. Res. Clin. Endocrinol. Metab. 2010, 24,1-11. [CrossRef]

50. Kim, J.Y.; Moon, S.J.; Kim, K.R.; Sohn, C.Y.; Oh, J.J. Dietary iodine intake and urinary iodine excretion in normal Korean adults. Yonsei Med. J. 1998, 39, 355-362. [CrossRef] [PubMed] 
51. Ballew, C. Final Report on the Alaska Traditional Diet Survey. Available online: http://anthctoday.org/ epicenter/publications/Reports_Pubs/traditional_diet.pdf (accessed on 4 March 2019).

52. Gershengorn, M.C.; Wolff, J.; Larsen, P.R. Thyroid-pituitary feedback during iodine repletion. J. Clin. Endocrinol. Metab. 1976, 43, 601-605. [CrossRef] [PubMed]

53. Chung, H.R. Iodine and thyroid function. Ann. Pediatric Endocrinol. Metab. 2014, 19, 8-12. [CrossRef] [PubMed]

54. Morton, M.E.; Chaikoff, I.L.; Rosenfeld, S. Inhibiting effect of inorganic iodide on the formation in vitro of thyroxine and diiodotyrosine by surviving thyroid tissue. J. Biol. Chem. 1944, 154, 381-387.

55. Wolff, J.; Chaikoff, I.L. Plasma inorganic iodide as a homeostatic regulator of thyroid function. J. Biol. Chem. 1948, 174, 555-564. [PubMed]

56. Ershow, A.; Skeaff, S.; Merkel, J.; Pehrsson, P. Development of databases on iodine in foods and dietary supplements. Nutrients 2018, 10, 100. [CrossRef] [PubMed]

57. Hetzel, B.S.; Dunn, J.T. The iodine deficiency disorders: Their nature and prevention. Annu. Rev. Nutr. 1989, 9, 21-38. [CrossRef]

58. Rasmussen, L.B.; Ovesen, L.; Christiansen, E. Day-to-day and within-day variation in urinary iodine excretion. Eur. J. Clin. Nutr. 1999, 53, 401. [CrossRef]

59. Als, C.; Helbling, A.; Peter, K.; Haldimann, M.; Zimmerli, B.; Gerber, H. Urinary iodine concentration follows a circadian rhythm: A study with 3023 spot urine samples in adults and children. J. Clin. Endocrinol. Metab. 2000, 85, 1367-1369. [CrossRef]

60. Als, C.; Haldimann, M.; Bürgi, E.; Donati, F.; Gerber, H.; Zimmerli, B. Swiss pilot study of individual seasonal fluctuations of urinary iodine concentration over two years: Is age-dependency linked to the major source of dietary iodine? Eur. J. Clin. Nutr. 2003, 57, 636. [CrossRef]

61. Moreno-Reyes, R.; Carpentier, Y.A.; Macours, P.; Gulbis, B.; Corvilain, B.; Glinoer, D.; Goldman, S. Seasons but not ethnicity influence urinary iodine concentrations in Belgian adults. Eur. J. Nutr. 2011, 50, 285-290. [CrossRef] [PubMed]

62. Bourdoux, P. Evaluation of the iodine intake: Problems of the iodine/creatinine ratio-comparison with iodine excretion and daily fluctuations of iodine concentration. Exp. Clin. Endocrinol. Diabetes 1998, 106, S17-S20. [CrossRef] [PubMed]

63. Ma, Z.F.; Skeaff, S.A. Thyroglobulin as a biomarker of iodine deficiency: A review. Thyroid 2014, 24, 1195-1209. [CrossRef] [PubMed]

64. Spencer, C.A.; Wang, C.-C. Thyroglobulin measurement: Techniques, clinical benefits, and pitfalls. Endocrinol. Metab. Clin. N. Am. 1995, 24, 841-863. [CrossRef]

(C) 2020 by the authors. Licensee MDPI, Basel, Switzerland. This article is an open access article distributed under the terms and conditions of the Creative Commons Attribution (CC BY) license (http://creativecommons.org/licenses/by/4.0/). 

Article

\title{
Association between Iodine Nutrition Status and Thyroid Disease-Related Hormone in Korean Adults: Korean National Health and Nutrition Examination Survey VI (2013-2015)
}

\author{
Sohye Kim ${ }^{1,2}$, Yong Seok Kwon ${ }^{3}$, Ju Young Kim ${ }^{4}$, Kyung Hee Hong ${ }^{5}$ and Yoo Kyoung Park ${ }^{1, *}$ \\ 1 Department of Medical Nutrition, Graduate School of East-West Medical Science, Kyung Hee University, \\ Yongin 17104, Korea; sohye76@daum.net \\ 2 Nutrition Care Services, Seoul National University of Bundang Hospital, Seongnam 13620, Korea \\ 3 F\&D Communication, Gyeonggi 10433, Korea; shafrang@naver.com \\ 4 Department of Family Medicine, Seoul National University of Bundang Hospital, Seongnam 13620, Korea; \\ kkamburi@gmail.com \\ 5 Department of Food Science and Nutrition, Dongseo University, Pusan 47011, Korea; \\ hkhee@gdsu.dongseo.ac.kr \\ * Correspondence: ypark@khu.ac.kr
}

Received: 8 October 2019; Accepted: 11 November 2019; Published: 13 November 2019

\begin{abstract}
This study aimed to observe the relationship between iodine nutrition status (dietary iodine intake and estimated iodine intake based on urinary iodine concentration (UIC)) and thyroid disease-related hormones. This study involved 6090 subjects $>19$ years old with valid UIC, assessed between 2013 and 2015 by the Korean National Health and Nutrition Examination Survey, using a stratified, multistage, clustered probability-sampling design. The estimated iodine intake in participants was measured using UIC and urine creatinine. To examine the effect of iodine intake on thyroid disease, the iodine intake was divided into Korean Dietary Reference Intakes groups, and logistic regression analysis was performed via the surveylogistic procedure to obtain odds ratios (ORs) and 95\% confidence intervals (CIs). The estimated iodine intake showed a significant positive correlation with dietary iodine intake $(\mathrm{r}=0.021, p<0.001)$, UIC $(\mathrm{r}=0.918, p<0.001)$, and thyroid-stimulating hormone (TSH) $(\mathrm{r}=0.043, p<0.001)$, but a significant negative correlation with free thyroxine (FT4) $(r=-0.037, p<0.001)$. Additionally, as the estimated iodine intake increased, age, TSH, and UIC increased, but FT4 decreased ( $p$ for trend $<0.0001)$. The risk of thyroid disease was higher in the " $\geq$ tolerable upper intake level ( $\mathrm{UL} \geq 2400 \mu \mathrm{g} /$ day)" group than in the "<estimated average requirement (EAR < $150 \mu \mathrm{g} /$ day)" group in females (OR: 2.418; 95\% CI: 1.010-5.787). Also, as iodine intake increased, the risk of thyroid disease increased ( $p$ for trend $<0.038$ ).
\end{abstract}

Keywords: iodine nutrition status; thyroid disease; thyrotropin; urine iodine; epidemiologic studies; Korean

\section{Introduction}

Korea is geographically rich in iodine and one of the iodine-rich countries with a high intake of seaweeds [1]. According to a recent study, the mean dietary iodine intake was $763.5 \mu \mathrm{g}$ for Korean female subjects and $953.1 \mu \mathrm{g}$ for males [2]. In a study involving the trend analysis of iodine intake, the iodine intake for males was 326.2-817.0 $\mu \mathrm{g}$ and for females 257.0-802.4 $\mu \mathrm{g}$ [3]. It seems that a majority of the studies indicate that most of the Koreans' iodine intake is within the upper limit (UL) $(2400 \mu \mathrm{g})$ intake, but over two times higher than the recommended nutrient intake (RNI) (150 $\mu \mathrm{g})$ [4-8]. Iodine controls the speed of, and is therefore an essential element in, thyroid hormone synthesis. When 
the iodine intake is insufficient, the hypothalamus hormones, thyrotropin-releasing hormone (TRH) is secreted, and thyroid-stimulating hormone (TSH) further increases the secretion of the thyroid to increase the synthesis and secretion of the thyroid hormone. When blood levels of triiodothyronine (T3) and thyroxine (T4) decrease, and in response the thyroid activity is increased to compensate for iodine deficiency, a sudden excessive intake can increase the risk of hyperthyroidism. Additionally, excessive iodine intake can change the thyroid function, and according to several studies, the prevalence of hypothyroidism, hyperthyroidism, and autoimmune thyroiditis has increased [9-13]. Many studies have reported that deficiency and excess of iodine are associated with thyroid dysfunction $[7,10,14,15]$. Therefore, it is important to find out effects on thyroid hormones made by level of iodine nutrition status. The iodine nutrition status of the population is measured based on dietary iodine intake or urinary iodine concentration (UIC), which is a well-accepted, cost-effective, and readily available indicator. Furthermore, according to the iodine nutritional epidemiology standard of the World Health Organization (WHO), UIC is a recommended barometer for iodine intake that assesses the iodine status of the population and is a sensitive indicator $[16,17]$.

$\mathrm{TSH}, \mathrm{T} 4, \mathrm{~T} 3$, and thyroid autoantibodies (TPOAb) measurements are biochemical tests in the diagnosis and control of thyroid disease [18]. Serum TSH is the most sensitive marker for assessing the status of thyroid function and measurement of serum TSH level is used as a screening test for patients with thyroid dysfunction [19]. TSH is known to be affected by factors such as age, sex, race, iodine intake, smoking, presence of antibodies, and body mass index (BMI) $[15,20]$.

The purpose of this study is to investigate the relationship between iodine nutrition status (dietary iodine intake and estimated iodine intake based on UIC) and thyroid disease-related hormones, such as serum TSH and free thyroxine (FT4). Also, we investigated the association of the iodine nutrition status and the thyroid disease incidence among Korean adults.

This is the nationwide study to observe the relationship between thyroid disease-related functions, such as serum TSH and FT4 level, and UIC, which was first introduced by the Korean National Health and Nutrition Examination Survey (KNHANES) VI (2013-2015), and also examined the relationship between iodine nutrition status including iodine intake in people's diet and estimated iodine intake.

\section{Methods and Materials}

\subsection{Study Population}

The KNHANES is conducted to obtain national estimates of the health and nutrition status of Koreans by the Korea Centers for Disease Control and Prevention (KCDC) that uses a stratified, multistage clustered probability-sampling design [21]. KNHANES is a nationwide, population-based, cross-sectional study to assess the health and nutrition status of the Korean civilian, noninstitutionalized population. Each survey consists of three sections: health interview, health examinations, and nutritional survey.

We selected from the total population $(n=22,938)$ after the exclusion of $<19$ years $(n=4914)$, subjects with thyroid cancer $(n=135)$, pregnant and lactating women $(n=239)$, subjects reporting unrealistic daily total energy intakes $(<500 \mathrm{kcal},>5000 \mathrm{kcal})(n=2251)$, subjects who did not test UIC $(n=9312)$, and subjects with missing weight variables $(n=2)$. As a result, a total of 6095 subjects were included in the final analysis $(m e n=2852$, women=3243). This subsample of KNHANES VI (2013-2015) consisted of 6095 participants who underwent the thyroid function test (serum TSH and FT4) and UIC stratified subsampling with consideration of sex and age.

This study protocol was approved by the Institutional Review Board of the KCDC and the KNHANES (2013-07CON-03-4C, 2013-12EXP-03-5C, and 2015-01-02-6C). All participants gave written informed consent. 


\subsection{Measurement of TSH, FT4, and UIC}

Serum TSH and FT4 levels analyzed via electrochemiluminescence immunoassay were used. Serum TSH (reference range 0.35-5.50 mU/L) and FT4 (reference range 0.89-1.76 ng/dL) levels were analyzed using E-TSH kit (Roche Diagnostics, Mannheim, Germany) and E-Free T4 kit (Roche Diagnostics, Mannheim, Germany), respectively. UIC, analyzed through inductively coupled plasma mass spectrometry (ICPMS; PerkinElmer, Waltham, MA, USA) using iodine standard (Inorganic Venture, Christiansburg, VA, USA), was used [22].

\subsection{Estimated Iodine Intake}

The estimated iodine intake in populations was calculated by measuring the UIC and urine creatinine (Ucr) level and the following equation (1) [6,23,24]:

$$
\begin{gathered}
\text { Estimated of iodine intake }(\mu \mathrm{g} / \text { day })=\mathrm{UIC}(\mu \mathrm{g} / \mathrm{L}) \times\{879.89+(\text { weight }(\mathrm{kg}) \times 12.51)- \\
[(6.19 \times \text { age })+(34.51 \text { if black })-(379.42 \text { if female })]\} /(\mathrm{Ucr} \times 0.92 \times 10) .
\end{gathered}
$$

\subsection{Establishment of Iodine Database of Commercial Foods in Korea}

The iodine content of foods was based on the values shown in the Food Values of the Korean Nutrition Society [25], Food Composition Tables, 9th revision by the Korean National Institute of Agricultural Science, Rural Development Administration [26], a thesis that established the iodine database for common Korean foods [2], and the Standard tables of food composition in Japan (7th revised version) of the Ministry of Education, Culture, Sport, Science, and Technology, Tokyo, 2015 [27].

The value was selected if the food source existed on the database; however, if there was no matching food, it was replaced by something a similar food item from the database. If there were variations in terms of the processing method for certain foods, such as drying methods, we calculated the iodine values based on the values of the existing source of the foods. Moreover, if there were multiple values from different sources of data for one specific food, the mean value for the specific food was used. The total number of food items was 837, and the number of foods with iodine content was 559 , which provided $66.8 \%$ coverage.

\subsection{Measurement of Dietary Iodine Intake Using 24-hr-Dietary Recall}

The nutrition survey data were collected using the 24-h dietary recall method and face-to-face health interviews by trained dietitians and health examination [28]. The daily intake of energy was calculated using the Korean Foods and Nutrients Database of the Rural Development Administration [26]. To calculate the dietary iodine intake, we established an iodine database by merging the data on food items from the $24 \mathrm{~h}$ diet recall in the KNHANES database (2013-2015) with the established iodine value for each food item.

\subsection{Statistics}

As the KNHANES data is based on stratified multistage probability extraction rather than simple random extraction data, this study analyzed the weight (2013, KNHANES; Wt_hmnt, 2014, 2015 KNHANES; Wt_trnt), the stratification variable (KSTRATA) and the primary sampling unit (PSU). To test for significant differences, the $t$-test was used when calibration was not performed using the surveyreg procedure, and the general linear model was used when calibration was performed using the surveyreg procedure. Additionally, the age and total daily energy intake were used as calibration variables. In addition, the correlation between each of the iodine intake and thyroid function tests was analyzed using Pearson correlation. Using the paired $t$-test, associations were determined with weighted measures among the estimated iodine intake, dietary iodine intake, and UIC. Lastly, to examine the effect of iodine intake on thyroid disease, this study divided iodine intake into Korean Dietary Reference Intakes (KDRI) groups [4], and logistic regression analysis was performed via the 
surveylogistic procedure to obtain odds ratios (OR) and 95\% confidence intervals (CI). All statistical analyses were performed using SAS Ver. 9.4 (SAS Institute, Cary, NC, USA).

\section{Results}

\subsection{Iodine Nutrition Status}

The mean estimated iodine intake for all subjects was $790.1 \mu \mathrm{g}$, which was higher than the mean dietary iodine intake $(551.0 \mu \mathrm{g})$. These results were identical for both the male and female groups (Figure 1).

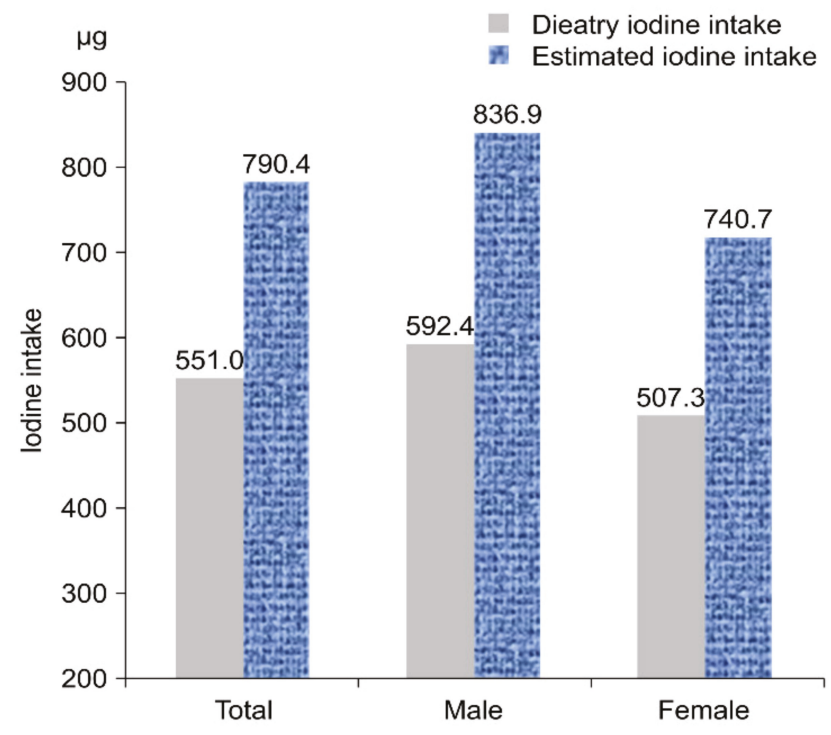

Figure 1. Mean of dietary iodine intake vs. estimated iodine intake.

The results of the analysis of the iodine nutrition status of the subjects are shown in Table 1. The thyroid disease group was higher in the total subjects' energy than in the non-thyroid disease group (unadjusted $p<0.0001$, adjusted for age $p=0.001$ ). In total subjects, the mean dietary iodine intake of the non-thyroid disease group was $554.0 \pm 35.8 \mu \mathrm{g}$, which was higher than that of the thyroid disease group of $458.8 \pm 93.6 \mu \mathrm{g}$. However, the mean of estimated iodine intake of the non-thyroid disease group was $780.0 \pm 56.1 \mu \mathrm{g}$, which was lower than that of the thyroid disease group of $1108.1 \pm 195.8 \mu \mathrm{g}$. In total subjects, the mean UIC of the non-thyroid disease group was $883.2 \pm 92.1 \mu \mathrm{g}$, which was lower than that of the thyroid disease group of $1085.9 \pm 183.9 \mu \mathrm{g}$, but there was no significant difference. Additionally, the same result was obtained in the female group (non-thyroid disease $849.8 \mu \mathrm{g}$, thyroid disease group $1145.5 \mu \mathrm{g}$ ), but the result of the male group was the opposite (non-thyroid disease $913.5 \mu \mathrm{g}$, thyroid disease group $745.1 \mu \mathrm{g}$ ), and there were no significant differences between these groups. Moreover, there were no significant differences in all groups with UIC, dietary iodine intake, and estimated iodine intake. 
Nutrients 2019, 11, 2757

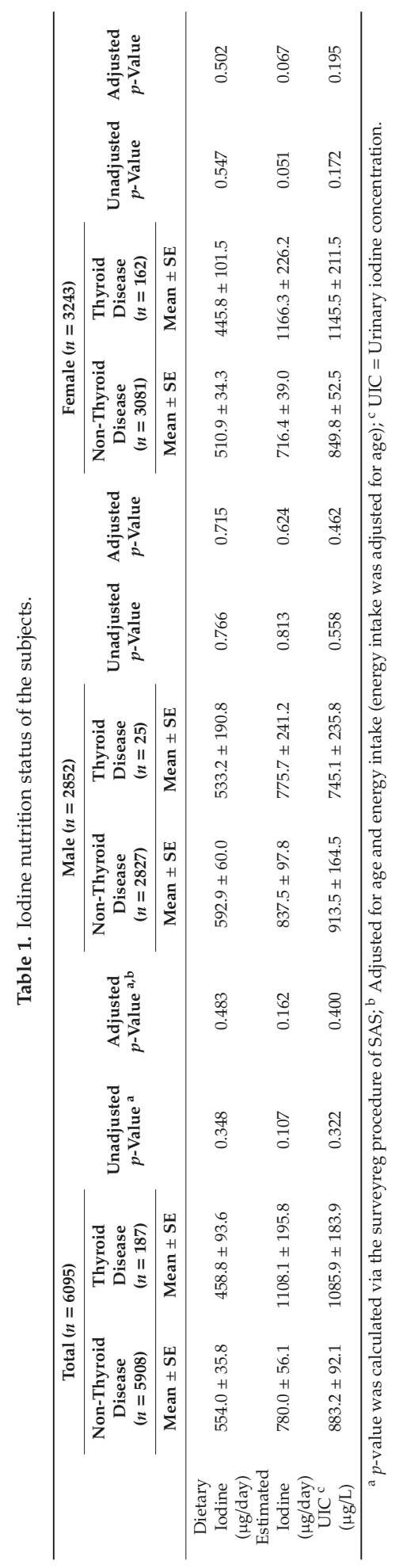




\subsection{TSH and FT4 of the Subjects}

The TSH and FT4 levels of the non-thyroid disease group vs. the thyroid disease group are shown in Figure 2. The mean TSH of the non-thyroid disease group was $2.8 \pm 0.1 \mathrm{mIU} / \mathrm{L}$, which was lower than that of the thyroid disease group $(3.7 \pm 0.4 \mathrm{mIU} / \mathrm{L})$ (adjusted for age and energy intake $p=0.029$ ). As a result, TSH in the total subjects was significantly higher in the thyroid disease group than in the non-thyroid disease group. Male and female groups showed similar results, but there were no significant differences. Additionally, the mean FT4 of the non-thyroid disease group was lower than that of the thyroid disease group, but there was no significant difference.
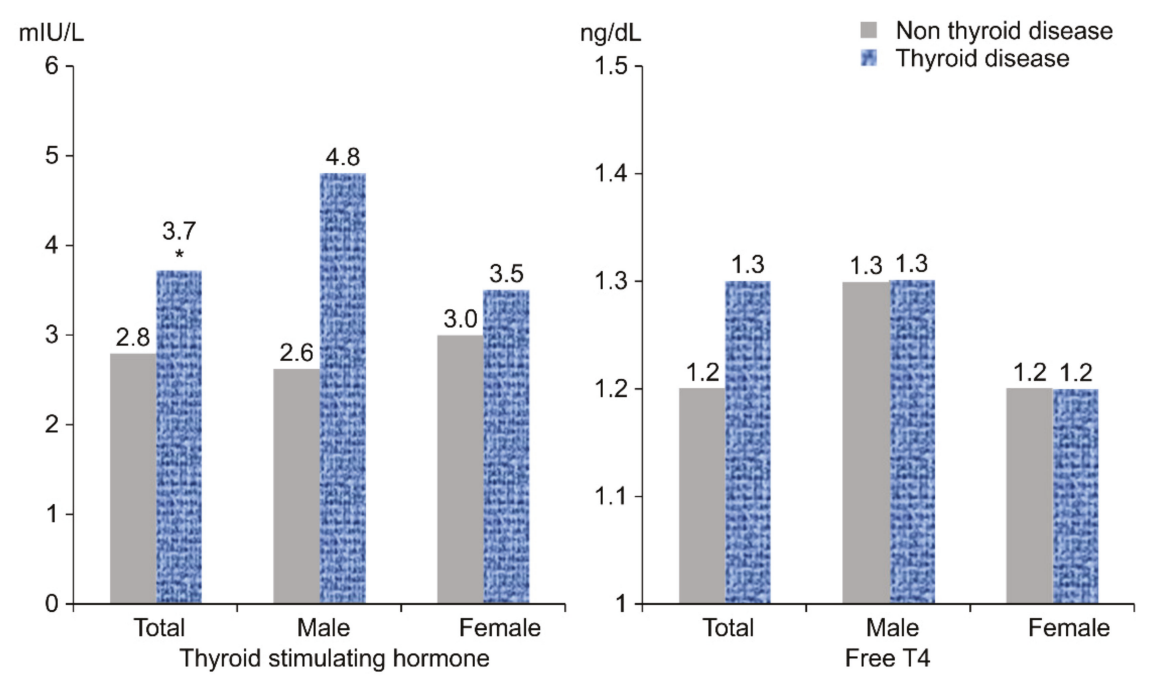

Figure 2. TSH and FT4 of thyroid disease status by sex.

\subsection{UIC, TSH, and FT4 According to KDRI of the Estimated Iodine Intake}

The estimated iodine intake was divided into KDRI groups, and the results of UIC, TSH, and FT4 tests for each group are presented in Table 2.

The KDRI groups were as follows: " $<$ EAR (estimated average requirement)", $<95 \mu \mathrm{g} / \mathrm{day}$; " $\geq \mathrm{EAR}$, $<$ RNI (recommended nutrient intake)," $\geq 95 \mu \mathrm{g} /$ day, $<150 \mu \mathrm{g} /$ day; " $\geq \mathrm{RNI}$, $<\mathrm{UL}$ (tolerable upper intake)," $\geq 150 \mu \mathrm{g} /$ day, $2400 \mu \mathrm{g} / \mathrm{day}$; and " $\geq \mathrm{UL}$," $\geq 2400 \mu \mathrm{g} /$ day by KDRI [4]. The mean and median values of the UL group were dramatically higher than those of the other groups (Figure 3). In total subjects, both unadjusted and adjusted for age and energy intake, as iodine intake increased, age ( $p$ for trend $<$ $0.0001)$, TSH ( $p$ for trend $=0.009$ ) (Figure 3$)$, and UIC ( $p$ for trend $<0.0001$ ) tended to increase, but FT4 showed a tendency to decrease ( $p$ for trend $<0.0001$ ) (Figure 4 ). In addition, in both male and female groups, as iodine intake increased, age, TSH, and UIC tended to increase, but FT4 showed a tendency to decrease. All results are significant except for TSH in the female group. 


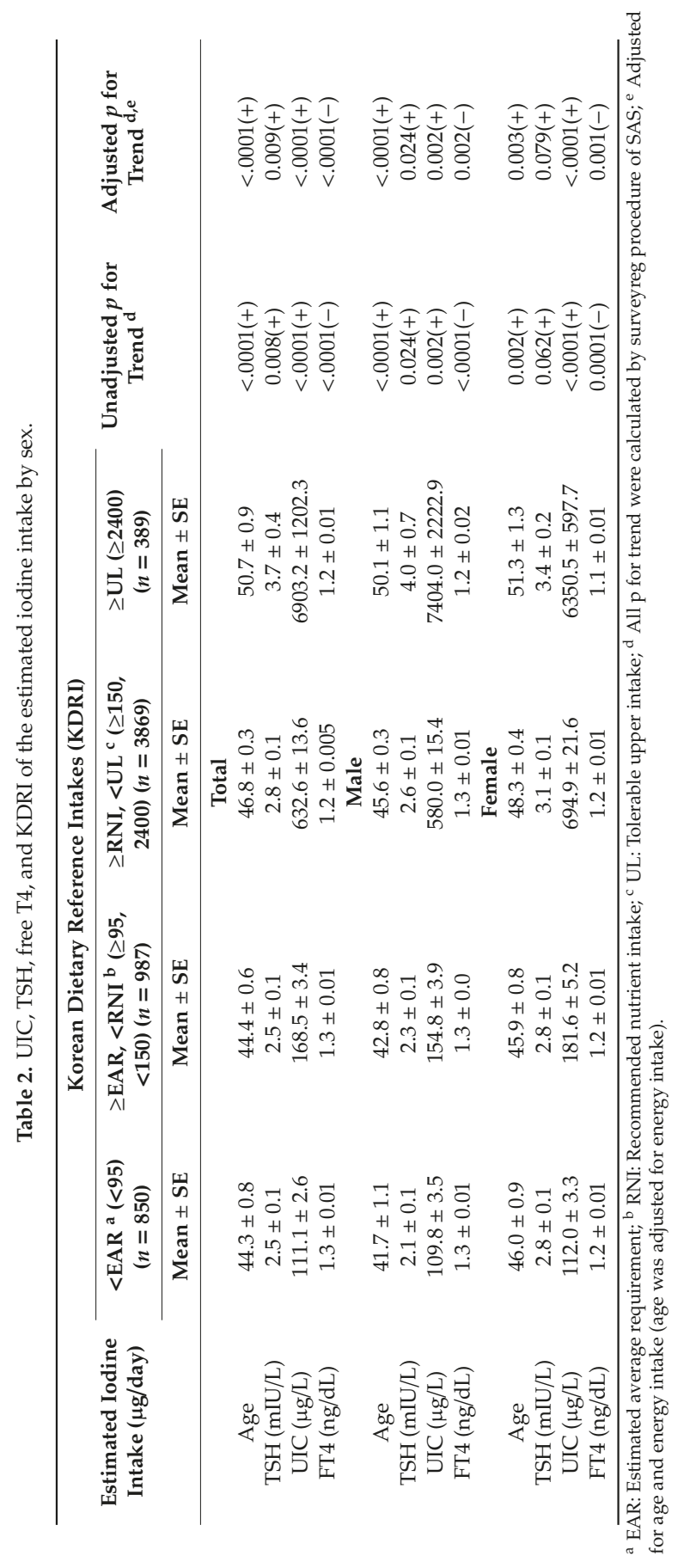




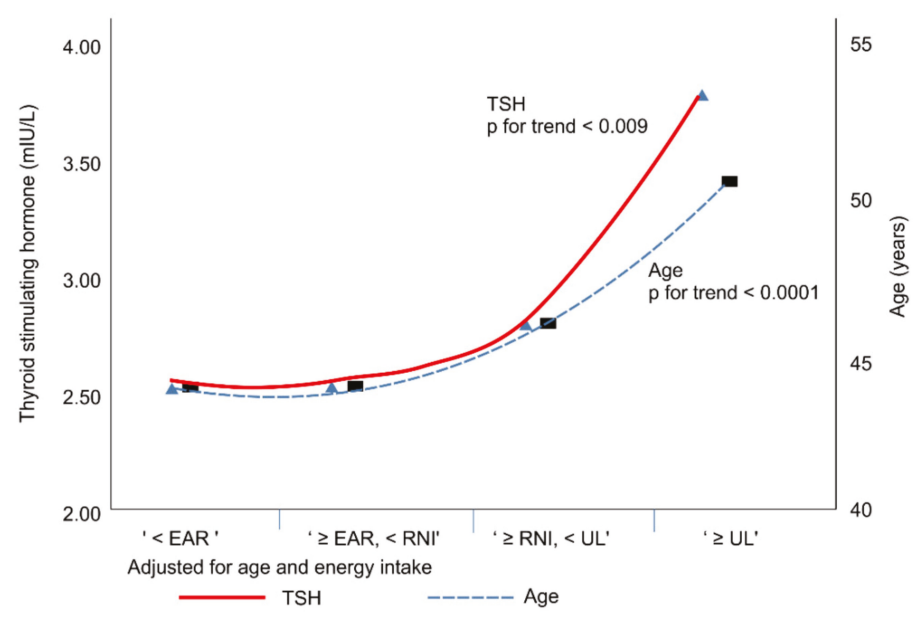

Figure 3. Correlation of TSH and age with the estimated iodine intake.

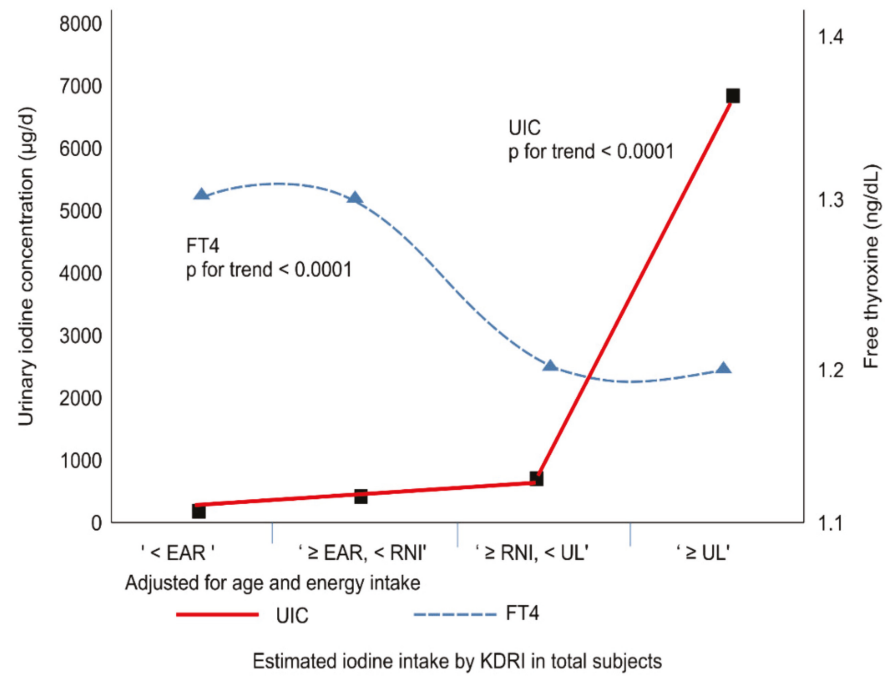

Figure 4. Correlation of UIC and free thyroxine (FT4) with the estimated iodine intake.

3.4. Prevalence of Thyroid Disease and Distribution of Iodine Intake According to the Estimated Iodine Intake by KDRI

The intake range, median, and mean of the estimated iodine intake classified by KDRI groups are shown in Table 3. 


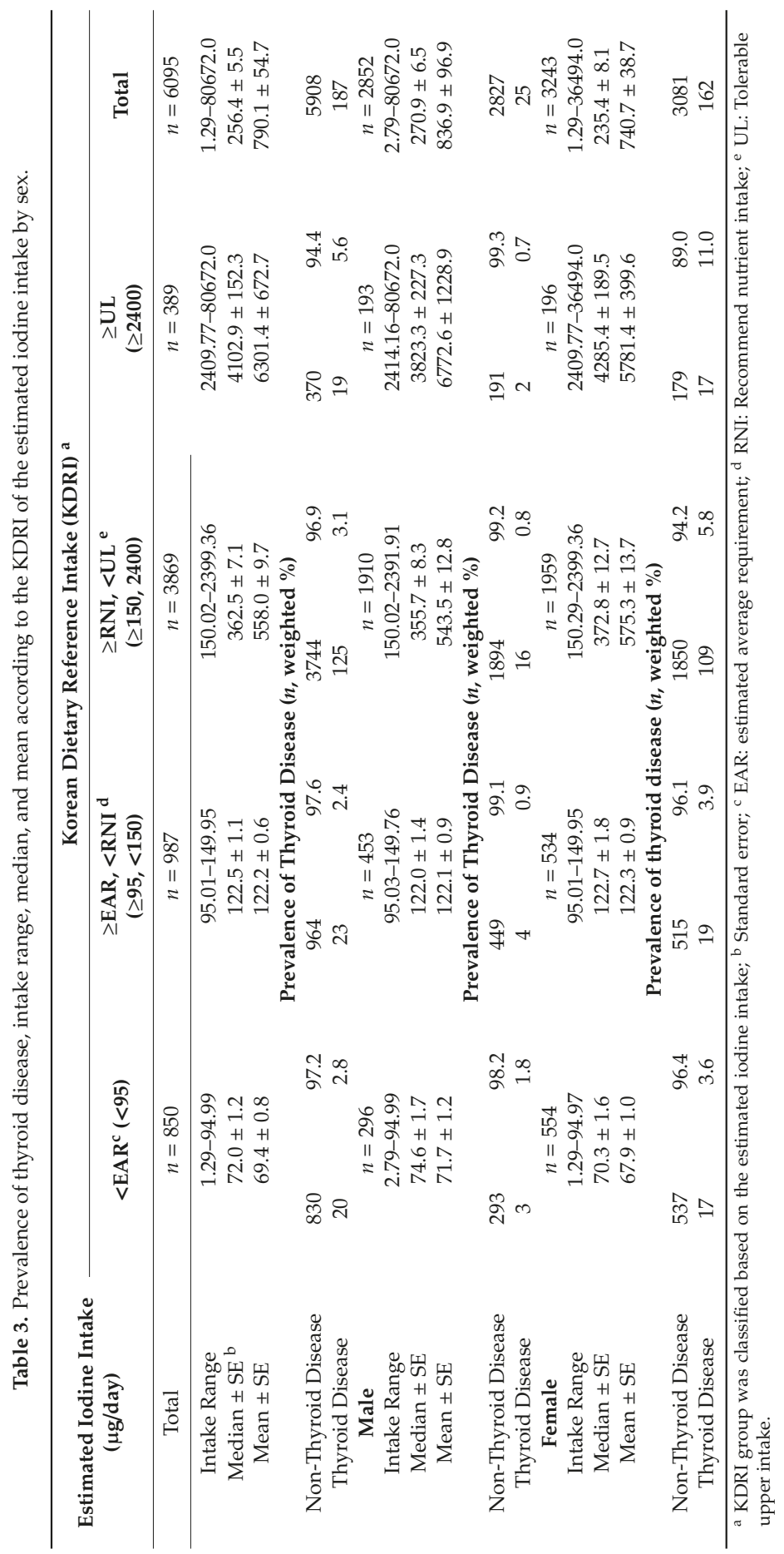


The population distribution with respect to the dietary iodine intake and estimated iodine intake of all the subjects was divided into KDRI groups. The " $\geq \mathrm{RNI},<\mathrm{UL}$ " group had the largest population- $65.1 \%$ with respect to dietary iodine intake and $63.5 \%$ with respect to estimated iodine intake, while the "UL" group had the smallest population (Figure 5).
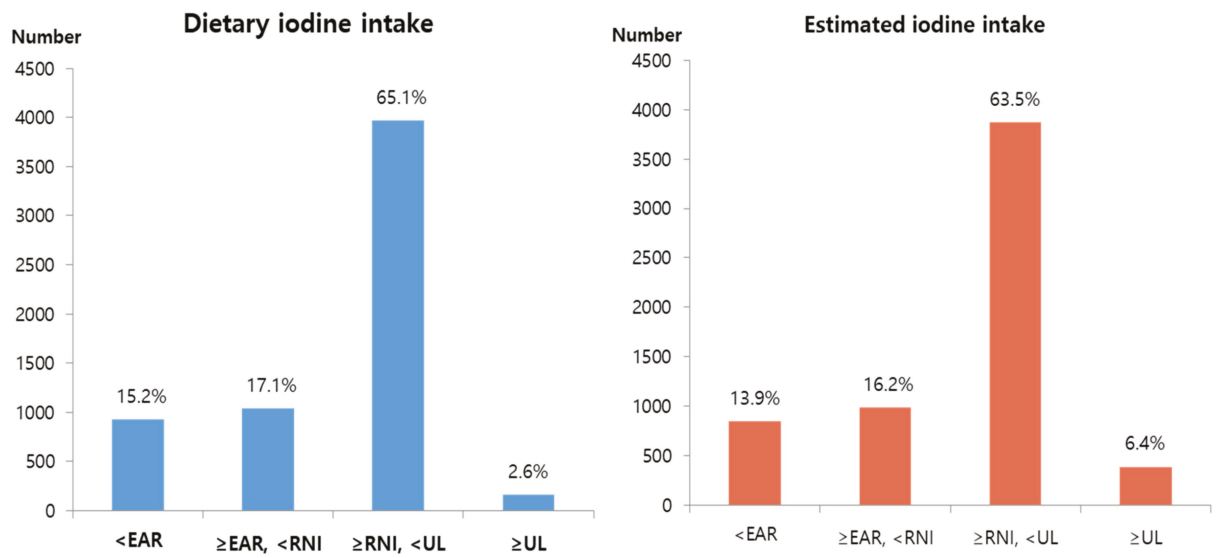

Figure 5. Population distribution of iodine intake by KDRI in the total subjects.

\subsection{Relation between Thyroid Disease and the Estimated Iodine Intake by KDRI}

The results of the relationship between the estimated iodine intake and the risk of thyroid disease incidence according to KDRI groups using logistic regression analysis are presented in Table 4.

In relation to the thyroid disease according to the estimated iodine intake, as the estimated iodine intake increased in Model 1, which was the unadjusted model in the female group, the odds ratio of the " $\geq \mathrm{UL}$ " group was 2.940 (95\% CI: 1.267-6.823), which showed a tendency to increase the risk of thyroid disease incidence ( $p$ for trend $=0.014$ ). Additionally, as the iodine intake increased in Model 2 adjusted for age and energy intake, the odds ratio of Model 2 was 2.773 (95\% CI: 1.198-6.420) in the " $\geq \mathrm{UL}$ " group compared with the " $<\mathrm{EAR}$ " group, and the risk of thyroid disease tended to be increased ( $p$ for trend $=0.023$ ). In Model 3, adjusted for age, energy intake, weight status, exercise status, smoking status, and alcohol consumption, the odds ratio was 2.686 (95\% CI: 1.161-6.215) in the " $\geq \mathrm{UL}$ " group compared with the " $<\mathrm{EAR}$ " group, and the risk of thyroid disease tended to be increased ( $p$ for trend $=0.026$ ). Also, in Model 4 adjusted for age, energy intake, weight status, exercise status, smoking status, alcohol consumption, breakfast, and frequency of eating out, the odds ratio was 2.554 (95\% CI: 1.113-5.861) in the " $\geq$ UL" group compared with the " $<$ EAR" group, and the risk of thyroid disease tended to be increased ( $p$ for trend $=0.34$ ). Lastly, in Model 5, adjusted for age, energy intake, weight status, exercise status, smoking status, alcohol consumption, breakfast, frequency of eating out, education level, region of residence, household income level, and occupation, the odds ratio was 2.418 (95\% CI: 1.010-5.787) in the " $\geq U L$ " group compared with the " $<E A R$ " group, and the risk of thyroid disease tended to be increased ( $p$ for trend $=0.038$ ). However, there was no risk of iodine intake incidence and thyroid disease in the male group and in the total subjects.

This might support the idea that iodine intake by $>U L(\geq 2400 \mu \mathrm{g} /$ day $)$ can increase the risk of thyroid disease in females (Figure 6). However, the same results were not observed in the male group. Also, dietary iodine intake did not indicate any risk of thyroid disease incidence. 
Table 4. Logistic regression analysis of thyroid disease across KDRI of the estimated iodine intake by sex.

\begin{tabular}{|c|c|c|c|c|c|}
\hline \multirow{2}{*}{$\begin{array}{c}\text { Estimated } \\
\text { Iodine Intake } \\
(\mu \mathrm{g} / \text { day })\end{array}$} & \multicolumn{4}{|c|}{ Korean Dietary Reference Intake (KDRI) } & \multirow{2}{*}{$\begin{array}{c}p \text { for } \\
\text { Trend } \\
d\end{array}$} \\
\hline & $\begin{array}{c}<\text { EAR }^{a} \\
(<95)\end{array}$ & $\begin{array}{c}\geq{\text { EAR },<\text { RNI }^{b}}^{\text {b }} \\
(\geq 95,<150)\end{array}$ & $\begin{array}{l}\geq \mathrm{RNI},<\mathrm{UL}^{\mathrm{c}} \\
(\geq 150,2400)\end{array}$ & $\geq \mathrm{UL}(\geq 2400)$ & \\
\hline \multicolumn{6}{|l|}{ Total } \\
\hline Model 1 & $1^{\mathrm{e}}$ & $0.832(0.409-1.692)^{\mathrm{f}}$ & $1.084(0.634-1.854)$ & $1.788(0.820-3.898)$ & $0.059(+)$ \\
\hline Model 2 & 1 & $0.854(0.416-1.750)$ & $1.092(0.631-1.891)$ & $1.692(0.773-3.704)$ & $0.096(+)$ \\
\hline Model 3 & 1 & $0.887(0.428-1.838)$ & $1.144(0.657-1.992)$ & $1.796(0.815-3.960)$ & $0.076(+)$ \\
\hline Model 4 & 1 & $0.891(0.422-1.882)$ & $1.166(0.662-2.056)$ & $1.846(0.840-4.058)$ & $0.066(+)$ \\
\hline Model 5 & 1 & $0.847(0.390-1.836)$ & $1.095(0.612-1.957)$ & $1.726(0.760-3.923)$ & $0.085(+)$ \\
\hline \multicolumn{6}{|l|}{ Male } \\
\hline Model 1 & 1 & $0.499(0.095-2.620)$ & $0.440(0.108-1.792)$ & $0.414(0.051-3.359)$ & $0.720(-)$ \\
\hline Model 2 & 1 & $0.474(0.089-2.528)$ & $0.390(0.095-1.609)$ & $0.325(0.041-2.568)$ & $0.607(-)$ \\
\hline Model 3 & 1 & $0.397(0.075-2.098)$ & $0.317(0.073-1.378)$ & $0.251(0.034-1.839)$ & $0.549(-)$ \\
\hline Model 4 & 1 & $0.405(0.080-2.054)$ & $0.353(0.079-1.566)$ & $0.278(0.036-2.161)$ & $0.582(-)$ \\
\hline Model 5 & 1 & $0.419(0.084-2.084)$ & $0.311(0.070-1.378)$ & $0.240(0.029-1.954)$ & $0.5573(-)$ \\
\hline \multicolumn{6}{|l|}{ Female } \\
\hline Model 1 & 1 & $1.056(0.492-2.263)$ & $1.667(0.908-3.061)$ & $2.940(1.267-6.823)$ & $0.014(+)$ \\
\hline Model 2 & 1 & $1.054(0.490-2.267)$ & $1.629(0.887-2.989)$ & $2.773(1.198-6.420)$ & $0.023(+)$ \\
\hline Model 3 & 1 & $1.063(0.488-2.315)$ & $1.608(0.873-2.961)$ & $2.686(1.161-6.215)$ & $0.026(+)$ \\
\hline Model 4 & 1 & $1.048(0.479-2.292)$ & $1.561(0.846-2.881)$ & $2.554(1.113-5.861)$ & $0.034(+)$ \\
\hline Model 5 & 1 & $0.979(0.438-2.192)$ & $1.426(0.766-2.654)$ & $2.418(1.010-5.787)$ & $0.038(+)$ \\
\hline
\end{tabular}

${ }^{a}$ KDRI group was classified based on the estimated iodine intake; ${ }^{b}$ Standard error; ${ }^{c}$ EAR: Estimated average requirement; ${ }^{\mathrm{d}} p$ for trend was calculated by surveylogistic procedure of SAS; ${ }^{\mathrm{e}}$ Reference; ${ }^{\mathrm{f}}$ Odds ratio $(95 \% \mathrm{CI}$, confidence interval); Model 1: Unadjusted model; Model 2: Adjusted for age and energy intake; Model 3: Adjusted for age, energy intake, weight status, exercise status, smoking status, and alcohol consumption; Model 4: Adjusted for age, energy intake, weight status, exercise status, smoking status, alcohol consumption, breakfast, and frequency of eating out; Model 5: Adjusted for age, energy intake, weight status, exercise status, smoking status, alcohol consumption, breakfast, frequency of eating out, education level, region of residence, household income level, and occupation.

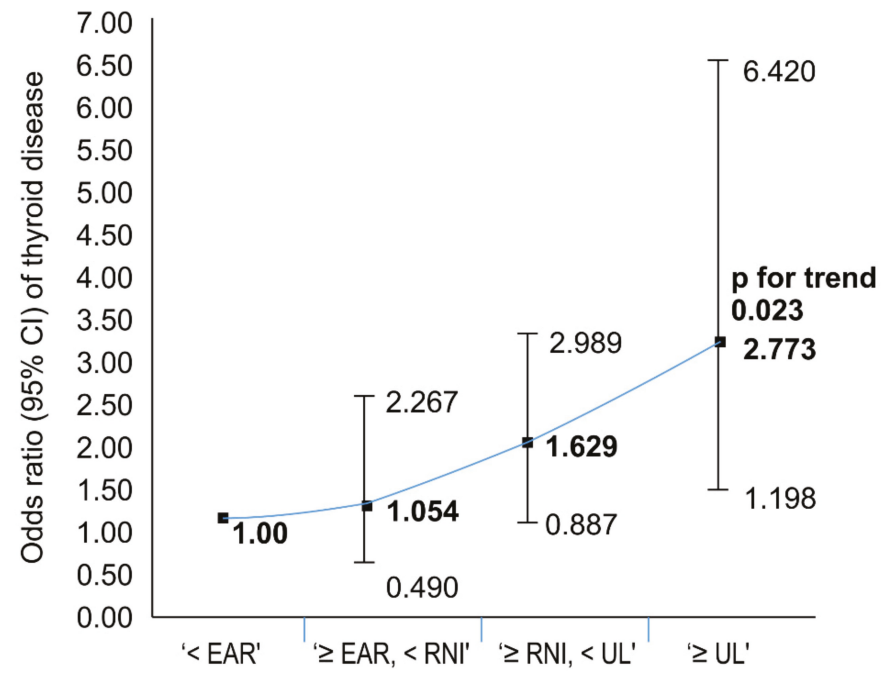

Adjusted for age and energy intake

\section{Estimated iodine intake by KDRI}

Figure 6. The odds ratio for thyroid disease by the estimated iodine intake in female. 


\section{Discussion}

In this study, we investigated the relationship between iodine intake status and thyroid disease-related functions, and we found that as the estimated iodine intake increased, TSH increased and the risk of thyroid disease also increased. In Korea, iodine-replete areas generally have a high risk of thyroid disease and autoimmune thyroid disease tends to develop into hypothyroidism. Excessive iodine intake is considered to be an important factor in thyroid disease; however, the mechanism or cause is uncertain at present.

Currently, the iodine nutrition status is measured by dietary iodine intake or UIC. The dietary iodine intake is calculated by the iodine content of the food ingredient composition and measured using the $24 \mathrm{~h}$ dietary recall method, food record, and food frequency questionnaire. However, the $24 \mathrm{~h}$ dietary recall and food record methods do not accurately reflect the amount of iodine in soup stocks such as salt and kelp. In addition, the iodine content of the food composition varies greatly depending on the production area and production period. Also, the amount of iodine in the food is so low [3], and the dietary intake of iodine-rich foods also varies widely among individuals. Hence, it is very difficult to measure the amount of iodine in food and to obtain individual iodine intakes for meals $[29,30]$.

Furthermore, iodine is mainly supplied by meals or drugs. The intake level is highly influenced by the environment, and iodine-which is a micronutrient-is present in a small amount in most foods and is concentrated in specific foods. It is difficult to accurately measure the iodine status [31,32]. Despite these limitations, the $24 \mathrm{~h}$ recall method is still valid for measuring dietary iodine intake in individuals. Hence, the UIC method is used more than the dietary iodine intake [8].

One of the most commonly used methods for measuring iodine nutrition status is the UIC as an epidemiologic criteria for the status of the population in the WHO [33]. Since, after metabolization in the body, more than $90 \%$ of iodine is excreted in the urine, UIC can estimate the recent intake of iodine by urinary iodine excretion amount and is used as a biomarker to determine the iodine status at the population level, which is a valuable and useful index [34,35]. However, UIC is inappropriate for evaluating the prevalence of iodine deficiency or excessive intake [16]. Therefore, in this study, we calculated and used the estimated iodine intake based on UIC.

Kim et al. [36] showed that 27 patients with Grave's disease showed higher urinary iodine excretion than the normal group, and in a similar article [37], urinary iodine excretion was higher in patients with simple goiter $(n=17 ; 2.88 \mathrm{mg} / \mathrm{L})$, hyperthyroidism $(n=42 ; 4.90 \mathrm{mg} / \mathrm{L})$, hypothyroidism $(n=15$; $4.57 \mathrm{mg} / \mathrm{L})$, and thyroid cancer $(n=11 ; 6.18 \mathrm{mg} / \mathrm{L})$ than in the normal group $(2.11 \mathrm{mg} / \mathrm{L})$. Additionally, in our study, the mean UIC based on prevalence was higher in the thyroid disease group than in the non-thyroid disease group, and the estimated iodine intake showed the same result, although the difference was not significant. These results indicate that UIC concentration is higher in the thyroid disease (such as goiter, hypothyroidism, and hyperthyroidism) group than in the disease-free group.

In this study, the correlation between UIC and dietary iodine intake showed a significant correlation with the total subject $(\mathrm{r}=0.014, p<0.001)$ and also in the female group $(\mathrm{r}=0.089, p<0.001)$, but, as mentioned, the male group showed the opposite result $(\mathrm{r}=-0.005, p<0.001)$. Also, in another study [38], UIC was associated with dietary iodine intake $(\mathrm{r}=0.60, p<0.01)$, and as iodine intake increased, the UIC gradually increased, which indicates a positive correlation between iodine intake and UIC. Additionally, the correlation between the estimated iodine intake and dietary iodine intake also showed a significant correlation with the total subjects $(\mathrm{r}=0.021, p<0.001)$ and also in the female group $(r=0.095, p<0.001)$, but the male group showed the opposite result $(r=-0.001, p<0.001)$. Comparing the dietary iodine intake and UIC between these groups and understanding the differences will enable us to determine the iodine nutrition status of the population more accurately.

In this study, the estimated iodine intake, which was calculated from UIC and dietary iodine intake, was divided into KDRI intervals to determine the risk of thyroid disease. These results show that the intake of iodine in Korea is higher than that in other countries, but there were more subjects who consume $<95 \mathrm{ug}(<\mathrm{EAR})$ and $\geq 2400 \mathrm{ug}$ (UL) (Figure 2). Most subjects consumed $>150 \mu \mathrm{g}$ and 
$<2400 \mu \mathrm{g}$, and $2.6 \%$ of them consume $>2400 \mu \mathrm{g}$ (dietary iodine intake) and $6.2 \%$ (estimated iodine intake) of iodine.

Furthermore, many other studies have shown that the median and upper limit of TSH increases with age [39-41]. In NHANES III, a higher TSH concentration was found to be associated with a higher UI/Cr excretion [42]. Additionally, TSH and FT4 levels were compared based on the presence of the disease. Moreover, similar results were found in the reference population: TSH levels were lower than that of the disease-free population. Therefore, a more in-depth study is required to clarify the link between TSH and iodine status; however, it has been confirmed that the excessive intake of iodine may be correlated with TSH.

In this study, the relationship between the estimated iodine intake, which was divided into KDRI intervals, and thyroid disease incidence was evaluated using the logistic regression analysis. It was found that the incidence of thyroid disease increased with increasing iodine intake. The correlation between the risk of thyroid disease according to the estimated iodine intake and the correlation between UIC and dietary iodine intake were significant only in the female group, but not in males.

These results support that the degree of response to iodine intake is higher due to the role of estrogen in women than in men, but more research is required on the concentration of estradiol and other cofactors [43-47].

One advantage of the study is that KNHANES VI (2013-2015) introduced TSH, FT4, TPOAb, and thyroid disease-related items, making it possible to observe the correlation of the iodine nutrition status with TSH and FT4 levels and to evaluate the effects of excessive iodine intake on thyroid disease. Additionally, the study cohort provided the most recently released nationally representative data of the Korean population.

However, there are some limitations to this study. First, KNHANES is a cross-sectional database; therefore, it cannot demonstrate the relationship between iodine intake and TSH or FT4 levels and thyroid disease, and it does not prove causality. Second, even though we have constructed a new iodine database for commercial foods in Korea, there is a limitation in the accurate determination of iodine intake by the food intake method. Finally, we did not consider various thyroid diseases.

The present study had limitations and further research is necessary to identify the factors contributing to the findings and to build accurate dietary sources. Despite these limitations and despite the need for further studies to identify the mechanisms involved in these findings and to build accurate dietary sources, this study provided important information. The study demonstrated the relationship between dietary iodine intake, UIC, and TSH along with a higher risk of thyroid disease-related hormone levels in groups with estimated iodine intake by over the UL ( $\geq 2400 \mu \mathrm{g} / \mathrm{day})$.

Author Contributions: Conceptualization, Y.K.P., and J.Y.K.; Study design Y.K.P., and S.K. methodology, Y.S.K., and S.K.; formal analysis, Y.S.K., K.H.H., and S.K.; investigation, Y.S.K., and S.K.; writing -original draft preparation, S.K.; writing -review and editing, S.K., and Y.K.P.; validation, J.Y.K., and K.H.H.; visualization, S.K.; supervision, Y.K.P.

Funding: This research received no external funding.

Conflicts of Interest: The authors declare no conflict of interest.

\section{References}

1. Korean Food \& Drug Administration. Report on the Intake of Sugar, Sodium, and the Rest of Korean; Korean Food \& Drug Administration: Cheongju, Korea, 2007.

2. Han, M.R.; Ju, D.L.; Park, Y.J.; Paik, H.Y.; Song, Y. An iodine database for common Korean foods and the association between iodine intake and thyroid disease in Korean adults. Int. J. Thyroidol. 2015, 8, 170-182. [CrossRef]

3. Ko, Y.M.; Kwon, Y.S.; Park, Y.K. An iodine database establishment and iodine intake in Korean adults: Based on the 1998 2014 Korea National Health and Nutrition Examination Survey. J. Nutr. Health 2017, 50, 624-644. [CrossRef] 
4. The Korean Nutrition Society. Dietary Reference Intakes for Koreans; The Korean Nutrition Society: Seoul, Korea, 2010.

5. Choi, J.; Kim, H.S.; Hong, D.J.; Lim, H.; Kim, J.H. Urinary iodine and sodium status of urban Korean subjects: A pilot study. Clin. Biochem. 2012, 45, 596-598. [CrossRef] [PubMed]

6. Institute of Medicine. Dietary Reference Intakes for Vitamin A, Vitamin K, Arsenic, Boron, Chromium, Copper, Iodine, Iron, Molybdenum, Nickel, Silicon, Vanadium and Zinc. Food and Nutrition Board; National Academy Press: Washington, DC, USA, 2001.

7. Hwang, S.; Lee, E.Y.; Lee, W.K.; Shin, D.Y.; Lee, E.J. Correlation between iodine intake and thyroid function in subjects with normal thyroid function. Biol. Trace Elem. Res. 2011, 143, 1393-1397. [CrossRef]

8. Lee, H.S.; Min, H. Iodine intake and tolerable upper intake level of iodine for Koreans. Korean J. Nutr. 2011, 44, 82-91. [CrossRef]

9. Laurberg, P.; Cerqueira, C.; Ovesen, L.; Rasmussen, L.B.; Perrild, H.; Andersen, S.; Pedersen, I.B.; Carlé, A. Iodine intake as a determinant of thyroid disorders in populations. Best Pract. Res. Clin. Endocrinol. Metab. 2010, 24, 13-27. [CrossRef]

10. Braverman, L.E. Iodine and the thyroid: 33 years of study. Thyroid 1994, 4, 351-356. [CrossRef]

11. Roti, E.; Uberti, E.D. Iodine excess and hyperthyroidism. Thyroid 2001, 11, 493-500. [CrossRef]

12. Laurberg, P.; Bulow Pedersen, I.; Knudsen, N.; Ovesen, L.; Andersen, S. Environmental iodine intake affects the type of nonmalignant thyroid disease. Thyroid 2001, 11, 457-469. [CrossRef]

13. Burgi, H. Iodine excess. Best Pract. Res. Clin. Endocrinol. Metab. 2010, 24, 107-115. [CrossRef]

14. Clark, O.H. Excess iodine intake and thyroid function and growth. Thyroid 1990, 1, 69-72. [CrossRef] [PubMed]

15. Sun, X.; Shan, Z.; Teng, W. Effects of increased iodine intake on thyroid disorders. Endocrinol. Metab. 2014, 29, 240-247. [CrossRef] [PubMed]

16. Zimmermann, M.B.; Andersson, M. Assessment of iodine nutrition in populations: Past, present, and future. Nutr. Rev. 2012, 70, 553-570. [CrossRef] [PubMed]

17. Zimmermann, M. Iodine deficiency and excess in children: Worldwide status in 2013. Endocr. Pract. 2013, 19, 839-846. [CrossRef] [PubMed]

18. Ross, D.S.; Burch, H.B.; Cooper, D.S.; Greenlee, M.C.; Laurberg, P.; Maia, A.L.; Rivkees, S.A.; Samuels, M.; Sosa, J.A.; Stan, M.N.; et al. 2016 American Thyroid Association Guidelines for Diagnosis and Management of Hyperthyroidism and Other Causes of Thyrotoxicosis. Thyroid 2016, 26, 1343-1421. [CrossRef] [PubMed]

19. Sheehan, M.T. Biochemical testing of the thyroid: TSH is the best and, oftentimes, only test needed-A review for primary care. Clin. Med. Res. 2016, 14, 83-92. [CrossRef] [PubMed]

20. Chaker, L.; Korevaar, T.I.; Medici, M.; Uitterlinden, A.G.; Hofman, A.; Dehghan, A.; Franco, O.H.; Peeters, R.P. Thyroid function characteristics and determinants: The Rotterdam study. Thyroid 2016, 26, 1195-1204. [CrossRef]

21. Ministry of Health and Welfare, Korea Centers for Disease Control and Prevention. Korea National Health and Nutrition Examination Survey (KNHANES VI). 2016. Available online: https://knhanes.cdc.go.kr/ knhanes/main.do2016.

22. Kim, W.G.; Kim, W.B.; Woo, G.; Kim, H.; Cho, Y.; Kim, T.Y.; Kim, S.W.; Shin, M.-H.; Park, J.W.; Park, H.-L.; et al. Thyroid stimulating hormone reference range and prevalence of thyroid dysfunction in the Korean population: Korea National Health and Nutrition Examination Survey 2013 to 2015. Endocrinol. Metab. 2017, 32, 106-114. [CrossRef]

23. Leung, A.M.; Braverman, L.E. Consequences of excess iodine. Nat. Rev. Endocrinol. 2014, 10, 136. [CrossRef]

24. Kim, H.I.; Oh, H.K.; Park, S.Y.; Jang, H.W.; Shin, M.H.; Kim, S.W.; Kim, T.H.; Chung, J.H. Urinary iodine concentration and thyroid hormones: Korea National Health and Nutrition Examination Survey 2013-2015. Eur. J. Nutr. 2019, 58, 233-240. [CrossRef]

25. The Korean Nutrition Society. Food Values; The Korean Nutrition Society: Seoul, Korea, 2009.

26. National Rural Resources Development Institute. Administration RD 9th Revision; Rural Development Administration: Jeonju, Korea, 2018.

27. Ministry of Education, Culture, Sports, Science and Technology. Japan Standard Tables of Food Composition in Japan; Seventh Revised Version; Ministry of Education, Culture, Sports, Science and Technology: Tokyo, Japan, 2015. 
28. Kweon, S.; Kim, Y.; Jang, M.J.; Kim, Y.; Kim, K.; Choi, S.; Chun, C.; Khang, Y.H.; Oh, K. Data resource profile: The Korea National Health and Nutrition Examination Survey (KNHANES). Int. J. Epidemiol. 2014, 43, 69-77. [CrossRef] [PubMed]

29. Freedman, L.S.; Commins, J.M.; Moler, J.E.; Willett, W.; Tinker, L.F.; Subar, A.F.; Spiegelman, D.; Rhodes, D.; Potischman, N.; Neuhouser, M.L. Pooled results from 5 validation studies of dietary self-report instruments using recovery biomarkers for potassium and sodium intake. Am. J. Epidemiol. 2015, 181, 473-487. [CrossRef] [PubMed]

30. McLean, R.M. Measuring population sodium intake: A review of methods. Nutrients 2014, 6, 4651-4662. [CrossRef] [PubMed]

31. Woeber, K.A. Iodine and thyroid disease. Med. Clin. N. Am. 1991, 75, 169-178. [CrossRef]

32. Winichagoon, P.; Svasti, S.; Munkongdee, T.; Chaiya, W.; Boonmongkol, P.; Chantrakul, N.; Fucharoen, S. Rapid diagnosis of thalassemias and other hemoglobinopathies by capillary electrophoresis system. Transl. Res. 2008, 152, 178-184. [CrossRef]

33. World Health Organization. Urinary Iodine Concentrations for Determining Iodine Status in Populations; World Health Organization: Geneva, Switzerland, 2013.

34. Nath, S.; Moinier, B.; Thuillier, F.; Rongier, M.; Desjeux, J. Urinary excretion of iodide and fluoride from supplemented food grade salt. Int. J. Vitam. Nutr. Res. 1992, 62, 66-72.

35. Jolin, T.; Escobar, D.R. Evaluation of iodine/creatinine ratios of casual samples as indices of daily urinary iodine output during field studies. J. Clin. Endocrinol. Metab. 1965, 25, 540-542. [CrossRef]

36. Kim, H.; Lee, H.; Park, K.; Joo, H.; Kim, K.; Hong, C.; Huh, K.; Lee, S.; Ryu, K. A study on the urinary iodide excretion in normal subjects and patients with thyroid disease. Korean J. Intern. Med. 1985, 29, 625-631.

37. Kim, J.Y.; Kim, K.R. Dietary iodine intake and urinary iodine excretion in patients with thyroid diseases. Yonsei Med. J. 2000, 41, 22-28. [CrossRef]

38. Kim, J.Y.; Moon, S.J.; Kim, K.R.; Sohn, C.Y.; Oh, J.J. Dietary iodine intake and urinary iodine excretion in normal Korean adults. Yonsei Med. J. 1998, 39, 355-362. [CrossRef]

39. Haymart, M.R.; Glinberg, S.L.; Liu, J.; Sippel, R.S.; Jaume, J.C.; Chen, H. Higher serum TSH in thyroid cancer patients occurs independent of age and correlates with extrathyroidal extension. Clin. Endocrinol. 2009, 71, 434-439. [CrossRef]

40. Hadlow, N.C.; Rothacker, K.M.; Wardrop, R.; Brown, S.J.; Lim, E.M.; Walsh, J.P. The relationship between TSH and free $\mathrm{T} 4 \mathrm{in}$ a large population is complex and monlinear and differs by age and sex. J. Clin. Endocrinol. Metab. 2013, 98, 2936-2943. [CrossRef] [PubMed]

41. Lee, Y.K.; Kim, J.E.; Oh, H.J.; Park, K.S.; Kim, S.K.; Park, S.W.; Kim, M.J.; Cho, Y.W. Serum TSH level in healthy Koreans and the association of TSH with serum lipid concentration and metabolic syndrome. Korean J. Intern. Med. 2011, 26, 432-439. [CrossRef] [PubMed]

42. Hollowell, J.G.; Staehling, N.W.; Flanders, W.D.; Hannon, W.H.; Gunter, E.W.; Spencer, C.A.; Braverman, L.E. Serum TSH, T4, and thyroid antibodies in the United States population (1988 to 1994): National Health and Nutrition Examination Survey (NHANES III). J. Clin. Endocrinol. Metab. 2002, 87, 489-499. [CrossRef]

43. Ishii, K.; Hayashi, A.; Tamaoka, A.; Mizusawa, H.; Shoji, S. A case of Hashimoto's encephalopathy with a relapsing course related to menstrual cycle. Clin. Neurol. 1993, 33, 995-997.

44. Leo, V.D.; D'Antona, D.; Lanzetta, D. Thyrotropin secretion before and after ovariectomy in premenopausal women. Gynecol. Endocrinol. 1993, 7, 279-283. [CrossRef]

45. Fujimoto, N.; Watanabe, H.; Ito, A. Blockade of the estrogen induced increase in progesterone receptor caused by propylthiouracil, an anti-thyroid drug, in a transplantable pituitary tumor in rats. Endocr. J. 1996, 43, 329-334. [CrossRef]

46. Ogard, C.G.; Ogard, C.; Almdal, T.P. Thyroid-associated orbitopathy developed during hormone replacement therapy. Acta Ophthalmol. Scand. 2001, 79, 426-427. [CrossRef]

47. Abalovich, M.; Gutierrez, S.; Alcaraz, G.; Maccallini, G.; Garcia, A.; Levalle, O. Overt and subclinical hypothyroidism complicating pregnancy. Thyroid 2002, 12, 63-68. [CrossRef]

(C) 2019 by the authors. Licensee MDPI, Basel, Switzerland. This article is an open access article distributed under the terms and conditions of the Creative Commons Attribution (CC BY) license (http://creativecommons.org/licenses/by/4.0/). 



\title{
Communication \\ Endemic Goiter and Iodine Prophylaxis in Calabria, a Region of Southern Italy: Past and Present
}

\author{
Cinzia Giordano ${ }^{1,2}$, Ines Barone ${ }^{1}$, Stefania Marsico ${ }^{1,2}$, Rosalinda Bruno ${ }^{1,2}$, \\ Daniela Bonofiglio ${ }^{1,2, *}$, Stefania Catalano ${ }^{1,2, *}$ and Sebastiano Andò ${ }^{1,2, *}$ \\ 1 Department of Pharmacy, Health and Nutritional Sciences, University of Calabria, 87036 Rende (CS), Italy; \\ cinzia.giordano@unical.it (C.G.); ines.barone@unical.it (I.B.); stefania.marsico@unical.it (S.M.); \\ rosalinda.bruno@unical.it (R.B.) \\ 2 Centro Sanitario, University of Calabria, 87036 Rende (CS), Italy \\ * Correspondence: daniela.bonofiglio@unical.it (D.B.); stefcatalano@libero.it (S.C.); \\ sebastiano.ando@unical.it (S.A.); Tel.: +39-0984-496208 (D.B. \& S.C. \& S.A.); \\ Fax: +39-0984-496203 (D.B. \& S.C. \& S.A.)
}

Received: 11 September 2019; Accepted: 8 October 2019; Published: 11 October 2019

\begin{abstract}
Iodine, a micronutrient that plays a pivotal role in thyroid hormone synthesis, is essential for proper health at all life stages. Indeed, an insufficient iodine intake may determine a thyroid dysfunction also with goiter, or it may be associated to clinical features such as stunted growth and mental retardation, referred as iodine deficiency disorders (IDDs). Iodine deficiency still remains an important public health problem in many countries, including Italy. The effective strategy for the prevention and control of IDDs is universal salt iodization, which was implemented in Italy in 2005 as a nationwide program adopted after the approval of an Italian law. Despite an improvement in the iodine intake, many regions in Italy are still characterized by mild iodine deficiency. In this review, we provide an overview of the historical evolution of the iodine status in the Calabria region, located in the South of Italy, during the past three decades. In particular, we have retraced an itinerary from the first epidemiological surveys at the end of the 1980s to the establishment of the Regional Observatory of Endemic Goiter and Iodine Prophylaxis, which represents an efficient model for the surveillance of IDDs and monitoring the efficacy of iodine prophylaxis.
\end{abstract}

Keywords: iodine deficiency; iodine prophylaxis; goiter; urinary iodine concentration

\section{Introduction}

Iodine deficiency and related disorders are still a public health problem that affects most countries, including industrialized and developing regions [1,2]. At the end of 2018, a global survey on iodine status, covering more than $97 \%$ of the world's population, indicated that 21 countries remain vulnerable to iodine deficiency. Specifically, nationally-representative surveys revealed insufficient iodine intake in 14 countries (Burkina Faso, Burundi, Finland, Haiti, Israel, Iraq, the Democratic People's Republic of Korea, Lebanon, Mali, Madagascar, Mozambique, Samoa, Vanuatu, and Vietnam). Moreover, in sub-national surveys, seven other countries, including Angola, Italy, Morocco, Norway, Russia, South Sudan, and Sudan were reported as being iodine insufficient [3].

Iodine deficiency impairs thyroid hormone production and has many adverse effects during the course of life, which are collectively termed the iodine deficiency disorders (IDDs). The frequency and severity of IDD manifestations are related to the degree of iodine deficiency and the age of the affected subjects. Although thyroid enlargement (goiter) is the classic sign of iodine deficiency, and can take place at any age, the most serious adverse effects of iodine deficiency occur during pregnancy, including impaired fetal growth and brain development [4-6]. The iodine status of the population can be assessed by using four methods: urinary iodine (UI) concentration, the goiter rate, serum thyroid 
stimulating hormone (TSH), and serum thyroglobulin (Tg) levels [7-10]. UI is the most sensitive indicator of current iodine intake because $>90 \%$ of dietary iodine is excreted in the urine [11]. UI concentration can be measured in spot urine samples and the median UI values were used to assess iodine nutrition among school-age children, as recommended by World Health Organization (WHO), United Nations International Children's Emergency Fund (UNICEF), and the Iodine Global Network (IGN) [7]. The cut-off values for urinary iodine levels were used to define iodine deficiency $(<100 \mu \mathrm{g} / \mathrm{L})$ were classified as mild $(50-99 \mu \mathrm{g} / \mathrm{L})$, moderate $(20-49 \mu \mathrm{g} / \mathrm{L})$, or severe $(<20 \mu \mathrm{g} / \mathrm{L})$. Daily iodine intake for population can be extrapolated from UI concentration using the following formula: urinary iodine $(\mu \mathrm{g} / \mathrm{L}) \times 0.0235 \times$ body weight $(\mathrm{Kg})=$ daily intake $(\mu \mathrm{g})[12]$.

This allows us to assume that a median UI concentration of $100 \mu \mathrm{g} / \mathrm{L}$ corresponds roughly to an average daily iodine intake of $150 \mu \mathrm{g}$.

An important indicator of IDDs is represented by the goiter rate measured by ultrasound in school-age children. However, a standardized approach should be adopted worldwide to improve the reliability of thyroid volume in the context of IDD monitoring [8]. Supplementary indicators of iodine deficiency include blood-spot TSH measurement only in neonates [13], while Tg measured in a dried blood spot has been reported to be a good marker of iodine intake in infancy [14].

Universal salt iodization is the most cost-effective strategy for IDDs and the WHO, UNICEF, and IGN recommend that iodine is added at a concentration of $20-40 \mathrm{mg}$ per $\mathrm{kg}$ salt, dependent on local salt intake [15].

Over the last decades, intensive efforts have been made by the governments of IDD-affected countries to implement and control salt iodization program [9,16-19]. India was one of the first countries in the world to initiate and maintain a sustained increase in the coverage of adequately iodized salt, achieving the goal of universal salt iodization levels of greater than $90 \%$ in urban areas of the Central, North, and North-East zones of its territory in 2015 [20-22]. Following the introduction of mandatory salt iodization in 1995, Madagascar showed a swift growth in iodized salt coverage, however a recent national survey reported that iodine deficiency remains a serious public health problem there [23]. This implies that to maintain an effective program on salt iodization over the long term, it is necessary to set up a system that coordinates and monitors the sale trend of iodized salt and communicates the health benefits of consuming iodized salt. A good example of national progress is represented by Ethiopia in which the national coverage of iodized salt increased from $4.2 \%$ in 2005 to $95 \%$ in 2014. These results stem from multi-level and multi-sector efforts involving public-private partnerships that focused on enforcing iodization legislation [24,25]. Also in Italy, a nationwide salt iodization program was implemented in 2005 with the approval of the law n. 55/2005 that requires the addition of potassium iodate to table salt at $30 \mathrm{mg} / \mathrm{kg}$ and the mandatory availability of iodized salt in food shops and supermarkets. The law also permits the use of iodized salt in the food and catering industries. To the aim of evaluating the efficiency and effectiveness of the nationwide program of iodine prophylaxis, in 2009 the Italian National Observatory for Monitoring Iodine Prophylaxis (OSNAMI) was established at the Italian National Institute of Health [26]. Although a significant improvement of iodine nutrition has been observed over the years, some regions in Italy still remain at risk of deficiency.

In this review we provide an overview of the iodine status in Calabria, a region of Southern Italy, over the past three decades. Particularly, we report data obtained from the first epidemiological surveys up to the establishment of the Regional Observatory of Endemic Goiter and Iodine Prophylaxis (Figure 1), that represents an efficient model for the surveillance of IDDs and monitoring the efficacy of iodine prophylaxis. 


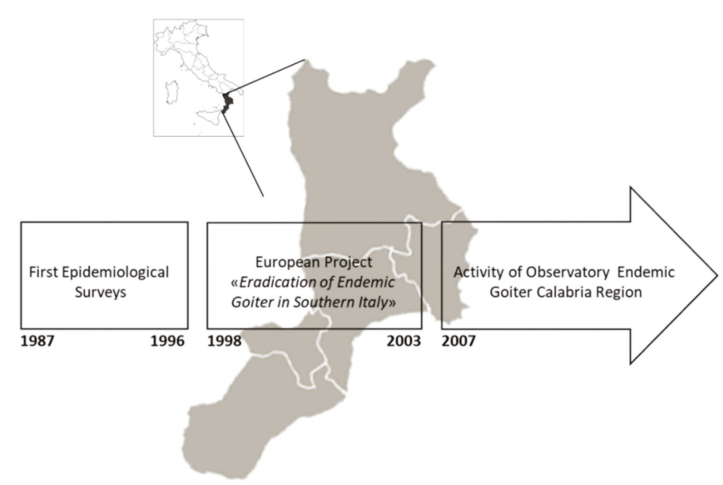

Figure 1. Schematic representation of the key steps of epidemiological surveys conducted from the late 1980 s to the present for assessing and monitoring iodine status in the Calabria region.

\section{History of Goiter and Iodine Deficiency in Calabria: Epidemiological Surveys during the 1980-2000 Period}

The Calabria region located in the Southern of Italy is a peninsula of irregular shape, referred to as the "toe" of the Italian "boot", with a coastline of $738 \mathrm{~km}$ on the Ionian and Tyrrhenian coasts of the Mediterranean Basin. The regional orography highlights mountainous features: $42 \%$ of the land is mountainous, $49 \%$ is hilly, and only $8 \%$ is completely flat with an average elevation of $597 \mathrm{~m}$ [27]. This region, comprising five provinces with a total population of about 2 million inhabitants, has been historically exposed to iodine deficiency.

Data obtained from epidemiological surveys carried out between 1987-1996 allowed us to draw a first map of iodine deficiency and endemic goiter in Calabria by evaluating the mean of UI excretion and the size of thyroid gland. Since ultrasonography was not easy to perform in a large scale of epidemiological screening and the reference values for ultrasound thyroid volume measurement in children living in iodine-sufficient areas were not well established, the goiter rate was assessed using WHO's 1960 palpation system [28].

The first study was conducted by our research group [29] in 1987-1989 on 34 villages of extraurban areas of Catanzaro (A) and Cosenza (B) provinces. In this survey, 4468 and 2721 schoolchildren (aged between 6-12 years) of area A and area B, respectively, were examined. The prevalence of endemic goiter was $53 \%$ in the population living in Catanzaro's province with the highest percentage found in Zagarise $(67 \%)$, while the rate in schoolchildren from Cosenza's province was $44 \%$ with the highest percentage found in Laino Castello (69\%). Interestingly, in both areas the goiter prevalence was independent from area altitude as well as the distance of the villages from the main town, and was significantly higher than that observed among the 1170 age-matched schoolchildren living in the urban area of the Calabria region (7.7\%). Mean UI concentration was $49.7 \pm 5.3 \mu \mathrm{g} / \mathrm{L}$ and $70.7 \pm 3.1 \mu \mathrm{g} / \mathrm{L}$ in area $\mathrm{A}$ and $\mathrm{B}$, respectively, indicating the presence of a mild iodine deficiency respect to the UI values of urban area that reflect an iodine sufficiency $(104 \pm 6.6 \mu \mathrm{g} / \mathrm{L})$.

After two years of voluntary iodine prophylaxis (1991-1992) 855 schoolchildren from five small villages (Laino Borgo, Laino Castello, San Basile, Saracena and Mormanno) of Cosenza province were examined. These five villages were chosen since their drug-stores carried iodized salt and the population was advised to use it. As shown in Figure 2, an increase of UI concentration along with a reduced goiter prevalence were found, suggesting that an effective program of iodine prophylaxis is urgently needed in this region [29]. 


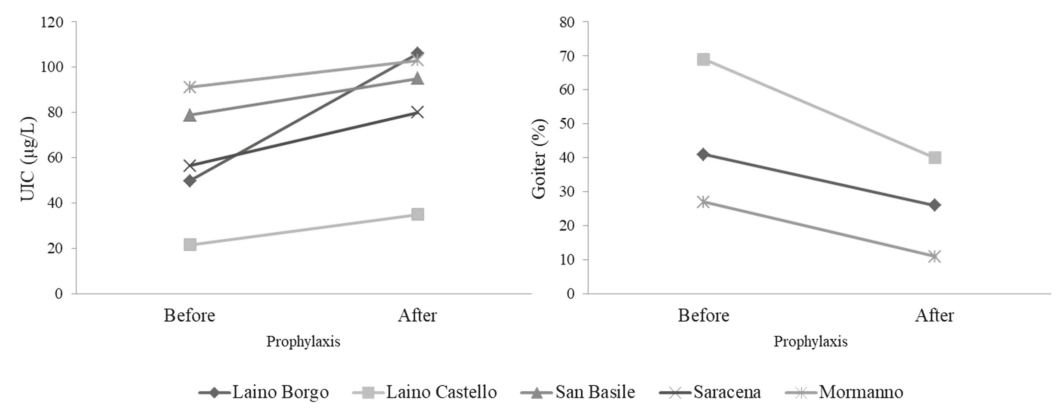

Figure 2. Urinary iodine concentration (UIC) and goiter prevalence before and after iodine prophylaxis in schoolchildren of the Cosenza province.

Another epidemiological study, which are useful to better define the map of endemic goiter and to characterize iodine deficiency in the whole Calabrian territory, was performed during the years 1990-1996 by Costante et al. [30]. A total of 13,984 schoolchildren, aged 6-14 years, was examined for the goiter prevalence, while UI excretion was evaluated in 284 samples that were randomly collected. Goiter prevalence ranged from $19 \%$ to $64 \%$ and from $5.3 \%$ to $25.7 \%$ in the inland territory and at the coastal area, respectively, while the mean of UI excretion was $53.8 \pm 43.4 \mu \mathrm{g} / \mathrm{L}$ in the inland territory and $89.6 \pm 59.8 \mu \mathrm{g} / \mathrm{L}$ at sea level, confirming that moderate levels along with pockets of severe iodine deficiency was present in the inland region, while iodine supply varied from sufficient to marginally low in the coastal areas. Moreover, the presence of mild to moderate iodine deficiency was also established by the results of neonatal TSH levels from the congenital hypothyroidism regional screening program. Indeed, the authors reported $14.8 \%$ frequency of TSH levels $>5 \mu \mathrm{U} / \mathrm{mL}$ in newborns from the inland territory and $14.1 \%$ frequency from coastal areas [30].

Overall, these first epidemiological surveys clearly indicate that at the end of the 1990s, the whole Calabria region was a mild to moderate iodine deficient area. Interestingly, the data obtained in the Calabria region were in line with a series of surveys carried out from 1978 to 1991 in different regions of Italy, in which a total number of 72,112 schoolchildren was examined, including 5046 controls living in urban areas and 66,066 subjects residing in rural endemic areas. Surveys were carried out throughout Italy in predominantly hilly and mountainous areas. Globally, the goiter prevalence ranged from $14 \%$ to $73 \%$, which inversely correlated with urinary iodine excretion (10-122 $\mu \mathrm{g} / \mathrm{g}$ creatinine) and was more prevalent in Central and Southern Italy (reference [31] and references therein).

At the end of the 1990s, as part of a European project entitled "Eradication of endemic goiter and of disorders of iodine deficiency in Southern Italy" with cooperation between the National Research Council and the Ministry of Health, and financed by the European Union, a survey to assess the iodine nutrition was conducted in eight regions of Southern Italy, including Calabria [32]. The grade of iodine deficiency was assessed through the measurement of UI excretion in 23,103 samples randomly collected from the schoolchildren population aged 11-14 years living in urban and rural areas and in different geographic locations. Median UI excretion in the all studied population was $74 \mu \mathrm{g} / \mathrm{L}$, showing significantly higher values in urban areas compared to rural areas $(81 \mu \mathrm{g} / \mathrm{L}$ vs. $73 \mu \mathrm{g} / \mathrm{L}, p<0.0001)$. Besides, median UI excretion was significantly lower in inland mountainous/hilly areas respect to coastal mountainous/hilly areas $(68 \mu \mathrm{g} / \mathrm{L}$ vs. $79 \mu \mathrm{g} / \mathrm{L}, p<0.0001)$. The results of this extensive survey indicated that in Southern Italy, mild to moderate iodine deficiency still persisted [32]. Particularly in the Calabria region, data obtained from a total of 2693 spot urinary samples expressed as median as well as mean $( \pm \mathrm{SD})$ displayed insufficient iodine intake in all five provinces of the Calabria region (Table 1, data unpublished). 
Table 1. Mean $( \pm \mathrm{DS})$ and median urinary iodine concentration (UIC) in schoolchildren in the Calabria region.

\begin{tabular}{cccc}
\hline Provinces & Samples $(n)$ & UIC Mean $( \pm$ SD) $\mu \mathrm{g} / \mathrm{L}$ & UIC Median $\mu \mathrm{g} / \mathrm{L}$ \\
\hline Catanzaro & 1024 & $85 \pm 71$ & 65 \\
Cosenza & 701 & $91 \pm 71$ & 73 \\
Crotone & 257 & $84 \pm 78$ & 54 \\
Reggio Calabria & 346 & $91 \pm 69$ & 75 \\
Vibo Valentia & 365 & $83 \pm 64$ & 67 \\
\hline
\end{tabular}

Similar results were obtained in Campania, another region of Southern Italy, in which UI excretion from 10,552 schoolchildren were determined. The analysis of frequency distribution showed values below 50 and $100 \mu \mathrm{g} / \mathrm{L}$ of UI in $32 \%$ and $61 \%$ of children, respectively, highlighting the Campania region as a mild iodine deficiency area [33].

As a part of the same European project, another important challenge was to implement the use of iodized salt through interactive meetings with schoolchildren. In the Calabria region, we have interviewed 49,840 subjects in their classrooms, providing detailed information on the beneficial effects of iodine salt prophylaxis along with informative materials consisting of leaflets and table-games about iodine deficiency disorders. A final goal of this project was to establish an Observatory for Monitoring Iodine Prophylaxis in each Italian region.

\section{Status of Iodine Intake Over the Last Two Decades in the Calabria Region: The Epidemiological Observatory for Endemic Goiter and Iodine Prophylaxis}

Based on our extensive studies carried out in the entire regional territory and taking into account the final goal of the European project, the Epidemiological Observatory and Promotion of Health of the Calabria Region, Section "Goiter Endemic and Iodine Prophylaxis" (OERC) was established by the Calabria region (regional law n. 755/2003) at the Health Center of the University of Calabria. The OERC represents the epidemiological structure through which the regional-scale surveillance of the iodine prophylaxis program is carried out using: (i) epidemiological surveys to periodically evaluate the iodine intake and the prevalence of goiter in the adolescent and to verify the prevalence of thyroid diseases in the adult population; (ii) a promotional campaign on the advantages of iodine prophylaxis; (iii) the sale trend of iodized salt.

\subsection{Epidemiological Surveys}

The first survey was carried out in the years 2007-2009 on 11-14 year old children recruited from long standing iodine sufficient urban areas (U) and from rural areas (R) in which an iodine insufficiency was previously documented $[29,30]$. In agreement with the guidelines of WHO, UNICEF, and International Council for Control of Iodine Deficiency Disorders (ICCIDD) [9], monitoring was based on both the percentage of goiter and the median value of UI concentration in schoolchildren. A total of 2733 subjects ( $1686 \mathrm{U}$ and $1047 \mathrm{R}$ ) from the five provinces of Calabria were examined to evaluate thyroid volume by ultrasonography, while 1358 (794 U and $565 \mathrm{R}$ ) spot-urine samples were collected to determine adequacy of iodine intake. The prevalence of goiter, calculated on the basis of the reference values proposed by WHO [8], and the median values of ioduria are shown in Figure 3 (data unpublished). 


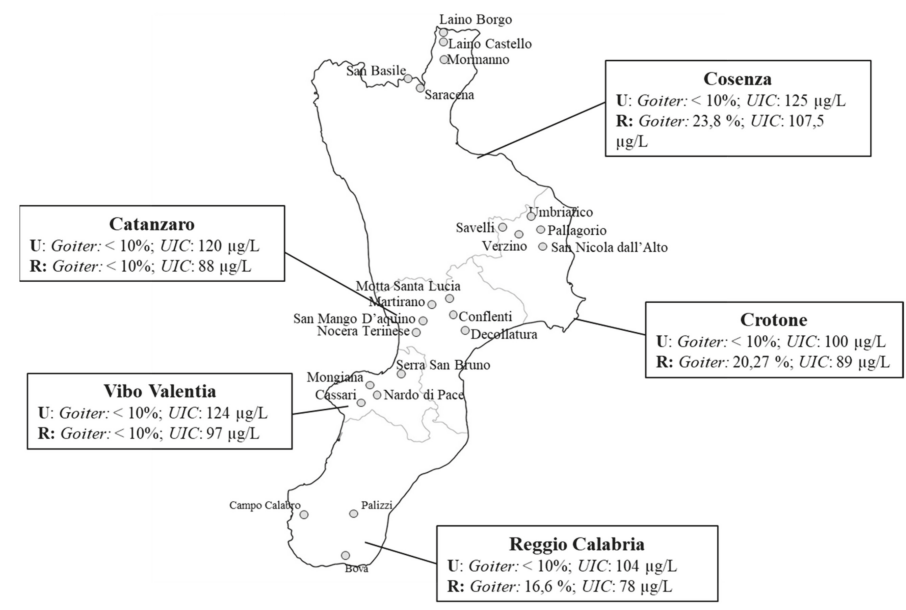

Figure 3. Goiter prevalence and median urinary iodine concentration in schoolchildren population from iodine sufficient urban areas $(\mathrm{U})$ and rural areas $(\mathrm{R})$ of the Calabria region.

Our data indicated that a mild iodine deficiency was still present in the rural areas of the provinces of Cosenza, Reggio Calabria, and Crotone, whereas all the areas in which the prevalence of goiter was less than $10 \%$ showed an adequate iodine status.

On the basis of these findings, we focused our attention on a vast territory of mild to-moderate endemic area of Cosenza province, including four villages (Laino, San Basile, Saracena, and Mormanno). In particular, we assessed both goiter prevalence and UI concentration in children aged 11-14 years. Using WHO criteria, the goiter prevalence was $7.1 \%$ and $10.95 \%$ normalized for body surface area (BSA) and age, respectively, while median UI excretion was $113 \mu \mathrm{g} / \mathrm{L}$. Moreover, we also evaluated the efficacy of the iodine prophylaxis in an adult population living in Laino. We observed reduced goiter prevalence in the studied population that was subjected for two decades to a program of salt iodization. More interestingly, the beneficial effects of iodine prophylaxis were also observed in the youngest adult population investigated (ranged 18-27 years), which showed almost an absence of thyroid enlargement, whereas the older adult population ( $>58$ years), which have mostly lived in a severe iodine deficient area before beginning iodine supplementation, were less responsive in reducing goiter prevalence [34].

The epidemiological studies on iodine status by OERC continued until 2012 in the context of the activities carried out by OSNAMI. Median UI concentration and goiter prevalence in 729 schoolchildren recruited in Calabria region were $87 \mu \mathrm{g} / \mathrm{L}$ and $7.5 \%$, respectively, which showed that further efforts were still required to encourage the use of iodized salt [35].

Despite the clear benefits of iodine prophylaxis, continuous surveillance of adverse effects induced by iodine intake needs to be carefully maintained. Thus, the frequency of thyroid disorders along with the levels of antithyroid antibodies (TgAb and TPOAb) in 560 adult subjects from Laino and from the urban area of Cosenza were evaluated [36]. As expected, the prevalence of subjects affected by goiter was significantly higher in the rural area than in the urban area, but interestingly it was significantly lower compared with that reported in the adult population living in the same rural area in 2007 (42.6\% rural area in 2007 vs. 13.8\% rural area in 2015, $p<0.0001)$. Moreover, we have observed a significant increase of $\mathrm{TgAb}$ levels in subjects living in a long-standing iodine sufficient area that may be an epiphenomenon with no pathogenic significance [37]. Interestingly, no changes were detected for concentrations of TPOAbs, the levels of which are typically high in thyroid autoimmune disease [38].

More recently, preliminary data from the national program of iodine deficiency monitoring activities of OSNAMI have reported an increased UI concentration in rural areas as well as urban areas 
together with a reduction in goiter prevalence in schoolchildren population of most Italian regions, including Calabria [39].

\subsection{Promotional Campaign}

An intense and widespread iodine prophylaxis campaign was carried out during 2007-2009. At the end of the promotional survey, the OERC medical team visited 1012 primary schools involving more than 100,000 children in all provinces of Calabria, outlining the health benefits of iodine through the distribution of information materials, pamphlets, gadgets, and posters. Besides, other strategies to increase consumer awareness towards iodized salt and its beneficial health effects have been developed and are currently ongoing. These include a promotional campaign using mass media (newspaper, TV), billboards on buses, and a website [40] that offers a useful platform containing national and international links to other reliable sources of information about iodine nutrition.

\subsection{Sale Trend of Iodized Salt}

The activities of the OERC also include an assessment of the iodine content in salt on the market. Salt samples, taken from the subjects screened (131 subjects from the rural area and 235 subjects from the urban area) during our epidemiological surveys, were found to be compliant with the iodine content permitted by Italian law (30 mg/kg) [36]. The data on sale trends of iodized salt in Calabria, supplied by the Italian Salt Company, one of the most important sales producers/distributors in the region, showed an increasing trend over the last few decades, reaching a coverage rate of approximately $65 \%$ [36]. These data are in line with those obtained from the national salt producers and collected by the Italian National Institute of Health that specifically reported an increase in the percentage of sold iodized salt from 34\% in 2006 to $65 \%$ in 2017 [39]. However, since a usage rate of iodized salt of at least $90 \%$ is recommended by WHO, UNICEF, and the ICCIDD [3] for effective prevention of IDDs, further efforts should be made to better inform the population on the benefits of using iodized salt.

\section{Conclusions}

The IDD control program in Calabria is one of the success stories of public health in Italy. The epidemiological data over the last three decades clearly indicate the improvement of iodine status in the Calabria region also due to the commitment of the Regional Observatory of Endemic Goiter and Iodine Prophylaxis. Although substantial progress has been made, efforts should focus on ensuring there is adequate iodine intake in the entire population to achieve and maintain the IDD control goal.

Author Contributions: D.B., S.C. and S.A. conceptualized, C.G., searched literature, I.B., S.M., R.B. searched literature and data curation, C.G., D.B., S.C. wrote the first versions of the manuscript. D.B., S.C. and S.A. took care of the final update, revision and editing. All authors approved the final version.

Funding: This work was supported by Osservatorio Epidemiologico e Promozione della Salute, "Sezione Gozzo Endemico e Iodoprofilassi", Regione Calabria, Italy; by Department of Excellence (Italian Law. 232/2016) Department of Pharmacy, Health and Nutritional Sciences, University of Calabria, Italy.

Acknowledgments: Authors thank the school-children, teachers and the authorities of the schools for their participation and collaboration.

Conflicts of Interest: The authors declare no conflict of interest.

\section{References}

1. Li, M.; Eastman, C.J. The changing epidemiology of iodine deficiency. Nat. Rev. Endocrinol. 2012, 8, 434-440. [CrossRef] [PubMed]

2. Mohammadi, M.; Azizi, F.; Hedayati, M. Iodine deficiency status in the WHO Eastern Mediterranean Region: A systematic review. Environ. Geochem. Health 2018, 40, 87-97. [CrossRef] [PubMed]

3. The Iodine Global Network: 2018 Annual Report. Available online: https://www.ign.org/cm_data/IGN_ 2018_Annual_Report_5_web.pdf (accessed on 5 September 2019). 
4. Zimmermann, M.B. The role of iodine in human growth and development. Semin Cell Dev. Biol. 2011, 22, 645-652. [CrossRef] [PubMed]

5. Eastman, C.J.; Zimmermann, M.B. The iodine deficiency disorders. In Endotext; Feingold, K.R., Anawalt, B., Boyce, A., Chrousos, G., Dungan, K., Grossman, A., Hershman, J.M., Kaltsas, G., Koch, C., Kopp, P., et al., Eds.; MDText.com, Inc.: South Dartmouth, MA, USA, 2000. Available online: https://www.ncbi.nlm.nih.gov/ books/NBK285556/ (accessed on 5 September 2019).

6. Morreale de Escobar, G.; Obregon, M.J.; Escobar del Rey, F. Role of thyroid hormone during early brain development. Eur. J. Endocrinol. 2004, 151 (Suppl. 3), U25-U37. [CrossRef]

7. World Health Organization. Urinary iodine concentrations for determining iodine status in populations. Available online: https://apps.who.int/iris/bitstream/handle/10665/85972/WHO_NMH_NHD_EPG_13.1_eng. pdf (accessed on 5 September 2019).

8. Zimmermann, M.B.; Hess, S.Y.; Molinari, L.; De Benoist, B.; Delange, F.; Braverman, L.E.; Fujieda, K.; Ito, Y.; Jooste, P.L.; Moosa, K.; et al. New reference values for thyroid volumen by ultrasound in iodine-sufficient school children: A World Health Organization/Nutrition for Health and Development Iodine Deficiency Study Group Report. Am. J. Nutr. 2004, 79, 231-237. [CrossRef] [PubMed]

9. World Health Organization/International Council for the Control of the Iodine Deficiency Disorders/United Nations Children's Fund (WHO/ICCIDD/UNICEF). Assessment of the Iodine Deficiency Disorders and Monitoring Their Elimination; World Health Organization: Geneva, Switzerland, 2007.

10. Zimmermann, M.B.; de Benoist, B.; Corigliano, S.; Jooste, P.L.; Molinari, L.; Moosa, K.; Pretell, E.A.; Al-Dallal, Z.S.; Wei, Y.; Zu-Pei, C.; et al. Assessment of iodine status using dried blood spot thyroglobulin: Development of reference material and establishment of an international reference range in iodine-sufficient children. J. Clin. Endocrinol. Metab. 2006, 91, 4881-4887. [CrossRef] [PubMed]

11. Principles of Nutritional Assessment; Gibson, R. (Ed.) Oxford University Press: Oxford, UK, 2005.

12. Institute of Medicine. Academy of Sciences 2001 Dietary Reference Intakes for Vitamin A, Vitamin K, Arsenic, Boron, Chromium, Copper, Iodine, Iron, Manganese, Molybdenum, Nickel, Silicon, Vanadium, and Zinc; National Academy Press: Washington, DC, USA, 2001.

13. Eastman, C.J. Screening for thyroid disease and iodine deficiency. Pathology 2012, 44, 153-159. [CrossRef] [PubMed]

14. Farebrother, J.; Zimmermann, M.B.; Assey, V.; Castro, M.C.; Cherkaoui, M.; Fingerhut, R.; Jia, Q.; Jukic, T.; Makokha, A.; San Luis, T.O.; et al. Thyroglobulin is markedly elevated in 6- to 24-month-old infants at both low and high iodine intakes and suggests a narrow optimal iodine intake range. Thyroid 2019, 29, 268-277. [CrossRef]

15. World Health Organization/International Council for the Control of the Iodine Deficiency Disorders/United Nations Children's Fund (WHO/ICCIDD/UNICEF). Assessment of the Iodine Deficiency Disorders and Monitoring Their Elimination; WHO/NHD/01.1; World Health Organization: Geneva, Switzerland, 2001.

16. World Health Organization. Guideline: Fortification of Food-Grade Salt with Iodine for the Prevention and Control of Iodine Deficiency Disorders; World Health Organization: Geneva, Switzerland, 2014; Available online: https://apps.who.int/iris/handle/10665/136908 (accessed on 5 September 2019).

17. Rasmussen, L.B.; Carlé, A.; Jørgensen, T.; Knudsen, N.; Laurberg, P.; Pedersen, I.B.; Perrild, H.; Vejbjerg, P.; Ovesen, L. Iodine intake before and after mandatory iodization in Denmark: Results from the Danish Investigation of Iodine Intake and Thyroid Diseases (DanThyr) study. Br. J. Nutr. 2008, 100, 166-173. [CrossRef]

18. Charlton, K.E.; Yeatman, H.; Brock, E.; Lucas, C.; Gemming, L.; Goodfellow, A.; Ma, G. Improvement in iodine status of pregnant Australian women 3 years after introduction of a mandatory iodine fortification programme. Prev. Med. 2013, 57, 26-30. [CrossRef]

19. Zimmermann, M.B.; Aeberli, I.; Torresani, T.; Bürgi, H. Increasing the iodine concentration in the Swiss iodized salt program markedly improved iodine status in pregnant women and children: A 5-y prospective national study. Am. J. Clin. Nutr. 2005, 82, 388-392. [CrossRef] [PubMed]

20. Ministry of Health and Family Welfare. Government of India \& International Institute of Population Sciences (2007) National Family Health Survey-3 National Report (2005-06). Available online: http: //rchiips.org/nfhs/nfhs3_national_report.shtml (accessed on 2 October 2019).

21. Pandav, C.S.; Yadav, K.; Srivastava, R.; Pandav, R.; Karmarkar, M.G. Iodine deficiency disorders (IDD) control in India. Indian J. Med. Res. 2013, 138, 418-433. [PubMed] 
22. Pandav, C.S.; Yadav, K.; Salve, H.R.; Kumar, R.; Goel, A.D.; Chakrabarty, A. High national and sub-national coverage of iodised salt in India: Evidence from the first National Iodine and Salt Intake Survey (NISI) 2014-2015. Public Health Nutr. 2018, 21, 3027-3036. [CrossRef] [PubMed]

23. Randremanana, R.V.; Bastaraud, A.; Rabarijaona, L.P.; Piola, P.; Rakotonirina, D.; Razafinimanana, J.O.; Ramangakoto, M.H.; Andriantsarafara, L.; Randriamasiarijaona, H.; Tucker-Brown, A.; et al. First national iodine survey in Madagascar demonstrates iodine deficiency. Matern. Child. Nutr. 2019, 15, e12717. [CrossRef] [PubMed]

24. Chuko, T.; Bagriansky, J.; Brown, A.T. Ethiopia's long road to USI. IDD Newsl. 2015, 43. Available online: https://www.ign.org/cm_data/IDD_may15_1.pdf (accessed on 2 October 2019).

25. IFPRI. Global Nutrition Report 2016: From Promise to Impact: Ending Malnutrition by 2030; International Food Policy Research Institute: Washington, DC, USA, 2016; p. 182. Available online: http://www.ifpri.org/ publication/global-nutrition-report-2016-promise-impact-ending-malnutrition-2030 (accessed on 2 October 2019).

26. OSNAMI-Istituto Superiore di Sanità. Osservatorio Nazionale per il Monitoraggio della Iodoprofilassi in Italia. Available online: http://old.iss.it/osnami/index.php?lang=1 (accessed on 5 September 2019).

27. Pellicone, G.; Caloiero, T.; Coletta, V.; Veltri, A. Phytoclimatic map of Calabria (Southern Italy). J. Maps 2014, 10, 109-113. [CrossRef]

28. Stanbury, J.B.; Ermans, A.M.; Hetzel, B.S.; Pretell, E.A.; Querido, A. Endemic goitre and cretinism: Public health significance and prevention. WHO Chron. 1974, 28, 220-228.

29. Andò, S.; Maggiolini, M.; Di Carlo, A.; Diodato, A.; Bloise, A.; De Luca, G.P.; Pezzi, V.; Sisci, D.; Mariano, A.; Macchia, V. Endemic goiter in Calabria: Etiopathogenesis and thyroid function. J. Endocrinol. Investig. 1994, 17, 329-333. [CrossRef]

30. Costante, G.; Grasso, L.; Schifino, E.; Marasco, M.F.; Crocetti, U.; Capula, C.; Chiarella, R.; Ludovico, O.; Nocera, M.; Parlato, G.; et al. Iodine deficiency in Calabria: Characterization of endemic goiter and analysis of different indicators of iodine status region-wide. J. Endocrinol. Investig. 2002, 25, 201-207. [CrossRef]

31. Aghini-Lombardi, F.; Antonangeli, L.; Vitti, P.; Pinchera, A. Status of iodine nutrition in Italy. In Iodine Deficiency in Europe; Delange, F., Dunn, J.T., Glinoer, D., Eds.; A continuing concern; Plenum Press: New York, NY, USA, 1993; pp. 403-408.

32. Aghini-Lombardi, F.; Vitti, P.; Antonangeli, L.; Fiore, E.; Piaggi, P.; Pallara, A.; Consiglio, E.; Pinchera, A. Southern Italy Study Group for Iodine Deficiency Disorders. The size of the community rather than its geographical location better defines the risk of iodine deficiency: Results of an extensive survey in Southern Italy. J. Endocrinol. Investig. 2013, 36, 282-286. [CrossRef]

33. Mazzarella, C.; Terracciano, D.; Di Carlo, A.; Macchia, P.E.; Consiglio, E.; Macchia, V.; Mariano, A. Iodine status assessment in Campania (Italy) as determined by urinary iodine excretion. Nutrition 2009, 25, 926-929. [CrossRef] [PubMed]

34. Bonofiglio, D.; Catalano, S.; Perri, A.; Baldini, M.P.; Marsico, S.; Tagarelli, A.; Conforti, D.; Guido, R.; Andò, S. Beneficial effects of iodized salt prophylaxis on thyroid volume in an iodine deficient area of southern Italy. Clin. Endocrinol. 2009, 71, 124-129. [CrossRef] [PubMed]

35. Olivieri, A.; Di Cosmo, C.; De Angelis, S.; Da Cas, R.; Stacchini, P.; Pastorelli, A.; Vitti, P. Regional Observatories for Goiter Prevention. The way forward in Italy for iodine. Minerva. Med. 2017, 108, 159-168. [PubMed]

36. Bonofiglio, D.; Catalano, S.; Perri, A.; Santoro, M.; Siciliano, L.; Lofaro, D.; Gallo, M.; Marsico, S.; Bruno, R.; Giordano, C.; et al. Monitoring the effects of iodine prophylaxis in the adult population of southern Italy with deficient and sufficient iodine intake levels: A cross-sectional, epidemiological study. Br. J. Nutr. 2017, 117, 170-175. [CrossRef] [PubMed]

37. Tomer, Y. Anti-thyroglobulin autoantibodies in autoimmune thyroid disease: Cross-reactive or pathogenic? Clin. Immunol. Immunopathol. 1997, 82,3-11. [CrossRef] [PubMed]

38. Chen, C.R.; Hamidi, S.; Braley-Mullen, H.; Nagayama, Y.; Bresee, C.; Aliesky, H.A.; Rapoport, B.; McLachlan, S.M. Antibodies to thyroid peroxidase arise spontaneously with age in NOD. H-2h4 mice and appear after thyroglobulin antibodies. Endocrinology 2010, 151, 4583-4593. [CrossRef] [PubMed] 
39. Olivieri, A.; De Angelis, S.; Rotondi, D.; Pastorelli, A.; Stacchini, P.; Da Cas, R.; Medda, E. The Regional Observatories for Goiter Prevention. Attività di monitoraggio del programma nazionale per la prevenzione dei disordini da carenza iodica: La situazione italiana a 14 anni dall'approvazione della Legge 55/2005. L'Endocrinologo. 2019, 20, 245-248. [CrossRef]

40. Osservatorio Epidemiologico e Promozione della Salute. "Sezione Gozzo Endemico e Iodoprofilassi", Regione Calabria, Italy. Available online: http://oer.unical.it/ (accessed on 5 September 2019).

(C) 2019 by the authors. Licensee MDPI, Basel, Switzerland. This article is an open access article distributed under the terms and conditions of the Creative Commons Attribution (CC BY) license (http://creativecommons.org/licenses/by/4.0/). 


\title{
Communication
}

\section{Iodine Status in Schoolchildren and Pregnant Women of Lazio, a Central Region of Italy}

\author{
Enke Baldini ${ }^{1}$, Camilla Virili ${ }^{2}$, Eleonora D'Armiento ${ }^{3}$, Marco Centanni ${ }^{2}$ and Salvatore Ulisse ${ }^{1, *}$ \\ 1 Department of Surgical Sciences, "Sapienza" University of Rome, 00161 Rome, Italy \\ 2 Department of Medico-Surgical Sciences and Biotechnologies, "Sapienza" University of Rome, \\ 04100 Latina, Italy \\ 3 Department of Internal Medicine and Medical Specialties, "Sapienza" University of Rome, 00161 Rome, Italy \\ * Correspondence: salvatore.ulisse@uniroma1.it; Tel.: +39-06-4997-0009
}

Received: 18 June 2019; Accepted: 16 July 2019; Published: 18 July 2019

\begin{abstract}
The inhabitants of Lazio, similarly to those of other Italian regions, have been historically exposed to the detrimental effects of an inadequate intake of iodine. The latter is a micronutrient essential for the biosynthesis of thyroid hormones (TH). Iodine deficiency is responsible for a number of adverse effects on human health known as iodine deficiency disorders (IDD), the most common of which worldwide are goiter and hypothyroidism. In order to reduce IDD, a national salt iodination program was started in Italy in 2005. In this article we reviewed the available data regarding iodine intake in the Lazio population before and after the introduction of the national salt iodination program, in order to evaluate its efficacy and the eventual problem(s) limiting its success. On the whole, the information acquired indicates that, following the introduction of the program, the dietary iodine intake in the Lazio population is improved. There is, however, still much work ahead to ameliorate the iodine prophylaxis in this region. In fact, although a generally adequate iodine intake in school-age children has been observed, there are still areas where a mild iodine insufficiency is present. Moreover, two independent epidemiological surveys on pregnant women evidenced a low urinary iodine concentration with respect to the reference range conceived by the World Health Organization. These findings demonstrate the need for greater attention to the iodine prophylaxis by health care providers (i.e., obstetricians, gynecologists, pediatricians, etc.), and the implementation of effective advertising campaigns aimed at increasing the knowledge and awareness of the favorable effects of iodine supplementation on population health.
\end{abstract}

Keywords: iodine deficiency; schoolchildren; pregnancy; iodine prophylaxis; iodine deficiency disorders; goiter; hypothyroidism

\section{Introduction}

Iodine is an indispensable micronutrient required by the thyroid gland for the appropriate synthesis of the thyroid hormones $(\mathrm{TH})$, i.e., triiodothyronine $\left(\mathrm{T}_{3}\right)$ and its prohormone thyroxine $\left(\mathrm{T}_{4}\right)$ [1]. By modulating key cellular processes (i.e., proliferation, differentiation, apoptosis, and metabolism), $\mathrm{TH}$ affect multiple body tasks from the early stages of prenatal life, when maternal thyroxinemia plays a fundamental role in neural growth and differentiation, to adulthood, in which they regulate metabolism, thermogenesis, feeding, memory/learning abilities, and cardiovascular and reproductive functions [2-5]. To guarantee an appropriate TH biosynthesis, the daily dietary iodine intake recommended by the World Health Organization (WHO), the United Nations Children's Emergency Fund (UNICEF), and the International Council for the Control of Iodine Deficiency Disorders (ICCIDD) is $90 \mu \mathrm{g}$ for preschool children (0 to 59 months), $120 \mu \mathrm{g}$ for schoolchildren (6 to 12 years), $150 \mu \mathrm{g}$ for adolescents (above 12 years) and adults, $250 \mu \mathrm{g}$ for pregnant and lactating women [6]. Failure to meet these requirements is held responsible for a number of adverse effects on human health known as iodine deficiency disorders 
(IDD) [7]. These affect almost 1.9 billion people worldwide and constitute a major public health issue in different countries, including Italy $[6,8,9]$. IDD may occur at all ages, from the early stages of fetal life to adulthood. Of particular relevance are the detrimental effects of an insufficient maternal intake of iodine on development and maturation of the fetal brain, which represents a foremost preventable cause of mental defects [10]. Further adverse effects include abortion, stillbirth, impairment of cognitive functions, delayed growth and puberty, hypothyroidism, goiter, and infertility [11-17].

The epidemiological criteria established by the WHO to evaluate the prevalence and severity of iodine deficiency in a specific population refer to the median urinary iodine concentration (UIC) in morning spot urine samples, along with the presence of goiter [6]. Assuming a daily diuresis of 1.5 liters, a given land area is considered iodine sufficient when the median UIC of the population is comprised between 100 and $199 \mu \mathrm{g} / \mathrm{L}$, and goiter prevalence in school-age children ( $\geq 6$ years) is below $5 \%$ [6]. In pregnant women, median UIC should be comprised between 150 and $250 \mu \mathrm{g} / \mathrm{L}$ to guarantee normal fetal development. Reported in Table 1 are the WHO reference values of UIC for classifying the iodine status in a population.

Table 1. Median urinary iodine concentrations (UIC) and iodine status in school-age children and pregnant women according to the World Health Organization (see reference [6]).

\begin{tabular}{cccc}
\hline & School-Age Children & \multicolumn{2}{c}{ Pregnant Women } \\
\hline UIC $(\mu \mathrm{g} / \mathrm{L})$ & Iodine Status & UIC $(\mu \mathrm{g} / \mathrm{L})$ & Iodine Status \\
\hline$<20$ & Severe iodine deficiency & $<150$ & Insufficient \\
$20-49$ & Moderate iodine deficiency & $150-249$ & Adequate \\
$50-99$ & Mild iodine deficiency & $250-499$ & Above requirements \\
$100-199$ & Adequate iodine nutrition & $\geq 500$ & Excessive \\
$200-299$ & More than adequate & & \\
$\geq 300$ & Excessive & & \\
\hline
\end{tabular}

In the attempt to establish an efficient iodine prophylaxis and to eradicate IDD, the law n.55/2005, introducing a national salt iodination program (30 mg of potassium iodate per kilogram of salt), was promulgated in 2005 in Italy [9]. The rules laid down by this law make the sale of iodized salt compulsory and favor the silent prophylaxis. Specifically, the sale points of salt for direct consumption have to expose iodine enriched salt while ensuring the availability of non-iodized salt, which is provided only upon specific request of the consumer. In the public catering sector, such as bars and restaurants, and in workplace or community canteens, iodine-enriched salt should also be available to consumers. Furthermore, the law recommends the use of iodized salt in the food industries as an ingredient in preparation and food storage [9].

In the present manuscript, we will review the available information on iodine status in Lazio (a region of central Italy) before and after the introduction of the Italian law n.55/2005, along with the encountered problems hampering the actuation of the national iodine prophylaxis program. All papers analyzed have been obtained from PubMed. Additional data are from the National Observatory for the Monitoring of Iodoprophylaxis in Italy (OSNAMI) of the Italian National Institute of Health.

\section{Iodine Status in the Lazio Region before the Introduction of the National Iodine Prophylaxis Program}

The Italian population, including the inhabitants of Lazio, has historically been exposed to the negative effects of iodine food shortages [9,18-20].

In the seventies of the last century, epidemiological studies carried out in about 5700 school-age children (6-13 years old) of southern Lazio documented the presence of iodine deficiency [21]. Reported mean UIC values varied from $22 \mu \mathrm{g}$ per gram of creatinine ( $\mu \mathrm{g} / \mathrm{g} \mathrm{Cr}$ ) to $40 \mu \mathrm{g} / \mathrm{g} \mathrm{Cr}$, consistent with an iodine deficiency of moderate degree, as shown in Figure 1 and Table 1 . In these children the prevalence of goiter, evaluated by palpation, varied from $6.9 \%$ to $11.7 \%$, as shown in Figure 1 . In a subsequent 
case study, performed in 1998 in the city of Rome, UIC and goiter prevalence were investigated in 1040 school-age children (6-14 years old) [22]. A median UIC value of $92 \mu \mathrm{g} / \mathrm{L}$ (mean UIC value of $98 \mu \mathrm{g} / \mathrm{L})$, consistent with a mild iodine deficiency, as shown in Table 1, was still observed, as shown in Figure 1. On the other hand, goiter prevalence determined by ultrasound was 4.7\% [22]. Hence, before the introduction of the nationwide iodine prophylaxis program, the data collected indicated a condition of mild to moderate iodine deficiency of children residing in Lazio. To the best of our knowledge, no studies were performed on iodine status in pregnant women before 2005 .
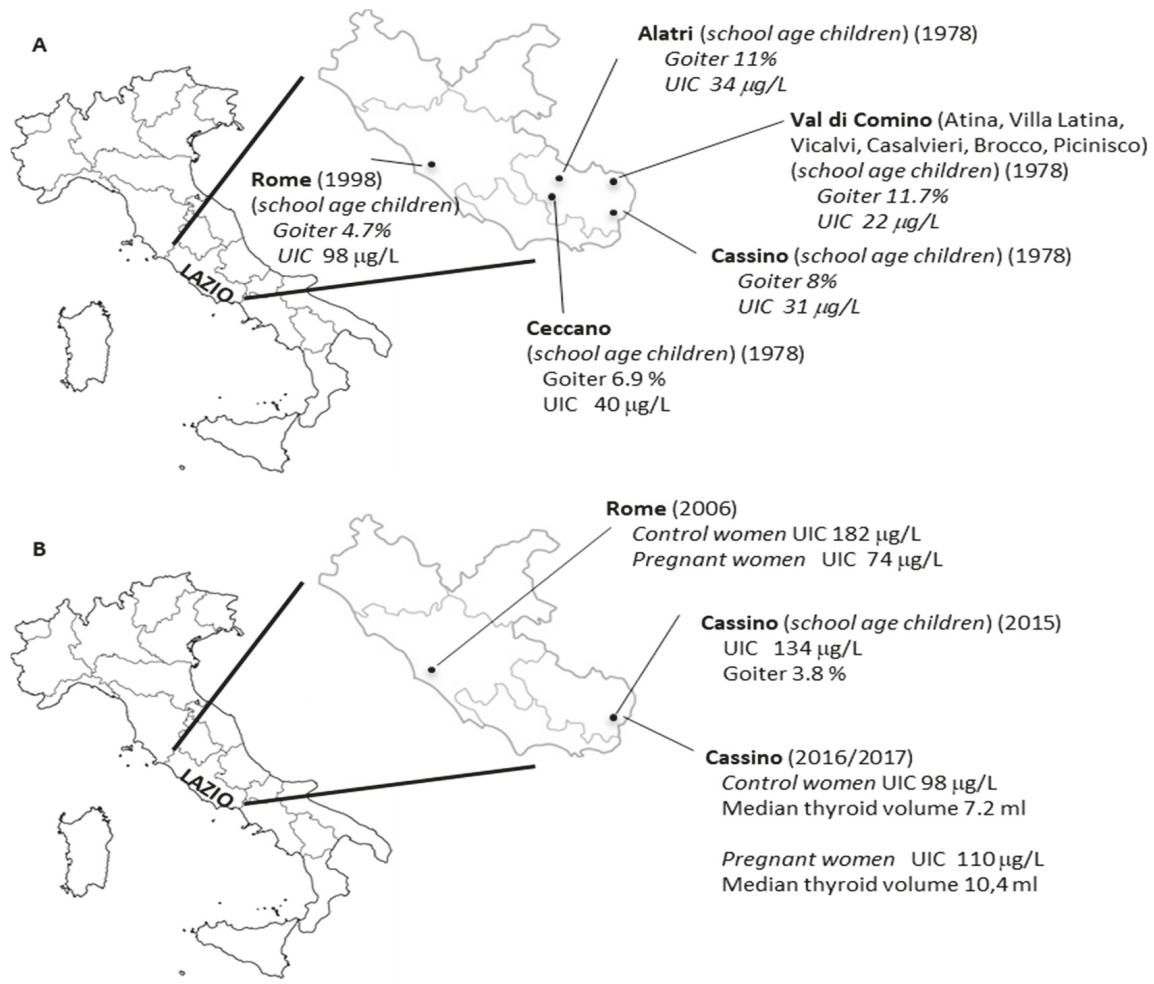

Figure 1. Urinary iodine concentrations (UIC) and goiter prevalence in the inhabitants of Lazio before (A) and after (B) the introduction of the national salt iodination program.

\section{Iodine Status in the Lazio Region after the Introduction of the National Iodine Prophylaxis Program}

Following the introduction of the iodine prophylaxis program, three independent studies were performed in order to assess iodine status in both school-age children and pregnant women [23-25].

A first observational study was realized in 2006 in the city of Rome to evaluate iodine intake in pregnant women compared to non-pregnant age-matched ones [23]. The study enrolled 51 clinically healthy pregnant women in their first gestational trimester, and 100 clinically healthy non-pregnant women [23]. The median UIC value observed in control women was $182 \mu \mathrm{g} / \mathrm{L}$, suggestive of an adequate iodine intake, as shown in Figure 1. However, pregnant women showed poor iodine consumption, attested by a median UIC value of $74 \mu \mathrm{g} / \mathrm{L}$. In particular, the UIC was found below the normal range only in $4 \%$ of control women but in $92 \%$ of pregnant women. These observations pointed out that, despite the iodine sufficiency recognized in control women, the majority of pregnant women and their fetuses were exposed to detrimental consequences of iodine deficiency. 
After that, a new survey was performed in 2015 in the city of Cassino, located in the south of Lazio, whose residents were previously found to have a moderate iodine deficiency, as shown in Figure 1B [24]. In this study, UIC and thyroid volume measured by ultrasonography were evaluated in 234 school-age children (13-14 years old). At the same time an inquiry was conducted to estimate the percentage of iodized salt sold in the preceding year by the major local retailers. The latter showed only $42 \%$ of all salt sold in 2014 in this city was iodized. Despite that, a median UIC of $134 \mu \mathrm{g} / \mathrm{L}$ was observed in the school children under examination, suggesting an adequate iodine intake. This result was also corroborated by the low prevalence of goiter, encountered only in 3.8\% of subjects. However, when children were grouped based on the regular consumption of iodized salt or milk or both, those referring no consumption of either iodized salt or milk had a median UIC value $(96.4 \mu \mathrm{g} / \mathrm{L})$, compatible with a mild iodine deficiency. On the other hand, optimal median UIC values were found in school children regularly taking either iodized salt $(132.1 \mu \mathrm{g} / \mathrm{L})$ or milk $(131 \mu \mathrm{g} / \mathrm{L})$ or both $(147.9 \mu \mathrm{g} / \mathrm{L})$. Such evidence strengthens the importance of eating iodized salt and iodine-rich food to achieve the right amount of iodine in the body for thyroid function [24].

A further study was aimed to analyze iodine intake in pregnant women from the same area of Cassino [25]. Study participants were enrolled in the period from January 2016 to April 2017, for a total of 96 pregnant women and 79 age-matched non-pregnant women. In the control group, median UIC was nearby $98 \mu \mathrm{g} / \mathrm{L}$, consistent with a mild iodine deficiency, while pregnant women had a median UIC of about $110 \mu \mathrm{g} / \mathrm{L}$, below the lower value $(150 \mu \mathrm{g} / \mathrm{L})$ recommended by the WHO for categorizing iodine adequacy in a pregnant population. In agreement with this finding, a significantly increased thyroid volume was recorded in pregnant women compared to non-pregnant ones, as shown in Figure 1 [25]. In this study the effects of iodized salt and/or milk consumption on UIC levels of both control and pregnant women, considered as a whole, were also examined. The analysis showed an increasing trend of UIC from women not using either iodized salt or milk (median UIC $79.8 \mu \mathrm{g} / \mathrm{L}$ ) compared to those using iodized salt (median UIC $94 \mu \mathrm{g} / \mathrm{L}$ ) or milk (median UIC $112 \mu \mathrm{g} / \mathrm{L}$ ) or both (median UIC $118 \mu \mathrm{g} / \mathrm{L}$ ) [25]. Thus, once again the data obtained highlight the need to implement the national salt iodination program, as well as the importance of inserting initiatives targeted at control of iodine prophylaxis and prevention of IDD in regional health plans. It has to be mentioned, however, that the aforementioned studies rely on a limited number of subjects analyzed and should be corroborated on larger case studies.

\section{Encountered Problems Hampering the Actuation of the National Iodine Prophylaxis Program}

As reported above, the available epidemiological data demonstrated that, following the introduction of the national salt iodination program, the iodine intake in the inhabitants of Lazio is somewhat improved. However, prevention measures are still needed to fully avoid the risks of IDD in this region. In particular, there are three main lines of action that should be pursued.

The first is devising strategies to increment the amount of iodized salt sold by retailers. In fact, due to the lack of penalties related to non-compliance with the law n.55/2005, vendors are not discouraged from exhibiting non-iodized salt on store shelves, and they sell both iodized salt and or even just non-iodized salt [24]. This, at least in part, may explain the low percentage of iodized salt sold $(42 \%)$ in the city of Cassino, and why $45 \%$ of the school children and $50 \%$ of women of child-bearing age do not use iodized salt. Moreover, the latest data provided by OSNAMI indicated that the percentage of iodized salt used in collective catering is still very low (about $24 \%$ ), and that used by the food industry is even lower (3-8\%) [26]. Thus, it is of great importance to encourage this manufacturing sector to make more extensive use of iodized salt.

The second line of intervention should be to adequately inform the population on the beneficial effects on human health deriving from the consumption of iodized salt. This task could be accomplished by creating effective advertising campaigns able to reach every single citizen. In this context, an initiative of the Ministry of Health is taking place that aims to provide all students with comprehensive 
information about the beneficial effects of the use of iodized salt through meetings with medical staff organized by individual schools [27].

Finally, greater attention by the major health care providers of the National Health System is highly desirable, especially obstetricians, gynecologists, and pediatricians. Different surveys, in fact, noticed that obstetricians and midwives do not recommend iodine supplementation either to women planning pregnancy or during pregnancy or lactation $[28,29]$. To this regard, a position statement on the use of iodized salt in adulthood and children was signed by the Italian Ministry of Health, the National Institute of Health, the Italian Society of Endocrinology, the Italian Thyroid Association, the Medical Association of Endocrinologists, the Italian Society of Pediatric Endocrinology and Diabetology, the Italian Society of Pediatrics, the Italian Society of Gynecology and Obstetrics, the Italian Association of Consultative Gynecologists, the Italian Society of Human Nutrition, the Italian Society of Nutraceuticals, the Italian Association of Dietetics and Clinical Nutrition, the Italian Society for the Study of Food Behavior Disorders, the Italian Federation of Nutrition, and the National Federation of General Practitioners [30]. The joint implementation of all these actions should provide a consistent contribution toward the eradication of iodine deficiency in Italy.

\section{Conclusions}

The available epidemiological data indicate that, following the introduction of the national salt iodination program, the iodine intake of the inhabitants of Lazio has only partially improved. In fact, although a generally adequate iodine intake in school-age children has been observed, pregnant women still show an iodine deficiency. Thus, it is necessary to encourage compliance with the law in order to reach optimal iodine nutrition and to completely eradicate the IDD in this region. The situation recorded in Lazio corroborates the recent Krakow Declaration on Iodine reporting an increased concern about the fading commitment of policymakers to address iodine deficiency in Europe and the poor attention of policymakers, opinion leaders, and the public toward the resolution of IDD [31]. Thus, it has become of primary importance to join forces with policymakers, public health officials, and scientists to guarantee that existing European strategies to prevent IDD are fulfilled and implemented.

Author Contributions: All authors participated in the review design, contributed to the first draft and manuscript revisions, and approved the final version.

Funding: This work received no external funding.

Conflicts of Interest: The authors declare that there is no conflict of interest that could be perceived as prejudicing the impartiality of the research reported.

\section{References}

1. Citterio, C.E.; Targovnik, H.M.; Arvan, P. The role of thyroglobulin in thyroid hormonogenesis. Nat. Rev. Endocrinol. 2019. [CrossRef] [PubMed]

2. Cheng, S.Y.; Leonard, J.L.; Davis, P.J. Molecular aspects of thyroid hormone actions. Endocr. Rev. 2010, 31, 139-170. [CrossRef] [PubMed]

3. Bernal, J. Thyroid hormone receptors in brain development and function. Nat. Clin. Pract. Endocrinol. Metab. 2007, 3, 249-259. [CrossRef] [PubMed]

4. Angelousi, A.; Kassi, E.; Nasiri-Ansari, N.; Weickert, M.O.; Randeva, H.; Kaltsas, G. Clock genes alterations and endocrine disorders. Eur. J. Clin. Investig. 2018, 48, e12927. [CrossRef] [PubMed]

5. Krassas, G.E.; Poppe, K.; Glinoer, D. Thyroid function and human reproductive health. Endocr. Rev. 2010, 31, 702-755. [CrossRef] [PubMed]

6. World Health Organization; International Council for the Control of Iodine Deficiency Disorders; United Nations Children's Fund (WHO/ICCIDD/UNICEF). Assessment of the Iodine Deficiency Disorders and Monitoring Their Elimination, 3rd ed.; World Health Organization: Geneva, Switzerland, 2007; Available online: https://apps.who.int/iris/bitstream/handle/10665/43781/9789241595827_eng.pdf?sequence=1 (accessed on 4 June 2019).

7. Hetzel, B.S. Iodine deficiency disorders (IDD) and their eradication. Lancet 1983, 2, 1126-1129. [CrossRef] 
8. Vanderpump, M.P.J. The epidemiology of thyroid disease. Br. Med. Bull. 2011, 99, 39-51. [CrossRef] [PubMed]

9. Olivieri., A.; Di Cosmo, C.; De Angelis, S.; Da Cas, R.; Stacchini, P.; Pastorelli, A.; Vitti, P.; Regional Observatories for Goiter Prevention. The way forward in Italy for iodine. Minerva Med. 2017, 108, 159-168. [PubMed]

10. Delange, F. Iodine deficiency as a cause of brain damage. Postgrad. Med. J. 2001, 77, 217-220. [CrossRef] [PubMed]

11. Salazar, P.; Cisternas, P.; Martinez, M.; Inestrosa, N.C. Hypothyroidism and Cognitive Disorders during Development and Adulthood: Implications in the Central Nervous System. Mol. Neurobiol. 2019, 56, 2952-2963. [CrossRef]

12. Walsh, V.; Brown, J.V.E.; McGuire, W. Iodine supplementation for the prevention of mortality and adverse neurodevelopmental outcomes in preterm infants. Cochrane Database Syst. Rev. 2019, 2, CD005253. [CrossRef]

13. Farebrother, J.; Naude, C.E.; Nicol, L.; Sang, Z.; Yang, Z.; Jooste, P.L.; Andersson, M.; Zimmermann, M.B. Effects of Iodized Salt and Iodine Supplements on Prenatal and Postnatal Growth: A Systematic Review. Adv. Nutr. 2018, 9, 219-237. [CrossRef] [PubMed]

14. Eastman, C.J.; Zimmermann, M.B. The Iodine Deficiency Disorders. In Endotext [Internet]; Feingold, K.R., Anawalt, B., Boyce, A., Chrousos, G., Dungan, K., Grossman, A., Hershman, J.M., Kaltsas, G., Koch, C., Kopp, P., et al., Eds.; MDText.com, Inc.: South Dartmouth, MA, USA, 2018. Available online: https: //www.ncbi.nlm.nih.gov/books/NBK285556/ (accessed on 4 June 2019).

15. Dunn, J.T.; Delange, F. Damaged reproduction: The most important consequence of iodine deficiency. J. Clin. Endocrinol. Metab. 2001, 86, 2360-2363. [CrossRef]

16. Ferri, N.; Ulisse, S.; Aghini-Lombardi, F.; Graziano, F.M.; Di Mattia, T.; Russo, F.P.; Arizzi, M.; Baldini, E.; Trimboli, P.; Attanasio, D.; et al. Iodine supplementation restores fertility of sheep exposed to iodine deficiency. J. Endocrinol. Investig. 2003, 26, 1081-1087. [CrossRef] [PubMed]

17. Baldini, E.; Sorrenti, S.; Catania, A.; Tartaglia, F.; Pironi, D.; Vergine, M.; Monti, M.; Filippini, A.; Ulisse, S. Nodular thyroid disease with aging. In Aging: Exploring a Complex Phenomenon; Shamin, A., Ed.; Taylor and Francis/CRC Press: Abingdon, UK, 2018; pp. 95-118.

18. Aghini-Lombardi, F.; Antonangeli, L.; Vitti, P.; Pinchera, A. Status of iodine nutrition in Italy. In Iodine Deficiency in Europe; Delange, F., Dunn, J.T., Glinoer, D., Eds.; Plenum Press: New York, NY, USA, 1993; pp. 403-408.

19. Vitti, P.; Rago, T.; Aghini-Lombardi, F.; Pinchera, A. Iodine deficiency disorders in Europe. Public Health Nutr. 2001, 4, 529-535. [CrossRef] [PubMed]

20. Andersson, M.; de Benoist, B.; Darton-Hill, J.; Delange, F. Iodine Deficiency in Europe: A Continuing Public Health Problem; WHO Press: Geneva, Switzerland, 2007; Available online: https://www.who.int/nutrition/ publications/VMNIS_Iodine_deficiency_in_Europe.pdf (accessed on 5 June 2019).

21. Baschieri, L.; Costa, A.; Basile, A. L'endemia. In Il Gozzo; Fegiz, G., Ed.; Edizioni Luigi Pozzo: Rome, Italy, 1978; pp. 399-427.

22. Panunzi, C.; Manca Bitti, M.L.; Di Paolo, A.; Fabbrini, R.; Valle, D.; Spadoni, G.L.; Del Duca, E.; Guglielmi, R.; Valente, M.; Finocchi, A.; et al. Goiter prevalence and urinary excretion of iodine in a sample of school age children in the city of Rome. Ann. Ist. Super. Sanità 1998, 34, 409-412. [PubMed]

23. Marchioni, E.; Fumarola, A.; Calvanese, A.; Piccirilli, F.; Tommasi, V.; Cugini, P.; Ulisse, S.; Rossi Fanelli, F.; D'Armiento, M. Iodine deficiency in pregnant women residing in an area with adequate iodine intake. Nutrition 2008, 24, 458-461. [CrossRef]

24. Coccaro, C.; Tuccilli, C.; Prinzi, N.; D'Armiento, E.; Pepe, M.; Del Maestro, F.; Cacciola, G.; Forlini, B.; Verdolotti, S.; Bononi, M.; et al. Consumption of iodized salt may not represent a reliable indicator of iodine adequacy: Evidence from a cross-sectional study on schoolchildren living in an urban area of central Italy. Nutrition 2016, 32, 662-666. [CrossRef]

25. Tuccilli, C.; Baldini, E.; Truppa, E.; D'Auria, B.; De Quattro, D.; Cacciola, G.; Aceti, T.; Cirillo, G.; Faiola, A.; Indigeno, P.; et al. Iodine deficiency in pregnancy: Still a health issue for the women of Cassino city, Italy. Nutrition 2018, 50, 60-65. [CrossRef] 
26. OSNAMI, Osservatorio Nazionale per il Monitoraggio della Iodoprofilassi in Italia. Istituto Superiore di Sanità. Available online: http://old.iss.it/binary/osna/cont/dati_vendita.pdf (accessed on 4 June 2019).

27. OSNAMI, Osservatorio Nazionale per il Monitoraggio della Iodoprofilassi in Italia. Istituto Superiore di Sanità. Available online: http://old.iss.it/osnami/index.php?lang=1\&anno=2019\&tipo=27 (accessed on 9 July 2019).

28. De Leo, S.; Pearce, E.N.; Braverman, L.E. Iodine supplementation in women during preconception, pregnancy, and lactation: Current clinical practice by U.S. obstetricians and midwives. Thyroid 2017, 27, 434-439. [CrossRef]

29. Malek, L.; Umberger, W.; Makrides, M.; Zhou, S.J. Poor adherence to folic acid and iodine supplement recommendations in preconception and pregnancy: A cross-sectional analysis. Aust. N. Z. J. Public Health 2016, 40, 424-429. [CrossRef] [PubMed]

30. Ministero della Salute. Available online: http://www.salute.gov.it/imgs/C_17_pubblicazioni_2593_allegato. pdf (accessed on 4 June 2019).

31. The EUthyroid Consortium. The Krakow Declaration on Iodine. Available online: https:// www.iodinedeclaration.eu/wp-content/uploads/2018/04/Krakow-Declaration-2018_03_29.pdf (accessed on 9 July 2019).

(C) 2019 by the authors. Licensee MDPI, Basel, Switzerland. This article is an open access article distributed under the terms and conditions of the Creative Commons Attribution (CC BY) license (http://creativecommons.org/licenses/by/4.0/). 

Article

\title{
Sodium, Potassium and Iodine Intake, in a National Adult Population Sample of the Republic of Moldova
}

\author{
Lanfranco D'Elia $^{1,2}$, Galina Obreja ${ }^{3}$, Angela Ciobanu ${ }^{4,5}$, Joao Breda ${ }^{6}$, Jo Jewell ${ }^{5,7}$, \\ Francesco P. Cappuccio ${ }^{1,8, *}$ and on behalf of the Salt Consumption Survey in the Republic of \\ Moldova Study Group ${ }^{\dagger}$ \\ 1 World Health Organization Collaborating Centre for Nutrition, University of Warwick, \\ Coventry CV4 7AL, UK; lanfranco.delia@unina.it \\ 2 Department of Clinical Medicine and Surgery, "Federico II" University of Naples, 80131 Naples, Italy \\ 3 Department of Social Medicine and Health Management, State University of Medicine and Pharmacy \\ Nicolae Testemitanu, 2004 Chişinău, Moldova; galina.obreja@gmail.com \\ 4 World Health Organization Country Office, 2012 Chişinău, Moldova; ciobanua@who.int \\ 5 World Health Organization European Office for Prevention and Control of Noncommunicable Diseases, \\ 2100 Copenhagen, Denmark; jewellj@who.int \\ 6 World Health Organization European Office for Prevention and Control of Noncommunicable Diseases, \\ 229994 Moscow, Russia; rodriguesdasilvabred@who.int \\ 7 United Nations Children's Fund, UNICEF, New York, NY 10017, USA \\ 8 Division of Health Sciences, Warwick Medical School, University of Warwick, Coventry CV4 7AL, UK \\ * Correspondence: f.p.cappuccio@warwick.ac.uk; Tel.: +44-24765-73129 \\ + Membership of the Salt Consumption Survey in the Republic of Moldova Study Group is provided in \\ the Acknowledgments.
}

Received: 7 November 2019; Accepted: 25 November 2019; Published: 28 November 2019

\begin{abstract}
In the Republic of Moldova, more than half of all deaths due to noncommunicable diseases (NCDs) are caused by cardiovascular disease (CVD). Excess salt (sodium) and inadequate potassium intakes are associated with high CVD. Moreover, salt iodisation is the preferred policy to prevent iodine deficiency and associated disorders. However, there is no survey that has directly measured sodium, potassium and iodine consumption in adults in the Republic of Moldova. A national random sample of adults attended a screening including demographic, anthropometric and physical measurements. Sodium, potassium and iodine intakes were assessed by $24 \mathrm{~h}$ urinary sodium (UNa), potassium (UK) and iodine (UI) excretions. Knowledge, attidues and behaviours were collected by questionnaire. Eight-hundred and fifty-eight participants (326 men and 532 women, 18-69 years) were included in the analysis (response rate 66\%). Mean age was 48.5 years (SD 13.8). Mean UNa was 172.7 (79.3) $\mathrm{mmoL} /$ day, equivalent to $10.8 \mathrm{~g}$ of salt/day and potassium excretion 72.7 (31.5) $\mathrm{mmoL} /$ day, equivalent to $3.26 \mathrm{~g} /$ day. Only $11.3 \%$ met the World Health Organization (WHO) recommended salt targets of $5 \mathrm{~g} /$ day and $39 \%$ met potassium targets ( $>90 \mathrm{mmoL} /$ day). Whilst $81.7 \%$ declared limiting their consumption of processed food and over $70 \%$ not adding salt at the table, only $8.8 \%$ looked at sodium content of food, $31 \%$ still added salt when cooking and less than $1 \%$ took other measures to control salt consumption. Measures of awareness were significantly more common in urban compared to rural areas. Mean urinary iodine was 225 (SD: 152; median 196) mcg/24 h, with no difference between sexes. According to WHO criteria, $41.0 \%$ had adequate iodine intake. Iodine content of salt table was 21.0 (SD: 18.6) $\mathrm{mg} / \mathrm{kg}$, lower in rural than urban areas (16.7, SD = $18.6 \mathrm{vs.} 28.1$, $\mathrm{SD}=16.5 \mathrm{mg} / \mathrm{kg}, p<0.001)$. In most cases participants were not using iodised salt as their main source of salt, more so in rural areas. In the Republic of Moldova, salt consumption is unequivocally high, potassium consumption is lower than recommended, both in men and in women, whilst iodine intake is still inadequate in one in three people, although severe iodine deficiency is rare. Salt consumed is often not iodised.
\end{abstract}

Keywords: Republic of Moldova; salt; sodium; potassium; iodine; population 


\section{Introduction}

Non-communicable diseases (NCDs) are the leading causes of death globally [1] and their reduction is a health priority [2], with reduction in population salt consumption a cost-effective policy option ('best buys') [3]. In the Republic of Moldova, NCDs are the leading causes of death, and cardiovascular disease (CVD) represents the main cause of population morbidity and mortality, accounting for every second death in 2016 [4]. High blood pressure (BP) and unhealthy diets are major causes CVD in the world and account for most of the disease burden in the Republic of Moldova [5]. High salt in the diet (i.e., sodium chloride, $1 \mathrm{~g}=17.1 \mathrm{mmoL}$ of sodium) causes high $\mathrm{BP}$, a high risk of vascular diseases [6-10] and other adverse health effects [11-13]. A lower salt intake reduces BP [7,8], cardiovascular events and overall mortality $[9,10]$.

The World Health Organization (WHO) currently recommends for adults a consumption not higher than $5 \mathrm{~g}$ of salt daily [14]. However, in most countries in the world this recommendation is unmet [15-17]. Salt enters our diet not only as added salt to food and cooking by the consumer, but, in the Western diet, more often from processed food, food prepared in restaurants and other food outlets $[18,19]$. There is no direct estimate of population dietary salt intake in Republic of Moldova. However, it is likely to be high, as in neighbouring countries like Serbia (9.85 g/day) [20], Slovenia (11.3 g/day) [21] and Montenegro (11.6 g/day) [22]. In the Republic of Moldova it is a common habit to add salt to food at the table and when cooking, as well as eating processed food that have high salt content. In 2013 a national survey indicated that $24.3 \%$ of those surveyed always or often added salt to food, and $32.4 \%$ always or often ate processed foods that are high in salt [5]. Salt reduction strategies in the European region, including the Republic of Moldova, include monitoring and evaluation actions as one of their pillars [23].

In contrast to sodium, dietary potassium has beneficial effects on BP and cardiovascular health [24-26]. The Republic of Moldova lacks data on actual potassium consumption. The WHO currently recommends that adults should consume not less than $90 \mathrm{mmoL}$ of potassium daily [27]. Finally, in the Republic of Moldova the prevention of iodine deficiency disorders recommends universal salt iodization [28]. Starting in 2009, the Ministry of Health authorised the production and placing on the market of iodized bottled water additionally to iodized salt. Since more than $90 \%$ of iodine consumed is excreted in the urine within 24-48 hours [29,30], $24 \mathrm{~h}$ urinary iodine excretion is a good marker of recent iodine intake and an ideal biomarker for estimating iodine status [31] in the entire adult population.

The aim of the present study was to establish current baseline average consumption of sodium, potassium and iodine by $24 \mathrm{~h}$ urine collection, in a national random sample of men and women. The study also aimed to explore knowledge, attitudes and behaviour towards dietary salt.

\section{Materials and Methods}

\subsection{Participants and Recruitment}

A total of 1307 randomly selected men and women participated in the survey. They were all aged 18-69 years. They comprised residents of all Districts and Administrative Territorial Units 'Gagauz-Yeri', along with Chişinău and Bălti Municipalities. The survey did not cover the Districts from the left bank of the Nistru River and the Municipality of Bender (Figure 1). A probabilistic master sample from the National Bureau of Statistics' Household Budget Survey was used to select the sample for the survey which was extracted in three phases: 150 Primary Sampling Units (PSU—communes, cities or sectors within cities) were selected; list of households from PSU were drawn; eligible individuals from households were identified. Random sampling proportional to size were stratified by sex, geography (north, centre, south and Chişinău), urban/rural, size of cities. 


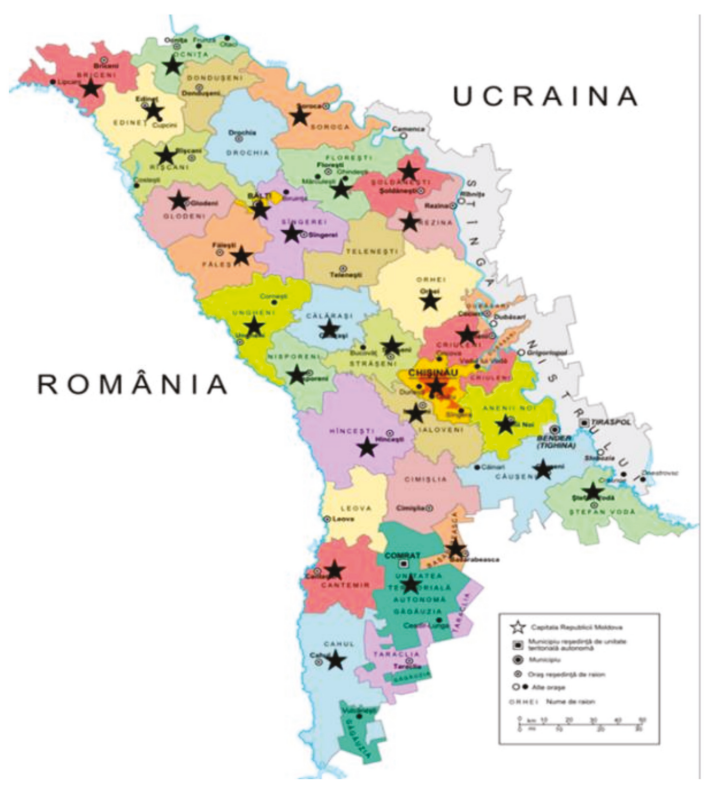

Figure 1. Geographical sampling from the Republic of Moldova. National proportional random sampling from 28 (marked with a star) of 37 Districts and Administrative Territorial Units 'Gagauz-Yeri', along with Chişinău and Bălti Municipalities. The sampling was as follows: Anenii Noi (1.3\%), Balti (0.8\%), Basarabeasca (1.4\%), Briceni (4.7\%), Cahul (3.5\%), Călăraşi $(2.4 \%)$, Cantemir (2.4\%), Căuşeni $(0.8 \%)$, Chişinău (30.7\%), Comrat/ATU 'Gagauz-Yeri' (4.4\%), Criuleni (4.3\%), Edineț (3.1\%), Făleşti (2.4\%), Floreşti (2.2\%), Glodeni (1.2\%), Hînceşti (0.7\%), Ialoveni (4.4\%), Nisporeni (3.0\%), Ocnița (2.7\%), Orhei $(4.8 \%)$, Rezina (1.7\%), Rîşcani (0.6\%), Sîngerei (1.9\%), Șoldaneşti $(2.6 \%)$, Soroca $(2.2 \%)$, Ștefan Vodă $(0.6 \%)$, Străşeni $(2.7 \%)$ and Ungheni $(6.3 \%)$.

From the sampling frame and according to PAHO/WHO and EMRO-WHO Protocols [32,33], we excluded the following groups: pregnant women, individuals with heart failure, severe kidney disease, stroke, liver disease, people who had started diuretic therapy in the last two weeks, any other conditions that would compromise the collection of $24 \mathrm{~h}$ urine samples or a reliable informed consent.

The survey took place between 21st July and 5th September 2016. From the 1307 participants interviewed, $858(66 \%)$ provided data for inclusion in the analysis. Thirteen had missing data, 263 admitted missing more than one void, 77 provided either under-collections $(<23 \mathrm{~h})$ or over-collections ( $>25 \mathrm{~h}$ ) and 37 had urinary creatinine excretion outside two standard deviations (SDs) of the sex-specific distribution of urinary creatinine in the sample (Figure 2).

The survey was carried out in accordance with the Declaration of Helsinki and Good Clinical Practice [34]. Ethical approval for the survey was obtained from the Committee of Research Ethics of the National Agency for Public Health of the Republic of Moldova and participants provided written informed consent to take part. 


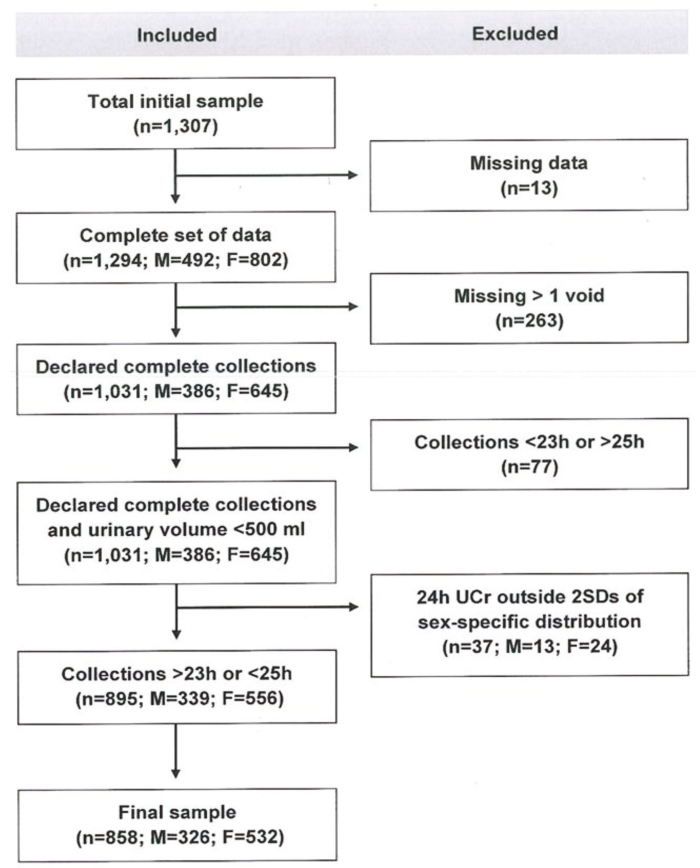

Figure 2. Stepwise procedure for the selection of valid participants according to protocol adherence, quality control and completeness of 24 hour urine collections.

\subsection{Data Collection}

The full methodology is reported in the supplementary material (Text S1). In brief, there were three stages: (a) questionnaire, (b) physical measurements and (c) $24 \mathrm{~h}$ urine collections.

The questionnaire (adapted version of the WHO STEPS Instrument for NCD Risk Factor Surveillance) [35] obtained demographic and socio-economic status, frequency of salty food, fruit and vegetable consumptions, knowledge attitudes and behaviour on dietary salt.

Anthropometry, blood pressure (BP) and heart rate were measured in all participants with standardized protocols and validated equipment, as also described elsewhere [22,32,33]. Hypertension is defined as systolic and/or diastolic BP $\geq 140 / 90 \mathrm{mmHg}$ or regular antihypertensive treatment [36].

After detailed and careful instructions (Text S1), participants provided a $24 \mathrm{~h}$ urine collection [32,33]. Sodium, potassium and creatinine determinations were carried out immediately [37,38]. Sodium and potassium concentration in the urine samples were determined using a Ion Selective Electrode with a Beckman Coulter Synchron CX5PRO system (High Wycombe, UK) and expressed in mmoL/L [37]. Creatinine concentration was determined through the Creatinine (urinary) Jaffé kinetic method and expressed in $\mathrm{mg} / \mathrm{dL}$ [38]. These determinations were carried out at the ICS Medical Laboratory Synevo SRL in Chişinău. Urinary iodine was measured separately at the National Agency for Public Health of the Republic of Moldova using the ammonium persulfate digestion method with spectrophotometric detection by Sandell-Kolthoff reaction, expressed as mcg/L [39]. Iodine determinations in table salt were carried out by the titration method [40].

\subsection{Statistical Analysis}

With a standard deviation of $75 \mathrm{mmoL} / 24 \mathrm{~h}$ (alpha $=0.05$, power $=0.80)$ in urinary sodium excretion, the study was designed to detect a reduction in salt consumption over time of around $1 \mathrm{~g}$ per day ( $20 \mathrm{mmoL}$ sodium/24 h). Considering an attrition rate of $50 \%$, we aimed to select 
240 participants per age and sex group [32,33]. The population was stratified in groups by sex (men and women), age (18-29 years, 30-44 years, $45-59$ years, $60-69$ years) and urban/rural areas. Therefore, 1920 individuals were originally needed to be selected (total $n=120 \times 8$ groups $/ 0.5$ attrition $=1920$ ). T-test for unpaired samples or analysis of variance (ANOVA) was used to test differences between groups. The chi-square test was used for categorical variables. To convert urinary output into dietary intake, the urinary excretion of sodium (UNa) or potassium (UK) in $\mathrm{mmoL} /$ day were first converted to $\mathrm{mg} /$ day (for sodium $1 \mathrm{mmol}=23 \mathrm{mg}$ of sodium, for potassium $1 \mathrm{mmol}=39 \mathrm{mg}$ ). The conversion from dietary sodium $(\mathrm{Na})$ intake to salt $(\mathrm{NaCl})$ intake was made by multiplying the sodium value by 2.542 . Then, sodium values were multiplied by 1.05 (assuming that aproximately $95 \%$ of sodium ingested is excreted) [41]. For potassium dietary intake was calculated assuming $80 \%$ of the potassium ingested is excreted in the urine [42]. Urinary iodine was expressed in mcg/day. We used the cut-off targets for iodine consumption set by $\mathrm{WHO}$ (based on urinary iodine concentrations in $\mathrm{mcg} / \mathrm{L}$ derived from $24 \mathrm{~h}$ collections) [31]. Statistical analyses were carried out using SPSS, version 20 (SPSS Inc., Chicago, IL, USA). The results were reported as mean (SD and/or 95\% CI) or as percentages, as appropriate. Two-sided $p$ below 0.05 were considered statistically significant.

\section{Results}

The final population sample included 858 participants between 18 and 69 years old $(n=326$ or $38 \%$ men and $n=532$ or $62 \%$ women), recruited nationally (Figure 1).

\subsection{Characteristics of the Participants}

Mean age was similar in men and women, but men were taller and heavier than women and had a higher systolic BP (Table 1). The point prevalence of hypertension was $45.5 \%$ (385/858), comparable in men (148/326 or $45.8 \%)$ and women (237/532 or $45.2 \%$; $p>0.05)$.

Table 1. Characteristics of the participants.

\begin{tabular}{cccc}
\hline Variable & $\begin{array}{c}\text { All } \\
(\boldsymbol{n}=\mathbf{8 5 8})\end{array}$ & $\begin{array}{c}\text { Men } \\
(\boldsymbol{n}=\mathbf{3 2 6})\end{array}$ & $\begin{array}{c}\text { Women } \\
(\boldsymbol{n}=\mathbf{5 3 2})\end{array}$ \\
\hline Age (years) & $48.5(13.8)$ & $47.3(13.6)$ & $49.2(13.9)$ \\
Height $(\mathrm{cm})$ & $166.7(8.8)$ & $172.8(8.1)$ & $162.9(7.0)^{\dagger}$ \\
Weight $(\mathrm{kg})$ & $78.2(15.8)$ & $82.0(15.8)$ & $75.8(15.3)^{\dagger}$ \\
B.M.I. $\left(\mathrm{kg} / \mathrm{m}^{2}\right)$ & $28.1(5.4)$ & $27.4(4.9)$ & $28.6(5.7)^{\ddagger}$ \\
Waist circumference $(\mathrm{cm})$ & - & $93.8(15.5)$ & $91.8(15.1)$ \\
Hip circumference $(\mathrm{cm})$ & - & $100.5(12.3)$ & $106.5(14.0)$ \\
Systolic BP $(\mathrm{mmHg})$ & $134.3(21.2)$ & $136.1(18.5)$ & $133.1(22.6)^{*}$ \\
Diastolic BP $(\mathrm{mmHg})$ & $86.8(11.9)$ & $87.1(10.8)$ & $86.6(12.6)$ \\
Pulse rate $(\mathrm{b} / \mathrm{min})$ & $76.2(9.5)$ & $78.0(10.3)$ & $75.2(8.8)$ \\
Hypertension ${ }^{\#} n(\%)$ & $385(45.5)$ & $148(45.8)$ & $237(45.2)$ \\
\hline
\end{tabular}

Results are mean (SD) or as percentage; ${ }^{\dagger} p<0.001 ;{ }^{\ddagger} p=0.002 ;{ }^{*} p=0.04$ vs. men. ${ }^{\#} \mathrm{SBP} \geq 140 \mathrm{mmHg}$ and/or $\mathrm{DBP} \geq 90 \mathrm{mmHg}$ or on anti-hypertensive medications.

\subsection{Daily Urinary Excretions of Volume, Sodium, Potassium and Creatinine and Salt and Potassium Intake}

Urinary volume excretion was, on average, $1441 \mathrm{~mL}$ per day, higher in men than women, and higher in urban than rural areas (Table 2). Urinary creatinine excretion was $11.7 \mathrm{mmol}$ per day, higher in men than women, but lower in urban than rural areas (Table 2). Mean urinary sodium was 172.7 (SD 79.3, median 161.9) $\mathrm{mmoL} / 24 \mathrm{~h}$ (Table 2), equivalent to a mean consumption of 10.8 (4.9) $\mathrm{g}$ of salt per day (Table 2). Men excreted more sodium than women (mean difference $18.1 \mathrm{mmoL} / 24 \mathrm{~h}, p<0.001$ ), equivalent to $\sim 1.1 \mathrm{~g}$ of higher salt consumption than women. WHO recommended levels of $5 \mathrm{~g}$ or less were met by just 97 participants $(11.3 \%)$, with no difference between sex and area of residence. Mean urinary potassium was 72.7 (SD 31.5, median 68.8) (Table 2), equivalent to a mean consumption of 3.40 (1.47) g of potassium per day (Table 2). 
Table 2. Daily urinary excretions of volume, sodium, potassium and creatinine and estimates of salt and potassium intake.

\begin{tabular}{cccccc}
\hline Variables & $\begin{array}{c}\text { All } \\
(n=858)\end{array}$ & $\begin{array}{c}\text { Men } \\
(n=326)\end{array}$ & $\begin{array}{c}\text { Women } \\
(n=532)\end{array}$ & $\begin{array}{c}\text { Rural } \\
(n=531)\end{array}$ & $\begin{array}{c}\text { Urban } \\
(n=327)\end{array}$ \\
\hline Volume $(\mathrm{mL} / 24 \mathrm{~h})$ & $1441(529)$ & $1505(536)$ & $1401(521)$ & $1333(427)$ & $1616(624)^{\#}$ \\
Sodium $(\mathrm{mmoL} / 24 \mathrm{~h})$ & $172.7(79.3)$ & $183.9(86.0)$ & $165.8(74.1)^{+}$ & $180.4(80.2)$ & $160.1(76.2)^{\#}$ \\
Salt intake $(\mathrm{g} /$ day $)$ & $10.8(4.9)$ & $11.5(5.4)$ & $10.3(4.6)^{\#}$ & $11.3(5.0)$ & $10.0(4.8)^{\#}$ \\
Potassium $(\mathrm{mmoL} / 24 \mathrm{~h})$ & $72.7(31.5)$ & $76.0(33.4)$ & $70.7(30.1)^{*}$ & $73.8(31.6)$ & $71.0(31.2)$ \\
Potassium intake (g/day) & $3.40(1.47)$ & $3.55(1.56)$ & $3.31(1.41)^{*}$ & $3.45(1.47)$ & $3.32(1.46)$ \\
Creatinine (mmol/24h) & $11.7(5.0)$ & $13.3(5.6)$ & $10.7(4.2)^{\#}$ & $12.3(4.8)$ & $11.4(5.0)^{+}$ \\
\hline
\end{tabular}

Results are mean (SD). ${ }^{\#} p<0.001 ;{ }^{\wedge} p<0.005 ;{ }^{\dagger} p<0.01 ;{ }^{*} p<0.02$ vs. men or vs. rural

Men excreted more potassium than women. Thirty-nine per cent of particiants met the levels of potassium excretion of $90 \mathrm{mmoL} /$ day or more recommended by the WHO, with no difference between sexes and areas of residence.

\subsection{Daily Intake of Iodine and Use of Iodised Salt}

Urinay iodine excretion (as measure of intake) was adequate in $40.9 \%$ of participants, irrespective of sex or area of residence (Table 3). Iodine consumption was above requirement or excessive in $30.3 \%$ of the participants, irrespective of sex or area of residence. Of the $28.6 \%$ who fell into the category indicating insufficient consumption (equally distributed by sex or area of residence), only $2.3 \%$ had severe deficiency (Table 3).

Table 3. Proportions of participants meeting WHO targets for iodine consumption (based on urinary iodine concentrations in $\mathrm{mcg} / \mathrm{L}$ derived from $24 \mathrm{~h}$ collections).

\begin{tabular}{cccccc}
\hline Group $(\mathbf{m c g} / \mathbf{L})$ & $\begin{array}{c}\text { All } \\
(n=858)\end{array}$ & $\begin{array}{c}\text { Men } \\
(n=326)\end{array}$ & $\begin{array}{c}\text { Women } \\
(n=532)\end{array}$ & $\begin{array}{c}\text { Rural } \\
(n=531)\end{array}$ & $\begin{array}{c}\text { Urban } \\
(n=327)\end{array}$ \\
\cline { 2 - 6 } & $n \mathbf{( \% )}$ & $n \mathbf{( \% )}$ & $n \mathbf{( \% )}$ & $n \mathbf{( \% )}$ & $n \mathbf{( \% )}$ \\
\hline Insufficient $(<100)$ & $245(28.6)$ & $95(29.1)$ & $150(28.2)$ & $104(31.8)$ & $141(26.6)$ \\
Severe (<20) & $20(2.3)$ & $6(1.8)$ & $14(2.6)$ & $4(1.2)$ & $16(3.0)$ \\
Moderate (20-49) & $60(7.0)$ & $24(7.4)$ & $36(6.8)$ & $28(8.6)$ & $32(6.0)$ \\
Mild (50-99) & $165(19.2)$ & $65(19.9)$ & $100(18.8)$ & $72(22.0)$ & $93(17.5)$ \\
Adequate $(100-199)$ & $351(40.9)$ & $132(40.5)$ & $219(41.2)$ & $131(40.1)$ & $220(41.4)$ \\
Above requirement $(200-299)$ & $152(17.7)$ & $59(18.1)$ & $93(17.5)$ & $58(17.7)$ & $94(17.7)$ \\
Excessive $(\geq 300)$ & $108(12.6)$ & $40(12.3)$ & $68(12.8)$ & $34(10.4)$ & $74(13.9)$ \\
\hline
\end{tabular}

Results are number (\%).

Average urinary iodine excretion was 225 (SD: 152, median 196) mcg per day (Table 4), with no difference between sexes or areas of residence. Iodine salt content was, on average 21.0 (18.6) $\mathrm{mg} / \mathrm{kg}$, with no difference between men and women. However, participants in rural areas consumed table salt with significantly less iodine concentrations than those samples consumed in urban areas $(p<0.001$; Table 4).

Table 4. Daily urinary excretions of iodine and iodine content of household salt samples.

\begin{tabular}{cccccc}
\hline Variables & $\begin{array}{c}\text { All } \\
(n=858)\end{array}$ & $\begin{array}{c}\text { Men } \\
(n=326)\end{array}$ & $\begin{array}{c}\text { Women } \\
(n=532)\end{array}$ & $\begin{array}{c}\text { Rural } \\
(n=531)\end{array}$ & $\begin{array}{c}\text { Urban } \\
(n=327)\end{array}$ \\
\hline Iodine $(\mathrm{mcg} / 24 \mathrm{~h})$ & $225(152)$ & $232(154)$ & $221(150)$ & $225(145)$ & $224(128)$ \\
Iodine in table salt $(\mathrm{mg} / \mathrm{kg})$ & $21.0(18.6)$ & $22.1(18.2)$ & $20.3(18.9)$ & $16.7(18.6)$ & $28.1(16.5)^{\#}$ \\
\hline
\end{tabular}


There were weak correlations between the amount of sodium excreted in the urine and the amount of excreted iodine in men and women or rural and urban settings (Figure 3).
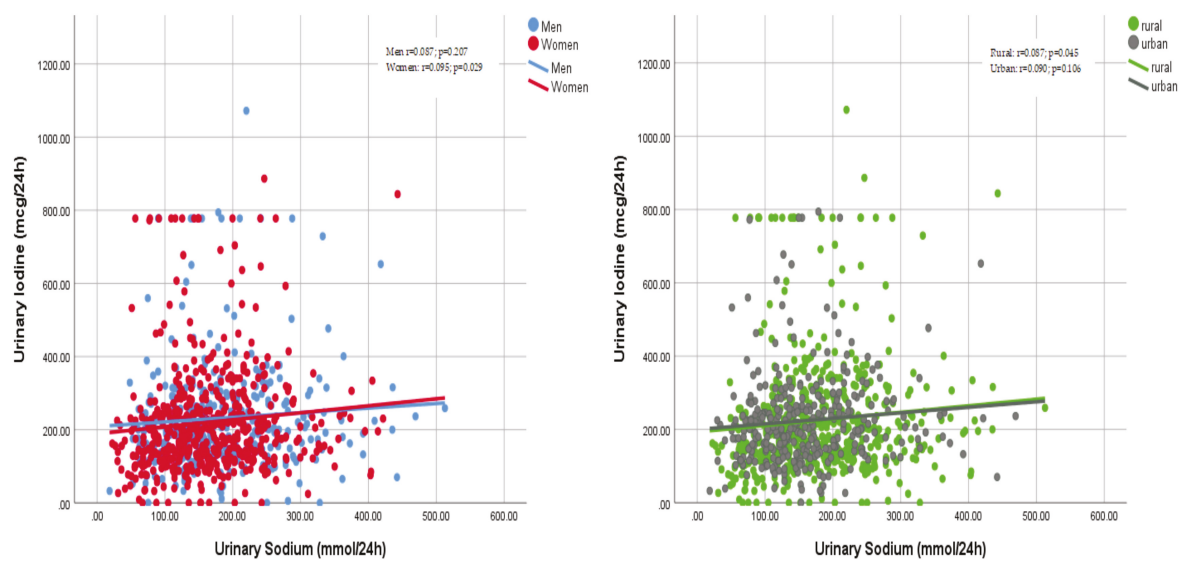

Figure 3. Correlations between urinary sodium and urinary iodine excretions by sex (left) and areas of residence (right). Left: men $\mathrm{r}=0.087, p=0.207$, women $\mathrm{r}=0.095, p=0.029$; right: rural $\mathrm{r}=0.087$, $p=0.045$, urban $\mathrm{r}=0.090, p=0.106$.

There were also weak correlations between the amount of urinary iodine excreted in a day and the amount of iodine present in the table salt sampled from the households of individual participants (Figure 4).
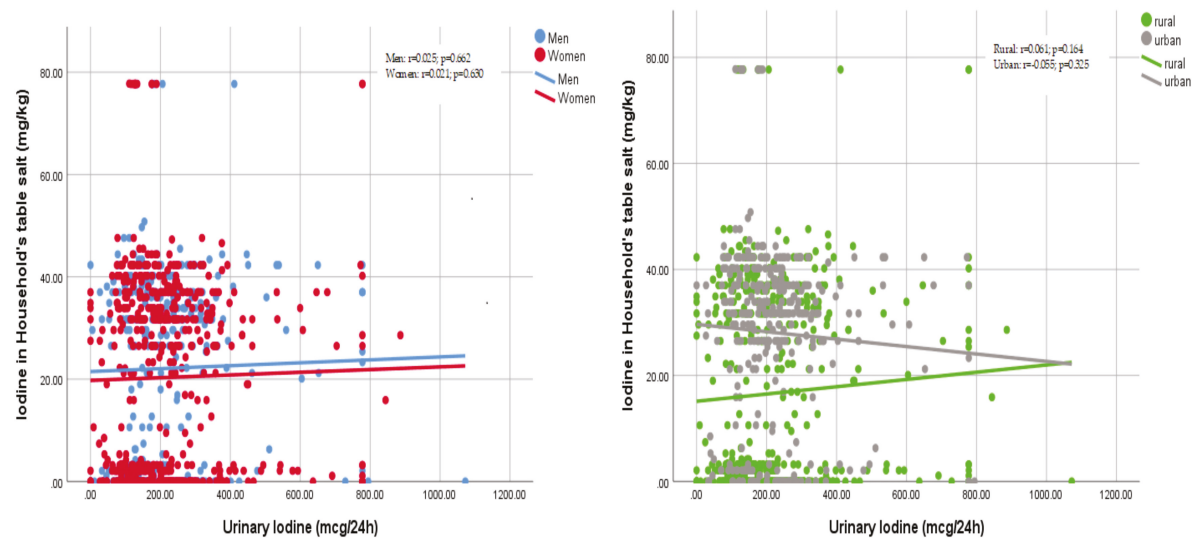

Figure 4. Correlations between urinary iodine excretions and iodine content of household's table salt by sex (left) and areas of residence (right). Left: men $\mathrm{r}=0.025, p=0.662$, women $\mathrm{r}=0.021, p=0.630$; right: rural $\mathrm{r}=0.061, p=0.164$, urban $\mathrm{r}=-0.055, p=0.325$.

\subsection{Knowledge, Attitude and Behaviours Towards Salt Intake}

Knowledge, attitude and behaviours toward the consumption of salt was assessed by asking participants about the frequency, quantity and type of salt used in the household, as well as their cooking habits and their attitudes towards dietary salt. A total of $35.4 \%$ of respondents mentioned that they added salt always or often before or while eating. The percentage of men who added salt always or often to their meal was significantly higher than that of women $(47.8 \%$ vs. $27.7 \% ; p<0.001)$. A total 
of $61.3 \%$ of respondents reported that they always or often added salt when cooking or preparing food at home; this was the case more often in rural than in urban areas $(69.8 \%$ vs. $47.5 \%$; $p<0.001)$. More than half of the respondents (64.4\%) mentioned that they used iodised salt when cooking or preparing food at home. Consumption of iodised salt, however, was higher in urban than in rural areas $(86.1 \% \mathrm{vs}$. $52.9 \% ; p<0.001)$. About a quarter $(26.7 \%)$ felt they consumed too much or far too much salt, women being more likely $(32.1 \%$ vs. $23.3 \% ; p<0.01)$. More than half $(67.2 \%)$ acknowledged that consuming too much salt could cause serious health problems; however, only $28.2 \%$ considered lowering salt intake in the diet to be very important. More than a quarter of respondents $(27.8 \%)$ mentioned that they consumed processed foods high in salt, with more men than women doing so (34.9\% vs. $23.5 \%$; $p<0.001)$, and more often in urban than rural settings (39.2\% vs. $20.8 \% ; p<0.001$ ).

Participants were asked about actions they take to control salt intake on a regular basis. A total of $81.7 \%$ limited their consumption of processed food high in salt (Table 5). A total of $22.3 \%$ would use spices rather than salt, one in three would not add salt when cooking. Only $8 \%$ looked at salt/sodium content on food labels and $14.3 \%$ bought alternatives to salt. One in three avoided eating food prepared outside home and $0.8 \%$ took any other measure to reduce salt intake.

Table 5. Knowledge, attitudes and behaviour towards the consumption of salt.

\begin{tabular}{cccccc}
\hline Participants Who: & $\begin{array}{c}\text { All } \\
(n=858)\end{array}$ & $\begin{array}{c}\text { Men } \\
(n=326)\end{array}$ & $\begin{array}{c}\text { Women } \\
(n=532)\end{array}$ & $\begin{array}{c}\text { Rural } \\
(n=531)\end{array}$ & $\begin{array}{c}\text { Urban } \\
(n=327)\end{array}$ \\
\hline Limit their consumption of processed food & 81.7 & 79.7 & 82.4 & 80.4 & 83.9 \\
Look at salt/sodium content in foods & 8.8 & 10.1 & 8.2 & 3.8 & $17.2^{*}$ \\
Buy low salt/sodium alternatives & 14.3 & 17.4 & 13.2 & 3.8 & $24.7^{*}$ \\
Do not add salt at the table & 77.3 & 69.6 & 80.2 & 75.9 & 79.6 \\
Do not add salt when cooking & 31.1 & 24.6 & 33.5 & 13.3 & $61.3^{*}$ \\
Use spices instead of salt when cooking & 22.3 & 15.9 & 24.7 & 25.3 & 17.2 \\
Avoid eating food prepared outside a home & 33.1 & 27.5 & 35.2 & 43.7 & $15.1^{*}$ \\
Take other measures to control salt intake & 0.8 & 1.4 & 0.5 & 1.3 & 0 \\
\hline
\end{tabular}

Results are expressed as $\%$ of column total. ${ }^{*} p \leq 0.001$ vs. rural by Fisher's exact test.

\section{Discussion}

This is the first national survey on sodium, potassium and iodine consumption ever carried out in adults in the Republic of Moldova, using the gold standard measure of $24 \mathrm{~h}$ urinary sodium, potassium and iodine excretions as biomarkers of intake. The results show unequivocally that salt consumption is high, potassium consumption is lower than recommended, both in men and in women. Furthermore, iodine intake is still inadequate in one in three people, although severe iodine deficiency is rare. However, universal salt iodization cover is still inadequate in many households both in urban and rural areas, where the use of iodized salt is still limited in the Moldovan diet.

\subsection{Salt Consumption}

Average salt intake was nearly $11 \mathrm{~g}$ per day, over two-fold of the WHO recommended maximum population target of $5 \mathrm{~g}$ per day [14]. Only $11.3 \%$ of the participants met the WHO salt targets. Men excreted more sodium than women, and in rural areas salt consumption was higher than in urban areas. Discretionary use of salt is common in the Republic of Moldova, with a third of participants adding salt regularly to food and half also using it regularly when cooking. The majority of participants knew that high salt causes serious health problems. However, only less than half thought it would be useful to reduce its consumption, and even fewer felt their own intake was not excessive and were doing anything to reduce it. The answers to these questions reveal an insufficient level of knowledge of the problem associated with high salt consumption amongst the participants and the unreadiness to transfer this knowledge to behavioural changes in using discretionary salt. 


\subsection{Potassium Consumption}

Average population potassium intake was estimated at around $3.26 \mathrm{~g}$ per day, still lower than the WHO recommended minimum population target of $3.51 \mathrm{~g}$ per day (equivalent to $90 \mathrm{mmol}$ per day [27]. Between $31 \%$ and $50 \%$ met WHO potassium targets. Men ate more potassium than women, likely due to the larger body size and volume of food eaten, rather than the quality of it. Salt and potassium are expressed as total quantities rather than consumption per calorie intake, hence the gender difference is mainly explained by the larger body size of men compared to women and the corresponding total food consumption compared to women. No difference in potassium intake was detected between rural and urban areas.

\subsection{Iodine Consumption}

Average daily iodine consumption was $225 \mathrm{mcg}$ per day, with no difference between sexes or areas of residence. Severe iodine deficiency ( $<20 \mathrm{mcg} / \mathrm{L}$ according to WHO criteria [31]) was rare. However, more than a quarter had levels below $100 \mathrm{mcg} / \mathrm{L}$ (insufficient), and a quarter had levels either above requirement or excessive (above $300 \mathrm{mcg} / \mathrm{L}$ ). The Republic of Moldova has adopted for a long time a policy of universal salt iodization for the control of iodine deficiency disorders [28]. It should be mentioned that as from 2009 the production and placing on the market of iodized bottled water was authorised by the government, which may have contributed to the increasing iodine supply, especially among more affluent population groups. By measuring the iodine content of the table salt used in the households visited for the screening, we were able to detect a significant lower iodine content in rural compared to urban areas (16.7 vs. $28.1 \mathrm{mg} / \mathrm{kg})$. Moreover, the percentage of households with no iodized salt was greater in rural than urban areas $(30.9 \%$ vs. $9.8 \% ; p<0.001)$. These results seem to suggest a variety of barriers, including possibly deterioration of iodized salt before reaching the users, reduced access, lower use, lack of awareness, costs, lack of use of iodized salt in food preparation by local producers, street vendors and the food industry. Another finding in our study was the lack of strong relationships between urinary sodium and iodine excretions and between urinary iodine excretion and iodine content in households' table salt. These findings may, in part, indicate that some salt in diet derives from non-iodized sources. Assuming that the food eaten in the households is prepared with iodized salt (since the country has a national policy of universal salt iodization), a major component of the salt consumed may derive from food eaten outside the household prepared with non-iodized salt. It is also possible that the use of iodized bottled water has become an important source of iodine, not captured in the correaltions with iodized salt.

\subsection{Comparison with Other European Countries}

Our main findings show that the salt intake in the Republic of Moldova is as high or higher than that reported in many other European and neighbouring countries, both in men and women. In the recent MINISAL study in Italy, the daily salt intake of Italians was $10.9 \mathrm{~g}$ for men and $8.5 \mathrm{~g}$ for women [43], with large variations by region and socio-economic status [44]. In Northern Greece average intakes were 11.1 and $9.1 \mathrm{~g}$ per day for men and women, respectively [45]. In the national survey of salt consumption in Slovenia men ate $13.0 \mathrm{~g}$ and women $9.9 \mathrm{~g}$ per day [21]. Recently, in the city of Podgorica, in Montenegro, salt consumption was measured at $13.9 \mathrm{~g}$ in men and $9.9 \mathrm{~g}$ per day in women [22]. In the SALTURK II survey in Turkey, men consumed $15.7 \mathrm{~g}$ of salt per day and women $14.0 \mathrm{~g}$ per day, with higher salt consumption in rural compared to urban areas [46]. Finally, in Portugal a national survey as estimated the consumption of salt at $10.7 \mathrm{~g}$ per day in men and $10.2 \mathrm{~g}$ per day in women [47]. Potassium intake in the Republic of Moldova was lower than in Portugal [47] and higher than that measured in Italy [43], Greece [45], and Montenegro [22]. Men eat more potassium than women. 


\subsection{Strengths and Limitations}

Our study included a large random sample of men and women representative of the Republic of Moldova. Salt and potassium intake were measured using the gold-standard method of $24 \mathrm{~h}$ urine collections [33]. We applied a rigorous quality control and used a highly standardized protocol to ensure completeness of urine collections, and a strict protocol of inclusion only of those fulfilling the quality control criteria, such as length of collection time and urinary creatinine excretion, markers of the accuracy of the collection. Our study is one of few studies having carried out at the same time a population based evaluation of daily iodine excretion in an adult population using $24 \mathrm{~h}$ urinary iodine excretion as a biomarker (rathe than spot urine samples), to assess the iodine status of a group of individuals who, whilst being supplemented with the universal salt iodization program, is not usually included in the population monitoring and surveillance on the effects of such policy.

Selection bias remains a possibility that we cannot rule out. We excluded a third of the participants as a result of the robust quality control for completeness of urine collections. Participants not delivering complete urines had lower weight, BMI, waist and hip circumferences and lower diastolic BP than those complying. No other differences were seen in their general characteristics (Table S1). Urinary sodium and potassium excretions were only assessed once. Whilst we cannot characterise an individual's intake [48], there is less likelihood that group estimates be biased. Finally, the absence of measurements of thyroid hormones does not allow a full assessment of the impact of both insufficient and excessive iodine intake on the adult population.

\subsection{Impact and Policy Implications}

The population of the Republic of Moldova is of just over 4 million, of whom approximately $75 \%$ over the age of 25 years. According to national health statistics from 2016, the mortality rate from diseases of the cardiovascular system is 617.3 per 100,000 population [49]. To meet the $30 \%$ reduction in population salt consumption set by WHO, the Republic of Moldova should aim at a $3.24 \mathrm{~g}$ per day reduction nationally. This reduction would be expected to avert 7.9\% CVD events and 10.7\% strokes every year, approximately 1460 CVD deaths per year.

The Republic of Moldova adopted the National Strategy on Prevention and Control of Noncommunicable Diseases 2012-2020 and its Action Plan [50]. Part of this pledge is to continue on the awareness campaigns already in place and to establish a comprehensive strategy involving legal measures, mandatory reformulation, nutritional labelling, efficient enforcement and good leadership [28]. Furthermore, a feasibility study of implementation and evaluation of essential interventions for the prevention of CVD in primary healthcare is currently under way in the Republic of Moldova, with a view towards a national scale-up [51].

The evidence of the level of sodium and potassium intake in the Republic of Moldova provides robust evidence to support action and to facilitate evaluation. Awareness, attitudes and behaviours about salt and its implication for health suggest that there is an intensification of public awareness campaigns and health promotion to improve the take up of preventive strategies aiming at reducing salt consumption, whilst at the same time increasing potassium intake by encouraging higher consumption of potassium-rich food. Awareness about hidden salt in processed food should be highlighted. The national program for reducing salt intake in the Republic of Moldova needs a multisectoral collaborative approach including not only public awareness and behaviour-change communication (including via health care professionals), but, more importantly, structured programs for reformulation that set the framework for the food industry to reduce salt in bread and bakery products and processed foods, major source of salt intake.

\subsection{Conclusions}

The present study provides valuable insights into ways to improve and adapt the universal salt iodization program. From one hand our results suggest that there are improvements to be made for a 
comprehensive take up of the policy nationally. On the other hand it confirms that both iodization and salt reduction policies are fully compatible, as agreed in a WHO Consensus Statement [31] and more recently confirmed in case studies in Italy [52] and China [53] where a moderate salt reduction in unlikely to compromise iodine status. Our data provides a useful baseline against which to monitor the impact of future initiatives.

Supplementary Materials: The following are available online at http://www.mdpi.com/2072-6643/11/12/2896/s1 Table S1: Characteristics of the excluded participants and comparison with those included in the study, Text S1: Data collection.

Author Contributions: F.P.C. developed the protocol, trained local teams, co-ordinated quality control and data analysis and drafted the manuscript. L.D. carried out quality control and statistical analysis. G.O. and A.C. developed the research protocol, trained local teams, coordinated the study, carried out the fieldwork and liaised with the local laboratory. J.J. and J.B. contributed to the design and interpretation of the findings. All authors contributed significantly to the final version of the manuscript.

Funding: This research was funded, in part, by the Swiss Agency for Development and Cooperation

Acknowledgments: The following are members of Salt Consumption Survey in the Republic of Moldova Study Group (in alphabetical order): Igor Berbec, Iurie Bobu, Valentina Bors, Joao Breda, DumitruCalincu, Francesco P Cappuccio, Veaceslav Carp, Angela Ciobanu, Nicolae David, Lanfranco D’Elia, Tatiana Eremciuc, Lilian Galer, Ala Gheorghiev, Mariana Gincu, Lilia Gurin, Jo Jewell, Alexandra Mandric, Vasile Moraru, Galina Obreja, Vasile Odobescu, Sveatoslav Ovcinicov, Vitalie Puris, Elena Revenco, Ecaterina Salaru, Ion Salaru, Stefan Savin, Raisa Scurtu, Natalia Silitrari, Alexandra Silnic, Nelea Tabuncic. The present analysis was carried out under the terms of reference of the WHO Collaborating Centre for Nutrition at the University of Warwick. The WHO Office for Europe and the authors would like to express gratitude to Svetlana Cebotari, Minister of Health, Labour and Social Protection, Aliona Serbulenco, State Secretary of the Ministry of Health, Labour and Social Protection and Haris Hajrulahovic, WHO Representative to the Republic of Moldova, for their keen interest, encouragement, support and endorsement. Special thanks go to the team of the National Agency for Public Health involved in the preparation of the survey and data collection. The authors alone are responsible for the content and views expressed in this publication and they do not necessarily represent the decisions, policy or views of the World Health Organization.

Conflicts of Interest: L.D. was a technical advisor to the World Health Organization and is a member of the scientific committee of the Italian Society of Human Nutrition. A.C., J.J. and J.B. are staff members of the World Health Organization. F.P.C. is a technical advisor to the World Health Organization, unpaid member of Action on Salt and WASH. G.O. has no conflict of interest to declare.

\section{References}

1. GBD 2015 Mortality and Causes of Death Collaborators. Global, regional, and national life expectancy, all-cause mortality, and cause-specific mortality for 249 causes of death, 1980-2015: A systematic analysis for the Global Burden of Disease Study 2015. Lancet 2016, 388, 1459-1544.

2. World Health Organization. Global Action Plan. for the Prevention and Control of NCDs 2013-2020; World Health Organization: Geneva, Switzerland, 2013; pp. 1-103.

3. World Health Organization. Tackling NCDs: "Best buys" and Other Recommended Interventions for the Prevention and Control of Noncommunicable Diseases. 2017. Available online: http://www.who.int/ncds/ management/best-buys/en/ (accessed on 27 October 2019).

4. National Center for Health Management. Health Yearbook: Public Health in Moldova. 2015. Available online: http://www.cnms.md/ro/rapoarteo (accessed on 27 October 2019).

5. World Health Organization. Prevalence of Noncommunicable Disease Risk Factors in the Republic of Moldova (STEPS 2013); Regional Office for Europe, World Health Organization: Copenhagen, Denmark, 2014; pp. 1-221.

6. European Heart Network. Transforming European Food and Drink Policies for Cardiovascular Health; European Heart Network: Brussels, Belgium, 2017; pp. 1-137.

7. Aburto, N.J.; Ziolkovska, A.; Hooper, L.; Elliott, P.; Cappuccio, F.P.; Meerpohl, J. Effect of lower sodium intake on health: Systematic review and meta-analysis. Br. Med. J. 2013, 346, f1326. [CrossRef] [PubMed]

8. He, F.J.; Li, J.; MacGregor, G.A. Effect of longer-term modest salt reduction on blood pressure: Cochrane systematic review and meta-analysis of randomised trials. Br. Med. J. 2013, 346, f1325. [CrossRef] [PubMed]

9. Strazzullo, P.; D’Elia, L.; Kandala, N.-B.; Cappuccio, F.P. Salt intake, stroke, and cardiovascular disease: Meta-Analysis of prospective studies. Br. Med. J. 2009, 339, b4567. [CrossRef] [PubMed] 
10. Cook, N.R.; Cutler, J.A.; Obarzanek, E.; Buring, J.E.; Rexrode, K.M.; Kumanyika, S.K.; Appel, L.J.; Whelton, P.K. Long term effects of dietary sodium reduction on cardiovascular disease outcomes: Observational follow-up of the Trials of Hypertension Prevention (TOHP). Br. Med. J. 2007, 334, 885-888. [CrossRef]

11. Cappuccio, F.P. Cardiovascular and other effects of salt consumption. Kidney Int. 2013, 3, 312-315. [CrossRef]

12. D'Elia, L.; Rossi, G.; Schiano di Cola, M.; Savino, I.; Galletti, F.; Strazzullo, P. Meta-Analysis of the effect of dietary sodium restriction with or without concomitant renin-angiotensin-aldosterone system-inhibiting treatment on albuminuria. Clin. J. Am. Soc. Nephrol. 2015, 10, 1542-1552. [CrossRef]

13. D'Elia, L.; Galletti, F.; La Fata, E.; Sabino, P.; Strazzullo, P. Effect of dietary sodium restriction on arterial stiffness: Systematic review and meta-analysis of the randomized controlled trials. J. Hypertens. 2018, 36, 734-743. [CrossRef]

14. World Health Organization. Guideline: Sodium Intake for Adults and Children; World Health Organization (WHO): Geneva, Switzerland, 2012.

15. Brown, I.J.; Tzoulaki, I.; Candeias, V.; Elliott, P. Salt intakes around the world: Implications for public health. Int. J. Epidemiol. 2009, 38, 791-813. [CrossRef]

16. Cappuccio, F.P.; Capewell, S. Facts, issues, and controversies in salt reduction for the prevention of cardiovascular disease. Funct. Food Rev. 2015, 7, 41-61.

17. WHO Regional Office for Europe. Mapping Salt Reduction Initiatives in the WHO European Region; WHO Regional Office for Europe: Copenhagen, Denmark, 2013.

18. Mattes, R.D.; Donnelly, D. Relative contributions of dietary sources. J. Am. Coll. Nutr. 1991, 10, $383-393$. [CrossRef] [PubMed]

19. Sanchez-Castillo, C.P.; Warrender, S.; Whitehead, T.P.; James, W.P. An assessment of the sources of dietary salt in a British population. Clin. Sci. 1987, 72, 95-102. [CrossRef] [PubMed]

20. Jovicic-Bata, J.; Grujicic, M.; Raden, S.; Novakovic, B. Sodium intake and dietary sources of sodium in a sample of undergraduate students from Novi Sad, Serbia. Vojnosanit. Pregl. 2016, 73, 1044-1049. [CrossRef] [PubMed]

21. Ribič, C.H.; Zakotnik, J.M.; Vertnik, L.; Vegnuti, M.; Cappuccio, F.P. Salt intake of the Slovene population assessed by 24-hour urinary sodium excretion. Public Health Nutr. 2010, 13, 1803-1809. [CrossRef]

22. D'Elia, L.; Brajovic, M.; Klisic, A.; Breda, J.; Jewell, J.; Cadjenovic, V.; Cappuccio, F.P.; on behalf of Salt Consumption Survey in Montenegro Study Group. Sodium and potassium intake, knowledge attitudes and behaviour towards salt consumption, amongst adults in Podgorica, Montenegro. Nutrients 2019, 11, 160. [CrossRef]

23. Cappuccio, F.P.; Capewell, S.; Lincoln, P.; McPherson, K. Policy options to reduce population salt intake. Br. Med. J. 2011, 343, 402-405. [CrossRef]

24. Aburto, N.J.; Hanson, S.; Gutierrez, H.; Hooper, L.; Elliott, P.; Cappuccio, F.P. Effect of increased potassium intake on cardiovascular risk factors and disease: Systematic review and meta-analyses. Br. Med. J. 2013, 346, f1378. [CrossRef]

25. D'Elia, L.; Barba, G.; Cappuccio, F.P.; Strazzullo, P. Potassium Intake, Stroke, and Cardiovascular Disease: A meta-analysis of Prospective Studies. J. Am. Coll. Cardiol. 2011, 57, 1210-1219. [CrossRef]

26. D'Elia, L.; Iannotta, C.; Sabino, P.; Ippolito, R. Potassium rich-diet and risk of stroke: Updated meta-analysis. Nutr. Metab. Cardiovasc. Dis. 2014, 24, 585-587. [CrossRef]

27. World Health Organization. Guideline: Potassium Intake for Adults and Children; World Health Organization (WHO): Geneva, Switzerland, 2012; pp. 1-52.

28. Obreja, G.; Raevschi, E.; Penina, O. Informing national salt reduction strategy. Mold. Med. J. 2018, 61, 9-16.

29. Nath, S.K.; Moinier, B.; Thullier, F.; Rongier, M.; Desjeux, J.F. Urinary excretion of iodide and fluoride from supplemented food grade salt. Int. J. Vitam. Nutr. Res. 1992, 62, 66-72. [PubMed]

30. Jahreis, G.; Hausmann, W.; Kiessling, G.; Franke, K.; Leiterer, M. Bioavailability of iodine from normal diets rich in dairy products: Results of balance studies in women. Exp. Clin. Endocrinol. Diabetes 2001, 109, 163-167. [CrossRef] [PubMed]

31. World Health Organization. Guideline: Fortification of Food-Grade Salt with Iodine for the Prevention and Control of Iodine Deficiency Disorders; World Health Organization: Geneva, Switzerland, 2014; pp. 1-54.

32. Pan American Health Organization/World Health Organization. Salt-Smart Americas: A Guide for Country-Level Action; PAHO: Washington, DC, USA, 2013; pp. 1-159. 
33. World Health Organization. How to Obtain Measures of Population-Level Sodium Intake in 24-Hour Urine Samples; WHO-EM/NUT/279/E; World Health Organization/Regional Office of the Eastern Mediterranean: Cairo, Egypt, 2018; pp. 1-51.

34. World Medical Association. Declaration of Helsinki: Recommendations guiding doctors in clinical research. Bull. World Health Org. 2008, 86, 650-651.

35. World Health Organization. The WHO STEPwise Approach to Chronic Disease Risk Factor Surveillance (STEPS); World Health Organization: Geneva, Switzerland, 2014; Available online: https://www.who.int/ncds/ surveillance/steps/STEPS_Instrument_v2.1.pdf (accessed on 27 October 2019).

36. Mancia, G.; Fagard, R.; Narkiewicz, K.; Redón, J.; Zanchetti, A.; Böhm, M.; Christiaens, T.; Cifkova, R.; De Backer, G.; Dominiczak, A.; et al. 2013 ESH/ESC Guidelines for the management of arterial hypertension: The Task Force for the management of arterial hypertension of the European Society of Hypertension (ESH) and of the European Society of Cardiology (ESC). J. Hypertens. 2013, 31, 1281-1357. [CrossRef] [PubMed]

37. Oesch, U.; Ammann, D.; Simon, W. Ion-Selective membrane electrodes for clinical use. Clin. Chem. 1986, 32, 1448-1459. [PubMed]

38. Junge, W.; Wilke, B.; Halabi, A.; Klein, G. Determination of reference intervals for serum creatinine, creatinine excretion and creatinine clearance with an enzymatic and a modified Jaffé method. Clin. Chim. Acta 2004, 344, 137-148. [CrossRef] [PubMed]

39. Ohashi, T.; Yamaki, M.; Pandav, C.S.; Karmarkar, M.G.; Irie, M. Simple microplate method for determination of urinary iodine. Clin. Chem. 2000, 46, 529-536.

40. Jooste, P.L.; Strydom, E. Methods for determination of iodine in urine and salt. Best Pract. Res. Clin. Endocrinol. Metab. 2010, 24, 77-88. [CrossRef]

41. Lucko, A.M.; Doktorchik, C.; Woodward, M.; Cogswell, M.; Neal, B.; Rabi, D.; Anderson, C.; He, F.J.; MacGregor, G.A.; L'Abbe, M.; et al. Percentage of ingested sodium excreted in 24-hour urine collections: A systematic review and meta-analysis. J. Clin. Hypertens. 2018, 20, 1220-1229. [CrossRef]

42. Stamler, J.; Elliott, P.; Chan, Q.; for the INTERMAP Research group. INTERMAP Appendix tables. J. Hum. Hypertens. 2003, 17, 665-758. [CrossRef]

43. Donfrancesco, C.; Ippolito, R.; Lo Noce, C.; Palmieri, L.; Iacone, R.; Russo, O.; Vanuzzo, D.; Galletti, F.; Galeone, D.; Giampaoli, S.; et al. Excess dietary sodium and inadequate potassium intake in Italy: Results of the MINISAL study. Nutr. Metab. Cardiovasc. Dis. 2013, 23, 850-856. [CrossRef]

44. Cappuccio, F.P.; Ji, C.; Donfrancesco, C.; Palmieri, L.; Ippolito, R.; Vanuzzo, D.; Giampaoli, S.; Strazzullo, P. Geographic and socio-economic variation of sodium and potassium intake in Italy. Results from the MINISAL-GIRCSI programme. BMJ Open 2015, 5, e007467. [CrossRef] [PubMed]

45. Vasara, E.; Marakis, G.; Breda, J.; Skepastianos, P.; Hassapidou, M.; Kafatos, A.; Rodopaios, N.; Koulouri, A.; Cappuccio, F.P. Sodium and Potassium Intake in Healthy Adults in Thessaloniki Greater Metropolitan Area-The Salt Intake in Northern Greece (SING) Study. Nutrients 2017, 22, 417. [CrossRef] [PubMed]

46. Erdem, Y.; Akpolat, T.; Derici, Ü.; Şengül, Ş.; Ertürk, Ş.; Ulusoy, Ş.; Altun, B.; Arici, M. Dietary sources of high sodium intake in Turkey: SALTURK II. Nutrients 2017, 9, 933. [CrossRef] [PubMed]

47. Polonia, J.; Martins, L.; Pinto, F.; Nazare, J. Prevalence, awareness, treatment and control of hypertension and salt intake in Portugal: Changes over a decade. The PHYSA study. J. Hypertens. 2014, 32, 1211-1221. [CrossRef]

48. Lerchl, K.; Rakova, N.; Dahlmann, A.; Rauh, M.; Goller, U.; Basner, M.; Dinges, D.F.; Beck, L.; Agureev, A.; Larina, I.; et al. Agreement between 24-hour salt ingestion and sodium excretion in a controlled environment. Hypertension 2015, 66, 850-857. [CrossRef]

49. National Centre for Health Management. Statistical Yearbook of the Republic of Moldova; Ministry of Health, Labour and Social Protection of the Republic of Moldova: Chişinău, Moldova, 2017.

50. Government of the Republic of Moldova. Decision no. 403 of 6 April 2016 on the approval of the National Action Plan for 2016-2020 on the implementation of the National Strategy on Prevention and Control of Noncommunicable Diseases. Monitorul Oficial Republicii Moldova 2016, 100, 464. (In Romanian)

51. Collins, D.; Ciobanu, A.; Laatikainen, T.; Curocichin, G.; Salaru, V.; Zatic, T.; Anisei, A.; Farrington, J. Protocol for the evaluation of a pilot implementation of essential interventions for the prevention of cardiovascular diseases in primary healthcare in the Republic of Moldova. BMJ Open 2019, 9, e025705. [CrossRef] 
52. Pastorelli, A.A.; Stacchini, P.; Olivieri, A. Daily iodine intake and the impact of salt reduction on iodine prophylaxis in the Italian population. Eur. J. Clin. Nutr. 2015, 69, 211-215. [CrossRef]

53. He, F.J; Ma, Y.; Feng, X.; Zhang, W.; Lin, L.; Guo, X.; Zhang, J.; Niu, W.; Wu, Y.; MacGregor, G.A. Effect of salt reduction on iodine status assessed by 24 hours urinary iodine excretion in children and their families in northern China: A substudy of a cluster randomised controlled trial. BMJ Open 2016, 6, e011168. [CrossRef]

(C) 2019 by the authors. Licensee MDPI, Basel, Switzerland. This article is an open access article distributed under the terms and conditions of the Creative Commons Attribution (CC BY) license (http://creativecommons.org/licenses/by/4.0/). 
Article

\title{
Breast Milk Iodine Concentration Is Associated with Infant Growth, Independent of Maternal Weight
}

\author{
Lindsay Ellsworth ${ }^{1}$, Harlan McCaffery ${ }^{2}$, Emma Harman ${ }^{3}$, Jillian Abbott ${ }^{4}$ and Brigid Gregg ${ }^{5, *}$ \\ 1 Division of Neonatal-Perinatal Medicine, Department of Pediatrics, University of Michigan, \\ Ann Arbor, MI 48109, USA; ellsworl@med.umich.edu \\ 2 Center for Human Growth and Development, University of Michigan, Ann Arbor, MI 48109, USA; \\ hmccaff@umich.edu \\ 3 School of Public Health, University of Michigan, Ann Arbor, MI 48109, USA; erharman@umich.edu \\ 4 Metals Laboratory, Division of Clinical Biochemistry and Immunology, Mayo Clinic, \\ Rochester, MN 55905, USA; abbott.jillian@mayo.edu \\ 5 Division of Pediatric Endocrinology, Department of Pediatrics, University of Michigan, \\ Ann Arbor, MI 48109, USA \\ * Correspondence: greggb@med.umich.edu
}

Received: 30 October 2019; Accepted: 27 January 2020; Published: 30 January 2020

\begin{abstract}
In breastfed infants, human milk provides the primary source of iodine to meet demands during this vulnerable period of growth and development. Iodine is a key micronutrient that plays an essential role in hormone synthesis. Despite the importance of iodine, there is limited understanding of the maternal factors that influence milk iodine content and how milk iodine intake during infancy is related to postnatal growth. We examined breast milk samples from near 2 weeks and 2 months post-partum in a mother-infant dyad cohort of mothers with pre-pregnancy weight status defined by body mass index (BMI). Normal (NW, BMI $<25.0 \mathrm{~kg} / \mathrm{m}^{2}$ ) is compared to overweight/obesity $\left(\mathrm{OW} / \mathrm{OB}, \mathrm{BMI} \geq 25.0 \mathrm{~kg} / \mathrm{m}^{2}\right)$. The milk iodine concentration was determined by inductively coupled plasma mass spectrometry. We evaluated the associations between iodine content at 2 weeks and infant anthropometrics over the first year of life using multivariable linear mixed modeling. Iodine concentrations generally decreased from 2 weeks to 2 months. We observed no significant difference in iodine based on maternal weight. A higher iodine concentration at 2 weeks was associated with a larger increase in infant weight-for-age and weight-for-length Z-score change per month from 2 weeks to 1 year. This pilot study shows that early iodine intake may influence infant growth trajectory independent of maternal pre-pregnancy weight status.
\end{abstract}

Keywords: iodine status; human milk; lactation; infant growth

\section{Introduction}

Iodine is a key micronutrient required for adequate growth and development through its critical role in thyroid hormone synthesis [1]. Deficiency in iodine during the neonatal and infant periods may result in impairments in brain development, cognitive outcomes, motor function, and growth stunting. Exposure to excess iodine can lead to iodine-induced hyperthyroidism or hypothyroidism [2-5]. Newborns are a particularly vulnerable population for iodine related disorders given their low storage of iodine in the thyroid at birth and their relatively high requirements for iodine relative to their body size $[2,3,6-9]$.

Exclusively breast-fed infants depend primarily on breast milk iodine to meet their daily iodine needs $[7,10]$. The United States Institute of Medicine recommends $110 \mu \mathrm{g} /$ day iodine intake for infants from birth to 6 months of age, while the World Health Organization (WHO) recommends $90 \mu \mathrm{g} /$ day to achieve adequate intake $[11,12]$. In order to support fetal and neonatal development, the American 
Thyroid Association recommends all pregnant and lactating women supplement their iodine intake with $150 \mu \mathrm{g} /$ day iodine [3,13]. Iodine supplementation for mothers is intended to achieve the United States Institute of Medicine recommendation of $290 \mu \mathrm{g}$ /day iodine intake and WHO recommendation of $250 \mu \mathrm{g} /$ day. Through this degree of supplementation during lactation, the goal is to reach a sufficient breast milk iodine concentration (BMIC) to support a breast-fed infant's daily requirements $[5,13]$. However, the exact BMIC needed to meet infant needs is not universally defined $[3,14]$.

BMIC is impacted by the maternal degree of iodine sufficiency from dietary iodine sources or supplementation. BMIC also varies based on the time point during lactation, maternal smoking, maternal health conditions, and with day to day fluctuation [3,15-19]. In establishing maternal iodine insufficiency, iodine is thought to be secreted into breast milk rather than excreted into the urine, to promote adequate levels of intake for offspring. The concentrating ability of mammary epithelial cells has been modeled with in vivo rat studies showing that the sodium/iodine symporter (NIS) mediates transport; however, published studies on the activity of the NIS in human mammary epithelial cells remain limited [20]. BMIC is a stronger marker of maternal iodine status than urine concentration $[7,10,14,21-25]$. BMIC is the greatest in the colostrum and then decreases in early lactation, with an over $40 \%$ reduction over the first 6 months of lactation $[2,3,6,7,10,15,16]$. To date, the impact of maternal health factors on BMIC has not been well described.

In pregnant and non-pregnant women, body mass index (BMI) has been negatively associated with urinary iodine concentration, which is measured as an indicator of iodine status [26-28]. Iodine deficiency has also been reported to be higher in those with morbid obesity [29]. The evaluation of BMIC in the establishment of obesity during pregnancy and lactation has not been well studied. Given the documented relationship with BMI, BMIC may have an important connection with rising levels of obesity in adulthood, as well as a potential contributing factor to childhood obesity. Iodine studies in mother-infant cohorts have shown mixed results regarding birth anthropometric outcomes, with some studies associated with an increased mean birth weight with improved maternal iodine status [30-34]. Postnatal studies of iodine levels have shown an impact on growth factors but have not shown a consistent association with infant growth [1,31,35-38].

With this study, we aimed to determine maternal BMIC over the first 2 months of lactation in mothers with normal weight compared to mothers with elevated pre-pregnancy BMI to characterize the impact of maternal metabolic factors on BMIC. We also assessed the impact of BMIC on infant growth trajectory over the first year of life while taking into account maternal pre-pregnancy weight status to gain a greater understanding of the impact of iodine on post-natal growth.

\section{Materials and Methods}

\subsection{Subjects and Methods}

This pilot study included a subset of 57 mother-infant dyads recruited in 2016 to 2018 at the University of Michigan and St. Joseph Mercy Ann Arbor Hospital during hospital admission at the time of infant delivery as part of the prospective Infant Metabolism and Gestational Endocrinopathies (IMAGE) cohort. This study was developed to detect differences in breast milk insulin concentration. This is a secondary analysis of the collected breast milk samples. The mothers included in this study were enrolled if they (1) planned to breastfeed their infant, (2) were $>18$ years of age, and (3) had a healthy singleton infant delivered at $\geq 35$ weeks gestation. Maternal health conditions, including obesity, gestational diabetes, and polycystic ovary syndrome were included. Maternal demographics and health history were obtained through an electronic medical record review and paper surveys. The maternal pre-pregnancy weight status was determined through a calculation of BMI using obstetrics recorded pre-pregnancy or the early first trimester weight and height as documented in the medical record. Mother-infant dyads were categorized by maternal pre-pregnancy weight status as normal weight (NW, BMI $<25.0 \mathrm{~kg} / \mathrm{m}^{2}$ ) or overweight/obese (OW/OB, BMI $\geq 25.0 \mathrm{~kg} / \mathrm{m}^{2}$ ). 
The study was approved by the institutional review boards at the University of Michigan (HUM00107801, approved 01/05/2016) and St. Joseph Mercy Ann Arbor Hospital (HSR-17-1686, approved 03/07/17). Mothers gave written informed consent for themselves and assent for their infants prior to participation in the study. The study was conducted in accordance with the protocol approved by the institutional review boards. Participants received reimbursement for their involvement in this study.

\subsection{Milk Collection}

A written milk collection protocol was provided to the mothers, and in person verbal instruction was given by the study team. Mothers were instructed to collect a $25 \mathrm{~mL}$ milk sample on the morning of their infant's 2 week (transitional milk) and 2 month (mature milk) routine well-child visit. The milk collection protocol was based on the published methods by Fields and Demerath, with modifications as described [39]. Mothers collected milk samples between 8:00 and 10:00 am and at least $2 \mathrm{~h}$ after feeding their infant by hand expression or pumping of an entire breast based on the maternal preference of expression type. Mothers expressed milk into a large container and then mixed the milk by inversion before the milk was transferred to five glass vials ( $5 \mathrm{~mL}$ each). Samples were immediately placed in the mother's home freezer and then transported on ice to the clinic for storage at $-20^{\circ} \mathrm{C}$ prior to transport on ice to the final storage location at $-80^{\circ} \mathrm{C}$ within one week. The milk was thawed on ice for subsequent analyses, at which time $250 \mu \mathrm{L}$ was aliquoted for further iodine assessment after refreezing at $-80^{\circ} \mathrm{C}$ and shipment on dry ice.

\subsection{Laboratory Analysis}

Frozen whole milk $250 \mu \mathrm{L}$ aliquots were shipped on dry ice to the Mayo Clinic Metals Laboratory (Rochester, MN) for iodine analysis. PerkinElmer Sciex ELAN Dynamic Reaction Cell (DRC) II Inductively Coupled Plasma Mass Spectrometer (ICP-MS), manufactured in Waltham, Massachusetts, USA was used for testing. The gold standard of ICP-MS was used [3]. All samples had one freeze-thaw cycle additional before dilution and were tested within an International Standards Organization (ISO) class 7 cleanroom. The analysis performed followed the standard operating procedure of a test that was developed and consistent with Clinical Laboratory Improvement Amendments (CLIA) requirements. The method used commercially prepared calibrators (Inorganic Ventures, Christiansburg, VA, USA) in $1 \% \mathrm{TMAH}, 7.5 \mathrm{~g} / \mathrm{L} \mathrm{NaCl}$ and $0.5 \mathrm{~g} / \mathrm{L} \mathrm{CaCl}_{2}$ matrix with iodine concentrations at $0,10,100,500,1000$, $5000 \mu \mathrm{g} / \mathrm{L}$, having an analytical measurement range (AMR) from 10 to $40,000 \mu \mathrm{g} / \mathrm{L}$, with the use of 10,000 $\mu \mathrm{g} / \mathrm{L}$ and $40,000 \mu \mathrm{g} / \mathrm{L}$ linearity standards. Results above linearity were diluted with $\mathrm{SRW}(\geq 18 \mathrm{M} \Omega \mathrm{cm}$ Special Reagent Water using a NANOpure system, Thermo Scientific, Waltham, MA, USA).

To assess the degree of error for the test method, a recovery study was performed on 3 breast milk samples by spiking them with iodine calibration standards $(0,100$ and $500 \mu \mathrm{g} / \mathrm{L})$ and two levels of Quality Control UTAK Serum Trace Element (UTAK Laboratories, Inc. Valencia, CA, USA), as shown in Table 1. Initial dilutions were repeated five times in duplicate for an intra-assay coefficient of variation (CV). Samples were then run with subsequent loads over a period of five days for an inter-assay CV. The average percentages of recovery were all within $10 \%$ of the expected values and $<10 \%$ for the intra and inter-assay CV. 
Table 1. Performance characteristics of the iodine assay.

\begin{tabular}{cccccc}
\hline \multicolumn{7}{c}{ Breast Milk Precision and Recovery } \\
\hline Target & 0 Standard & $\mathbf{1 0 0} \boldsymbol{\mu g} / \mathrm{L}$ & $\mathbf{5 0 0} \boldsymbol{\mu g} / \mathrm{L}$ & NR UTAK QC & HR UTAK QC \\
\hline Mean & 42.89 & $145.56 \mu \mathrm{g} / \mathrm{L}$ & $551.52 \mu \mathrm{g} / \mathrm{L}$ & $49 \mathrm{ng} / \mathrm{mL}$ & $186 \mathrm{ng} / \mathrm{mL}$ \\
\hline CV\% & $9.32 \%$ & $6.65 \%$ & $0.43 \%$ & $9.6 \%$ & $2.5 \%$ \\
\hline Recovery & & $97.40 \mu \mathrm{g} / \mathrm{L}$ & $450.9 \mu \mathrm{g} / \mathrm{L}$ & $46 \mu \mathrm{g} / \mathrm{L}$ & $179 \mu \mathrm{g} / \mathrm{L}$ \\
\hline$\%$ Recovery & & $97.40 \%$ & $90.18 \%$ & $93.88 \%$ & $96.24 \%$ \\
\hline
\end{tabular}

The same levels of UTAK Serum Trace Elements were used for the Quality Control Analysis; levels were analyzed identically to those of the patient samples in duplicate. QC was run after every 20 samples and at the end of each load. During the sample preparation step each specimen was thoroughly vortexed immediately before performing a two-step dilution using a Hamilton MicorLab diluter (Hamilton Company, Reno, NV, USA) to aspirate $60 \mu \mathrm{g} / \mathrm{L}$ of the sample and $60 \mu \mathrm{g} / \mathrm{L}$ of the Iodine 0 Solution, combined with Iodine Diluent $(50 \mu \mathrm{g} / \mathrm{L} \mathrm{Te}(30 \% \mathrm{HCl} v / v)$ and $10 \mu \mathrm{g} / \mathrm{L} \mathrm{Rh}(21 \% \mathrm{HCl}$ $v / v)$ in $1 \% \mathrm{TMAH}$ ) for a total of $3 \mathrm{~mL}$. The iodine concentration was measured in $\mathrm{ng} / \mathrm{mL}$. Samples were analyzed in duplicate, and the results were averaged for reporting.

One milk sample at 2 weeks had a significantly elevated iodine concentration upon initial analysis, which was consistent on repeat analysis at a separate run time point; given this outlier concentration of $>7000 \mathrm{ng} / \mathrm{mL}$ without biological plausibility, this value was truncated to the next highest iodine concentration value in our cohort $(649.1 \mathrm{ng} / \mathrm{mL})$. A potential etiology may include iodine exposure peri-partum through antiseptics; however, this was unable to be verified.

\subsection{Infant Anthropometric Measurements}

Infant health history was reviewed from the electronic medical record, including documentation of birth history during hospital admission and follow-up routine outpatient well-child pediatric visits. The type of nutritional intake, such as human milk, formula, or combinations, was determined from the pediatrician notes at the well-child visits. Infant growth anthropometric measures were extracted from the medical record measurements for weight and length obtained in the hospital at birth and during outpatient well-child visits at 2 weeks, 2 months, 6 months, and 1 year. Age and sex specific WHO Z-scores for weight-for-age (WFA), length-for-age (LFA), and weight-for-length (WFL) were extracted from the medical record [40].

\subsection{Statistical Analysis}

The statistical analysis was completed using R version 3.6.1 (R Foundation for Statistical Computing, Vienna, Austria) and the package nlme version 3.1-140 for this pilot study. Descriptive statistics, comparisons of overweight and obese mothers, and unadjusted comparisons of $\log$ (BMIC) were done using Fisher's exact tests or $t$-tests, as appropriate, on all dyads with complete data for each test $(n=49$ for comparisons involving 2 week BMIC; $n=50-57$ for all other covariates).

Linear mixed models with random intercepts at the subject level were fit using the 35 dyads that had exclusively breast milk feedings at 2 weeks and 2 months, with BMIC measured at 2 weeks. WFA Z-score (WFAZ), LFA Z-score (LFAZ), and WFL Z-score (WFLZ) were considered dependent variables. Estimates were obtained for the fixed effects for the following independent variables: 2 weeks BMIC, time (in months, $0.5,2,6,12$ ), birth anthropometric Z-score, maternal BMI, gender, interaction of maternal BMI and time, and interaction of 2 week BMIC and time. The interaction of BMIC and time was used to test the association between BMIC and infant growth, and the interaction of maternal BMI and time was included to control for the effects of maternal BMI on infant growth. An initial time point of 2 weeks was used due to the anticipated fluid shift in the first 2 weeks of life in newborns. Parameter estimates were considered statistically significant at $p<0.05$. 


\section{Results}

This mother-infant cohort included 57 dyads with infant growth measures from birth to 1 year of age, with the descriptive analysis shown in Table 2. Of the 57 dyads, 25 mothers provided milk samples only at 2 weeks, 8 mothers provided milk samples only at 2 months, and 24 mothers provided milk samples at both 2 weeks and 2 months. Mothers in our Midwestern population were primarily Caucasian in the OW/OB maternal group compared to the NW maternal group. Infants were delivered at term gestational age, with $47 \%$ male infants. At the 2 week time point of milk collection (mean 16.5 days, SD 3.0 days), 49 milk samples were available for analysis. At the 2 month time point of time collection (mean 63.0 days, SD 5.6 days), 32 milk samples were available for analysis. At the 2 week time point with milk samples collected, $86 \%$ of the infants were reported to be exclusively breastfed, $10 \%$ received breast milk and formula, $4 \%$ did not have their nutrition intake reported, and no infants were exclusively formula fed. By the 2 month time point after the milk samples were collected, $81 \%$ of infants received exclusively breast milk, $12 \%$ of infants received breast milk and formula, $6 \%$ of infants did not have their nutritional intake documented, and no infants were exclusively formula fed. Higher rates of formula supplementation were seen among mothers with OW/OB at 2 weeks (17\%) and 2 months (20\%). The exact amount of formula supplementation was not quantified.

Table 2. Participant demographics.

\begin{tabular}{|c|c|c|c|}
\hline Participant Characteristics & $\begin{array}{c}\text { NW } \\
(n=24)\end{array}$ & $\begin{array}{l}\text { OW/OB } \\
(n=33)\end{array}$ & $p$ \\
\hline Maternal Age: years, mean (SD) & $31.00(3.66)$ & $31.61(3.06)$ & 0.5 \\
\hline${ }^{*}$ Maternal Pre-Pregnancy BMI: $\mathrm{kg} / \mathrm{m}^{2}$, mean (SD) & $21.25(1.99)$ & $30.95(4.69)$ & $<0.001$ \\
\hline \multicolumn{4}{|l|}{ * Maternal Race/Ethnicity } \\
\hline Caucasian, no. $(\%)$ & $11(46)$ & $28(85) *$ & \multirow{6}{*}{0.002} \\
\hline African American, no. (\%) & $2(8)$ & $1(3)$ & \\
\hline Hispanic/Latino, no. (\%) & $4(17)$ & $1(3)$ & \\
\hline Asian/Pacific Islander, no. (\%) & $6(25)$ & $1(3)$ & \\
\hline Indian, no. $(\%)$ & $1(4)$ & $0(0)$ & \\
\hline $\mathrm{N} / \mathrm{A}$, no. $(\%)$ & $0(0)$ & $2(6)$ & \\
\hline Gestational Age: weeks, mean (SD) & $39.5(1.0)$ & $39.1(1.3)$ & 0.16 \\
\hline \multicolumn{4}{|l|}{ Mode of Delivery } \\
\hline Vaginal, no. (\%) & $18(75)$ & $20(60)$ & \multirow[t]{2}{*}{0.39} \\
\hline C-section, no. (\%) & $6(25)$ & $13(40)$ & \\
\hline \multicolumn{4}{|l|}{ Country } \\
\hline Washtenaw, no. (\%) & $18(75)$ & $17(52)$ & \multirow[t]{2}{*}{0.1} \\
\hline Other, no. $(\%)$ & $6(25)$ & $16(49)$ & \\
\hline \multicolumn{4}{|l|}{ Maternal income: dollars, mean (SD) } \\
\hline$<60,000$, no. $(\%)$ & $21(88)$ & $19(68)$ & \multirow{3}{*}{0.04} \\
\hline$>60,000$, no. $(\%)$ & $3(12)$ & $9(32)$ & \\
\hline Unknown, no. (\%) & $0(0)$ & $5(15)$ & \\
\hline \multicolumn{4}{|l|}{ Smoker } \\
\hline Yes, no. (\%) & $1(4)$ & $1(3)$ & \multirow{2}{*}{$>0.99$} \\
\hline No, no. $(\%)$ & $19(80)$ & $27(82)$ & \\
\hline N/A, no. $(\%)$ & $4(17)$ & $5(15)$ & \\
\hline Infant birth weight: $\mathrm{kg}$ mean (SD) & $3.42(0.36)$ & $3.52(0.42)$ & 0.35 \\
\hline Infant birth weight: Z-score mean (SD) & $0.33(0.78)$ & $0.42(0.81)$ & 0.68 \\
\hline \multicolumn{4}{|l|}{ Infant sex } \\
\hline Male, no. (\%) & $11(54)$ & $16(49)$ & \multirow[t]{2}{*}{$>0.99$} \\
\hline Female, no. $(\%)$ & $13(54)$ & $17(51)$ & \\
\hline Infant age at 2 week time point: days, mean (SD) & $15.9(3)$ & $16.9(3)$ & 0.27 \\
\hline Infant age at 2 month time point: days, mean (SD) & $62.0(7.2)$ & $62.5(6.7)$ & 0.8 \\
\hline
\end{tabular}

Descriptive statistics on maternal and infant demographics from the cohort of 57 mother-infant dyads presented as the mean (standard deviation) or number (percentage). The sample size is slightly smaller than the totals presented for infants aged at 2 weeks (missing data for 9 infants). Statistical analysis using a $t$-test or Fischer's exact test. * represents statistical significance, with a $p$-value $<0.05$. Abbreviations: normal weight (NW), overweight and obesity (OW/OB), not available (N/A) number (no.). BMI $p<0.001$, Maternal race/ethnicity $p=0.002$. 
BMIC ranged from 16.0 to $649.1 \mathrm{ng} / \mathrm{mL}$ in samples collected near 2 weeks and 2 months. The median BMIC at 2 weeks was $160.7 \mathrm{ng} / \mathrm{mL}$, and, by 2 months, it was $86.0 \mathrm{ng} / \mathrm{mL}$. For comparisons of the mean BMIC, we used a log-transformation BMIC to satisfy the normality assumptions ( $p=0.73$ and 0.56 for the 2 week and 2 month BMIC, respectively, with a Shapiro-Wilk test). There was no significant difference in the log-BMIC between NW and OW/OB mothers at 2 weeks $(p=0.54)$ or at 2 months ( $p=0.57)$. The log-BMIC decreased from 2 weeks to 2 months by $0.59(39 \%, p=0.007)$ in the 24 mothers who had iodine measurements at both time points. There was no impact of infant sex, maternal county of residence, or maternal income on BMIC. Untransformed BMIC is shown by the weight status and time of measurement in Figure 1.

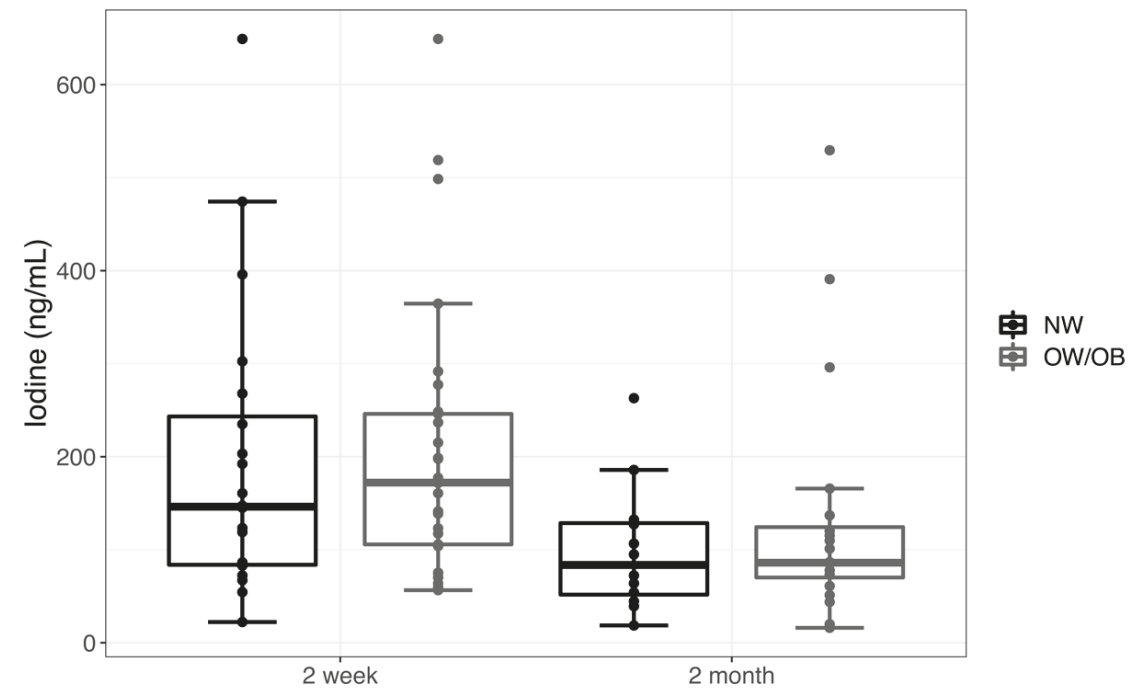

Figure 1. Breast milk iodine concentration (based on the maternal pre-pregnancy weight status for normal weight (NW) compared to overweight and obese (OW/OB) mothers) in transitional milk at 2 weeks (NW $n=20, \mathrm{OW} / \mathrm{OB} n=29$ ) and mature milk at 2 months (NW $n=12, \mathrm{OW} / \mathrm{OB} n=20)$. Data are represented as a box plot, with the box showing median (IQR) and the whiskers equal to the farthest observation less than 1.5 times IQR from the box edge.

We then explored the impact of maternal weight and BMIC on infant growth from 2 weeks to 1 year using linear mixed models, with a subset of dyads who had complete data for all variables included in the model, and who were exclusively breastfed at 2 weeks and 2 months $(n=35)$. We evaluated infant growth by testing the interactions of maternal BMI with time, and BMIC at 2 weeks with time, using an anthropometric Z-score through the first year of life, with the WFA, LFA, and WFL Z-scores as dependent variables. We found no significant interactions between maternal pre-pregnancy BMI and time for WFA $(\beta=-0.00126, p=0.534)$, LFA $(\beta=0.00359, p=0.118)$, or WFL $(\beta=-0.00452$, $p=0.089)$ Z-score changes per month from 2 weeks to 1 year. A higher milk iodine concentration at 2 weeks was associated with a larger increase in infant WFA $(\beta=0.00033, p=0.0007)$ and WFL Z-score ( $\beta=0.00029, p=0.0212$ ) change per month from 2 weeks to 1 year, with no significant association with LFA ( $\beta=0.00015, p=0.154)$, as shown in Table 3. Figure 2 represents the model interaction terms of BMIC and time, showing the predicted WFAZ, LFAZ, and WFLZ for a male infant with a mean birth Z-score, breastfed by a mother with mean BMI based on a 2 week BMIC mean, mean +1 standard deviation (SD), and -1 SD. 

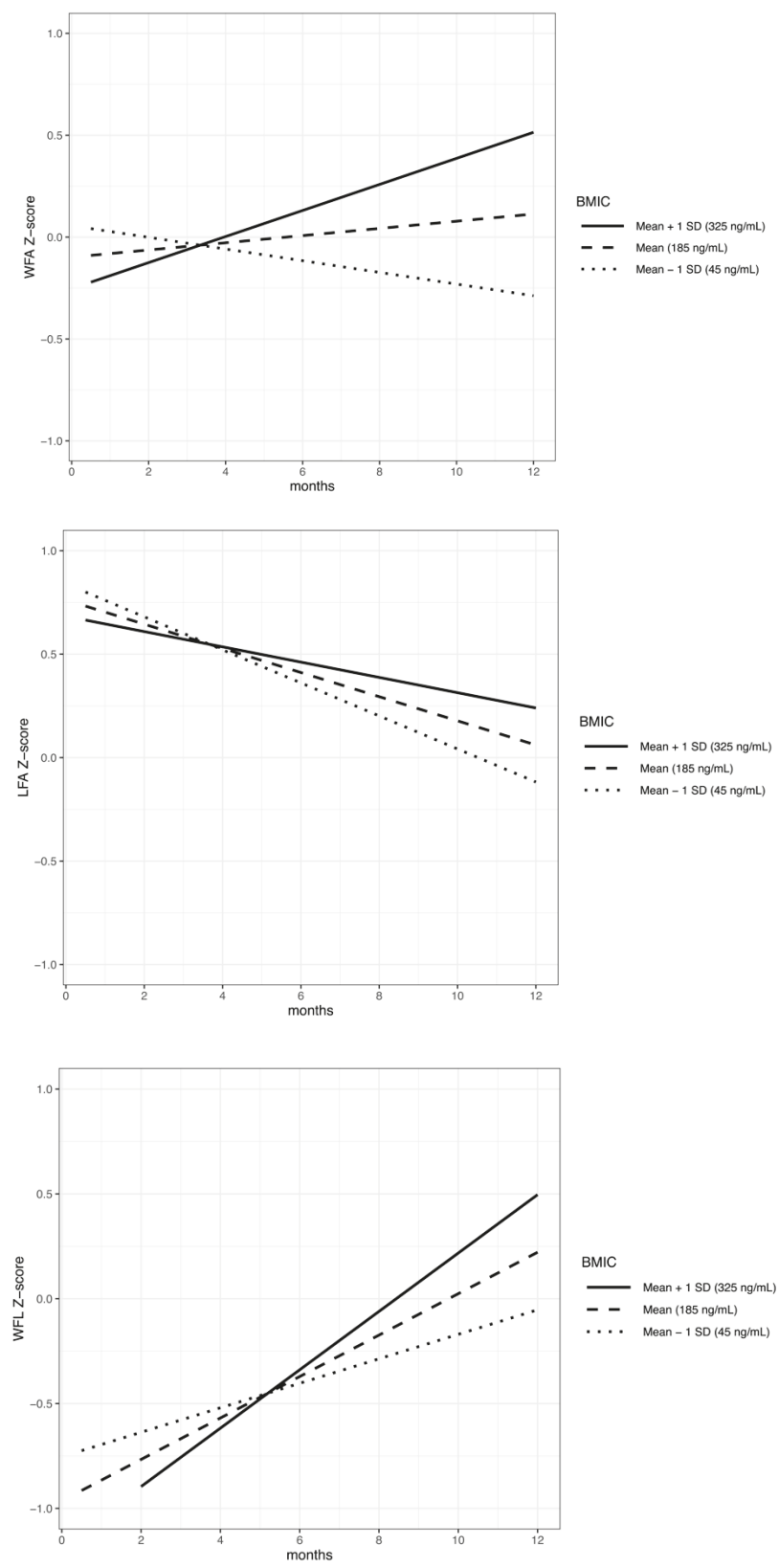

Figure 2. Infant growth anthropometric Z-score from 2 weeks to 1 year, with BMIC predicted by linear mixed models (model $n=35$ ). Graphs depict the difference in the predicted growth lines for the mean \pm 1 standard deviation BMIC as measured at 2 weeks for dyads with a male infant, the mean birth anthropometric Z-score, and the mean maternal BMI. Interaction effect of BMIC and time (months) on infant WFA ( $\beta=0.00033, p<0.001)$, infant LFA $(\beta=0.00015, p=0.154)$, and infant WFL $(\beta=0.00029, p=0.021)$. Abbreviations: weight-for-age Z-score (WFA), length-for-age Z-score (LFA), and weight-for-length Z-score (WFL); breast milk iodine concentration (BMIC). 
Table 3. Association of maternal weight status and 2 week breast milk iodine concentration with change in weight-for-age, length-for-age, and weight-for-length Z-score across the first year of life.

\begin{tabular}{|c|c|c|c|c|}
\hline \multirow[t]{2}{*}{ Variables } & \multirow[b]{2}{*}{ Model $n$} & WFAZ & LFAZ & WFLZ \\
\hline & & \multicolumn{3}{|c|}{$\begin{array}{c}\text { Difference ( } \beta \text { ( } p \text {-value)) in change in infant } \\
\text { anthropometry Z-score }\end{array}$} \\
\hline BMIC at 2 weeks $(\mathrm{ng} / \mathrm{mL})$ & 35 & $-0.1883(0.706)$ & $1.23581(0.028)^{*}$ & $-1.1945(0.053)$ \\
\hline Time (months) & 35 & $-0.0011(0.170)$ & $-0.00056(0.527)$ & $-0.0015(0.136)$ \\
\hline Birth WFAZ & 35 & $0.53027(0.0006) *$ & $-0.18117(0.002) *$ & $0.16434(0.016) *$ \\
\hline Maternal BMI $\left(\mathrm{kg} / \mathrm{m}^{2}\right)$ & 35 & $-0.00532(0.769)$ & $0.42163(0.0004) *$ & $0.24395(0.022) *$ \\
\hline Infant sex & 35 & $0.23087(0.247)$ & $-0.03543(0.080)$ & $0.01866(0.411)$ \\
\hline Maternal BMI interaction with time & 35 & $-0.00126(0.536)$ & $0.00359(0.118)$ & $-0.00452(0.089)$ \\
\hline BMIC at 2 weeks interaction with time & 35 & $0.00033(0.0007) *$ & $0.00015(0.154)$ & $0.00029(0.021)^{*}$ \\
\hline
\end{tabular}

* Statistical significance based on an estimation of the fixed effects in linear mixed models, with a significance threshold at $p<0.05$. Abbreviations: weight-for-age Z-score (WFAZ), length-for-age Z-score (LFAZ), weight-for-length Z-score (WFLZ), body mass index (BMI), and breastmilk iodine concentration (BMIC).

\section{Discussion}

In the maternal-infant dyads in this study, transitional milk BMIC was positively associated with infant WFA and WFL Z-score changes over the first year of life, and these iodine-related growth differences were not related to maternal pre-pregnancy weight status based on this pilot study. The importance of early milk iodine may point to a critical period of offspring development during high vulnerability and a time during which formula fed infants may consume less iodine than breastfed infants.

Milk iodine concentrations were not associated with maternal pre-pregnancy weight status in our cohort. While literature on adult obesity has described iodine deficiency as associated with elevated BMI, we did not find similar findings related to BMI as a marker of iodine status [26-29]. Limited literature on BMIC during lactation has focused on the maternal health influences on milk iodine concentration $[26,27,29]$. A study by Dumrongwongsiri, in Thailand, showed an association of BMIC with maternal weight; however, there was no association with maternal age or lactation stage [41]. This study did not define the time point of maternal weight measurement and may not reflect the weight prior to pregnancy, as assessed in our study. It is important for future studies on BMIC to include an analysis of maternal pre-pregnancy weight status in order to understand the role of maternal health on milk micronutrient composition.

The milk iodine concentrations in our cohort showed considerable variability. The BMIC to achieve adequate iodine delivery to infants is debated, with the lower most BMIC proposed to range from 60 to $150 \mathrm{ng} / \mathrm{mL}[3,13,14,22]$. While exact values of the ideal BMIC for sufficient infant intake ranges are not well described, a goal of $150 \mathrm{ng} / \mathrm{mL}$ in breast milk has been reported [3]. The levels in our study showed a high degree of values below $150 \mathrm{ng} / \mathrm{mL}$ at 2 weeks $(47 \%)$ and even more below $150 \mathrm{ng} / \mathrm{mL}$ at 2 months (81\%). These results are higher than those of a study from the Netherlands, showing that $33 \%$ of infants were anticipated to be iodine deficient based on BMIC $<1.1 \mu \mathrm{mol} / \mathrm{L}$ $(139 \mathrm{ng} / \mathrm{mL})$ [42]. Mothers with low BMIC may signify a population with iodine insufficiency, as BMIC has been shown to be positively correlated with maternal urinary iodine concentration, the standard measure of iodine sufficiency [43]. Currently, the United States has salt iodization programs, with a reported use near $90 \%$ due to a decline in iodized salt into the 1990s, based on National Health and Nutrition Examination Survey (NHANES) data [44]. Additionally, the NHANES reports on iodine status during pregnancy showed a concerning degree of iodine insufficiency (56.9\%) in 2005-2008 [45]. Previous cohorts from Boston have shown a similar degree of iodine insufficiency (47\%) based on estimated infant milk intake; however, this group had higher milk iodine concentrations (median $155 \mathrm{ng} / \mathrm{mL}$ ) at a median of 48 days collection compared to BMIC at our 2 month time point (median $86 \mathrm{ng} / \mathrm{mL}$ ) [43]. A meta-analysis by Nazeri described overall lower mature milk iodine level in iodine 
sufficient countries (mean $71.5 \mathrm{ng} / \mathrm{mL}$ ) [46]. This difference may represent population, geographic, or nutritional intake differences.

While our cohort may be a population at risk for infant iodine insufficiency based on BMIC, we also noted some elevated BMIC levels in both NW and OW/OB throughout the first 2 months of lactation. The level of BMIC that may lead to iodine excess has not been defined in the same manner that urinary iodine concentration $>300 \mathrm{ng} / \mathrm{mL}$ in children and $>500 \mathrm{ng} / \mathrm{mL}$ in pregnancy is defined as iodine excess [47]. Prior studies of high iodine exposure through elevated water iodine levels by Liu identified a BMIC $>200 \mathrm{ng} / \mathrm{mL}$ in mothers with high iodine intake [48]. A further evaluation of excessive iodine exposure through breast milk is necessary to determine the safe levels of exposure, particularly in mothers at risk for iodine excess, including those with high dietary, oral, or topical iodine exposure [49].

Our data on BMIC overall, independent of maternal pre-pregnancy weight status, suggests a relationship between infant iodine exposure and growth, with a higher BMIC at 2 weeks associated with an increased change in Z-score for WFA and WFL over the first year of life. However, the clinical implications of these small growth changes are unclear, and future long-term studies into childhood growth and adiposity are needed. Prior literature has focused on the impact of iodine status and supplementation on prenatal growth, with a systematic review showing low quality evidence for increased birth weight in infants of mothers with severe iodine deficiency who are receiving iodine supplementation [31]. Postnatal growth studies are limited in both observational and iodine supplementation intervention studies during lactation [31]. In a study performed in China by Yang, a maternal iodine deficiency based on urinary iodine levels $<50 \mu \mathrm{g} / \mathrm{L}$ during lactation was linked to a decreased infant WFA and LFA for infants $<6$ months of age, with positive effects of maternal iodine status on infant weight; however, BMIC was not measured to determine infant intake [1]. A review of survey data by Mason showed a positive relationship with iodine salt use and increased infant WFA and mid-upper-arm-circumference at 2 years. This study also assessed maternal BMI, showing that the positive relationship between iodinated salt use and WFA was increasingly greater with a lower maternal BMI [50]. However, there have been opposing trials and systematic reviews showing no impact of iodine intake on infant growth. In a multicenter randomized control trial of iodine supplementation during infancy in breastfeeding infants compared to placebo or formula fed infants, there was no difference found for 12 month WFA Z-score or WFL Z-score in infants receiving high or low iodine supplementation; however, infants receiving no intervention had higher LFA Z-scores and formula fed infants had higher WFA, WFL, and LFA Z-scores [51]. In a systematic review by Farebrother, on the impact of iodine supplementation on postnatal growth outcomes based on limited supplementation studies during pregnancy and one randomized clinical trial of preterm infant formula supplementation, there was no difference at 12 and 24 months in infant weight, length, or head circumference with maternal iodine supplementation [31].

Our prospective observational cohort study without specific iodine supplementation evaluated the association of BMIC with infant anthropometrics and found positive associations between growth over the first year and early BMIC near 2 weeks. The potential mechanisms for iodine related infant growth may be related to the role of iodine in the endocrine pathways of the thyroid hormone (TH) and growth hormone-insulin-like growth factor (GH-IGF) axis [31,32]. Zimmerman showed in a prospective intervention of iodine repletion in school age children that there was improved somatic growth in the WFA and head circumference-for-age Z-score associated with increased IGF-I and IGF binding protein-3 (IGFBP-3) concentrations in children [38]. Future work evaluating the link between BMIC, infant somatic growth, and growth related hormone levels (TSH, free thyroxine, IGF-1, and IGFBP-3) may provide further insight into mediators and identify areas for intervention for the promotion of iodine sufficient status during lactation.

This study provides insight into longitudinal BMIC in a United States Midwestern population, with corresponding assessments of infant growth through the first year of life in this pilot study. The strength of this study is that the population was selected for their initial plans to breastfeed 
without selection for predetermined maternal iodine status. This pilot study is limited by the small sample size used for its secondary analysis, which the initial study was not powered for; the mixed modeling involved a large number of parameters for the sample size, which could raise questions about the generalizability of these models among the larger population. However, the significant associations with BMIC and infant growth seen with these small numbers highlights the importance of consideration for BMIC analysis in more expansive mother-infant lactation focused cohorts to further understand this potential early programming influence. Additional limitations, including the assessment of infant growth outcomes, were measured by medical staff at pediatrician well-child visits, possibly resulting in inaccurate anthropometrics. Infant growth is complex, and this study is not able to address the numerous factors contributing to infant growth, which are not limited to genetic, environmental, later formula supplementation quantity, complimentary feedings, milk volume intake, and the complex composition of human milk, including macronutrients, micronutrients, bioactive factors, growth hormones, and immune factors [52,53]. Our cohort did not assess iodine status during pregnancy, which could impact fetal growth and development. Maternal iodine intake was also not quantified in this study. This will be important in future studies to provide a further explanation for the high BMIC among the population of lactating mothers. An assessment of infant iodine status will also be an important addition to future work to determine the relationship with BMIC based on detailed $24 \mathrm{~h}$ infant breast milk volume intake.

\section{Conclusions}

While the importance of maternal health during pregnancy and lactation in promoting infant growth and development cannot be understated, this study did not show the impact of maternal pre-pregnancy BMI on BMIC. We have identified a positive association between transitional BMIC and infant weight and weight-for-length growth over the first year of life based on a Z-score irrespective of maternal pre-pregnancy weight status. These findings highlight the critical need for knowledge of breast milk composition, particularly in micronutrients (such as iodine), which play a key role in infant growth. A further evaluation of the complex components in breast milk and the impact of these components during ongoing organ development in infancy is necessary to promote targeted interventions to support optimal childhood health.

Author Contributions: Conceptualization, L.E. and B.G.; formal analysis, L.E. and H.M.; methodology, L.E., E.H., J.A., and B.G.; supervision, B.G.; validation, J.A.; Writing-original draft, L.E., E.H., J.A., and B.G.; writing-review and editing, L.E., H.M., E.H., J.A., and B.G. All authors have read and agreed to the published version of the manuscript.

Funding: University of Michigan Charles Woodson Biostatistics Award.

Acknowledgments: Thanks to all of the participating families for allowing this research to be possible. We appreciate the assistance from Judith Ivacko for help in coordinating our research sites. This project was made possible by biostatistics support from the University of Michigan Center for Human Growth and Development with guidance by Niko Kaciroti.

Conflicts of Interest: The authors declare no conflict of interest. The funders had no role in the design of the study; in the collection, analyses, or interpretation of data; in the writing of the manuscript, or in the decision to publish the results.

\section{References}

1. Yang, J.; Zhu, L.; Li, X.; Zheng, H.; Wang, Z.; Hao, Z.; Liu, Y. Maternal iodine status during lactation and infant weight and length in Henan Province, China. BMC Pregnancy Childbirth 2017, 17. [CrossRef] [PubMed]

2. Azizi, F.; Smyth, P. Breastfeeding and maternal and infant iodine nutrition. Clin. Endocrinol. (Oxf) 2009, 70, 803-809. [CrossRef] [PubMed]

3. Dror, D.K.; Allen, L.H. Iodine in Human Milk: A Systematic Review. Adv. Nutr. (Bethesda, Md.) 2018, 9, 347S-357S. [CrossRef] 
4. Michaelsen, K.F.; Larsen, P.S.; Thomsen, B.L.; Samuelson, G. The Copenhagen Cohort Study on Infant Nutrition and Growth: Breast-milk intake, human milk macronutrient content, and influencing factors. Am. J. Clin. Nutr. 1994, 59, 600-611. [CrossRef] [PubMed]

5. Zimmermann, M.B. The role of iodine in human growth and development. Semin. Cell Dev. Biol. 2011, 22, 645-652. [CrossRef] [PubMed]

6. Etling, N.; Padovani, E.; Fouque, F.; Tato, L. First-month variations in total iodine content of human breast milks. Early Hum. Dev. 1986, 13, 81-85. [CrossRef]

7. Semba, R.D.; Delange, F. Iodine in human milk: Perspectives for infant health. Nutr. Rev. 2001, 59, $269-278$. [CrossRef]

8. van den Hove, M.F.; Beckers, C.; Devlieger, H.; de Zegher, F.; De Nayer, P. Hormone synthesis and storage in the thyroid of human preterm and term newborns: Effect of thyroxine treatment. Biochimie 1999, 81, 563-570. [CrossRef]

9. Zimmermann, M.B. Are weaning infants at risk of iodine deficiency even in countries with established iodized salt programs? Nestle Nutr. Inst. Workshop Ser. 2012, 70, 137-146. [CrossRef]

10. Mulrine, H.M.; Skeaff, S.A.; Ferguson, E.L.; Gray, A.R.; Valeix, P. Breast-milk iodine concentration declines over the first 6 mo postpartum in iodine-deficient women. Am. J. Clin. Nutr. 2010, 92, 849-856. [CrossRef]

11. WHO. Reaching Optimal Iodine Nutrition in Pregnant and Lactating Women and Young Children; World Health Organization: Geneva, Switzerland, 2007.

12. Institute of Medicine (US). Panel on Micronutrients. Dietary Reference Intakes for Vitamin A, Vitamin K, Arsenic, Boron, Chromium, Copper, Iodine, Iron, Manganese, Molybdenum, Nickel, Silicon, Vanadium, and Zinc. 2001. Available online: https:/www.ncbi.nlm.nih.gov/books/NBK222310/ (accessed on 10 November 2019).

13. ACOG Committee opinion No. 549: Obesity in pregnancy. Obstet. Gynecol. 2013, 121, 213-217.

14. Dold, S.; Zimmermann, M.B.; Baumgartner, J.; Davaz, T.; Galetti, V.; Braegger, C.; Andersson, M. A dose-response crossover iodine balance study to determine iodine requirements in early infancy. Am. J. Clin. Nutr. 2016, 104, 620-628. [CrossRef]

15. Chierici, R.; Saccomandi, D.; Vigi, V. Dietary supplements for the lactating mother: Influence on the trace element content of milk. Acta Paediatr. (Oslo, Norway: 1992) Suppl. 1999, 88, 7-13. [CrossRef]

16. Henjum, S.; Lilleengen, A.M.; Aakre, I.; Dudareva, A.; Gjengedal, E.L.F.; Meltzer, H.M.; Brantsaeter, A.L. Suboptimal Iodine Concentration in Breastmilk and Inadequate Iodine Intake among Lactating Women in Norway. Nutrients 2017, 9. [CrossRef]

17. Osei, J.; Andersson, M.; Reijden, O.V.; Dold, S.; Smuts, C.M.; Baumgartner, J. Breast-Milk Iodine Concentrations, Iodine Status, and Thyroid Function of Breastfed Infants Aged 2-4 Months and Their Mothers Residing in a South African Township. J. Clin. Res. Pediatr. Endocrinol. 2016, 8, 381-391. [CrossRef]

18. Sabatier, M.; Garcia-Rodenas, C.L.; Castro, C.A.; Kastenmayer, P.; Vigo, M.; Dubascoux, S.; Andrey, D.; Nicolas, M.; Payot, J.R.; Bordier, V.; et al. Longitudinal Changes of Mineral Concentrations in Preterm and Term Human Milk from Lactating Swiss Women. Nutrients 2019, 11. [CrossRef]

19. Chen, Y.; Gao, M.; Bai, Y.; Hao, Y.; Chen, W.; Cui, T.; Guo, W.; Pan, Z.; Lin, L.; Wang, C.; et al. Variation of iodine concentration in breast milk and urine in exclusively breastfeeding women and their infants during the first 24 wk after childbirth. Nutrition (Burbank, Los Angeles County, Calif.) 2019, 71, 110599. [CrossRef]

20. Tazebay, U.H.; Wapnir, I.L.; Levy, O.; Dohan, O.; Zuckier, L.S.; Zhao, Q.H.; Deng, H.F.; Amenta, P.S.; Fineberg, S.; Pestell, R.G.; et al. The mammary gland iodide transporter is expressed during lactation and in breast cancer. Nat. Med. 2000, 6, 871-878. [CrossRef]

21. Brown-Grant, K. The iodide concentrating mechanism of the mammary gland. J. Physiol 1957, 135, 644-654. [CrossRef]

22. Dold, S.; Zimmermann, M.B.; Aboussad, A.; Cherkaoui, M.; Jia, Q.; Jukic, T.; Kusic, Z.; Quirino, A.; Sang, Z.; San Luis, T.O.; et al. Breast Milk Iodine Concentration Is a More Accurate Biomarker of Iodine Status Than Urinary Iodine Concentration in Exclusively Breastfeeding Women. J. Nutr. 2017, 147, 528-537. [CrossRef]

23. Eskin, B.A.; Bartuska, D.G.; Dunn, M.R.; Jacob, G.; Dratman, M.B. Mammary gland dysplasia in iodine deficiency. Studies in rats. JAMA 1967, 200, 691-695. [CrossRef] [PubMed]

24. Nazeri, P.; Dalili, H.; Mehrabi, Y.; Hedayati, M.; Mirmiran, P.; Azizi, F. Breast Milk Iodine Concentration Rather than Maternal Urinary Iodine Is a Reliable Indicator for Monitoring Iodine Status of Breastfed Neonates. Biol. Trace Elem. Res. 2018, 185, 71-77. [CrossRef] [PubMed] 
25. Strum, J.M. Effect of iodide-deficiency on rat mammary gland. Virchows Arch. B Cell Pathol. Incl. Mol. Pathol. 1979, 30, 209-220. [CrossRef] [PubMed]

26. Robinson, S.M.; Crozier, S.R.; Miles, E.A.; Gale, C.R.; Calder, P.C.; Cooper, C.; Inskip, H.M.; Godfrey, K.M. Preconception Maternal Iodine Status Is Positively Associated with IQ but Not with Measures of Executive Function in Childhood. J. Nutr. 2018, 148, 959-966. [CrossRef]

27. Soriguer, F.; Valdes, S.; Morcillo, S.; Esteva, I.; Almaraz, M.C.; de Adana, M.S.; Tapia, M.J.; Dominguez, M.; Gutierrez-Repiso, C.; Rubio-Martin, E.; et al. Thyroid hormone levels predict the change in body weight: A prospective study. Eur. J. Clin. Invest. 2011, 41, 1202-1209. [CrossRef]

28. Torlinska, B.; Bath, S.C.; Janjua, A.; Boelaert, K.; Chan, S.Y. Iodine Status during Pregnancy in a Region of Mild-to-Moderate Iodine Deficiency is not Associated with Adverse Obstetric Outcomes; Results from the Avon Longitudinal Study of Parents and Children (ALSPAC). Nutrients 2018, 10. [CrossRef]

29. Lecube, A.; Zafon, C.; Gromaz, A.; Fort, J.M.; Caubet, E.; Baena, J.A.; Tortosa, F. Iodine deficiency is higher in morbid obesity in comparison with late after bariatric surgery and non-obese women. Obes. Surg. 2015, 25, 85-89. [CrossRef]

30. Alvarez-Pedrerol, M.; Guxens, M.; Mendez, M.; Canet, Y.; Martorell, R.; Espada, M.; Plana, E.; Rebagliato, M.; Sunyer, J. Iodine levels and thyroid hormones in healthy pregnant women and birth weight of their offspring. Eur. J. Endocrinol. 2009, 160, 423-429. [CrossRef]

31. Farebrother, J.; Naude, C.E.; Nicol, L.; Sang, Z.; Yang, Z.; Jooste, P.L.; Andersson, M.; Zimmermann, M.B. Effects of Iodized Salt and Iodine Supplements on Prenatal and Postnatal Growth: A Systematic Review. Adv. Nutr. (Bethesda, Md.) 2018, 9, 219-237. [CrossRef]

32. Gunnarsdottir, I.; Dahl, L. Iodine intake in human nutrition: A systematic literature review. Food Nutr. Res. 2012, 56. [CrossRef]

33. Rydbeck, F.; Rahman, A.; Grander, M.; Ekstrom, E.C.; Vahter, M.; Kippler, M. Maternal urinary iodine concentration up to $1.0 \mathrm{mg} / \mathrm{L}$ is positively associated with birth weight, length, and head circumference of male offspring. J. Nutr. 2014, 144, 1438-1444. [CrossRef] [PubMed]

34. Iodine supplementation for women during the preconception, pregnancy and postpartum period - Harding, KB - 2017. Cochrane Libr. 2019. [CrossRef]

35. Aboud, F.E.; Bougma, K.; Lemma, T.; Marquis, G.S. Evaluation of the effects of iodized salt on the mental development of preschool-aged children: A cluster randomized trial in northern Ethiopia. Matern. Child Nutr. 2017, 13. [CrossRef]

36. Gowachirapant, S.; Jaiswal, N.; Melse-Boonstra, A.; Galetti, V.; Stinca, S.; Mackenzie, I.; Thomas, S.; Thomas, T.; Winichagoon, P.; Srinivasan, K.; et al. Effect of iodine supplementation in pregnant women on child neurodevelopment: A randomised, double-blind, placebo-controlled trial. Lancet Diabetes Endocrinol. 2017, 5, 853-863. [CrossRef]

37. Zimmermann, M.B.; Connolly, K.; Bozo, M.; Bridson, J.; Rohner, F.; Grimci, L. Iodine supplementation improves cognition in iodine-deficient schoolchildren in Albania: A randomized, controlled, double-blind study. Am. J. Clin. Nutr. 2006, 83, 108-114. [CrossRef]

38. Zimmermann, M.B.; Jooste, P.L.; Mabapa, N.S.; Schoeman, S.; Biebinger, R.; Mushaphi, L.F.; Mbhenyane, X. Vitamin A supplementation in iodine-deficient African children decreases thyrotropin stimulation of the thyroid and reduces the goiter rate. Am. J. Clin. Nutr. 2007, 86, 1040-1044. [CrossRef]

39. Fields, D.A.; Demerath, E.W. Relationship of insulin, glucose, leptin, IL-6 and TNF-alpha in human breast milk with infant growth and body composition. Pediatr. Obes. 2012, 7, 304-312. [CrossRef]

40. WHO Child Growth Standards based on length/height, weight and age. Acta Paediatr. (Oslo, Norway: 1992) Suppl. 2006, 450, 76-85.

41. Dumrongwongsiri, O.; Chatvutinun, S.; Phoonlabdacha, P.; Sangcakul, A.; Chailurkit, L.O.; Siripinyanond, A.; Suthutvoravut, U.; Chongviriyaphan, N. High Urinary Iodine Concentration Among Breastfed Infants and the Factors Associated with Iodine Content in Breast Milk. Biol. Trace Elem. Res. 2018, 186, 106-113. [CrossRef]

42. Stoutjesdijk, E.; Schaafsma, A.; Dijck-Brouwer, D.A.J.; Muskiet, F.A.J. Iodine status during pregnancy and lactation: A pilot study in the Netherlands. Neth J. Med. 2018, 76, 210-217.

43. Pearce, E.N.; Leung, A.M.; Blount, B.C.; Bazrafshan, H.R.; He, X.; Pino, S.; Valentin-Blasini, L.; Braverman, L.E. Breast milk iodine and perchlorate concentrations in lactating Boston-area women. J. Clin. Endocrinol. Metab. 2007, 92, 1673-1677. [CrossRef] 
44. Hollowell, J.G.; Staehling, N.W.; Hannon, W.H.; Flanders, D.W.; Gunter, E.W.; Maberly, G.F.; Braverman, L.E.; Pino, S.; Miller, D.T.; Garbe, P.L.; et al. Iodine nutrition in the United States. Trends and public health implications: Iodine excretion data from National Health and Nutrition Examination Surveys I and III (1971-1974 and 1988-1994). J. Clin. Endocrinol. Metab. 1998, 83, 3401-3408. [CrossRef]

45. Caldwell, K.L.; Makhmudov, A.; Ely, E.; Jones, R.L.; Wang, R.Y. Iodine status of the U.S. population, National Health and Nutrition Examination Survey, 2005-2006 and 2007-2008. Thyroid 2011, 21, 419-427. [CrossRef]

46. Nazeri, P.; Kabir, A.; Dalili, H.; Mirmiran, P.; Azizi, F. Breast-Milk Iodine Concentrations and Iodine Levels of Infants According to the Iodine Status of the Country of Residence: A Systematic Review and Meta-Analysis. Thyroid 2018, 28, 124-138. [CrossRef]

47. WHO. Assessment of Iodine Deficiency Disorders and Monitoring Their Elimination. Available online: https://apps.who.int/iris/bitstream/handle/10665/43781/9789241595827_eng.pdf (accessed on 24 October 2019).

48. Liu, L.; Liu, J.; Wang, D.; Shen, H.; Jia, Q. Effect of Urinary Iodine Concentration in Pregnant and Lactating Women, and in Their Infants Residing in Areas with Excessive Iodine in Drinking Water in Shanxi Province, China. Biol. Trace Elem. Res. 2019. [CrossRef]

49. Iodine. In Drugs and Lactation Database (LactMed) [Internet], [Updated 2019 Feb 28] ed.; National Library of Medicine (US): Bethesda, MD, USA, 2006.

50. Mason, J.B.; Deitchler, M.; Gilman, A.; Gillenwater, K.; Shuaib, M.; Hotchkiss, D.; Mason, K.; Mock, N.; Sethuraman, K. Iodine fortification is related to increased weight-for-age and birthweight in children in Asia. Food Nutr. Bull. 2002, 23, 292-308. [CrossRef]

51. Nazeri, P.; Tahmasebinejad, Z.; Mehrabi, Y.; Hedayati, M.; Mirmiran, P.; Azizi, F. Lactating Mothers and Infants Residing in an Area with an Effective Salt Iodization Program Have No Need for Iodine Supplements: Results from a Double-Blind, Placebo-Controlled, Randomized Controlled Trial. Thyroid 2018, 28, 1547-1558. [CrossRef]

52. Ballard, O.; Morrow, A.L. Human milk composition: Nutrients and bioactive factors. Pediatr. Clin. N. Am. 2013, 60, 49-74. [CrossRef]

53. Eriksen, K.G.; Christensen, S.H.; Lind, M.V.; Michaelsen, K.F. Human milk composition and infant growth. Curr. Opin. Clin. Nutr. Metab. Care 2018, 21, 200-206. [CrossRef]

(C) 2020 by the authors. Licensee MDPI, Basel, Switzerland. This article is an open access article distributed under the terms and conditions of the Creative Commons Attribution (CC BY) license (http://creativecommons.org/licenses/by/4.0/). 



\title{
The Joint Role of Thyroid Function and Iodine Status on Risk of Preterm Birth and Small for Gestational Age: A Population-Based Nested Case-Control Study of Finnish Women
}

\author{
Alexandra C. Purdue-Smithe ${ }^{1}$, Tuija Männistö ${ }^{2,3,4,5}$, Griffith A. Bell ${ }^{6,7}$, Sunni L. Mumford ${ }^{1}$, \\ Aiyi Liu ${ }^{8}$, Kurunthachalam Kannan ${ }^{9}$, Un-Jung Kim ${ }^{9}$, Eila Suvanto ${ }^{2}$, Heljä-Marja Surcel ${ }^{10,11}$, \\ Mika Gissler ${ }^{5,12}$ and James L. Mills ${ }^{1, *}$ \\ 1 Epidemiology Branch, Division of Intramural Population Health Research, Eunice Kennedy Shriver National \\ Institute of Child Health and Human Development, National Institutes of Health, Bethesda, MD 20892, USA; \\ alexandra.purdue-smithe@nih.gov (A.C.P.-S.); mumfords@mail.nih.gov (S.L.M.) \\ 2 Northern Finland Laboratory Centre NordLab, 90120 Oulu, Finlan; Tuija.Mannisto@Nordlab.fi (T.M.); \\ Eila.Suvanto@ppshp.fi (E.S.) \\ 3 Department of Clinical Chemistry, University of Oulu, 90120 Oulu, Finland \\ 4 Medical Research Center Oulu, Oulu University Hospital and University of Oulu, 90120 Oulu, Finland \\ 5 Finnish Institute for Health and Welfare, 00290 Helsinki, Finland; mika.gissler@thl.fi \\ 6 Ariadne Labs, Brigham and Women's Hospital, Harvard T.H. Chan School of Public Health, \\ Boston, MA 02115, USA; griffith.bell@gmail.com \\ 7 Harvard T.H. Chan School of Public Health, Department of Health Policy and Management, \\ Boston, MA 02115, USA \\ 8 Biostatistics and Bioinformatics Branch, Division of Intramural Population Health Research, Eunice Kennedy \\ Shriver National Institute of Child Health and Human Development, National Institutes of Health, \\ Bethesda, MD 20892, USA; liua@mail.nih.gov \\ 9 Wadsworth Center, New York State Department of Health, Albany, NY 12201, USA; \\ kurunthachalam.kannan@health.ny.gov (K.K.); changetm2011@gmail.com (U.-J.K.) \\ 10 Biobank Borealis of Northern Finland, Oulu University Hospital, 90120 Oulu, Finland; \\ helja-marja.surcel@thl.fi \\ 11 Faculty of Medicine, University of Oulu, 90120 Oulu, Finland \\ 12 Karolinska Institute, 17177 Stockholm, Sweden \\ * Correspondence: millsj@exchange.nih.gov; Tel.: +1-301-496-5394
}

Received: 19 September 2019; Accepted: 22 October 2019; Published: 25 October 2019

\begin{abstract}
Normal maternal thyroid function during pregnancy is essential for fetal development and depends upon an adequate supply of iodine. Little is known about how iodine status is associated with preterm birth and small for gestational age (SGA) in mildly iodine insufficient populations. Our objective was to evaluate associations of early pregnancy serum iodine, thyroglobulin (Tg), and thyroid-stimulating hormone (TSH) with odds of preterm birth and SGA in a prospective, population-based, nested case-control study from all births in Finland (2012-2013). Cases of preterm birth $(n=208)$ and SGA $(n=209)$ were randomly chosen from among all singleton births. Controls were randomly chosen from among singleton births that were not preterm $(n=242)$ or SGA $(n=241)$ infants during the same time period. Women provided blood samples at 10-14 weeks' gestation for serum iodide, Tg and TSH measurement. We used logistic regression to estimate odds ratios (ORs) and $95 \%$ confidence intervals (CIs) for preterm birth and SGA. Each log-unit increase in serum iodide was associated with higher odds of preterm birth (adjusted OR $=1.19,95 \% \mathrm{CI}=1.02-1.40$ ), but was not associated with SGA (adjusted OR $=1.01,95 \% \mathrm{CI}=0.86-1.18$ ). $\mathrm{Tg}$ was not associated with preterm birth (OR per 1 log-unit increase $=0.87,95 \% \mathrm{CI}=0.73-1.05$ ), but was inversely associated with SGA (OR per log-unit increase $=0.78,95 \% \mathrm{CI}=0.65-0.94$ ). Neither high nor low TSH (versus normal) were associated with either outcome. These findings suggest that among Finnish women, iodine status is not related to SGA, but higher serum iodide may be positively associated with preterm birth.
\end{abstract}


Keywords: iodine; thyroid hormones; thyroglobulin; thyroid stimulating hormone; pregnancy; preterm birth; small for gestational age

\section{Introduction}

Normal maternal thyroid function during pregnancy is essential for fetal development [1]. Hypothyroidism is associated with adverse pregnancy outcomes including pregnancy loss, preeclampsia, and preterm birth, as well as cognitive deficiencies and cretinism in the offspring [2]. Iodine, found in fish, eggs, dairy products, and iodized salt [3], plays an essential role in the production of thyroid hormones. Thyroid hormone production is regulated by the hypothalamic-pituitary-thyroid axis via thyroid-stimulating hormone (TSH) and requires the iodination of thyroglobulin (Tg) in the follicular lumen of thyrocytes [1]. Pregnant women are especially vulnerable to iodine deficiency due to fetal dependency on the maternal iodine supply and to a lesser extent, hemodilution, increased renal clearance of inorganic iodide, and estrogen-stimulated production of $\mathrm{Tg}$, which collectively necessitate higher iodine intake [4].

Despite increased risk of iodine deficiency during pregnancy, even in developed countries $[5,6]$, and ample data indicating that thyroid dysfunction is associated with adverse neonatal and obstetric outcomes, relatively few studies have evaluated how iodine status during pregnancy is related to preterm birth and infants being born small for gestational age (SGA), and the results are conflicting [7-13]. Importantly, previous studies were conducted in populations with high prevalence of other nutritional deficiencies and concurrent illnesses or included mostly iodine sufficient pregnant women $[9,12]$. Several of these studies also lacked information on thyroid hormones and therefore were unable to evaluate whether associations of iodine with preterm birth and SGA may be different among potentially hypo-or hyperthyroid women [9-11,13]. Additionally, prior studies used a single spot urinary iodine measurement to classify iodine status, which has been shown to have high intraindividual variability reflective of recent dietary intake, seasonal variation, urine dilution, and circadian rhythmicity [13-16]. Although urine iodine concentrations are useful for assessing the iodine status of whole populations, serum iodide may be less sensitive to recent dietary intake and may, therefore, better reflect individual long-term and bioavailable iodine status [17-19], reducing potential for misclassification.

The aim of the present study was to evaluate associations of serum iodide concentrations and thyroid hormones indicative of iodine status (i.e., $\mathrm{Tg}$ and TSH) with risk of preterm birth and SGA among pregnant Finnish women, a population considered to be mildly iodine deficient, but with relatively low prevalence of other nutritional deficiencies [3].

\section{Materials and Methods}

\subsection{Study Population}

We conducted a population-based, nested case-control study within the Finnish Maternity Cohort (FMC), using the Finnish Medical Birth Register (MBR) to ascertain pregnancy and perinatal outcome data. Beginning in 1983, the FMC has collected more than 2 million serum samples from more than 950,000 pregnant women living in Finland, which reflects $~ 98 \%$ coverage of the pregnant population. Blood samples were collected to screen for hepatitis B, human immunodeficiency virus (HIV), syphilis, and rubella antibodies. The samples were drawn in general between 10 and 14 weeks gestation at local maternity care units and sent to the prenatal serology laboratory of the Finnish Institute for Health and Welfare in Oulu. There, sera were separated by centrifugation, screening analyses were performed and the remaining serum $(1-3 \mathrm{~mL})$ was stored at $-25^{\circ} \mathrm{C}$.

Biochemical data were linked to clinical data from the MBR via unique personal identification numbers given to all Finnish citizens and residents at birth or at time of permanent residence. The MBR includes data on all live births and stillbirths in Finland with a birth weight $\geq 500 \mathrm{~g}$ or a gestational age 
at birth $\geq 22$ gestational weeks. Maternal data collected by the MBR includes age, height and weight, socioeconomic status based on self-reported occupation, marital status, pregnancy history, smoking status, and other factors. Data collected on infants included sex, gestational age at birth, and birth height and weight.

Women gave written informed consent for their samples to be used for research purposes. This study was approved by the steering committee of the FMC, the ethical review boards of the Northern Ostrobothnia Hospital District and the Finnish Institute for Health and Welfare, Oulu, Finland, and the Office of Human Subjects Research, National Institutes of Health, Bethesda, MD, USA (\#13459).

\subsection{Case and Control Ascertainment}

We randomly selected 200 cases of preterm birth (defined as a live birth $<37$ weeks gestation) and 250 potential controls from among all singleton births in Finland between 2012 and 2013 with available serum samples in the FMC. Because the 250 potential controls were randomly selected without regard to case/control status, 8 control pregnancies were delivered preterm and were thus reclassified as cases. After reclassification, the final analytic sample included 208 cases and 242 controls. Similarly, we randomly selected 200 cases of SGA (defined as birthweight $<10^{\text {th }}$ percentile for gestational age), using the same control group. Nine control pregnancies were SGA and reclassified as such, resulting in 209 SGA cases and 241 controls.

\subsection{Measurement of Iodide, Thyroglobulin, and Thyroid-Stimulating Hormone}

Details regarding the iodide measurement in this study population have been published previously and are provided in Appendix A [20]. Briefly, serum samples were thawed at room temperature, vortexed, and transferred to polypropylene tubes. Samples were pretreated, centrifuged, and analyzed by high-performance liquid chromatography (Alliance 2695 HPLC) coupled with electrospray triple-quadrupole mass spectrometry (Micromass, ESI-MS/MS; Waters Corporation, Milford, MA, USA). Identification and quantification of ${ }^{18} \mathrm{O}$-labeled-perchlorate, ${ }^{13} \mathrm{C}$-labeled-thiocyante, and iodide was performed using electrospray negative ionization (ESI-) and multiple reaction monitoring. Serum $\mathrm{Tg}$ and TSH concentrations were measured using a commercial immunoassay (Siemens AG, Munich, Germany), as they have been shown to be reliable markers of thyroid function in pregnant women [21]. The intra- and inter-assay coefficients of variation for $\mathrm{Tg}$ were $<8 \%$ and $<12 \%$, respectively, and for TSH $<5 \%$ and $<5 \%$, respectively.

\subsection{Statistical Analysis}

Characteristics of the cases and controls were compared using t-tests for continuous variables and $\chi^{2}$ tests for categorical variables. Equivalent non-parametric tests were used where appropriate. For analyses evaluating continuous exposures, serum iodide, $\mathrm{Tg}$, and TSH values were normalized by log-transformation. Participants were divided into quartiles of iodide and $\mathrm{Tg}$ based on the distribution of these biomarkers in the control group. For TSH, we categorized participants as having high TSH ( $>3.1$ and $>3.5 \mathrm{mIU} / \mathrm{L}$ in the 1st and 2nd trimesters, respectively), normal TSH (0.1-3.1 and 0.2-3.5 in the 1st and 2nd trimesters, respectively), or low TSH $(<0.1$ and $<0.2 \mathrm{mIU} / \mathrm{L}$ in the 1 st and 2nd trimesters, respectively), according to previously defined reference ranges for this population [22].

Using logistic regression, we estimated unadjusted odds ratios (ORs) and $95 \%$ confidence intervals (CIs) for preterm birth and SGA according to each biomarker. We then estimated adjusted ORs and 95\% CIs adjusting for maternal age, maternal body mass index (BMI), socioeconomic status, smoking status, parity, and marital status. Covariates were selected for inclusion in multivariable models based on directed acyclic graphs [23]. Individuals with missing data on BMI ( $\mathrm{N}=7$ for preterm birth and $\mathrm{N}=3$ for SGA) were dropped from multivariable analyses.

We also examined possible non-linear associations of iodide with preterm birth and SGA non-parametrically utilizing restricted cubic spline models. In these models, we specified 3 knots and evaluated the individual spline term contributions to the model fit and overall test for nonlinearity. 
In sensitivity analyses, we excluded women with conditions associated with medically-indicated preterm birth (i.e., chronic hypertension, gestational hypertension, gestational diabetes, pre-existing diabetes, thyroid disease) to determine whether these conditions may have influenced the results. All analyses were run using SAS, version 9.4 (SAS Institute Inc., Cary, NC, U.S.).

\section{Results}

\subsection{Descriptive Characteristics}

Characteristics of preterm birth and SGA cases and controls at blood draw are presented in Table 1. For preterm birth, cases and controls were similar with regard to maternal age, BMI, smoking status, marital status, parity, gravidity, and socioeconomic status (SES). Preterm birth cases and controls were also similar in terms of gestational age at blood draw (10.9 weeks vs. 10.8 weeks). As expected, cases were more likely to have chronic hypertension ( $10 \%$ vs. $3 \%)$, preeclampsia ( $30 \%$ vs. $3 \%)$, Type 1 or 2 diabetes $(13 \%$ vs. $1 \%)$, and gestational diabetes ( $38 \%$ vs. $22 \%)$, compared to controls. For SGA, cases had lower BMI ( 24 vs. $\left.25 \mathrm{~kg} / \mathrm{m}^{2}\right)$, gravidity (1.3 vs. 1.4 ) and parity ( 0.8 vs. 1.1$)$ than controls, and were also more likely to be smokers ( $52 \%$ vs. $37 \%$ ). SGA cases were also more likely than controls to have preeclampsia during the pregnancy ( $16 \%$ vs. $4 \%)$. The Spearman rank correlation coefficients for each biomarker were as follows: iodide and $\mathrm{Tg}, \mathrm{r}_{\mathrm{S}}=0.02(P=0.54)$; iodide and $\mathrm{TSH}, \mathrm{r}_{\mathrm{S}}=0.001(P=0.97)$; and $\mathrm{Tg}$ and TSH, $\mathrm{r}_{\mathrm{s}}=-0.13(P<0.001)$.

Table 1. Maternal characteristics at blood draw according to preterm birth and small for gestational age cases and controls in the Finnish Maternity Cohort and Medical Birth Register, 2012-2013.

\begin{tabular}{|c|c|c|c|c|c|c|}
\hline \multirow[b]{2}{*}{ Characteristic $^{1}$} & \multicolumn{3}{|c|}{ Preterm Birth } & \multicolumn{3}{|c|}{ Small for Gestational Age } \\
\hline & $\begin{array}{l}\text { Controls } \\
(n=242)\end{array}$ & $\begin{array}{c}\text { Cases } \\
(n=208)\end{array}$ & $P$-value ${ }^{2}$ & $\begin{array}{l}\text { Controls } \\
(n=241)\end{array}$ & $\begin{array}{c}\text { Cases } \\
(n=209)\end{array}$ & $P$-value ${ }^{2}$ \\
\hline Maternal age (years) & $29.5(5.3)$ & $29.8(5.5)$ & 0.49 & $29.5(5.3)$ & $29.7(5.6)$ & 0.70 \\
\hline Body mass index $\left(\mathrm{kg} / \mathrm{m}^{2}\right)$ & $24.6(4.4)$ & $25.3(6.0)$ & 0.75 & $24.8(4.9)$ & $23.6(5.1)$ & $<0.001$ \\
\hline Gravidity & $1.4(1.8)$ & $1.4(1.8)$ & 0.80 & $1.4(1.8)$ & $1.3(2.2)$ & 0.03 \\
\hline Parity & $1.1(1.6)$ & $0.9(1.4)$ & 0.19 & $1.1(1.6)$ & $0.8(1.5)$ & 0.01 \\
\hline Gestational age at screening (weeks) & $10.9(2.9)$ & $10.8(3.0)$ & 0.89 & $10.9(2.9)$ & $11.4(4.0)$ & 0.12 \\
\hline Gestational age at birth (weeks) & $39.7(1.1)$ & $34.1(2.7)$ & $<0.01$ & $39.6(1.5)$ & $38.4(2.9)$ & $<0.001$ \\
\hline Iodide $(\mathrm{ng} / \mathrm{mL})$ & $28.1(28.5)$ & $32.8(31.1)$ & 0.02 & $28.2(28.3)$ & $27.7(28.2)$ & 0.82 \\
\hline Thyroglobulin $(\mathrm{ng} / \mathrm{mL})$ & $29.6(29.5)$ & $31.5(63.3)$ & 0.36 & $29.9(29.6)$ & $27.9(32.9)$ & 0.05 \\
\hline Thyroid stimulating hormone (mIU/L) & $1.2(0.8)$ & $1.3(2.4)$ & 0.25 & $1.2(0.85)$ & $1.4(2.15)$ & 0.68 \\
\hline Nulliparous & $105(43.4)$ & $108(51.9)$ & 0.07 & $103(42.7)$ & $120(57.4)$ & $<0.01$ \\
\hline Smoking status & & & 0.33 & & & 0.03 \\
\hline Nonsmoker & $200(82.6)$ & $164(78.8)$ & & $199(82.6)$ & $155(74.2)$ & \\
\hline Smoker & $37(15.3)$ & $35(16.8)$ & & $37(15.4)$ & $52(24.9)$ & \\
\hline Unknown & $5(2.1)$ & $9(4.3)$ & & $5(2.1)$ & $2(1.0)$ & \\
\hline Socioeconomic status & & & 0.32 & & & 0.11 \\
\hline Blue-collar & $30(12.4)$ & $31(14.9)$ & & $31(12.9)$ & $30(14.4)$ & \\
\hline Lower white-collar & $64(26.4)$ & $60(28.8)$ & & $62(25.7)$ & $50(23.9)$ & \\
\hline Upper white-collar & $28(11.6)$ & $29(13.9)$ & & $28(11.6)$ & $34(16.3)$ & \\
\hline Entrepreneur & $10(4.1)$ & $4(1.9)$ & & $10(4.2)$ & $3(1.4)$ & \\
\hline Student & $25(10.3)$ & $12(5.8)$ & & $24(10.0)$ & $10(4.8)$ & \\
\hline Other/unknown & $85(35.1)$ & $72(34.6)$ & & $86(35.7)$ & $82(39.2)$ & \\
\hline Diagnosed thyroid disease & $0(0)$ & $7(3.4)$ & $<0.01$ & $0(0)$ & $1(0.5)$ & 0.28 \\
\hline Chronic hypertension & $3(1.2)$ & $10(4.8)$ & 0.024 & $3(1.2)$ & $4(1.9)$ & 0.71 \\
\hline Preeclampsia & $3(1.2)$ & $30(14.4)$ & $<0.01$ & $4(1.7)$ & $16(7.7)$ & $<0.01$ \\
\hline Gestational hypertension & $6(2.5)$ & $11(5.3)$ & 0.12 & $6(2.5)$ & $11(5.3)$ & 0.14 \\
\hline Type I or type II diabetes & $1(0.4)$ & $13(6.3)$ & $<0.01$ & $2(0.8)$ & $0(0)$ & 0.50 \\
\hline Gestational diabetes & $22(9.1)$ & $38(18.3)$ & 0.02 & $23(9.5)$ & $23(11.0)$ & 0.64 \\
\hline Marital status & & & 0.41 & & & 0.15 \\
\hline Married or cohabiting & $215(88.8)$ & $176(84.6)$ & & $211(87.6)$ & $177(84.7)$ & \\
\hline Single or widowed & $26(10.7)$ & $31(14.9)$ & & $30(12.5)$ & $29(13.9)$ & \\
\hline Unknown & $1(0.4)$ & $1(0.5)$ & & $0(0)$ & $3(1.4)$ & \\
\hline
\end{tabular}

${ }^{1}$ Values are means (SD) for continuous data and $\mathrm{N}(\%)$ for categorical data. ${ }^{2} P$-values were estimated using t-tests for continuous data and $\chi^{2}$ tests for categorical data. Equivalent non-parametric tests were used where appropriate. 


\subsection{Serum Iodine, Thyroid Hormones, and Preterm Birth}

In unadjusted models, each 1 log-unit increase in serum iodide was positively associated with preterm birth (unadjusted $\mathrm{OR}=1.22,95 \% \mathrm{CI}=1.04-1.42$ ) (Table 2). After adjusting for age, BMI, smoking, and other factors, the positive association persisted (adjusted OR $=1.19,95 \% \mathrm{CI}=1.02-1.40$ ), and was robust to the exclusion of women with conditions related to preterm birth $(\mathrm{OR}=1.29$, $95 \% \mathrm{CI}=1.06-1.58)$. In unadjusted models evaluating quartiles of iodide, the OR for preterm birth comparing women with high (quartile 4$)$ versus moderate (quartiles $2+3)$ serum iodide was $1.32(95 \%$ $\mathrm{CI}=0.86-2.04$ ). The OR for preterm birth comparing low (quartile 1) versus moderate (quartiles $2+3$ ) serum iodide was 0.75 (95\% CI = 0.46-1.22). In adjusted models, the ORs for preterm birth comparing women with high (quartile 4) and low (quartile 1) versus those with moderate (quartiles 2 and 3) serum iodide were $1.22(95 \% \mathrm{CI}=0.78-1.93)$ and $0.76(95 \% \mathrm{CI}=0.46-1.26)$, respectively. In spline analyses, no signifcant departure of linearity was observed for serum iodide and preterm birth ( $\mathrm{P}$ for non-linearity $>0.05$ ). No associations were observed for $\mathrm{Tg}$ and TSH and preterm birth (adjusted $\mathrm{OR}=0.87,95 \% \mathrm{CI}=0.73-1.05$ and $\mathrm{OR}=0.97,95 \% \mathrm{CI}=0.80-1.19$, respectively).

Table 2. Unadjusted and adjusted odds ratios (ORs) and 95\% confidence intervals (CIs) for preterm birth according to maternal serum iodide, thyroglobulin, and thyroid stimulating hormone in the Finnish Maternity Cohort and Maternal Birth Register, 2012-2013 1,2.

\begin{tabular}{ccccc}
\hline Biomarker & Cases: Controls & Median & $\begin{array}{c}\text { Unadjusted } \\
\text { OR (95\% CI) }\end{array}$ & $\begin{array}{c}\text { Adjusted }^{3} \\
\text { OR (95\% CI) }\end{array}$ \\
\hline Iodide (ng/mL) & & & & \\
Quartile (Q)1 & $38: 60$ & 3.4 & $0.75(0.46-1.22)$ & $0.76(0.46-1.26)$ \\
Q2 + Q3 & $102: 121$ & 20.3 & 1 (referent) & 1 (referent) \\
Q4 & $68: 61$ & 59.3 & $1.32(0.86-2.04)$ & $1.22(0.78-1.93)$ \\
Log(iodide) & $208: 242$ & & $1.22(1.04-1.42)$ & $1.19(1.02-1.40)$ \\
Log(iodide) & $132: 210$ & & $1.29(1.07-1.57)$ & $1.29(1.06-1.58)$ \\
\hline Thyroglobulin (ng/mL) & & & & \\
Q1 & $59: 59$ & 7.7 & $1($ referent) & 1 (referent) \\
Q2 & $55: 60$ & 17.4 & $0.91(0.55-1.53)$ & $0.83(0.49-1.41)$ \\
Q3 & $37: 60$ & 26.7 & $0.62(0.36-1.07)$ & $0.59(0.34-1.04)$ \\
Q4 & $57: 60$ & 52.1 & $0.95(0.57-1.58)$ & $0.88(0.51-1.50)$ \\
Log(thyroglobulin) & $208: 239$ & & $0.91(0.76-1.08)$ & $0.87(0.73-1.05)$ \\
\hline TSH (mIU/L) & & & \\
Low & $5: 11$ & 0.04 & $0.51(0.18-1.50)$ & $0.57(0.19-1.70)$ \\
Normal & $196: 217$ & 1.04 & $1($ referent) & 1 (referent) \\
High & $7: 11$ & 3.5 & $1.14(0.32-3.95)$ & $1.17(0.31-4.38)$ \\
Log(TSH) & $208: 239$ & & $0.99(0.82-1.20)$ & $0.97(0.80-1.19)$ \\
\hline
\end{tabular}

${ }^{1}$ ORs and $95 \%$ CIs were estimated using logistic regression. ${ }^{2}$ Data are missing for 3 controls. ${ }^{3}$ Multivariable models are adjusted for maternal age, maternal body mass index, socioeconomic status, smoking status, parity, and marital status. ${ }^{4}$ Analyses excluding women with conditions indicated for preterm birth (i.e., preeclampsia, chronic hypertension, gestational hypertension, gestational diabetes, pre-existing diabetes, thyroid disease)

\subsection{Serum Iodide, Thyroid Hormones, and Small for Gestational Age}

Serum iodide was not associated with odds of having an SGA infant in unadjusted or adjusted models. (Table 3) For example, the unadjusted OR for each log-unit increase in serum iodide was 0.99 (95\% CI = 0.85-1.14). Similarly, in unadjusted models, the OR for SGA comparing high (quartile 4) and low (quartile 1) versus moderate (quartiles $2+3)$ serum iodide was $1.15(95 \% \mathrm{CI}=0.74-1.80)$ and $1.05(95 \%$ CI $=0.85-1.14)$, respectively. Adjustment for age, BMI, and other factors resulted in similar findings (OR per $1 \mathrm{log}$-unit increase in serum iodide $=1.01,95 \% \mathrm{CI}=0.86-1.18$ ). In unadjusted models, log-transformed $\mathrm{Tg}$ was inversely associated with SGA (unadjusted OR $=0.84,95 \% \mathrm{CI}=0.71-0.99$ ). This inverse association was somewhat stronger after adjustment in multivariable analyses (adjusted $\mathrm{OR}=0.78,95 \% \mathrm{CI}=0.65-0.94$ ). Likewise, in adjusted models, the OR comparing high (quartile 4 ) versus 
low (quartile 1) Tg was $0.45(95 \% \mathrm{CI}=0.25-0.79)$. TSH was not associated with SGA (high versus normal $\mathrm{OR}=0.56,95 \% \mathrm{CI}=0.14-2.22$; low versus normal $\mathrm{OR}=1.11,95 \% \mathrm{CI}=0.44-2.79)$. Spline analyses revealed no significant departures of linearity for serum iodide and SGA (P for non-linearity $>0.05$ ).

Table 3. Unadjusted and adjusted odds ratios (ORs) and 95\% confidence intervals (CIs) for small for gestational age according to maternal serum iodide, thyroglobulin, and thyroid stimulating hormone in the Finnish Maternity Cohort and Maternal Birth Register, 2012-2013 1,2.

\begin{tabular}{ccccc}
\hline Biomarker & Cases: Controls & Median & $\begin{array}{c}\text { Unadjusted } \\
\text { OR (95\% CI) }\end{array}$ & $\begin{array}{c}\text { Adjusted }^{3} \\
\text { OR (95\% CI) }\end{array}$ \\
\hline Iodide (ng/mL) & & & & \\
Quartile (Q)1 & $52: 60$ & 3.3 & $1.05(0.85-1.14)$ & $1.01(0.68-1.79)$ \\
Q2 + Q3 & $99: 120$ & 19.3 & 1 (referent) & 1 (referent) \\
Q4 & $58: 61$ & 59.3 & $1.15(0.74-1.80)$ & $1.28(0.79-2.08)$ \\
Log(iodide) & $209: 241$ & & $0.99(0.85-1.14)$ & $1.01(0.86-1.18)$ \\
Log(iodide) & $162: 206$ & & $0.91(0.77-1.07)$ & $0.91(0.76-1.09)$ \\
\hline Thyroglobulin (ng/mL) & & & & \\
Q1 & $75: 58$ & 8.3 & 1 (referent) & 1 (referent) \\
Q2 & $50: 61$ & 17.7 & $0.63(0.38-1.05)$ & $0.52(0.30-0.89)$ \\
Q3 & $36: 59$ & 28.2 & $0.47(0.27-0.81)$ & $0.41(0.23-0.72)$ \\
Q4 & $45: 60$ & 52.3 & $0.58(0.35-0.97)$ & $0.45(0.25-0.79)$ \\
Log(thyroglobulin) & $206: 238$ & & $0.84(0.71-0.99)$ & $0.78(0.65-0.94)$ \\
\hline TSH (mIU/L) & & & & $1.11(0.44-2.79)$ \\
Low & $10: 11$ & 0.04 & $1.04(0.43-2.50)$ & 1 (referent) \\
Normal & $193: 221$ & 1.4 & 1 (referent) & $0.56(0.14-2.22)$ \\
High & $5: 6$ & 4.1 & $0.95(0.29-3.18)$ & $1.04(0.86-1.26)$ \\
\hline Log(TSH) & $208: 238$ & & $1.05(0.88-1.26)$ & \\
\hline
\end{tabular}

${ }^{1}$ ORs and 95\% CIs were estimated using logistic regression. ${ }^{2}$ Data are missing for 3 controls. ${ }^{3}$ Multivariable models are adjusted for maternal age, maternal body mass index, socioeconomic status, smoking status, parity, and marital status. ${ }^{4}$ Analyses excluding women with conditions indicated for preterm birth (i.e., preeclampsia, chronic hypertension, gestational hypertension, gestational diabetes, pre-existing diabetes, thyroid disease)

\section{Discussion}

In this population-based, nested case-control study, we found that neither low- nor high-serum iodide was associated with SGA, and some suggestion that higher serum iodide may be associated with increased risk of preterm birth. Levels of TSH, which were largely within the normal range, indicated a mostly euthyroid population. $\mathrm{Tg}$, which is generally higher during periods of both iodine insufficiency and extreme excess [24-26], was inversely associated with risk of having an SGA infant, but was not associated with preterm birth. Levels of TSH were not associated with either outcome, although very few women had values considered to be above or below the normal range in this population. Collectively, our findings suggest that iodine insufficiency, within the range observed among pregnant Finnish women, likely does not play a role in preterm birth or SGA, but that higher serum iodide may be associated with increased risk of preterm birth.

To date, only a handful of studies have evaluated associations of iodine status with preterm birth and SGA, and data are mixed [7-13]. A recent prospective study of pregnant women in the UK reported U-shaped relationships between urinary iodine concentrations and risks of preterm birth and SGA, with elevated risks observed among women with urinary iodine concentration (UIC) $<50$ and $\geq 250 \mu \mathrm{g} / \mathrm{L}$ versus those with UIC in the 150-249 $\mu \mathrm{g} / \mathrm{L}$ group; however, confidence intervals were wide and included the null value [10]. Another prospective study of pregnant women in the UK with low obstetrical risk reported a borderline significant increased risk of having an SGA infant with increasing UIC, but no association with preterm birth [13]. Similarly, in a largely iodine deficient population of pregnant women in Thailand, insufficient (UIC $<150 \mu \mathrm{g} / \mathrm{L}$ ) versus sufficient/excess (UIC $\geq 150 \mu \mathrm{g} / \mathrm{L}$ ) iodine status was associated with increased risks of both preterm birth and low birth weight (LBW) infants [9]. Similar associations were observed among pregnant Chinese women, in which UIC 
$<50 \mu \mathrm{g} / \mathrm{L}$ versus $\geq 50 \mu \mathrm{g} / \mathrm{L}$ was associated with a non-significant higher risk of LBW and SGA [12]. In another prospective study of Chinese women, both iodine insufficiency and excess were inversely associated with fetal femur length, a measure of fetal growth [11]. Among Spanish women, lower rates of SGA were observed among women with UIC 100-149 $\mu \mathrm{g} / \mathrm{L}$ compared to those with $<50 \mu \mathrm{g} / \mathrm{L}$ [8], but no associations of UIC with birth weight, SGA, or preterm birth were observed in another study of Spanish women [8]. In our study population of Finnish women, we found that higher serum iodide was positively associated with preterm birth, but neither high nor low serum iodide was associated with SGA.

Only a few previous studies have evaluated associations of Tg and TSH with preterm birth and SGA. In two prospective studies of pregnant Spanish women, high TSH, which is indicative of hypothyroidism, was associated with increased risk of SGA [7,8]. Similarly, in a prospective study of U.S. women, Männistö et al. reported a positive association of hypothyroidism and risk of preterm birth [27], which is consistent with findings of several other studies [28,29]. In our study of Finnish women, we observed an inverse association of $\mathrm{Tg}$ and SGA, but no association with preterm birth. TSH was not associated with either outcome, which was somewhat expected given that nearly all women were within the normal range.

While our findings for iodine are somewhat difficult to compare directly with prior studies due to our use of serum versus urine concentrations, the observed elevated risk of preterm birth associated with higher levels of serum iodide in our data are compatible with the possibility of a true U-shaped relationship observed in several previous studies, with both high and low levels of iodine being associated with increased risk of preterm birth. However, because the women who comprised our study population were only mildly iodine insufficient [3], and the prevalence of severe deficiency is low, our results may only capture the right side of this U-shaped relationship. Some data suggest that $\mathrm{Tg}$ levels may be sensitive indicators of iodine status among children and pregnant women [24,30], with a U-shaped relationship between $\mathrm{Tg}$ and UIC. Thus, the inverse association for SGA observed in analyses comparing high versus low Tg may be explained, at least in part, by mild iodine insufficiency among women with $\mathrm{Tg}$ in the lowest quartile. Additional explanations for conflicting findings of previous research and ours may relate to other underlying nutritional deficiencies (e.g., zinc or iron) present in other countries, bioavailable iodine in soil, and genetic factors, as well as differences in the underlying risk of obstetrical complications across study populations [3,31,32].

Potential biological mechanisms to explain our observed positive associations of serum iodide with preterm birth and inverse associations of Tg with SGA are somewhat unclear. During periods of iodine deficiency, TSH, which is secreted from the pituitary gland, increases and stimulates uptake of circulating iodine by thyrocytes in the thyroid [1]. The iodination of $\operatorname{Tg}$ produces $\mathrm{T}_{3}$ and $\mathrm{T}_{4}$, which are essential for fetal central nervous system and skeletal development. When iodine deficiency is severe (UIC $<50 \mu \mathrm{g} / \mathrm{L}$ ), the production of $\mathrm{T}_{3}$ and $\mathrm{T}_{4}$ is impaired, and circulating levels of the thyroid hormones decrease. Paradoxically, when iodine intake is excessive (defined as UIC $>500 \mu \mathrm{g} / \mathrm{L}$ ), a transient decrease in $\mathrm{T}_{3}$ and $\mathrm{T}_{4}$ also occurs, known as the Wolff-Chaikoff effect [33]. In normal, healthy individuals, this effect lasts only a few days; however, fetuses $<36$ weeks' gestation cannot escape this effect, resulting in fetal hypothyroidism [34]. Although this phenomenon is not well understood, it is possible that high levels of maternal serum iodide may induce this decrease in fetal thyroid hormones, which in turn, could have implications for fetal skeletal development, placentation, and preterm delivery [33].

Strengths of our study include the population-based, nested case-control design, which ensures minimal impact of selection and recall biases, and improves generalizability to the source population. In addition, our study population included women who were mildly iodine-insufficient, but with relatively low prevalence of other nutritional deficiencies that might otherwise confound the associations between iodine status and preterm birth and SGA [3]. Furthermore, our study is the first to evaluate associations of preterm birth and SGA with serum iodine, a measure of iodine hypothesized to be more stable than urinary iodine concentrations over time. Single spot urinary iodine, which was used to assess iodine status in all previous studies on this subject, exhibits considerable intraindividual 
variation owing to urine dilution, dietary intake, circadian rhythm, season, and other factors [14-16]. Because of this, UIC is considered an acceptable biomarker of iodine status for whole populations, but not for individuals [35]. Serum iodine on the other hand, is less sensitive to recent dietary intake and may better reflect individual iodine status over longer periods of time [19], possibly reducing misclassification of exposure.

Our study also has limitations. First, we were limited to a single serum iodide measurement, rather than longitudinal iodine measurements over the course of the pregnancy. Serum iodide decreases during pregnancy, and as such, some women may have developed iodine deficiency later in pregnancy. Additionally, serum iodide reference ranges have not been established in this population, making it difficult to compare with prior research and World Health Organization iodine recommendations established for pregnant women. We also cannot rule out potential confounding by unmeasured factors such as dietary patterns, chronic thyroid conditions or iodine supplementation initiated after blood collection. Residual confounding by measured factors such as smoking and socioeconomic status is also possible, but the similarity between unadjusted and adjusted estimates suggest that this is an unlikely source of substantial bias.

\section{Conclusions}

In conclusion, we found that in a mildly iodine insufficient population of Finnish women, higher-serum iodide was positively associated with risk of preterm birth, but was not associated with risk of having an SGA infant. High levels of Tg were inversely associated with risk of SGA. In light of our findings, it appears that mild iodine insufficiency is unlikely to be a substantial contributor to preterm birth and SGA in Finland. Findings of increased risk of preterm birth associated with high-serum iodide warrant further investigation.

Author Contributions: Conceptualization, J.L.M., T.M.; methodology, J.L.M., A.C.P.-S., K.K., G.A.B., S.L.M., A.L.; software, T.M.; validation, K.K., T.M., U.-J.K.; formal analysis, T.M., A.C.P.-S., G.A.B., A.L.; investigation, E.S., H.-M.S., T.M., M.G.; resources, E.S., H.-M.S., T.M., M.G.; data curation, E.S., H.-M.S., T.M., M.G.; writing-original draft preparation, A.C.P.-S.; writing—review and editing, J.L.M., G.A.B., S.L.M., A.L., E.S., H.-M.S., T.M., M.G., K.K., U.-J.K.; visualization, A.C.P.-S.; supervision, J.L.M.; project administration, J.L.M.; funding acquisition, J.L.M., E.S., H.-M.S., T.M., M.G.

Funding: This research was funded by the Office of Dietary Supplements of the National Institute of Health, U.S.A. (contracts \#HHSN2752011000011 and HHSN27500009), the Finnish Medical Association of Clinical Chemistry, and the Intramural Research Program of the Eunice Kennedy Shriver National Institute of Child Health and Human Development.

Conflicts of Interest: The authors declare no conflict of interest.

\section{Appendix A}

The methods used to measure serum iodide have been described previously by Bell et al. [20]. After samples were thawed at room temperature and vortex mixed for $30 \mathrm{~s}, 200 \mu \mathrm{L}$ were transferred to polypropylenes tubes. For sample pretreatment, an internal standard mixture of $40 \mathrm{ng} / \mathrm{mL} \mathrm{of} \mathrm{Cl}^{18} \mathrm{O}_{4}$ and $4 \mu \mathrm{g} / \mathrm{mL}$ of $\mathrm{S}^{13} \mathrm{CN}$ - was added and mixed. After the standard was thoroughly mixed, $20 \mu \mathrm{L}$ of acetic acid (HAc, $5 \%$ in water) and $10 \mu \mathrm{L}$ of ascorbic acid solution (AA, $2.5 \mathrm{mg} / \mathrm{mL}$ in water) were added, mixed, and incubated for $15 \mathrm{~min}$ in an incubator shaker at $37^{\circ} \mathrm{C}(100 \mathrm{rpm})$. Following this, $100 \mu \mathrm{L}$ of tetramethylammonium hydroxide (TMAH) (2.5 weight \% solution in water), mixed the solution, and then digested in an oven at $90{ }^{\circ} \mathrm{C}$ for $2.5 \mathrm{~h}$. Samples were then cooled to room temperature, after which we added $115 \mu \mathrm{L}$ of water and $30 \mu \mathrm{L}$ HAc, and then were mixed and centrifuged for $10 \mathrm{~min}$ at $5000 \mathrm{rpm}$. Finally, $500 \mu \mathrm{L}$ of the final sample supernatant was transferred to amber vial for high-performance liquid chromatography-triple quadrupole mass spectrometry (HPLC-MS/MS).

An Alliance 2695 high-performance liquid chromatograph (HPLC) coupled with a Micromass Quattro LC tandem mass spectrometer (MS/MS; Waters Corporation, Milford, MA, USA) was used for sample analysis. Micromass MassLynx 3.5 software was used for data acquisition and quantification. The IonPac AS-21 column (guard column; $50 \mathrm{~mm} \times 2 \mathrm{~mm}$, analytical column; 
$250 \mathrm{~mm} \times 2 \mathrm{~mm}$, Dionex, Sunnyvale, CA, USA) was used to separate iodide. Identification and quantification of ${ }^{18} \mathrm{O}$-labeled-perchlorate, ${ }^{13} \mathrm{C}$-labeled-thiocyanate, and iodide was performed using electrospray negative ionization (ESI-) and multiple-reaction monitoring (MRM) mode at $107\left({ }^{35} \mathrm{Cl}^{18} \mathrm{O} 4-\right)>89\left({ }^{35} \mathrm{Cl}^{18} \mathrm{O} 3-\right) ; 59\left(\mathrm{~S}^{13} \mathrm{CN}-\right)>59\left(\mathrm{~S}^{13} \mathrm{CN}-\right)$, and $127\left({ }^{127} \mathrm{I}-\right)>127\left({ }^{127} \mathrm{I}-\right)$.

A number of quality control checks were performed. A matrix matched calibration standard with a range of concentrations from 0.02 to $100 \mathrm{ng} / \mathrm{mL}$ of iodide was used for each 100-sample batch. Calibration curves had regression coefficients of $>0.99$. Each calibration standard had internal standards $\left(\mathrm{Cl}^{18} \mathrm{O} 4\right.$ - and $\mathrm{S}^{13} \mathrm{CN}$-) spiked into them at $2 \mathrm{ng} / \mathrm{mL}$ and $20 \mathrm{ng} / \mathrm{mL}$. Both internal standards had average recoveries of $70 \%$. Estimated limits of quantification for iodide in blood sera was $0.25 \mathrm{ng} / \mathrm{mL}$. Each 100-sample batch included a procedural blank, a matrix blank, a duplicate, standard reference material, and matrix spike of $25 \mathrm{ng} / \mathrm{mL}$ iodide. In analyses, no iodine was detected in procedural blanks, $<2 \mathrm{ng} / \mathrm{mL}$ of iodide was detected in matrix blanks, $90 \%-111 \%$ of iodine was recovered in standard reference material, and $101 \%-122 \%$ of iodine was recovered in spiked serum matrices. No carry-over was detected from water blanks injected every 20-25 samples. To measure instrumental drift, a mid-point calibration standard was injected in every $10 \mathrm{~h}$ as initial calibration verification (ICV) to monitor for drift in instrumental response.

\section{References}

1. Zimmermann, M.B.; Jooste, P.L.; Pandav, C.S. Iodine-deficiency disorders. Lancet 2008, 372, 1251-1262. [CrossRef]

2. Maraka, S.; Ospina, N.M.S.; O’Keeffe, D.T.; Espinosa De Ycaza, A.E.; Gionfriddo, M.R.; Erwin, P.J.; Coddington, C.C., 3rd; Stan, M.N.; Murad, M.H.; Montori, V.M. Subclinical Hypothyroidism in Pregnancy: A Systematic Review and Meta-Analysis. Thyroid 2016, 26, 580-590. [CrossRef]

3. Nystrom, H.F.; Brantsaeter, A.L.; Erlund, I.; Gunnarsdottir, I.; Hulthen, L.; Laurberg, P.; Mattisson, I.; Rasmussen, L.B.; Virtanen, S.; Meltzer, H.M. Iodine status in the Nordic countries-past and present. Food Nutr. Res. 2016, 60, 31969. [CrossRef]

4. Leung, A.M.; Pearce, E.N.; Braverman, L.E. Iodine nutrition in pregnancy and lactation. Endocrin. Metab. Clin. 2011, 40, 765-777. [CrossRef]

5. Mills, J.L.; Ali, M.; Buck Louis, G.M.; Kannan, K.; Weck, J.; Wan, Y.; Maisog, J.; Giannakou, A.; Sundaram, R. Pregnancy Loss and Iodine Status: The LIFE Prospective Cohort Study. Nutrients 2019, 11, 534. [CrossRef]

6. Granfors, M.; Andersson, M.; Stinca, S.; Åkerud, H.; Skalkidou, A.; Sundström Poromaa, I.; Wikström, A.-K.; Filipsson Nyström, H. Iodine deficiency in a study population of pregnant women in Sweden. Acta. Obstet. Gynecol. Scand. 2015, 94, 1168-1174. [CrossRef]

7. Alvarez-Pedrerol, M.; Guxens, M.; Mendez, M.; Canet, Y.; Martorell, R.; Espada, M.; Plana, E.; Rebagliato, M.; Sunyer, J. Iodine levels and thyroid hormones in healthy pregnant women and birth weight of their offspring. Eur. J. Endocrinol. 2009, 160, 423-429. [CrossRef]

8. Leon, G.; Murcia, M.; Rebagliato, M.; Alvarez-Pedrerol, M.; Castilla, A.M.; Basterrechea, M.; Iniguez, C.; Fernandez-Somoano, A.; Blarduni, E.; Foradada, C.M.; et al. Maternal thyroid dysfunction during gestation, preterm delivery, and birthweight. The Infancia y Medio Ambiente Cohort, Spain. Paediatr. Perinat. Epidemiol. 2015, 29, 113-122. [CrossRef]

9. Charoenratana, C.; Leelapat, P.; Traisrisilp, K.; Tongsong, T. Maternal iodine insufficiency and adverse pregnancy outcomes. Matern. Child Nutr. 2016, 12, 680-687. [CrossRef]

10. Torlinska, B.; Bath, S.C.; Janjua, A.; Boelaert, K.; Chan, S.Y. Iodine Status during Pregnancy in a Region of Mild-to-Moderate Iodine Deficiency is not Associated with Adverse Obstetric Outcomes; Results from the Avon Longitudinal Study of Parents and Children (ALSPAC). Nutrients 2018, 10, 291. [CrossRef]

11. Chen, R.; Li, Q.; Cui, W.; Wang, X.; Gao, Q.; Zhong, C.; Sun, G.; Chen, X.; Xiong, G.; Yang, X.; et al. Maternal Iodine Insufficiency and Excess Are Associated with Adverse Effects on Fetal Growth: A Prospective Cohort Study in Wuhan, China. J. Nutr. 2018, 148, 1814-1820. [CrossRef]

12. Yang, J.; Liu, Y.; Liu, H.; Zheng, H.; Li, X.; Zhu, L.; Wang, Z. Associations of maternal iodine status and thyroid function with adverse pregnancy outcomes in Henan Province of China. J. Trace Elem. Med. Biol. 2018, 47, 104-110. [CrossRef] 
13. Snart, C.J.P.; Keeble, C.; Taylor, E.; Cade, J.E.; Stewart, P.M.; Zimmermann, M.; Reid, S.; Threapleton, D.E.; Poston, L.; Myers, J.E.; et al. Maternal Iodine Status and Associations with Birth Outcomes in Three Major Cities in the United Kingdom. Nutrients 2019, 11, 411. [CrossRef]

14. Rasmussen, L.B.; Ovesen, L.; Christiansen, E. Day-to-day and within-day variation in urinary iodine excretion. Eur. J. Clin. Nutr. 1999, 53, 401-407. [CrossRef]

15. Als, C.; Helbling, A.; Peter, K.; Haldimann, M.; Zimmerli, B.; Gerber, H. Urinary iodine concentration follows a circadian rhythm: A study with 3023 spot urine samples in adults and children. J. Clin. Endocrinol. Metab. 2000, 85, 1367-1369. [CrossRef]

16. Pan, Z.; Cui, T.; Chen, W.; Gao, S.; Pearce, E.N.; Wang, W.; Chen, Y.; Guo, W.; Tan, L.; Shen, J.; et al. Serum iodine concentration in pregnant women and its association with urinary iodine concentration and thyroid function. Clin. Endocrinol. 2019, 90,711-718. [CrossRef]

17. Yu, S.; Yin, Y.; Cheng, Q.; Han, J.; Cheng, X.; Guo, Y.; Sun, D.; Xie, S.; Qiu, L. Validation of a simple inductively coupled plasma mass spectrometry method for detecting urine and serum iodine and evaluation of iodine status of pregnant women in Beijing. Scand. J. Clin. Lab. Inv. 2018, 78, 501-507. [CrossRef]

18. Michalke, B.; Witte, H. Characterization of a rapid and reliable method for iodide biomonitoring in serum and urine based on ion chromatography-ICP-mass spectrometry. J. Trace Elem. Med. Biol. 2015, 29, 63-68. [CrossRef]

19. Cui, T.; Wang, W.; Chen, W.; Pan, Z.; Gao, S.; Tan, L.; Pearce, E.N.; Zimmermann, M.B.; Shen, J.; Zhang, W. Serum Iodine Is Correlated with Iodine Intake and Thyroid Function in School-Age Children from a Sufficient-to-Excessive Iodine Intake Area. J. Nutr. 2019, 149, 1012-1018. [CrossRef]

20. Bell, G.A.; Mannisto, T.; Liu, A.; Kannan, K.; Yeung, E.H.; Kim, U.J.; Suvanto, E.; Surcel, H.M.; Gissler, M.; Mills, J.L. The joint role of thyroid function and iodine concentration on gestational diabetes risk in a population-based study. Acta. Obstet. Gynecol. Scand. 2019, 98, 500-506. [CrossRef]

21. Roti, E.; Gardini, E.; Minelli, R.; Bianconi, L.; Flisi, M. Thyroid function evaluation by different commercially available free thyroid hormone measurement kits in term pregnant women and their newborns. J. Endocrinol. Invest. 1991, 14, 1-9. [CrossRef]

22. Männistö, T.; Surcel, H.-M.; Ruokonen, A.; Vääräsmäki, M.; Pouta, A.; Bloigu, A.; Järvelin, M.-R.; Hartikainen, A.-L.; Suvanto, E. Early Pregnancy Reference Intervals of Thyroid Hormone Concentrations in a Thyroid Antibody-Negative Pregnant Population. Thyroid 2011, 21, 291-298. [CrossRef]

23. Shrier, I.; Platt, R.W. Reducing bias through directed acyclic graphs. BMC. Med. Res. Methodol. 2008, 8, 70. [CrossRef]

24. Stinca, S.; Andersson, M.; Weibel, S.; Herter-Aeberli, I.; Fingerhut, R.; Gowachirapant, S.; Hess, S.Y.; Jaiswal, N.; Jukić, T.; Kusic, Z.; et al. Dried Blood Spot Thyroglobulin as a Biomarker of Iodine Status in Pregnant Women. J. Clin. Endocrinol. Metab. 2016, 102, 23-32. [CrossRef]

25. Knudsen, N.; Bülow, I.; Jørgensen, T.; Perrild, H.; Ovesen, L.; Laurberg, P. Serum Tg-A Sensitive Marker of Thyroid Abnormalities and Iodine Deficiency in Epidemiological Studies. J. Clin. Endocrinol. Metab. 2001, 86, 3599-3603. [CrossRef]

26. Vejbjerg, P.; Knudsen, N.; Perrild, H.; Laurberg, P.; Carlé, A.; Pedersen, I.B.; Rasmussen, L.B.; Ovesen, L.; Jørgensen, T. Thyroglobulin as a marker of iodine nutrition status in the general population. Eur. J. Endocrinol. 2009, 161, 475. [CrossRef]

27. Mannisto, T.; Mendola, P.; Grewal, J.; Xie, Y.; Chen, Z.; Laughon, S.K. Thyroid diseases and adverse pregnancy outcomes in a contemporary US cohort. J. Clin. Endocrinol. Metab. 2013, 98, 2725-2733. [CrossRef]

28. Casey, B.M.; Dashe, J.S.; Wells, C.E.; McIntire, D.D.; Byrd, W.; Leveno, K.J.; Cunningham, F.G. Subclinical hypothyroidism and pregnancy outcomes. Obstet. Gynecol. 2005, 105, 239-245. [CrossRef]

29. Casey, B.M.; Thom, E.A.; Peaceman, A.M.; Varner, M.W.; Sorokin, Y.; Hirtz, D.G.; Reddy, U.M.; Wapner, R.J.; Thorp, J.M.; Saade, G.; et al. Treatment of Subclinical Hypothyroidism or Hypothyroxinemia in Pregnancy. N. Eng. J. Med. 2017, 376, 815-825. [CrossRef]

30. Zimmermann, M.B.; Aeberli, I.; Andersson, M.; Assey, V.; Yorg, J.A.; Jooste, P.; Jukic, T.; Kartono, D.; Kusic, Z.; Pretell, E.; et al. Thyroglobulin is a sensitive measure of both deficient and excess iodine intakes in children and indicates no adverse effects on thyroid function in the UIC range of 100-299 mug/L: A UNICEF/ICCIDD study group report. J. Clin. Endocrinol. Metab. 2013, 98, 1271-1280. [CrossRef]

31. Ertek, S.; Cicero, A.F.; Caglar, O.; Erdogan, G. Relationship between serum zinc levels, thyroid hormones and thyroid volume following successful iodine supplementation. Hormones (Athens) 2010, 9, 263-268. [CrossRef] 
32. Khatiwada, S.; Lamsal, M.; Gelal, B.; Gautam, S.; Nepal, A.K.; Brodie, D.; Baral, N. Anemia, Iron Deficiency and Iodine Deficiency among Nepalese School Children. Ind. J. Pediatr. 2016, 83, 617-621. [CrossRef]

33. Pearce, E.N.; Lazarus, J.H.; Moreno-Reyes, R.; Zimmermann, M.B. Consequences of iodine deficiency and excess in pregnant women: An overview of current knowns and unknowns. Am. J. Clin. Nutr. 2016, 104 (Suppl. 3), 918s-923s. [CrossRef]

34. Markou, K.; Georgopoulos, N.; Kyriazopoulou, V.; Vagenakis, A.G. Iodine-Induced hypothyroidism. Thyroid 2001, 11, 501-510. [CrossRef]

35. Konig, F.; Andersson, M.; Hotz, K.; Aeberli, I.; Zimmermann, M.B. Ten repeat collections for urinary iodine from spot samples or 24-h samples are needed to reliably estimate individual iodine status in women. J. Nutr. 2011, 141, 2049-2054. [CrossRef]

(C) 2019 by the authors. Licensee MDPI, Basel, Switzerland. This article is an open access article distributed under the terms and conditions of the Creative Commons Attribution (CC BY) license (http://creativecommons.org/licenses/by/4.0/). 



\title{
Review
}

\section{Interference on Iodine Uptake and Human Thyroid Function by Perchlorate-Contaminated Water and Food}

\author{
Giuseppe Lisco ${ }^{1}$, Anna De Tullio ${ }^{2}$, Vito Angelo Giagulli ${ }^{2,3}$, Giovanni De Pergola ${ }^{4}$ \\ and Vincenzo Triggiani ${ }^{2, *}$ \\ 1 ASL Brindisi, Unit of Endocrinology, Metabolism \& Clinical Nutrition, Hospital "A. Perrino", \\ Strada per Mesagne 7, 72100 Brindisi, Puglia, Italy; g.lisco84@gmail.com \\ 2 Interdisciplinary Department of Medicine-Section of Internal Medicine, Geriatrics, Endocrinology and Rare \\ Diseases, University of Bari "Aldo Moro", School of Medicine, Policlinico, Piazza Giulio Cesare 11, \\ 70124 Bari, Puglia, Italy; annadetullio16@gmail.com (A.D.T.); vitogiagulli58@gmail.com (V.A.G.) \\ 3 Clinic of Endocrinology and Metabolic Disease, Conversano Hospital, Via Edmondo de Amicis 36, \\ 70014 Conversano, Bari, Puglia, Italy \\ 4 Department of Biomedical Sciences and Human Oncology, Section of Internal Medicine and Clinical \\ Oncology, University of Bari Aldo Moro, Piazza Giulio Cesare 11, 70124 Bari, Puglia, Italy; \\ gdepergola@libero.it \\ * Correspondence: vincenzotriggiani@uniba.it
}

Received: 14 May 2020; Accepted: 1 June 2020; Published: 4 June 2020

\begin{abstract}
Background: Perchlorate-induced natrium-iodide symporter (NIS) interference is a well-recognized thyroid disrupting mechanism. It is unclear, however, whether a chronic low-dose exposure to perchlorate delivered by food and drinks may cause thyroid dysfunction in the long term. Thus, the aim of this review was to overview and summarize literature results in order to clarify this issue. Methods: Authors searched PubMed/MEDLINE, Scopus, Web of Science, institutional websites and Google until April 2020 for relevant information about the fundamental mechanism of the thyroid NIS interference induced by orally consumed perchlorate compounds and its clinical consequences. Results: Food and drinking water should be considered relevant sources of perchlorate. Despite some controversies, cross-sectional studies demonstrated that perchlorate exposure affects thyroid hormone synthesis in infants, adolescents and adults, particularly in the case of underlying thyroid diseases and iodine insufficiency. An exaggerated exposure to perchlorate during pregnancy leads to a worse neurocognitive and behavioral development outcome in infants, regardless of maternal thyroid hormone levels. Discussion and conclusion: The effects of a chronic low-dose perchlorate exposure on thyroid homeostasis remain still unclear, leading to concerns especially for highly sensitive patients. Specific studies are needed to clarify this issue, aiming to better define strategies of detection and prevention.
\end{abstract}

Keywords: perchlorate; Natrium/Iodide symporter; iodine; endocrine disruptors; review; drinking and Food; Hypothyroidism

\section{Introduction}

Endocrine disrupting chemicals (EDCs) have been defined as a group of compounds or a mixture of natural or man-housed exogenous chemicals which interfere with the hormonal network, or induce endocrine cell damage [1]. Interference may be attributable to several mechanisms such as receptor agonism or antagonism, modulation of receptor expression, modification of signal transduction, hormone synthesis or incretion, plasmatic distribution and clearance [2]. Moreover, epigenetic effects have been hypothesized for EDCs and concerns about a possible "transmission" of EDCs across 
the generations is a topic of debate [3,4]. To date, a wide range of environmental chemicals have been identified as being involved in the pathogenesis of thyroid diseases $[5,6]$ and several chemicals or common pollutants may act as thyroid disruptors [7-9]. Perfluorooctanoic acid [10], a chemical largely employed for the manufacturing of waxes, cosmetics, carpets, cleaning or waterproof products, and bisphenols [11], hugely used as plasticizers, were found to increase the prevalence of thyroid diseases in exposed patients [12], including thyroid autoimmunity [13]. Moreover, legacy pesticides were experimentally shown to affect thyroid function [14] and, despite some controversy, they may also induce hypothyroidism, thyroid autoimmunity, thyroid volume enlargement or nodules in humans [15]. The bactericide triclosan was mostly found in personal hygiene products (oral care, shampoos, hand sanitizers, soaps), and was proven to increase the risk of thyroid diseases, too [16]. Thyroid disruption includes different pathways, and may be due to either interference or synergism among different EDCs [17]. The leading mechanisms of thyroid interference by pollutant agents have been explored, and frequently include the inhibition of thyroperoxidase activity, competitive natrium-iodide symporter (NIS) inhibition, impairment of binding protein transport and peripheral deiodinase activity, enhancement of liver catabolism [18]. Since food and drinks are also a relevant source of thyroid disruptors, a lifelong human exposure to these chemicals could induce potentially harmful consequences on thyroidal homeostasis. Given this consideration, this review aims to specifically focalize on NIS interference by specific agents, mainly perchlorate compounds, which are commonly found in food and drinks.

\section{Materials and Methods}

The authors summarized iodine metabolism and its importance in thyroid homeostasis and hormonal synthesis. Furthermore, the authors searched PubMed/MEDLINE, Scopus, Web of Science, institutional websites and Google for relevant information about the fundamental mechanism of NIS interference induced by perchlorate compounds orally assumed and the consequences on thyroidal health status associated with chronic exposure to these chemicals.

\section{Results}

\subsection{Overview on Iodine Metabolism in Healthy Humans}

The primary source of iodine (I) is represented by natural food (seafood, milk, eggs, vegetables, legumes, fruits), fortified food (salt) and mineral waters. I is basically available in two forms, organic and inorganic (iodide); the latter form is absorbed at the level of stomach and duodenum [19] through a specific natrium-iodide symporter (NIS) which regulates iodine homeostasis in human body [20]. After gastrointestinal absorption, I enters the circulation, undergoing to a large distribution into the plasma, red blood cell cytoplasm and extracellular fluid, and is finally intercepted by tissues [21]. A wide range of tissues express the NIS, including salivary glands, breast, and thyroid [22]. Nevertheless, thyroid represents the most important reservoir of the ion considering that, in a healthy human body, the gland normally stores up to $80 \%$ of the entire iodine pool (15-20 mg). The NIS is a 13-domain transmembrane protein which mediates transmembrane I and sodium (1 to 2 ratio) transport at the level of thyrocyte's basolateral membrane $[23,24]$. Transmembrane sodium gradient is generated by the sodium-potassium ATPase pump which indirectly provides energy for an almost continuous intrathyroidal I uptake (secondary active transport). Given this thyroid avidity, I concentration in thyrocytes is 30 to 60 times higher than its plasmatic levels [25]. As a mean, thyroid secretes $80 \mu \mathrm{g}$ a day of $I$ in the form of both levothyroxine and triiodothyronine [26]. Due to peripheral metabolism of thyroid hormones, I circulates in bloodstream finally undergoing to both renal and hepato-biliary clearance and thyroidal re-uptake, as well. An intrathyroidal I recycling has also been described [27]. Thyroidal uptake considerably fluctuates according to I intake, and ranges from $10 \%$ to over $80 \%$ of the entire amount of ingested I. Contrariwise, urinary I excretion is inversely correlated with thyroid uptake, and in the case of adequate I intake, more than $90 \%$ of the ion is cleared by the kidneys with 
urine [28]. Urinary I concentration is thus a reliable biomarker of I intake, and is a useful tool for screening patients suspected for I deficiency [25]. Both the thyroid hormone synthesis and urinary I excretion increase during pregnancy [29], while 126 to $269 \mu \mathrm{g}$ of I could be excreted with each liter of breast milk in lactating women [30]. Iodine intake is generally recommended at $150 \mu \mathrm{g}$ per day for adults in order to ensure the daily iodine recycle [31]. Thus, the recommended dose of iodine intake raises at 200 - $250 \mu \mathrm{g}$ per day during pregnancy and lactation for sustaining an increased requirement [32]. I is an essential micronutrient for thyroid hormones synthesis [33,34]. Afterward the transition into thyrocyte cytoplasm, I moves towards the apical surface of thyrocyte's plasmatic membrane into the follicular lumen. This transport is mediated by a ionic carrier belonging to the SLC26A family, otherwise known as pendrin [35], and is also expressed at the level of the inner ear, kidney and bowel. Specifically, pendrin is essential for favoring the efflux of iodine into follicular space in exchange of chloride ( 1 to 1 ratio) and a defective synthesis or function of this carrier is responsible for a the so called Pendred's syndrome [36]. Once into follicular lumen, I undergoes oxidation by thyroperoxidase, thus becoming promptly available for thyroglobulin's organification. Thyroid I content is the most important regulator of thyroid hormone synthesis. Indeed, I overload reduces the expression of NIS, decreases both the thyroid peroxidase and deiodinases activities, and finally leads to a transient impairment of thyroid hormone synthesis [37]. In predisposed patients, iodine excess increases oxidative stress, and may induce or exacerbate thyroid autoimmunity and hypothyroidism (Wolff-Chaikoff effect) [38]. Finally, I overload may exacerbate a latent hyperthyroidism in patient with single thyroid nodule or multinodular goiter [39].

\subsection{Perchlorate Compounds and Iodine Interference}

The evidence that high doses of perchlorate $\left(\mathrm{ClO}_{4}^{-}\right)$anion decreased thyroid hormone synthesis has been known since the 1950s [40], and given this peculiarity, it has been used to effectively treat hyperthyroidism such as in Graves' disease and amiodarone-induced hyperthyroidism [41]. Specifically, $\mathrm{ClO}_{4}{ }^{-}$competes with I at the level of the NIS (Figure A1), the former having a 30-fold higher affinity for the symporter when compared to the latter [42]. A dose-response sigmoid curve has been reported for describing NIS sensitivity to $\mathrm{ClO}_{4}{ }^{-}$inhibition in different species and the half maximal inhibiting concentration in humans was found at $1.566 \mu \mathrm{M}$ [43]. To confirm these experimental results, an orally delivered acute exposure to up to $520 \mu \mathrm{g} / \mathrm{kg}$ of body weight (bw) induced a significant increase in serum thyroid stimulating hormone (TSH) levels, with a relevant decline in serum-free levothyroxine concentrations [44]. On the other hand, it is thought that a chronic low-dose exposure to $\mathrm{ClO}_{4}{ }^{-}$, normally observed as the consequence of food and drink intake, could impair thyroid function by reducing iodine uptake particularly in predisposed individuals, such as those with an underlying iodine deficiency $[45,46]$.

\subsection{Perchlorate Compounds in Food and Water}

$\mathrm{ClO}_{4}{ }^{-}$may naturally occur in the atmosphere from spontaneous photogenic reaction between chloride and ozone, or arises from man-made products such as oxidizers, fertilizers, explosives, propellants, fireworks, airbag inflators spread into environment. In addition, $\mathrm{ClO}_{4}^{-}$can be also produced from the degradation of the common water disinfectant hypochlorite [47]. Perchlorate compounds occur in different form, such as metal perchlorate, ammonium and alkali metal forms, organic and inorganic forms and salts. Antarctic ice represents the most important sediment of $\mathrm{ClO}_{4}^{-}$in the planet, with different concentrations depending on drilling areas [48]. The Atacama desert (Chile, South America) is another important natural source of geogenic $\mathrm{ClO}_{4}{ }^{-}$, and elevated concentrations of its compounds have been found in soil (290 to $2565 \mu \mathrm{g} / \mathrm{Kg}$ ) and surface waters (744 to $1480 \mu \mathrm{g} / \mathrm{L}$ ) [49]. Other relevant sources of natural $\mathrm{ClO}_{4}{ }^{-}$have been discovered in Alaska, Puerto Rico, New Mexico, Texas, California (United States of America, USA), and Bolivia (South America). Anthropogenic $\mathrm{ClO}_{4}{ }^{-}$compounds have been found in soil, sea and rainwater, surface and groundwaters, indoor and outdoor dust, ice and snow [50]. Given data from ice drilling 
analyses, anthropogenic $\mathrm{ClO}_{4}{ }^{-}$started to accumulate in Arctic ice from the 1980s [51]. In Devon Island (Canada, North America), $\mathrm{ClO}_{4}{ }^{-}$compounds were found in ice and snow at variable concentrations ranging from 1 to $18 \mathrm{ng} / \mathrm{L}$ [52]. A great variability in rainwater $\mathrm{ClO}_{4}{ }^{-}$levels was observed due to differences in analyzed geographical sites and seasonality. In fact, $\mathrm{ClO}_{4}{ }^{-}$concentration ranges from 0.02 to $1.6 \mu \mathrm{g} / \mathrm{L}$ in Texas (USA) [53], 0.02 to $6.9 \mu \mathrm{g} / \mathrm{L}$ in India (Asia) [54], and 0.35 to $27.3 \mathrm{ng} / \mathrm{mL}$ in China (Asia) [55]. Moreover, Munster et al. evaluated the levels $\mathrm{ClO}_{4}{ }^{-}$in total deposition from November 2005 to July 2007 in Long Island (New York State), relieving a mean concertation of $0.21 \mu \mathrm{g} / \mathrm{L}$ and with a maximum level of $2.81 \mu \mathrm{g} / \mathrm{L}$ recorded after fireworks displays occurred during the Independence day celebration [56]. Another observation reported different levels of $\mathrm{ClO}_{4}{ }^{-}$in wet deposition only, ranging from $<5$ to $105 \mathrm{ng} / \mathrm{L}$ (mean $14 \mathrm{ng} / \mathrm{L}$ ) with higher concentrations recorded in spring and summer than winter [57]. Soil usually does not retain $\mathrm{ClO}_{4}{ }^{-}$and more than $90 \%$ is confined in the aqueous phase [58] where $\mathrm{ClO}_{4}{ }^{-}$spreads and persists due to its high solubility and resistance to photolysis and anaerobic bacterial biodegradation [59]. Fruits and vegetables represent a relevant food source of $\mathrm{ClO}_{4}{ }^{-}$, particularly because of the widespread use of perchlorate-based fertilizers [60]. In particular, leafy vegetables, spinach, salad plants, raspberries, apricots, asparagus, cantaloupes, and tomatoes accumulate $\mathrm{ClO}_{4}{ }^{-}$as a consequence of farming techniques [61]. The mean concentration of perchlorate in tested food appears variable and the highest levels have been found in Guatemalan cantaloupes $(156 \mu \mathrm{g} / \mathrm{Kg})$, spinach $(133 \mu \mathrm{g} / \mathrm{Kg})$, Chilean green grapes $(45.5 \mu \mathrm{g} / \mathrm{Kg})$ and Romaine lettuce $(29 \mu \mathrm{g} / \mathrm{Kg})$ [62]. Vega et al. reported variable concentration of $\mathrm{ClO}_{4}{ }^{-}$in Chilean drinking waters which ranged from 4 to $120 \mu \mathrm{g} / \mathrm{L}$ [63]. Conversely, lower levels of $\mathrm{ClO}_{4}{ }^{-}$in drinking water have been observed in the USA [64] and Europe, including Italy $(0.5-75 \mu \mathrm{g} / \mathrm{L})[65]$.

\subsection{Chronic Esposure to Perchlorate Compounds by Food and Drinking Water}

The 2018 "Italian Institute for Food and Agriculture Market Services" ranking reported the USA as the most valuable country in exporting fruits and vegetables, followed by Mexico and Chile. Given the volume of exports, Spain (4th) and Italy (7th) are responsible for the $42 \%$ of the entire European market of fruits and vegetables, ahead of Poland, France and Greece [66]. Chile has a remarkable export economy [67], and usually exports several thousands of millions of kilograms of fruits a year worldwide [68]. Specifically, the European Union is Chile's third-largest trade partner in the world, after China and the USA, and currently imports 19\% of the Chilean global export of vegetable products [69]. Cherries and table grapes, followed by apples, Chilean blueberries and plums are the most exported vegetable products to Europe. Vegetables from Chile are notoriously rich in $\mathrm{ClO}_{4}{ }^{-}$and the excessive consumption of these products could have chronically negative consequences on thyroid homeostasis. Indeed, $\mathrm{ClO}_{4}{ }^{-}$food exposure is essentially driven by vegetables and fruits and widely ranged according to geographical area as well as seasonality [70]. To confirm this assumption, $\mathrm{ClO}_{4}{ }^{-}$was detected in a wide range of vegetable samples, ranging from 21 to $162 \mu \mathrm{g} / \mathrm{kg}$ [71]. Vegetables consumption in Italy seems to slightly but continuously increase over time and some of the most consumed vegetable products, such as spinach, leaf vegetables and spices were found to be a relevant source of $\mathrm{ClO}_{4}{ }^{-}$[72]. Normal consumption of these vegetables does not usually lead to exceeding the maximal total daily dose according to the European Food Safety Authority $2014(0.3 \mu \mathrm{g} / \mathrm{Kg}$ of bw). However, a higher daily consumption of these products led to a relevant exceeding of the maximal tolerated dose by $32 \%$ in adults, $61 \%$ in children and $56 \%$ in infant [72]. In addition, tea and herbal infusions could represent another relevant source of $\mathrm{ClO}_{4}{ }^{-}$, oscillating from 630 to $730 \mu \mathrm{g} / \mathrm{Kg}$ for dark tea; 80 to $430 \mu \mathrm{g} / \mathrm{Kg}$ for black tea; and 250 to $500 \mu \mathrm{g} / \mathrm{Kg}$ for green tea [73]. Therefore, the consumption of the aforementioned products should be moderate and intermittent for avoiding a consistent $\mathrm{ClO}_{4}{ }^{-}$overload. Indeed, acute exposure to high or very high levels of $\mathrm{ClO}_{4}{ }^{-}$ normally is not enough for overcoming thyroidal compensation and ability to maintain normal serum concentration of thyroid hormones in healthy individuals [64]. Chronic consumption of $\mathrm{ClO}_{4}{ }^{-}$in adults has been estimated as high as 0.07 to $0.34 \mu \mathrm{g} / \mathrm{Kg}$ of body weight per day in Europe [70], and 0.2 to $0.4 \mu \mathrm{g} / \mathrm{Kg}$ of body weight per day in the USA [74]. Despite $\mathrm{ClO}_{4}{ }^{-}$consumption being generally 
below the level of recommended reference dose in adults [75], it may become critical, especially in some categories, such as children, high sensitive patients, cigarette smokers, iodine deficient people, and pregnant and breast feeding women as well [76-78]. Indeed, the inhibition of I uptake and any potential downstream effects induced by $\mathrm{ClO}_{4}{ }^{-}$are strictly dependent on the exposure to other environmental NIS inhibitors, such as thiocyanates and nitrates, and iodine intake itself [79]. These potential confounders should therefore be considered in future studies and calculations for risk assessment [80]. Finally, breast milk and infant formulas are the most significant sources of $\mathrm{ClO}_{4}{ }^{-}$for newborns and infants [81-83]. Compared with adults, infants and children exhibited a greater $\mathrm{ClO}_{4}{ }^{-}$exposure per $\mathrm{Kg}$ of bw per day [75,84], particularly breastfed children $(0.22 \mu \mathrm{g} / \mathrm{Kg}$ of bw/day) respective to those fed by cow milk-based formula $(0.1 \mu \mathrm{g} / \mathrm{Kg}$ of bw/day) or soy-based formula $(0.027 \mu \mathrm{g} / \mathrm{Kg}$ of bw/day) [85]. Food intake more than drinking water is considered the main source of $\mathrm{ClO}_{4}{ }^{-}$for children [81] and adults [86], since $\mathrm{ClO}_{4}{ }^{-}$exposure from drinking water alone is not able to suppress thyroid function [87]. Nevertheless, this assumption is controversial considering that other results suggest opposite conclusions [70,74].

\subsection{Perchlorate Compounds Toxicity}

From this point of view, concerns have been supposed in case of $\mathrm{ClO}_{4}{ }^{-}$exposure during fetal and infantile life [88,89]. The placental NIS ensures maternal-to-fetal transition of I [90], therefore allowing fetal uptake of $\mathrm{ClO}_{4}{ }^{-}$and other goitrogen chemicals, too. Blount et al. specifically analyzed the perinatal exposure to goitrogen chemicals in 150 mothers from New Jersey (USA), showing that the placental barrier was more permeable to I respective to goitrogens and maternal urinary $\mathrm{ClO}_{4}{ }^{-}$ concentrations were directly correlated with $\mathrm{ClO}_{4}{ }^{-}$concentration in amniotic fluid, thus resulting an useful tool for assessing fetal exposure [91]. As observed in a Chinese population, $\mathrm{ClO}_{4}{ }^{-}$was detected in infant's urine $(22.4 \mathrm{ng} / \mathrm{mL})$ and cord blood serum $(3.2 \mathrm{ng} / \mathrm{mL})$ at a concentration about 22 times greater compared to that reported by Blount $(0.14 \mu \mathrm{g} / \mathrm{L})$ [92]. This finding is difficult to explain, but could be attributable to different environmental exposures or dissimilarities in assay or both. Several studies analyzed the impact of a mild-to-moderate exposure to $\mathrm{ClO}_{4}{ }^{-}$in early pregnancy on both maternal thyroid function and several neonatal outcomes. In a cross-sectional trial in Athens (Greece), 139 first-trimester pregnant women with mild iodine deficiency were chronically exposed to dietary sources of $\mathrm{ClO}_{4}{ }^{-}$as suggested by median levels of urinary $\mathrm{ClO}_{4}{ }^{-}$concentration at around $4 \mu \mathrm{g} / \mathrm{L}$. The authors specifically found that $\mathrm{ClO}_{4}{ }^{-}$urinary concentration, possibly associated with a moderate iodine deficiency, was inversely related with plasmatic levels of triiodothyronine and thyroxin in this cluster of patients [93]. A cross-sectional study in 200 first-trimester Thai pregnant women ( $<14$ weeks of gestation age) confirmed a chronic low-level environmental exposure to $\mathrm{ClO}_{4}{ }^{-}$compounds (and thiocyanates) and this exposure was positively associated with serum TSH concentration and negatively related with serum levothyroxine levels [94]. Data from San Diego (South California) reported a mean urinary $\mathrm{ClO}_{4}{ }^{-}$concentration of $8.5 \mu \mathrm{g} / \mathrm{L}$ in first-trimester pregnant women, and the higher the level of $\mathrm{ClO}_{4}{ }^{-}$, the higher the level of TSH and the lower those of total thyroxine and free thyroxine [95]. Pearce et al. analyzed the effects of environmental exposure to $\mathrm{ClO}_{4}{ }^{-}$in a cohort of 1600 first-trimester pregnant women, with mild-to-moderate iodine deficiency, who had been enrolled in the Controlled Antenatal Thyroid Screening Study (CATS) from Cardiff (Wales) and Turin (Italy). The results of this observation displayed a low-level environment exposure to $\mathrm{ClO}_{4}{ }^{-}$in all participants but no thyroidal impairment due to this contamination was noted [96]. These findings were also confirmed in first-trimester pregnant women from Los Angeles (California) and Cordoba (Argentina) in whom a low concentration of urinary $\mathrm{ClO}_{4}{ }^{-}$were detected (mean of 7.8 and $13.5 \mu \mathrm{g} / \mathrm{L}$, respectively) but no correlation with $\mathrm{ClO}_{4}{ }^{-}$exposure and thyroid function was demonstrated [97]. A cross-sectional association between urinary $\mathrm{ClO}_{4}{ }^{-}$, thiocyanate and nitrate concentration and thyroid function was also assessed in healthy pregnant women living in New York City (New York State). The results confirm that a co-occurrent exposure to $\mathrm{ClO}_{4}{ }^{-}$, thiocyanate and nitrate may possibly impair thyroid homeostasis leading to hypothyroidism and $\mathrm{ClO}_{4}{ }^{-}$specifically 
displayed the largest weight in driving this outcome [98]. Taylor et al. evaluated the relationship between maternal $\mathrm{ClO}_{4}{ }^{-}$exposure and neurocognitive development in first-trimester pregnant women with hypothyroidism or hypothyroxinemia and mild iodine deficiency. The results display that maternal urinary $\mathrm{ClO}_{4}{ }^{-}$concentration in the highest $10 \%$ of the population were associated with an higher risk of offspring's verbal intellective quotient impairment [odds ratio 3.14 (1.38-7.13), p 0.006] and levothyroxine replacement did not improve the outcome [99]. In addition, a high risk of mild reduction in the verbal intellective quotient in 3-year-old children who were prenatally exposed to $\mathrm{ClO}_{4}{ }^{-}$was observed irrespective of their mother's thyroid function during pregnancy [100]. Furthermore, maternal $\mathrm{ClO}_{4}{ }^{-}$concentration was found to positively correlate with male infant bodyweight, especially in preterm [101].

Several observations assessed the relationship between maternal perchlorate exposure and neonatal or infant thyroid homeostasis with controversial results according to the different clinical end-points used for the assessment of euthyroidism [102-104]. $\mathrm{ClO}_{4}{ }^{-}$may affect children growth as reported by Mervish et al., who observed that girls with higher $\mathrm{ClO}_{4}{ }^{-}$exposure displayed lower body mass index and waist circumference than controls [105]. In addition, the results of a cross-sectional study in 3151 participants (12-80 years old) displayed for each logarithmic unit increased exposure to both $\mathrm{ClO}_{4}{ }^{-}$and thiocyanate, the level of free thyroxine decreased by $8 \%$ in adolescent girls and $9 \%$ in adolescent boys, respectively [106].

\subsection{Overview on Other Halogenate Compounds}

Other halogenated compounds may interfere with I uptake as similarly observed for $\mathrm{ClO}_{4}{ }^{-}$, including bromine and brominated compounds [107] and fluoride and fluorinated compounds [108]. Bromine compounds naturally occur in marine and terrestrial plants, but industrial compounds account for $80 \%$ of bromine production [109]. In particular, bromine compounds are essentially found in phytochemical, pharmaceutics, pesticides, dyes, and photographic and water treatment chemicals [109]. Bromine has been found at higher concentrations in seawater $(65$ to $80 \mathrm{mg} / \mathrm{L}$ ) compared to natural waters (in mean $0.5 \mathrm{mg} / \mathrm{L}$ ) and groundwaters (1 to several $\mathrm{mg} / \mathrm{L}$ ) [110]. In addition, potassium bromate is an inexpensive oxidizing agent used as dough improver in the baking industry [111]. Specifically, it leads to the formation of disulfide bonds between gluten proteins, ameliorating bread's proprieties, such as swelling and volume [112]. Chronic exposure to potassium bromate was associated with toxic effects and carcinogenicity in animal models [113-115]. However, no data are currently available to also confirm toxicity and carcinogenicity in humans, thus the International Agency for Research on Cancer classified potassium bromate in group 2B (possibly carcinogen to humans) [116]. Given these considerations, potassium bromate has been precautionarily banned from several countries, such as those in Europe, the United Kingdom, Canada, Nigeria, China, South Korea, and several countries in South America, but it is still considered safe in the United States. Indeed, according to the Food and Drug Administration, no sufficient evidence of potassium bromate adverse effects has been collected in humans thus allowing the use of additives in the bread baking industry not exceeding 75 parts per million [117]. For this reason, bromate levels should be constantly and reliably monitored in bread whether potassium bromate has been used as an additive in flour processing [112]. In one observational study in Nanchang (China), bromine was detected in all 131 whole blood samples, thus suggesting a higher prevalence of contamination among people [84]. The daily intake of bromide ranged from 2 to $8 \mathrm{mg}$ in the USA and $9 \mathrm{mg}$ in Europe (the Netherlands) [110]. Regulatory agencies defined limits of concentration bromide in drinking-waters at $6 \mathrm{mg} / \mathrm{L}$ for adults and $2 \mathrm{mg} / \mathrm{L}$ for children and acceptable daily intake currently ranges from 0 to $1 \mathrm{mg} / \mathrm{Kg}$ of bw [110]. Human exposure to brominated compounds usually occurs by food intake and consistently increases over time, resulting particularly higher in Occidental countries [118]. Breast milk as well as hair and adipose tissue may accumulate these chemicals, thus resulting as reservoirs for further persistence of brominated compounds in the human body [118]. Bromide may interfere with thyroid homeostasis, particularly competing with I uptake and I clearance $[119,120]$ however, human toxicity data demonstrated that polybrominated compounds 
may interfere with gonadal function and sexual steroids' metabolism [118]. Fluoride and fluorinated compounds has been found in different rock-forming minerals, fertilizers, pesticides, and propellants, and has also been found in drinking water generally at acceptable levels according to regulatory agencies $(<1.5 \mathrm{mg} / \mathrm{L}$ or $<4 \mathrm{mg} / \mathrm{L})$ [121] and groundwater [122]. Considering that a low dose of fluoride increases overall oral health, several countries add it to their public water supply at 0.7 to $1.5 \mathrm{mg} / \mathrm{L}$ [118]. In Italy, public waters are naturally rich in fluoride $(1 \mathrm{mg} / \mathrm{L})$, thus making fluoride addition in public supply unnecessary [123]. However, fluoride concentration in public waters differs among regions, and is particularly higher in Lazio, where an excessive consumption of public drinking-water may lead to a fluoride overexposure [123]. Concerns over fluoride overexposure through drinking water have been raised in several countries [124], in which the levels of fluoride intake exceed safety limits, leading to a relevant increase in the prevalence of both dental and skeletal fluorosis [125]. Fluoride has been found to block I uptake by two fundamental mechanisms: inhibition of sodium-potassium ATPase and a cytokine-mediated reduction in NIS gene expression [126]. Indeed, fluoride exposure in early stages of life, mostly for preventing dental caries, is believed to be linked with an higher risk of future development of several diseases, including hypothyroidism and impaired intellective quotient [127]. Moreover, the exposure to fluoride concentration at $100 \mathrm{ppm}$ $(\mathrm{mg} / \mathrm{L})$ in experimental conditions were associated with apoptosis, organelle damage and oxidative stress resulting in neurodegeneration, endocrine dysfunction and diabetes mellitus [128]. Due to anthropogenic and industrial activities, a great number of pollutant entry in water systems leading to possible concerns for wildlife and human health. Defluoridation of water may contribute in reducing the level of fluoride contamination in water and different physicochemical and electrochemical methods have been used for this purpose [129]. Among these, biosorption should be considered an easily available, recyclable and inexpensive tool [129].

\section{Discussion}

I sufficiency and euthyroidism are essential for preventing negative neurodevelopmental [130] outcomes and processing disorders [131], thus I deficiency or interference should be hazardous particularly during pregnancy and earlier stages of life given the particularly vulnerable thyroid function in this developmental phase. Conventionally, I deficiency has been defined as a 24-h urinary excretion $<100 \mu \mathrm{g} / \mathrm{L}$ [132]. Given this criteria, more than 2 billion people worldwide are at high risk of iodine insufficiency and at least half of European citizens exhibit a mild to moderate I deficiency [133]. Italy has been historically defined as being endemic for I deficiency, particularly in the northern mountainous regions. Strategies of implementation of iodine intake have been allowed by law since 1972 through the use, on a voluntary basis, of fortified salt with an I content of $15 \mu \mathrm{g} / \mathrm{Kg}$, subsequently augmented to $30 \mu \mathrm{g} / \mathrm{kg}$ (law 55/2005). Supplementation provided a slow but progressive improvement of iodine status over time but did not completely eradicate the risk $[134,135]$ and the prevalence of mild-to-moderate I deficiency remains a current matter [136], especially in pregnancy and lactation [137]. Of note, patients with I deficiency should be considered as highly susceptible for developing I interference by food intake. $\mathrm{ClO}_{4}{ }^{-}$has a short half-life (up to $8 \mathrm{~h}$ ) due to a quick renal clearance [138], thus its accumulation in human body is clearly due to chronic exposure to drinks and food $[139,140]$. $\mathrm{ClO}_{4}{ }^{-}$exposure may be harmful for thyroid homeostasis, especially in childhood and pregnancy. Two trials were performed to assess short term effects of a $\mathrm{ClO}_{4}{ }^{-}$acute exposure ( 2 weeks) to either 0.5 or $3 \mathrm{mg}$ daily, showing no effect on thyroid function [141,142]. However, 2 weeks of $\mathrm{ClO}_{4}{ }^{-}$exposure at higher doses (10 to $30 \mathrm{mg}$ per day) resulted in significantly reduced iodine uptake, potentially affecting thyroid hormone synthesis $[143,144]$. The results of these studies should be interpreted with caution, particularly considering that short-term exposure is usually insufficient to affect thyroid secretion of levothyroxine. Moreover, to achieve these levels of exposure, it could be necessary to have an extremely high daily consumption of $\mathrm{ClO}_{4}{ }^{-}$for a limited period of time which is normally not reproducible in real life (i.e., 2 litres of drinking water at $\mathrm{ClO}_{4}{ }^{-}$content as high as $200 \mu \mathrm{g} / \mathrm{L}$ ). On the other hand, studies which assessed the effect of a chronic $\mathrm{ClO}_{4}{ }^{-}$exposure 
(i.e., occupational) on thyroid hormone synthesis reported inclusive or equivocal results, despite I uptake being usually impaired in almost all participants [145-147]. Given these findings, it was difficult to make an unequivocal conclusion. The National Research Council of the National Academics sustained that, in healthy individuals, I uptake would be reduced by at least $75 \%$ for months in order to significantly impair thyroid hormone synthesis [47]. Thus, a sustained exposure to $0.5 \mathrm{mg} / \mathrm{Kg}$ of bw/day of $\mathrm{ClO}_{4}{ }^{-}$would be most likely to induce a significant decline in I uptake consequentlyaffecting thyroid hormone synthesis [47]. However, the US Environmental Protection Agency adopted a recommended reference dose for $\mathrm{ClO}_{4}{ }^{-}$at $0.7 \mu \mathrm{g} / \mathrm{kg}$ of bw/day [141]. This conservative decision was based upon a non-observed effect level found by Greer et al. in $2002(7 \mu \mathrm{g} / \mathrm{Kg}$ of bw/day) divided for an uncertainty factor of 10 attributable to intra-human variability intended to calculate an acceptable daily intake [144]. The Office of Environmental Health Hazards Assessment developed a public health target for $\mathrm{ClO}_{4}{ }^{-}$in drinking water of $6 \mu \mathrm{g} / \mathrm{L}$ in 2002 to $1 \mu \mathrm{g} / \mathrm{L}$ in 2012 [148]. In 2011, the Joint Food and Agriculture Organization-World Health Organization recognized a maximum tolerable daily intake of $10 \mu \mathrm{g} / \mathrm{kg}$ of body weight [149]. In Europe (France and Germany), the acceptable level of exposure to $\mathrm{ClO}_{4}{ }^{-}$was set at $0.7 \mu \mathrm{g} / \mathrm{kg}$ of bw with a tolerable concentration in drinking water of $15 \mu \mathrm{g} / \mathrm{L}$, successively reduced to $4 \mu \mathrm{g} / \mathrm{L}$ [47]. Furthermore, the European Food Safety Authority in 2014 predisposed the maximum tolerable daily dose of $0.3 \mu \mathrm{g} / \mathrm{Kg}$ of bw/day [70]. Water and soil contaminations have become a concern due to detrimental consequences for both wildlife and human health. Efficient methods for reducing the levels of $\mathrm{ClO}_{4}{ }^{-}$in fruits and vegetables represent useful tools to decrease the levels of exposure. Considering that the contamination of fruits and vegetables should reflect $\mathrm{ClO}_{4}{ }^{-}$concentration in soil, water for irrigation and fertilizers, several processes found application in this field [150]. As an example, ion exchangers, which replace $\mathrm{ClO}_{4}{ }^{-}$with other resident anions, such as bicarbonate, sulfate and nitrate, are one of the most used methods for removing $\mathrm{ClO}_{4}{ }^{-}$ from water and may be considered as a tool for dropping $\mathrm{ClO}_{4}{ }^{-}$levels throughout soil watering [151]. Biological degradation by perchlorate-reductase producer bacteria [152] or plants [150] could be counted as another useful method for reducing $\mathrm{ClO}_{4}{ }^{-}$in water and soil, respectively. Photocatalytic reduction of aqueous oxyanions converts toxic anions (such as $\mathrm{ClO}_{4}{ }^{-}$or bromate) into harmless and less and/or not toxic ions in contaminated waters [153]. However, several limitations have been described for this method, which include high costs of technologies, sunlight harvesting capability and generation of dangerous radical substances [153]. Physical methods include reverse osmosis coupled with nanofiltration membrane systems [154], or a less expensive semipermeable membrane system coupled with electrodialysis [155]. Moreover, iron-media adsorbent have been used for removing $\mathrm{ClO}_{4}{ }^{-}$and other anions in aqueous solutions [156]. In particular, granular ferric hydroxide was found to induce a rapid uptake of $\mathrm{ClO}_{4}{ }^{-}$in water, considering that its maximum absorption and equilibrium were achieved in 30 and $60 \mathrm{~min}$, respectively at $25^{\circ} \mathrm{C}$ with optimal $\mathrm{pH}$ at 3-7 [157]. $\mathrm{ClO}_{4}{ }^{-}$contamination of soil and water is strictly related to geogenic $\mathrm{ClO}_{4}{ }^{-}$naturally occurred in the atmosphere and subsequently precipitated. However, fertilizes may be considered a source of $\mathrm{ClO}_{4}{ }^{-}$accumulated in food chain [158]. Among fertilizers, higher levels of $\mathrm{ClO}_{4}{ }^{-}$were detected in nitrogenous fertilizers $(32.6 \mathrm{mg} / \mathrm{Kg})$ compared to natrium-phosphorus-potassium $(12.6 \mathrm{mg} / \mathrm{Kg})$, non-nitrogen $(10.2 \mathrm{mg} / \mathrm{Kg})$ and phosphates $(11.5 \mathrm{mg} / \mathrm{Kg})$ fertilizers [159]. Thus, the type and the amount of fertilizer may influence the source of entry for $\mathrm{ClO}_{4}{ }^{-}$in crops. Additionally, agronomic practices of fertilization may also contribute in this risk. As an example, fertigation is an innovative and less expensive methods of fertilization which allows for less water being wasted, better distribution of fertilizers and superior micronutrient assimilation by crops, but given these principles, it may be easier to foster more significant accumulations of $\mathrm{ClO}_{4}$ - in fruits and vegetables [60].

\section{Conclusions}

In conclusion, acute exposure to $\mathrm{ClO}_{4}{ }^{-}$by food and drink should not be a harmful concern for thyroid homeostasis in healthy individuals. Generally, chronic exposure to $\mathrm{ClO}_{4}{ }^{-}$by eating and drinking does not exceed the safety reference levels. However, lifelong effects of a low-dose 
exposure to $\mathrm{ClO}_{4}{ }^{-}$are currently unknown and concerns remain, especially for highly susceptible individuals such as pregnant and breastfeeding women, infants and children, cigarette smokers and high vegetable consumers, such as vegans. These clusters of patients should be advised about this worry, and encouraged to limit daily consumption of rich in perchlorate vegetables, as well as to implement I intake.

On the other hand, producers should be encouraged to use specific culture systems, fertilizers (as an example nitrate-free) as well as technologies for reducing the level of $\mathrm{ClO}_{4}{ }^{-}$in soil and irrigation waters in order to prevent an unnecessary $\mathrm{ClO}_{4}{ }^{-}$enrichment of crops. For this purpose, economic sustainment should be considered particularly for small and medium-size companies in order to reduce management costs.

Finally, further and specific long-term studies are probably needed to better explore this issue, aiming to clarify whether monitoring of perchlorate exposure over time, especially in individuals at risk, could be of interest for endocrinologists for better defining strategies of detection and prevention in exposed patients.

Author Contributions: V.T. conceived the review. V.T., G.L. and A.D.T. provided database search. G.L. and A.D.T. drafted the manuscript. All the authors (V.T., G.L., A.D.T., V.A.G., G.D.P.) read, gave feedback, and approved the final manuscript. All authors have read and agreed to the published version of the manuscript.

Funding: This research received no external funding.

Conflicts of Interest: The authors declare no conflict of interest.

\section{Appendix A}

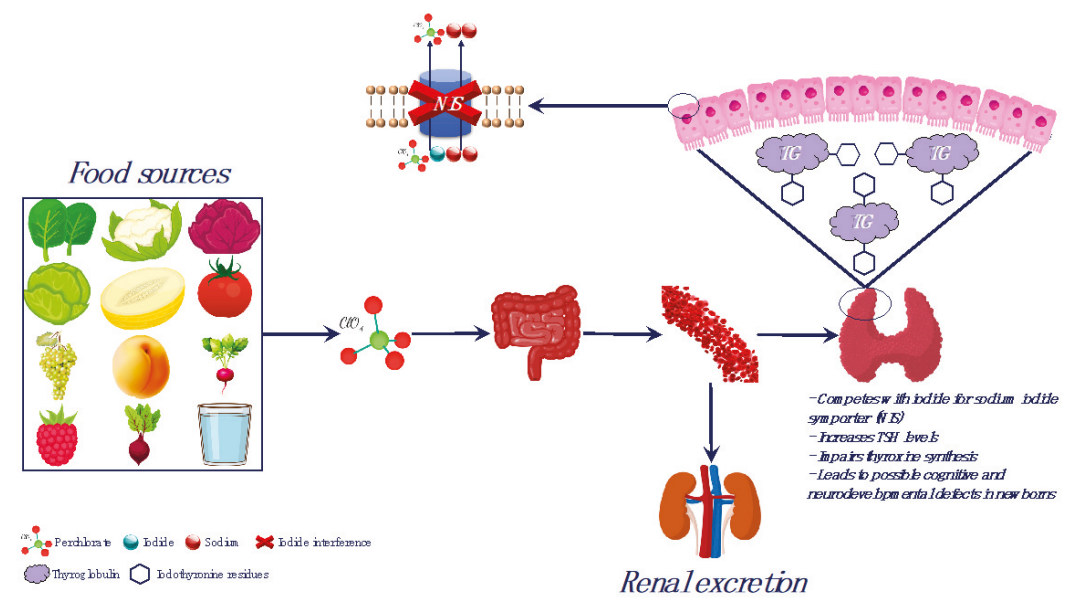

Figure A1. Simplified representation of perchlorate metabolism, distribution and iodide interference (specifically at the level of thyroid gland).

\section{References}

1. Thomas Zoeller, R.; Brown, T.R.; Doan, L.L.; Gore, A.C.; Skakkebaek, N.E.; Soto, A.M.; Woodruff, T.J.; Vom Saal, F.S. Endocrine-disrupting chemicals and public health protection: A statement of principles from the Endocrine Society. Endocrinology 2012, 153, 4097-4110. [CrossRef]

2. La Merrill, M.A.; Vandenberg, L.N.; Smith, M.T.; Goodson, W.; Browne, P.; Patisaul, H.B.; Guyton, K.Z.; Kortenkamp, A.; Cogliano, V.J.; Woodruff, T.J.; et al. Consensus on the key characteristics of endocrine-disrupting chemicals as a basis for hazard identification. Nat. Rev. Endocrinol. 2020, 16, 45-57. [CrossRef] 
3. Langer, P.; Kočan, A.; Tajtáková, M.; Koška, J.; Rádiková, Ž.; Kšinantová, L.; Imrich, R.; Hučková, M.; Drobná, B.; Gašperíková, D.; et al. Increased thyroid volume, prevalence of thyroid antibodies and impaired fasting glucose in young adults from organochlorine cocktail polluted area: Outcome of transgenerational transmission? Chemosphere 2008, 73, 1145-1150. [CrossRef]

4. Street, M.E.; Angelini, S.; Bernasconi, S.; Burgio, E.; Cassio, A.; Catellani, C.; Cirillo, F.; Deodati, A.; Fabbrizi, E.; Fanos, V.; et al. Current knowledge on endocrine disrupting chemicals (EDCs) from animal biology to humans, from pregnancy to adulthood: Highlights from a national italian meeting. Int. J. Mol. Sci. 2018, 19, 1647. [CrossRef] [PubMed]

5. Ferrari, S.M.; Fallahi, P.; Antonelli, A.; Benvenga, S. Environmental issues in thyroid diseases. Front. Endocrinol. 2017, 8, 50. [CrossRef]

6. Yilmaz, B.; Terekeci, H.; Sandal, S.; Kelestimur, F. Endocrine disrupting chemicals: Exposure, effects on human health, mechanism of action, models for testing and strategies for prevention. Rev. Endocr. Metab. Disord. 2019, 21, 127-147. [CrossRef]

7. Boas, M.; Feldt-Rasmussen, U.; Main, K.M. Thyroid effects of endocrine disrupting chemicals. Mol. Cell. Endocrinol. 2012, 355, 240-248. [CrossRef] [PubMed]

8. Calsolaro, V.; Pasqualetti, G.; Niccolai, F.; Caraccio, N.; Monzani, F. Thyroid disrupting chemicals. Int. J. Mol. Sci. 2017, 18, 2583. [CrossRef] [PubMed]

9. Mughal, B.B.; Fini, J.B.; Demeneix, B.A. Thyroid-disrupting chemicals and brain development: An update. Endocr. Connect. 2018, 7, R160-R186. [CrossRef] [PubMed]

10. Melzer, D.; Rice, N.; Depledge, M.H.; Henley, W.E.; Galloway, T.S. Association between serum perfluorooctanoic acid (PFOA) and thyroid disease in the U.S. National Health and Nutrition Examination Survey. Environ. Health Perspect. 2010, 118, 686-692. [CrossRef]

11. MacKay, H.; Abizaid, A. A plurality of molecular targets: The receptor ecosystem for bisphenol-A (BPA). Horm. Behav. 2018, 101, 59-67. [CrossRef] [PubMed]

12. Wang, N.; Zhou, Y.; Fu, C.; Wang, H.; Huang, P.; Wang, B.; Su, M.; Jiang, F.; Fang, H.; Zhao, Q.; et al. Influence of Bisphenol A on Thyroid Volume and Structure Independent of Iodine in School Children. PLoS ONE 2015, 10, e0141248. [CrossRef]

13. Li, L.; Ying, Y.; Zhang, C.; Wang, W.; Li, Y.; Feng, Y.; Liang, J.; Song, H.; Wang, Y. Bisphenol A exposure and risk of thyroid nodules in Chinese women: A case-control study. Environ. Int. 2019, 126, 321-328. [CrossRef] [PubMed]

14. Leemans, M.; Couderq, S.; Demeneix, B.; Fini, J.B. Pesticides With Potential Thyroid Hormone-Disrupting Effects: A Review of Recent Data. Front. Endocrinol. 2019, 10, 743. [CrossRef] [PubMed]

15. Campos, É.; Freire, C. Exposure to non-persistent pesticides and thyroid function: A systematic review of epidemiological evidence. Int. J. Hyg. Environ. Health 2016, 219, 481-497. [CrossRef] [PubMed]

16. Witorsch, R.J. Critical analysis of endocrine disruptive activity of triclosan and its relevance to human exposure through the use of personal care products. Crit. Rev. Toxicol. 2014, 44, 535-555. [CrossRef] [PubMed]

17. Demeneix, B.A. Evidence for Prenatal Exposure to Thyroid Disruptors and Adverse Effects on Brain Development. Eur. Thyroid J. 2019, 8, 283-292. [CrossRef]

18. Pearce, E.N.; Braverman, L.E. Environmental pollutants and the thyroid. Best Pract. Res. Clin. Endocrinol. Metab. 2009, 23, 801-813. [CrossRef]

19. Pironi, L.; Guidetti, M.; Agostini, F. Iodine status in intestinal failure in adults. Curr. Opin. Clin. Nutr. Metab. Care 2015, 18, 582-587. [CrossRef] [PubMed]

20. Nicola, J.P.; Carrasco, N.; Masini-Repiso, A.M. Dietary I- Absorption: Expression and Regulation of the $\mathrm{Na}+\mathrm{I}-$ Symporter in the Intestine. Vitam. Horm. 2015, 98, 1-31.

21. Cavalieri, R.R. Iodine metabolism and thyroid physiology: Current concepts. Thyroid 1997, 7, 177-181. [CrossRef] [PubMed]

22. Ravera, S.; Reyna-Neyra, A.; Ferrandino, G.; Amzel, L.M.; Carrasco, N. The Sodium/Iodide Symporter (NIS): Molecular Physiology and Preclinical and Clinical Applications. Annu. Rev. Physiol. 2017, 79, 261-289. [CrossRef] [PubMed]

23. Dai, G.; Levy, O.; Carrasco, N. Cloning and characterization of the thyroid iodide transporter. Nature 1996, 379, 458-460. [CrossRef] [PubMed]

24. Carrasco, N. Iodide transport in the thyroid gland. BBA Rev. Biomembr. 1993, 1154, 65-82. [CrossRef] 
25. Milanesi, A.; Brent, G.A. Iodine and Thyroid Hormone Synthesis, Metabolism, and Action. Mol. Genet. Nutr. Asp. Major Trace Miner. 2017, 143-150.

26. Lee, S.Y.; Chang, D.L.F.; He, X.; Pearce, E.N.; Braverman, L.E.; Leung, A.M. Urinary iodine excretion and serum thyroid function in adults after iodinated contrast administration. Thyroid 2015, 25, 471-477. [CrossRef]

27. Dunn, J.T.; Dunn, A.D. Update on intrathyroidal iodine metabolism. Thyroid 2001, 11, 407-414. [CrossRef]

28. Rohner, F.; Zimmermann, M.; Jooste, P.; Pandav, C.; Caldwell, K.; Raghavan, R.; Raiten, D.J. Biomarkers of Nutrition for Development-Iodine Review. J. Nutr. 2014, 144, 1322S-1342S. [CrossRef]

29. Glinoer, D. The regulation of thyroid function in pregnancy: Pathways of endocrine adaptation from physiology to pathology. Endocr. Rev. 1997, 18, 404-433. [CrossRef]

30. Osei, J.; Andersson, M.; van der Reijden, O.; Dold, S.; Smuts, C.M.; Baumgartner, J. Breast-milk iodine concentrations, iodine status, and thyroid function of breastfed infants aged $2-4$ months and their mothers residing in a south african township. JCRPE J. Clin. Res. Pediatr. Endocrinol. 2016, 8, 381-391. [CrossRef]

31. Guideline: Fortification of Food-Grade Salt with Iodine for the Prevention and Control of Iodine Deficiency Disorders. Available online: https://www.who.int/publications-detail/9789241507929 (accessed on 3 June 2020).

32. De Groot, L.; Abalovich, M.; Alexander, E.K.; Amino, N.; Barbour, L.; Cobin, R.H.; Eastman, C.J.; Lazarus, J.H.; Luton, D.; Mandel, S.J.; et al. Management of thyroid dysfunction during pregnancy and postpartum: An endocrine society clinical practice guideline. J. Clin. Endocrinol. Metab. 2012, 97, 2543-2565. [CrossRef] [PubMed]

33. Triggiani, V.; Tafaro, E.; Giagulli, V.; Sabba, C.; Resta, F.; Licchelli, B.; Guastamacchia, E. Role of Iodine, Selenium and Other Micronutrients in Thyroid Function and Disorders. Endocr. Metab. Immune Disord. Drug Targets 2009, 9, 277-294. [CrossRef] [PubMed]

34. Guastamacchia, E.; Giagulli, V.; Licchelli, B.; Triggiani, V. Selenium and Iodine in Autoimmune Thyroiditis. Endocr. Metab. Immune Disord. Targets 2015, 15, 288-292. [CrossRef] [PubMed]

35. Bizhanova, A.; Kopp, P. Minireview: The sodium-iodide symporter NIS and pendrin in iodide homeostasis of the thyroid. Endocrinology 2009, 150, 1084-1090. [CrossRef] [PubMed]

36. Wémeau, J.L.; Kopp, P. Pendred syndrome. Best Pract. Res. Clin. Endocrinol. Metab. 2017, 31, $213-224$. [CrossRef]

37. Leung, A.M.; Braverman, L.E. Consequences of excess iodine. Nat. Rev. Endocrinol. 2014, 10, 136-142. [CrossRef]

38. Sundick, R.S.; Bagchi, N.; Brown, T.R. The role of iodine in thyroid autoimmunity: From chickens to humans: A review. Autoimmunity 1992, 13, 61-68. [CrossRef]

39. Katagiri, R.; Yuan, X.; Kobayashi, S.; Sasaki, S. Effect of excess iodine intake on thyroid diseases in different populations: A systematic review and meta-analyses including observational studies. PLoS ONE 2017, 12, e0173722. [CrossRef]

40. Stanbury, J.B.; Wyngaarden, J.B. Effect of perchlorate on the human thyroid gland. Metabolism 1952, 1, 533-539.

41. Leung, A.M.; Pearce, E.N.; Braverman, L.E. Perchlorate, iodine and the thyroid. Best Pract. Res. Clin. Endocrinol. Metab. 2010, 24, 133-141. [CrossRef]

42. Tonacchera, M.; Pinchera, A.; Dimida, A.; Ferrarini, E.; Agretti, P.; Vitti, P.; Santini, F.; Crump, K.; Gibbs, J. Relative potencies and additivity of perchlorate, thiocyanate, nitrate, and iodide on the inhibition of radioactive iodide uptake by the human sodium iodide symporter. Thyroid 2004, 14, 1012-1019. [CrossRef] [PubMed]

43. Concilio, S.C.; Zhekova, H.R.; Noskov, S.Y.; Russell, S.J. Inter-species variation in monovalent anion substrate selectivity and inhibitor sensitivity in the sodium iodide symporter (NIS). PLOS ONE 2020, 15, e0229085. [CrossRef] [PubMed]

44. Chen, H.X.; Ding, M.H.; Li, Y.G.; Liu, Q.; Peng, K.L. Dose-Response Relationship between Orally Administered Ammonium Perchlorate and Urine Perchlorate Concentrations in Rats: Possible Biomarker to Quantify Environmental Ammonium Perchlorate Exposure on Thyroid Homeostasis. Arch. Environ. Occup. Health 2015, 70, 286-290. [CrossRef] [PubMed]

45. Hershman, J.M. Perchlorate and thyroid function: What are the environmental issues? Thyroid 2005, 15, 427-431. [CrossRef] 
46. Suh, M.; Abraham, L.; Hixon, J.G.; Proctor, D.M. The effects of perchlorate, nitrate, and thiocyanate on free thyroxine for potentially sensitive subpopulations o. The 2001-2002 and 2007-2008 National Health and Nutrition Examination Surveys. J. Expo. Sci. Environ. Epidemiol. 2014, 24, 579-587. [CrossRef]

47. EFSA Panel on Contaminants in the Food Chain (CONTAM). Scientific Opinion on the risks to public health related to the presence of perchlorate in food, in particular fruits and vegetables. EFSA J. 2014, 12, 3869. [CrossRef]

48. Kounaves, S.P.; Stroble, S.T.; Anderson, R.M.; Moore, Q.; Catling, D.C.; Douglas, S.; Mckay, C.P.; Ming, D.W.; Smith, P.H.; Tamppari, L.K.; et al. Discovery of natural Perchlorate in the Antarctic Dry Valleys and its global implications. Environ. Sci. Technol. 2010, 44, 2360-2364. [CrossRef]

49. Calderón, R.; Palma, P.; Parker, D.; Molina, M.; Godoy, F.A.; Escudey, M. Perchlorate levels in soil and waters from the Atacama Desert. Arch. Environ. Contam. Toxicol. 2014, 66, 155-161. [CrossRef]

50. Kumarathilaka, P.; Oze, C.; Indraratne, S.P.; Vithanage, M. Perchlorate as an emerging contaminant in soil, water and food. Chemosphere 2016, 150, 667-677. [CrossRef]

51. Furdui, V.I.; Zheng, J.; Furdui, A. Anthropogenic Perchlorate Increases since 1980 in the Canadian High Arctic. Environ. Sci. Technol. 2018, 52, 972-981. [CrossRef]

52. Furdui, V.I.; Tomassini, F. Trends and sources of perchlorate in Arctic snow. Environ. Sci. Technol. 2010, 44, 588-592. [CrossRef] [PubMed]

53. Dasgupta, P.K.; Martinelango, P.K.; Jackson, W.A.; Anderson, T.A.; Tian, K.; Tock, R.W.; Rajagopalan, S. The origin of naturally occurring perchlorate: The role of atmospheric processes. Environ. Sci. Technol. 2005, 39, 1569-1575. [CrossRef]

54. Kannan, K.; Praamsma, M.L.; Oldi, J.F.; Kunisue, T.; Sinha, R.K. Occurrence of perchlorate in drinking water, groundwater, surface water and human saliva from India. Chemosphere 2009, 76, 22-26. [CrossRef]

55. Qin, X.; Zhang, T.; Gan, Z.; Sun, H. Spatial distribution of perchlorate, iodide and thiocyanate in the aquatic environment of Tianjin, China: Environmental source analysis. Chemosphere 2014, 111, 201-208. [CrossRef] [PubMed]

56. Munster, J.; Hanson, G.N.; Jackson, W.A.; Rajagopalan, S. The fallout from fireworks: Perchlorate in total deposition. Water Air Soil Pollut. 2009, 198, 149-153. [CrossRef]

57. Rajagopalan, S.; Anderson, T.; Cox, S.; Harvey, G.; Cheng, Q.; Jackson, W.A. Perchlorate in Wet Deposition Across North America. Environ. Sci. Technol. 2009, 43, 616-622. [CrossRef] [PubMed]

58. Urbansky, E.T.; Brown, S.K. Perchlorate retention and mobility in soils. J. Environ. Monit. 2003, 5, 455-462. [CrossRef]

59. Dugan, N.R.; Williams, D.J.; Meyer, M.; Schneider, R.R.; Speth, T.F.; Metz, D.H. The impact of temperature on the performance of anaerobic biological treatment of perchlorate in drinking water. Water Res. 2009, 43, 1867-1878. [CrossRef]

60. Calderón, R.; Palma, P.; Eltit, K.; Arancibia-Miranda, N.; Silva-Moreno, E.; Yu, W. Field study on the uptake, accumulation and risk assessment of perchlorate in a soil-chard/spinach system: Impact of agronomic practices and fertilization. Sci. Total Environ. 2020, 719, 137411. [CrossRef]

61. Calderón, R.; Godoy, F.; Escudey, M.; Palma, P. A review of perchlorate (ClO4-) occurrence in fruits and vegetables. Environ. Monit. Assess. 2017, 189, 82. [CrossRef]

62. Wang, Z.; Forsyth, D.; Lau, B.P.Y.; Pelletier, L.; Bronson, R.; Gaertner, D. Estimated dietary exposure of canadians to perchlorate through the consumption of fruits and vegetables available in Ottawa markets. J. Agric. Food Chem. 2009, 57, 9250-9255. [CrossRef] [PubMed]

63. Vega, M.; Nerenberg, R.; Vargas, I.T. Perchlorate contamination in Chile: Legacy, challenges, and potential solutions. Environ. Res. 2018, 164, 316-326. [CrossRef]

64. Steinmaus, C.M. Perchlorate in Water Supplies: Sources, Exposures, and Health Effects. Curr. Environ. Health Rep. 2016, 3, 136-143. [CrossRef] [PubMed]

65. Iannece, P.; Motta, O.; Tedesco, R.; Carotenuto, M.; Proto, A. Determination of Perchlorate in Bottled Water from Italy. Water 2013, 5, 767-779. [CrossRef]

66. Agrarmarkt Informations-Gesellschaft MbH. European Statistics Handbook-FRUIT LOGISTICA 2019. Available online: www.AMI-informiert.de (accessed on 2 March 2020).

67. OEC. Chile (CHL) Exports, Imports, and Trade Partners. Available online: https://oec.world/en/profile/ country/chl/ (accessed on 11 May 2020). 
68. Chilean Table Grape Exports to Europe Increase by 36\%. Available online: https://www.freshplaza.com/ article/9196058/chilean-table-grape-exports-to-europe-increase-by-36/ (accessed on 11 May 2020).

69. Chile-Trade-European Commission. Available online: https://ec.europa.eu/trade/policy/countries-andregions/countries/chile/ (accessed on 11 May 2020).

70. Arcella, D.; Binaglia, M.; Vernazza, F. Dietary exposure assessment to perchlorate in the European population. EFSA J. 2017, 15, e05043.

71. Dong, H.; Xiao, K.; Xian, Y.; Wu, Y.; Zhu, L. A novel approach for simultaneous analysis of perchlorate (ClO4-) and bromate (BrO3-) in fruits and vegetables using modified QuEChERS combined with ultrahigh performance liquid chromatography-tandem mass spectrometry. Food Chem. 2019, 270, 196-203. [CrossRef]

72. Vejdovszky, K.; Grossgut, R.; Unterluggauer, H.; Inreiter, N.; Steinwider, J. Risk assessment of dietary exposure to perchlorate for the Austrian population. Food Addit. Contam. Part A Chem. Anal. Control. Expo. Risk Assess. 2018, 35, 623-631. [CrossRef]

73. Liu, Y.; Sun, H.; Zhou, L.; Luo, F.; Zhang, X.; Chen, Z. Quantitative determination and contamination pattern of perchlorate in tea by ultra performance liquid chromatography and tandem mass spectrometry. Food Chem. 2019, 274, 180-186. [CrossRef]

74. Huber, D.R.; Blount, B.C.; Mage, D.T.; Letkiewicz, F.J.; Kumar, A.; Allen, R.H. Estimating perchlorate exposure from food and tap water based on US biomonitoring and occurrence data. J. Expo. Sci. Environ. Epidemiol. 2011, 21, 395-407. [CrossRef]

75. Blount, B.C.; Valentin-Blasini, L.; Osterloh, J.D.; Mauldin, J.P.; Pirkle, J.L. Perchlorate exposure of the US population, 2001-2002. J. Expo. Sci. Environ. Epidemiol. 2007, 17, 400-407. [CrossRef]

76. Zoeller, T.R. Environmental chemicals targeting thyroid. Hormones 2010, 9, 28-40. [CrossRef]

77. Vandenberg, L.N.; Colborn, T.; Hayes, T.B.; Heindel, J.J.; Jacobs, D.R.; Lee, D.H.; Shioda, T.; Soto, A.M.; vom Saal, F.S.; Welshons, W.V.; et al. Hormones and endocrine-disrupting chemicals: Low-dose effects and nonmonotonic dose responses. Endocr. Rev. 2012, 33, 378-455. [CrossRef] [PubMed]

78. Lee, S.Y.; McCarthy, A.M.; Stohl, H.; Ibrahim, S.; Jeong, C.; Braverman, L.E.; Ma, W.; He, X.; Mestman, J.H.; Schuller, K.E.; et al. Urinary Iodine, Perchlorate, and Thiocyanate Concentrations in U.S. Lactating Women. Thyroid 2017, 27, 1574-1581. [CrossRef] [PubMed]

79. Leung, A.M.; LaMar, A.; He, X.; Braverman, L.E.; Pearce, E.N. Iodine status and thyroid function of Boston-area vegetarians and vegans. J. Clin. Endocrinol. Metab. 2011, 96, E1303-E1307. [CrossRef] [PubMed]

80. De Groef, B.; Decallonne, B.R.; Van der Geyten, S.; Darras, V.M.; Bouillon, R. Perchlorate versus other environmental sodium/iodide symporter inhibitors: Potential thyroid-related health effects. Eur. J. Endocrinol. 2006, 155, 17-25. [CrossRef]

81. Téllez, R.T.; Chacón, P.M.; Abarca, C.R.; Blount, B.C.; Van Landingham, C.B.; Crump, K.S.; Gibbs, J.P. Long-term environmental exposure to perchlorate through drinking water and thyroid function during pregnancy and the neonatal period. Thyroid 2005, 15, 963-975. [CrossRef]

82. Maffini, M.V.; Trasande, L.; Neltner, T.G. Perchlorate and Diet: Human Exposures, Risks, and Mitigation Strategies. Curr. Environ. Health Rep. 2016, 3, 107-117. [CrossRef]

83. Borjan, M.; Marcella, S.; Blount, B.; Greenberg, M.; Zhang, J.; Murphy, E.; Valentin-Blasini, L.; Robson, M. Perchlorate exposure in lactating women in an urban community in New Jersey. Sci. Total Environ. 2011, 409, 460-464. [CrossRef]

84. Zhang, T.; Wu, Q.; Sun, H.W.; Rao, J.; Kannan, K. Perchlorate and iodide in whole blood samples from infants, children, and adults in Nanchang, China. Environ. Sci. Technol. 2010, 44, 6947-6953. [CrossRef]

85. Valentín-Blasini, L.; Blount, B.C.; Otero-Santos, S.; Cao, Y.; Bernbaum, J.C.; Rogan, W.J. Perchlorate exposure and dose estimates in infants. Environ. Sci. Technol. 2011, 45, 4127-4132. [CrossRef]

86. Lau, F.K.; Decastro, B.R.; Mills-Herring, L.; Tao, L.; Valentin-Blasini, L.; Alwis, K.U.; Blount, B.C. Urinary perchlorate as a measure of dietary and drinking water exposure in a representative sample of the United States population 2001-2008. J. Expo. Sci. Environ. Epidemiol. 2013, 23, 207-214. [CrossRef]

87. Crump, C.; Michaud, P.; Téllez, R.; Reyes, C.; Gonzalez, G.; Montgomery, E.L.; Crump, K.S.; Lobo, G.; Becerra, C.; Gibbs, J.P. Does perchlorate in drinking water affect thyroid function in newborns or school-age children? J. Occup. Environ. Med. 2000, 42, 603-612. [CrossRef] [PubMed]

88. Levie, D.; Korevaar, T.I.M.; Bath, S.C.; Murcia, M.; Dineva, M.; Llop, S.; Espada, M.; van Herwaarden, A.E.; de Rijke, Y.B.; Ibarluzea, J.M.; et al. Association of Maternal Iodine Status With Child IQ: A Meta-Analysis of Individual Participant Data. J. Clin. Endocrinol. Metab. 2019, 104, 5957-5967. [CrossRef] [PubMed] 
89. Knight, B.A.; Shields, B.M.; He, X.; Pearce, E.N.; Braverman, L.E.; Sturley, R.; Vaidya, B. Effect of perchlorate and thiocyanate exposure on thyroid function of pregnant women from South-West England: A cohort study. Thyroid Res. 2018, 11, 9. [CrossRef] [PubMed]

90. Mitchell, A.M.; Manley, S.W.; Morris, J.C.; Powell, K.A.; Bergert, E.R.; Mortimer, R.H. Sodium iodide symporter (NIS) gene expression in human placenta. Placenta 2001, 22, 256-258. [CrossRef] [PubMed]

91. Blount, B.C.; Rich, D.Q.; Valentin-Blasini, L.; Lashley, S.; Ananth, C.V.; Murphy, E.; Smulian, J.C.; Spain, B.J.; Barr, D.; Ledoux, T.; et al. Perinatal exposure to perchlorate, thiocyanate, and nitrate in New Jersey mothers and newborns. Environ. Sci. Technol. 2009, 43, 7543-7549. [CrossRef]

92. Zhang, T.; Ma, Y.; Wang, D.; Li, R.; Chen, X.; Mo, W.; Qin, X.; Sun, H.; Kannan, K. Placental transfer of and infantile exposure to perchlorate. Chemosphere 2016, 144, 948-954. [CrossRef]

93. Pearce, E.N.; Alexiou, M.; Koukkou, E.; Braverman, L.E.; He, X.; Ilias, I.; Alevizaki, M.; Markou, K.B. Perchlorate and thiocyanate exposure and thyroid function in first-trimester pregnant women from Greece. Clin. Endocrinol. 2012, 77, 471-474. [CrossRef]

94. Charatcharoenwitthaya, N.; Ongphiphadhanakul, B.; Pearce, E.N.; Somprasit, C.; Chanthasenanont, A.; He, X.; Chailurkit, L.; Braverman, L.E. The association between perchlorate and thiocyanate exposure and thyroid function in first-trimester pregnant Thai women. J. Clin. Endocrinol. Metab. 2014, 99, 2365-2371. [CrossRef]

95. Steinmaus, C.; Pearl, M.; Kharrazi, M.; Blount, B.C.; Miller, M.D.; Pearce, E.N.; Valentin-Blasini, L.; DeLorenze, G.; Hoofnagle, A.N.; Liaw, J. Thyroid hormones and moderate exposure to perchlorate during pregnancy in women in southern California. Environ. Health Perspect. 2016, 124, 861-867. [CrossRef]

96. Pearce, E.N.; Lazarus, J.H.; Smyth, P.P.A.; He, X.; Dall'Amico, D.; Parkes, A.B.; Burns, R.; Smith, D.F.; Maina, A.; Bestwick, J.P.; et al. Perchlorate and thiocyanate exposure and thyroid function in first-trimester pregnant women. J. Clin. Endocrinol. Metab. 2010, 95, 3207-3215. [CrossRef] [PubMed]

97. Pearce, E.N.; Spencer, C.A.; Mestman, J.H.; Lee, R.H.; Bergoglio, L.M.; Mereshian, P.; He, X.; Leung, A.M.; Braverman, L.E. Effect of environmental perchlorate on thyroid function in pregnant women from Córdoba, Argentina, and Los Angeles, California. Endocr. Pract. 2011, 17, 412-417. [CrossRef] [PubMed]

98. Horton, M.K.; Blount, B.C.; Valentin-Blasini, L.; Wapner, R.; Whyatt, R.; Gennings, C.; Factor-Litvak, P. CO-occurring exposure to perchlorate, nitrate and thiocyanate alters thyroid function in healthy pregnant women. Environ. Res. 2015, 143, 1-9. [CrossRef] [PubMed]

99. Taylor, P.N.; Okosieme, O.E.; Murphy, R.; Hales, C.; Chiusano, E.; Maina, A.; Joomun, M.; Bestwick, J.P.; Smyth, P.; Paradice, R.; et al. Maternal perchlorate levels in women with borderline thyroid function during pregnancy and the cognitive development of their offspring: Data from the controlled antenatal thyroid study. J. Clin. Endocrinol. Metab. 2014, 99, 4291-4298. [CrossRef]

100. Brent, G.A. Perchlorate exposure in pregnancy and cognitive outcomes in children: It's not your mother's thyroid. J. Clin. Endocrinol. Metab. 2014, 99, 4066-4068. [CrossRef]

101. Rubin, R.; Pearl, M.; Kharrazi, M.; Blount, B.C.; Miller, M.D.; Pearce, E.N.; Valentin-Blasini, L.; DeLorenze, G.; Liaw, J.; Hoofnagle, A.N.; et al. Maternal perchlorate exposure in pregnancy and altered birth outcomes. Environ. Res. 2017, 158, 72-81. [CrossRef]

102. Buffler, P.A.; Kelsh, M.A.; Lau, E.C.; Edinboro, C.H.; Barnard, J.C.; Rutherford, G.W.; Daaboul, J.J.; Palmer, L.; Lorey, F.W. Thyroid function and perchlorate in drinking water: An evaluation among California newborns, 1998. Environ. Health Perspect. 2006, 114, 798-804. [CrossRef]

103. Amitai, Y.; Winston, G.; Sack, J.; Wasser, J.; Lewis, M.; Blount, B.C.; Valentin-Blasini, L.; Fisher, N.; Israeli, A.; Leventhal, A. Gestational exposure to high perchlorate concentrations in drinking water and neonatal thyroxine levels. Thyroid 2007, 17, 843-850. [CrossRef]

104. Steinmaus, C.; Miller, M.D.; Smith, A.H. Perchlorate in drinking water during pregnancy and neonatal thyroid hormone levels in California. J. Occup. Environ. Med. 2010, 52, 1217-1224. [CrossRef]

105. Mervish, N.A.; Pajak, A.; Teitelbaum, S.L.; Pinney, S.M.; Windham, G.C.; Kushi, L.H.; Biro, F.M.; Valentin-Blasini, L.; Blount, B.C.; Wolff, M.S. Thyroid antagonists (perchlorate, thiocyanate, and nitrate) and childhood growth in a longitudinal study of U.S. girls. Environ. Health Perspect. 2016, 124, 542-549. [CrossRef]

106. McMullen, J.; Ghassabian, A.; Kohn, B.; Trasande, L. Identifying subpopulations vulnerable to the thyroid-blocking effectsof perchlorateandthiocyanate. J. Clin. Endocrinol. Metab. 2017, 102, 2637-2645. [CrossRef] [PubMed] 
107. Van Sande, J.; Massart, C.; Beauwens, R.; Schoutens, A.; Costagliola, S.; Dumont, J.E.; Wolff, J. Anion selectivity by the sodium iodide symporter. Endocrinology 2003, 144, 247-252. [CrossRef] [PubMed]

108. Jianjie, C.; Wenjuan, X.; Jinling, C.; Jie, S.; Ruhui, J.; Meiyan, L. Fluoride caused thyroid endocrine disruption in male zebrafish (Danio rerio). Aquat. Toxicol. 2016, 171, 48-58. [CrossRef] [PubMed]

109. Yoffe, D.; Frim, R.; Ukeles, S.D.; Dagani, M.J.; Barda, H.J.; Benya, T.J.; Sanders, D.C. Bromine Compounds. In Ullmann's Encyclopedia of Industrial Chemistry; Wiley-VCH Verlag GmbH \& Co. KGaA: Weinheim, Germany, 2013; pp. 1-31.

110. Bromine as a Drinking-Water Disinfectant Alternative Drinking-Water Disinfectants: Bromine. 2018. Available online: http://apps.who.int/bookorders (accessed on 27 May 2020).

111. Thewlis, B.H. The fate of potassium bromate when used as a breadmaking improver. J. Sci. Food Agric. 1974, 25, 1471-1475. [CrossRef]

112. Shanmugavel, V.; Komala Santhi, K.; Kurup, A.H.; Kalakandan, S.; Anandharaj, A.; Rawson, A. Potassium bromate: Effects on bread components, health, environment and method of analysis: A review. Food Chem. 2020, 311, 125964. [CrossRef] [PubMed]

113. Mitsumori, K.; Maita, K.; Kosaka, T.; Miyaoka, T.; Shirasu, Y. Two-year oral chronic toxicity and carcinogenicity study in rats of diets fumigated with methyl bromide. Food Chem. Toxicol. 1990, 28, 109-119. [CrossRef]

114. Kurokawa, Y.; Maekawa, A.; Takahashi, M.; Hayashi, Y. Toxicity and carcinogenicity of potassium bromate-A new renal carcinogen. Environ. Health Perspect. 1990, 87, 309-335.

115. Umemura, T.; Sai, K.; Takagi, A.; Hasegawa, R.; Kurokawa, Y. A possible role for cell proliferation in potassium bromate (KBrO3) carcinogenesis. J. Cancer Res. Clin. Oncol. 1993, 119, 463-469. [CrossRef]

116. Last eval.: Potassium Bromate (IARC Summary \& Evaluation, Volume 73, 1999). Available online: http://www.inchem.org/documents/iarc/vol73/73-17.html (accessed on 31 May 2020).

117. FDA CFR - Code of Federal Regulations Title 21. Available online: https://www.accessdata.fda.gov/scripts/ cdrh/cfdocs/cfcfr/CFRSearch.cfm?fr=172.730 (accessed on 31 May 2020).

118. Wu, Z.; He, C.; Han, W.; Song, J.; Li, H.; Zhang, Y.; Jing, X.; Wu, W. Exposure pathways, levels and toxicity of polybrominated diphenyl ethers in humans: A review. Environ. Res. 2020, 187, 109531. [CrossRef]

119. Pavelka, S. Metabolism of Bromide and Its Interference With the Metabolism of Iodine. Physiol. Res. 2004, 53 (Suppl. 1), S81-S90.

120. Block, J. Nineteenth-Century Homeopathic Materia Medica Texts Predict Source Materials Whose Physiological Actions Influence Thyroid Activity. Homeopathy 2019, 108, 214-222. [CrossRef] [PubMed]

121. Yadav, K.K.; Gupta, N.; Kumar, V.; Khan, S.A.; Kumar, A. A review of emerging adsorbents and current demand for defluoridation of water: Bright future in water sustainability. Environ. Int. 2018, 111, 80-108. [CrossRef] [PubMed]

122. Kurwadkar, S. Occurrence and distribution of organic and inorganic pollutants in groundwater. Water Environ. Res. 2019, 91, 1001-1008. [CrossRef] [PubMed]

123. La Fluorazione Delle Acque in Italia. Available online: https://www.epicentro.iss.it/cavo_orale/nota (accessed on 27 May 2020).

124. WHO. Water-Related Diseases. Available online: https://www.who.int/water_sanitation_health/diseasesrisks/diseases/fluorosis/en/ (accessed on 31 May 2020).

125. Srivastava, S.; Flora, S.J.S. Fluoride in Drinking Water and Skeletal Fluorosis: A Review of the Global Impact. Curr. Environ. Health Rep. 2020, 7. [CrossRef]

126. Waugh, D.T. Fluoride exposure induces inhibition of sodium/iodide symporter (NIS) contributing to impaired iodine absorption and iodine deficiency: Molecular mechanisms of inhibition and implications for public health. Int. J. Environ. Res. Public Health 2019, 16, 1086. [CrossRef]

127. Nakamoto, T.; Ralph Rawls, H. Fluoride exposure in early life as the possible root cause of disease in later life. J. Clin. Pediatr. Dent. 2018, 42, 325-330. [CrossRef]

128. Johnston, N.R.; Strobel, S.A. Principles of fluoride toxicity and the cellular response: A review. Arch. Toxicol. 2020, 94, 1051-1069. [CrossRef]

129. Hegde, R.M.; Rego, R.M.; Potla, K.M.; Kurkuri, M.D.; Kigga, M. Bio-inspired materials for defluoridation of water: A review. Chemosphere 2020, 253. [CrossRef]

130. Leung, A.K.C.; Leung, A.A.C. Evaluation and management of the child with hypothyroidism. World J. Pediatr. 2019, 15, 124-134. [CrossRef] 
131. Hay, I.; Hynes, K.L.; Burgess, J.R. Mild-to-moderate gestational iodine deficiency processing disorder. Nutrients 2019, 11, 19674. [CrossRef]

132. Urinary Iodine Concentrations for Determining Iodine Status in Populations. Available online: https: //apps.who.int/iris/bitstream/handle/10665/85972/WHO_NMH_NHD_EPG_13.1_eng.pdf?ua=1 (accessed on 3 June 2020).

133. Zimmermann, M.B. Iodine deficiency. Endocr. Rev. 2009, 30, 376-408. [CrossRef] [PubMed]

134. Baldini, E.; Virili, C.; D'Armiento, E.; Centanni, M.; Ulisse, S. Iodine status in schoolchildren and pregnant women of lazio, a central region of Italy. Nutrients 2019, 11, 1674. [CrossRef] [PubMed]

135. Giordano, C.; Barone, I.; Marsico, S.; Bruno, R.; Bonofiglio, D.; Catalano, S.; Andò, S. Endemic goiter and iodine prophylaxis in calabria, a region of southern Italy: Past and present. Nutrients 2019, 11, 2428. [CrossRef]

136. Zimmermann, M.B.; Andersson, M. Assessment of iodine nutrition in populations: Past, present, and future. Nutr. Rev. 2012. [CrossRef] [PubMed]

137. Li, M.; Eastman, C.J. NATURE REVIEWS | ENDOCRINOLOGY The changing epidemiology of iodine deficiency. Nat. Publ. Gr. 2012. [CrossRef]

138. Soldin, O.P.; Braverman, L.E.; Lamm, S.H. Perchlorate Clinical Pharmacology and Human Health: A Review. Ther. Drug Monit. 2001, 23, 316. [CrossRef]

139. Murray, C.W.; Egan, S.K.; Kim, H.; Beru, N.; Bolger, P.M. US food and drug administration's total diet study: Dietary intake of perchlorate and iodine. J. Expo. Sci. Environ. Epidemiol. 2008, 18, 571-580. [CrossRef]

140. Mantovani, A. Endocrine disrupters and the safety of food chains. Horm. Res. Paediatr. 2016, 86, $279-288$. [CrossRef]

141. Council, N.R. Health Implications of Perchlorate Ingestion. 2005. Available online: https://books.google.com/books?hl=it\&lr=\&id=05F0iOqvwgAC\&oi=fnd\&pg=PR1\&ots=1byRT87Mff\& sig=Kf3cQjhexKXGQ24WspdAKos7iNM (accessed on 10 May 2020).

142. Lawrence, J.; Lamm, S.; Braverman, L.E. Low dose perchlorate (3 mg daily) and thyroid function. Thyroid 2001, 11, 295. [CrossRef] [PubMed]

143. Lawrence, J.E.; Lamm, S.H.; Pino, S.; Richman, K.; Braverman, L.E. The effect of short-term low-dose perchlorate on various aspects of thyroid function. Thyroid 2000, 10, 659-663. [CrossRef]

144. Greer, M.A.; Goodman, G.; Pleus, R.C.; Greer, S.E. Health effects perchlorate contamination: The dose response for inhibition of thyroidal radioiodine uptake in humans. Environ. Health Perspect. 2002, 110,927-937. [CrossRef] [PubMed]

145. Gibbs, J.P.; Ahmad, R.; Crump, K.S.; Houck, D.P.; Leveille, T.S.; Findley, J.E.; Francis, M. Evaluation of a population with occupational exposure to airborne ammonium perchlorate for possible acute or chronic effects on thyroid function. J. Occup. Environ. Med. 1998, 40, 1072-1082. [CrossRef] [PubMed]

146. Lamm, S.H.; Braverman, L.E.; Li, F.X.; Richman, K.; Pino, S.; Howearth, G. Thyroid health status of ammonium perchlorate workers: A cross-sectional occupational health study. J. Occup. Environ. Med. 1999, 41, 248-260. [CrossRef] [PubMed]

147. Braverman, L.E.; He, X.; Pino, S.; Cross, M.; Magnani, B.; Lamm, S.H.; Kruse, M.B.; Engel, A.; Crump, K.S.; Gibbs, J.P. The Effect of Perchlorate, Thiocyanate, and Nitrate on Thyroid Function in Workers Exposed to Perchlorate Long-Term. J. Clin. Endocrinol. Metab. 2005, 90, 700-706. [CrossRef] [PubMed]

148. Alexeeff, G.V.; Rodriquez, M.; Brown Governor, E.G., Jr. Office of Environmental Health Hazard Assessment OEHHA Adopts Updated Public Health Goal for Perchlorate. 2015. Available online: www.oehha.ca.gov (accessed on 10 May 2020).

149. WHO|JECFA. Evaluations of the Joint FAO/WHO Expert Committee on Food Additives (JECFA). Available online: https://apps.who.int/food-additives-contaminants-jecfa-database/chemical.aspx?chemID= 5885 (accessed on 11 May 2020).

150. Srinivasan, A.; Viraraghavan, T. Perchlorate: Health effects and technologies for its removal from water resources. Int. J. Environ. Res. Public Health 2009, 6, 1418-1442. [CrossRef]

151. Batista, J.R.; McGarvey, F.X.; Vieira, A.R. The Removal of Perchlorate from Waters Using Ion-Exchange Resins. In Perchlorate in the Environment; Springer: Boston, MA, USA, 2000; pp. 135-145.

152. Xu, J.; Song, Y.; Min, B.; Steinberg, L.; Logan, B.E. Microbial degradation of perchlorate: Principles and applications. Environ. Eng. Sci. 2003, 20, 405-422. [CrossRef] 
153. Zhao, X.; Zhang, G.; Zhang, Z. TiO2-based catalysts for photocatalytic reduction of aqueous oxyanions: State-of-the-art and future prospects. Environ. Int. 2020, 136. [CrossRef]

154. Han, J.; Kong, C.; Heo, J.; Yoon, Y.; Lee, H.; Her, N. Removal of perchlorate using reverse osmosis and nanofiltration membranes. Environ. Eng. Res. 2012, 17, 185-190. [CrossRef]

155. Roquebert, V.; Booth, S.; Cushing, R.S.; Crozes, G.; Hansen, E. Electrodialysis reversal (EDR) and ion exchange as polishing treatment for perchlorate treatment. Desalination 2000, 131, 285-291. [CrossRef]

156. Kumar, E.; Bhatnagar, A.; Hogland, W.; Marques, M.; Sillanpää, M. Interaction of inorganic anions with iron-mineral adsorbents in aqueous media-A review. Adv. Colloid Interface Sci. 2014, 203, 11-21. [CrossRef]

157. Kumar, E.; Bhatnagar, A.; Ji, M.; Jung, W.; Lee, S.H.; Kim, S.J.; Lee, G.; Song, H.; Choi, J.Y.; Yang, J.S.; et al. Defluoridation from aqueous solutions by granular ferric hydroxide (GFH). Water Res. 2009, 43, 490-498. [CrossRef] [PubMed]

158. Susarla, S.; Collette, T.W.; Garrison, A.W.; Wolfe, N.L.; Mccutcheon, S.C. Perchlorate identification in fertilizers. Environ. Sci. Technol. 1999, 33, 3469-3472. [CrossRef]

159. Calderon, R.; Rajendiran, K.; Kim, U.J.; Palma, P.; Arancibia-Miranda, N.; Silva-Moreno, E.; Corradini, F. Sources and fates of perchlorate in soils in Chile: A case study of perchlorate dynamics in soil-crop systems using lettuce (Lactuca sativa) fields. Environ. Pollut. 2020, 264. [CrossRef] [PubMed]

(C) 2020 by the authors. Licensee MDPI, Basel, Switzerland. This article is an open access article distributed under the terms and conditions of the Creative Commons Attribution (CC BY) license (http://creativecommons.org/licenses/by/4.0/). 

Article

\title{
Protective Effects of Myo-Inositol and Selenium on Cadmium-Induced Thyroid Toxicity in Mice
}

\author{
Salvatore Benvenga ${ }^{1, \dagger}{ }^{+}$Herbert R. Marini ${ }^{1,+}$, Antonio Micali ${ }^{2, *}$, Jose Freni ${ }^{2}$, Giovanni Pallio ${ }^{1}$, \\ Natasha Irrera ${ }^{1}$, Francesco Squadrito ${ }^{1}$, Domenica Altavilla ${ }^{2}$, Alessandro Antonelli ${ }^{3}$, \\ Silvia Martina Ferrari ${ }^{3}$, Poupak Fallahi ${ }^{3}$, Domenico Puzzolo ${ }^{2}$ and Letteria Minutoli ${ }^{1}$ \\ 1 Department of Clinical and Experimental Medicine, University of Messina, 98125 Messina, Italy; \\ s.benvenga@live.it (S.B.); hrmarini@unime.it (H.R.M.); gpallio@unime.it (G.P.); nirrera@unime.it (N.I.); \\ fsquadrito@unime.it (F.S.); lminutoli@unime.it (L.M.) \\ 2 Department of Biomedical and Dental Sciences and Morphofunctional Imaging, University of Messina, \\ 98125 Messina, Italy; freni.jose@gmail.com (J.F.); daltavilla@unime.it (D.A.); puzzolo@unime.it (D.P.) \\ 3 Department of Clinical and Experimental Medicine, University of Pisa, 56126 Pisa, Italy; \\ alessandro.antonelli@med.unipi.it (A.A.); sm.ferrari@int.med.unipi.it (S.M.F.); poupak.fallahi@unipi.it (P.F.) \\ * Correspondence: amicali@unime.it; Tel.: +39-090-692427; Fax: +39-090-2213630 \\ + Both authors equally contributed.
}

Received: 25 March 2020; Accepted: 23 April 2020; Published: 26 April 2020

\begin{abstract}
Cadmium (Cd) damages the thyroid gland. We evaluated the effects of myo-inositol (MI), seleno-L-methionine (Se) or their combination on the thyroids of mice simultaneously administered with $\mathrm{Cd}$ chloride $\left(\mathrm{CdCl}_{2}\right)$. Eighty-four male mice were divided into 12 groups (seven mice each). Six groups (controls) were treated with $0.9 \% \mathrm{NaCl}$ (vehicle), Se $(0.2 \mathrm{mg} / \mathrm{kg} /$ day), Se $(0.4 \mathrm{mg} / \mathrm{kg} / \mathrm{day})$, MI $(360 \mathrm{mg} / \mathrm{kg} / \mathrm{day}), \mathrm{MI}+\mathrm{Se}(0.2 \mathrm{mg} / \mathrm{kg})$ and MI+Se $(0.4 \mathrm{mg} / \mathrm{kg})$. The other six groups were treated with $\mathrm{CdCl}_{2}(2 \mathrm{mg} / \mathrm{kg}), \mathrm{CdCl}_{2}+\mathrm{MI}, \mathrm{CdCl}_{2}+\mathrm{Se}(0.2 \mathrm{mg} / \mathrm{kg}), \mathrm{CdCl}_{2}+\mathrm{Se}(0.4 \mathrm{mg} / \mathrm{kg}), \mathrm{CdCl}_{2}+\mathrm{MI}+\mathrm{Se}$ $(0.2 \mathrm{mg} / \mathrm{kg})$ and $\mathrm{CdCl}_{2}+\mathrm{MI}+\mathrm{Se}(0.4 \mathrm{mg} / \mathrm{kg})$. An additional group of $\mathrm{CdCl}_{2}$-challenged animals $(\mathrm{n}=7)$ was treated with resveratrol $(20 \mathrm{mg} / \mathrm{kg})$, an effective and potent antioxidant. All treatments lasted 14 days. After sacrifice, the thyroids were evaluated histologically and immunohistochemically. $\mathrm{CdCl}_{2}$ reduced the follicular area, increased the epithelial height, stroma, and cells expressing monocyte chemoattractant protein-1 (MCP-1) and C-X-C motif chemokine 10 (CXCL10). $\mathrm{CdCl}_{2}+\mathrm{Se}$ at $0.2 / 0.4 \mathrm{mg} / \mathrm{kg}$ insignificantly reversed the follicular and stromal structure, and significantly decreased the number of MCP-1 and CXCL10-positive cells. $\mathrm{CdCl}_{2}+\mathrm{MI}$ significantly reversed the thyroid structure and further decreased the number of MCP-1 and CXCL10-positive cells. CdCl ${ }_{2}+\mathrm{MI}+\mathrm{Se}$, at both doses, brought all indices to those of $\mathrm{CdCl}_{2}$-untreated mice. MI, particularly in association with Se, defends mice from Cd-induced damage. The efficacy of this combination was greater than that of resveratrol, at least when using the follicular structure as a read-out for a comparison. We suggest that the use of these nutraceuticals, more specifically the combination of MI plus SE, can protect the thyroid of Cd-exposed subjects.
\end{abstract}

Keywords: cadmium; nutraceuticals; myo-inositol; seleno-L-methionine; thyroid; MCP-1; CXCL10

\section{Introduction}

Thyroid disorders, including hypothyroidism, with its leading etiology (Hashimoto's thyroiditis) and cancer arising from the follicular epithelium, are very common diseases [1,2]. Indeed, with a prevalence of $10 \%-12 \%$ in the general population, Hashimoto's thyroiditis is the most common autoimmune disease [1]. The prevalence of thyroid cancer has increased considerably in recent decades.

Thyroid cancer incidence was relatively stable until the 1990s, when it began to increase dramatically. Overall, thyroid cancer incidence increased from 4.9 per 100,000 population to 14.7 per 
100,000 population in 2011 [2]. Dysfunction, autoimmunity and cancer of the thyroid are triggered by environmental factors, including pollutants such as organochlorine compounds, polychlorinated biphenyls, polybrominated diphenylethers, bisphenol A, triclosan, perchlorates, thiocyanates, nitrates and heavy metals [3-8].

One such heavy metal is cadmium (Cd). Cd is found in food, cigarette smoke, mines, phosphate fertilizers and nickel-cadmium batteries [9]. Cd enters the body through the gastrointestinal tract and the alveolar epithelium [9] and passes through the systemic circulation, bound to albumin. Cd is then transported to the liver, where it is released and induces the synthesis of metallothionein (MT), a stress protein first discovered in 1957 in horse kidneys [10], which protects against Cd toxicity and oxidative stress [11]. The complex MT-Cd accumulates in the liver, kidneys, skeletal muscles and thyroid. With a biological half-life of 5 to 30 years, exposure over time to even environmentally low levels of $\mathrm{Cd}$ is associated with several toxic effects on the liver, kidneys, bones, testes and the cardiovascular system [12-15]. Persons living in Cd-polluted areas have an intrathyroid concentration of Cd that is threefold greater than control persons [16]. Finally, $\mathrm{Cd}$ has been classified as a group 1 human carcinogen, with evidence existing of its association with lung, prostate and kidney cancers [17], and a possible association with other malignancies, such as breast [18], pancreas [19], and urinary bladder cancer [20]. Concerning thyroid cancer, a recent study on 66 patients with papillary thyroid cancer (PTC) showed that the content of selenium (Se) was significantly decreased (66 vs. $132 \mathrm{ng} / \mathrm{g}$ ), while the content of Cd (58 vs. $33 \mathrm{ng} / \mathrm{g}$ ) and the resulting Cd/Se ratio (0.055 vs. 0.018) were significantly higher in the cancerous tissue compared to the healthy, noncancerous thyroid tissue [21]. Furthermore, $\mathrm{Cd}$ and the $\mathrm{Cd} / \mathrm{Se}$ ratio were associated with the retrosternal thyroid growth of PTC [21].

$\mathrm{Cd}$ increases serum thyrotropin (TSH) concentration in rats [22,23] and humans [24]. After chronic exposure to $\mathrm{Cd}$, the presence of desquamated cells in the follicles, mononuclear cell infiltration in the connective tissue and follicles lined by higher cells with light cytoplasm were observed [25]. In a similar manner to mercury $(\mathrm{Hg})$, the interaction of $\mathrm{Cd}$ with Se, which is relatively abundant in the thyroid [26], as the inorganic component of the deiodinases [27-29], results in formation of insoluble complexes $[27,28,30]$. The consequence of such sequestration of Se is the impairment of selenoprotein synthesis and activities [28]. In over 5000 Chinese adults, blood levels of both Cd and lead $(\mathrm{Pb})$ were directly correlated with both thyroid hypofunction and serum thyroid autoantibody levels [31], even if the risk of hypothyroidism increased incrementally with blood cadmium in men, but not in women [32]. In the study on 5628 Chinese adults, women showed a positive correlation between $\log (\mathrm{ln})$-transformed blood concentrations of $\mathrm{Cd}$ and $\log (\mathrm{ln})$-transformed blood concentrations of thyroglobulin autoantibodies $(\mathrm{TgAb})$ [31]. In the adjusted logistic regression models, the $\log (\mathrm{ln})$-transformed blood concentrations of $\mathrm{Cd}$ of women were positively related to their $\mathrm{TgAb}$ tertiles and hypothyroid status [31]. Cd exposure also causes increased susceptibility to testicular autoimmunity [33]. Indeed, the role of $\mathrm{Cd}$ in autoimmunity is supported by studies on 24 individuals, in whom the authors measured the blood levels of three heavy metals $(\mathrm{Cd}, \mathrm{Hg}$ and $\mathrm{Pb})$ and blood mRNA expression of 98 genes that are implicated in stress, toxicity, inflammation, and autoimmunity [34].

Among the different mechanisms involved in Cd-induced thyroid damage (genome influence, apoptosis, mitochondrial dysfunction, oxidative stress), the the last mechanism seems to play a relevant role [24]. Indeed, the said depletion of Se stores leads to its decreased availability to form glutathione (GSH) peroxidase, which is one of the main natural antioxidants [35]. Se supplementation exerts some beneficial effects on the thyroid of Cd-exposed rats. Histopathological analysis of the thyroid of young rats whose mothers received Cd during pregnancy demonstrated the presence of microfollicles lined by a single layer of columnar epithelium; Cd administration resulted in a sharp decrease in the height of epithelial cells [36]. Furthermore, treatment of Cd-exposed rats with Se partially attenuated the Cd-induced decrease in serum T4 levels [22].

Beneficial effects against $\mathrm{Cd}$-induced damage of the thyroid or other organs were also described for other naturally occurring molecules that, like Se, are used as nutraceuticals. These molecules are quercetin [37] and myo-inositol (MI) [38-40]. Quercetin significantly increased serum thyroid hormones 
in rats treated with $\mathrm{CdCl} 2$, even if levels were significantly lower compared to unchallenged rats [37]. In mice, a 14-day treatment with $\mathrm{CdCl}_{2}(2 \mathrm{mg} / \mathrm{kg} /$ day) plus $\mathrm{MI}(360 \mathrm{mg} / \mathrm{kg} /$ day) protected the testis [39] and the kidney [40] from the damage induced by $\mathrm{CdCl}_{2}$. The $\mathrm{Cd}$-induced testicular damage consisted of smaller tubules, the discontinuity of the seminiferous epithelium, the detachment of spermatogonia from the basal membrane, and reduced claudin-11 immunoreactivity [39]. The Cd-induced renal damage consisted of alterations in glomerular and tubular morphology [40]. Concerning the testis, experiments were also conducted with Se alone and with a combination MI plus Se-L-methionine [39], with such a combination having the greatest protective effects on the seminiferous tubules, and in particular on the blood-testis barrier.

Aside from the Cd setting, the beneficial effects of MI have been shown in human sperm [41,42] and oocytes [43]. The antioxidant properties of MI are demonstrated by the MI-induced increase in the intracellular levels of GSH, superoxide dismutase (SOD) and catalase (CAT) [44]. Starting from the knowledge that chemokines are mechanistically involved in the initiation and maintenance of Hashimoto's thyroiditis [45,46], it was shown that MI and, to a greater extent, the combination of MI plus Se-L-methionine, decreased serum levels and lymphocyte secretion of the investigated chemokines [47,48]. These chemokines were chemokine (C-C motif) ligand 2 (CCL2; also known as monocyte chemoattractant protein-1 (MCP-1)), C-X-C motif chemokine 9 (CXCL9; also known as monokine induced by gamma interferon (MIG)), and C-X-C motif chemokine 10 (CXCL10). Such effects on chemokines explain the benefits of the combination of MI plus Se-L-methionine in patients with Hashimoto's thyroiditis, in terms of decreased oxidative stress [38], decreased serum levels of thyroid autoantibodies and an improved hormone profile [47-49].

Based on this background, considering (i) that no morphometric analysis has been conducted in previous studies on protection from Cd-induced thyroid damage [24,36,50], (ii) the lack of data regarding the effects of MI alone and the association of MI plus Se with Cd-induced thyroid damage, and (iii) that MI, Se and other natural compounds are being increasingly used as nutraceuticals in clinical practice [38], we aimed to demonstrate their protective role in the structure of thyroid glands in mice exposed to $\mathrm{Cd}$. We also wished to test whether $\mathrm{Cd}$ induced the expression of two aforementioned chemokines (MCP-1/CCL2 and CXCL10) and, if so, to test whether this expression could be counteracted by MI, Se or their combination.

\section{Materials and Methods}

\subsection{Experimental Protocol}

All procedures adhered to the standards for care and use of animals as per guidelines issued by Animal Research Reporting in Vivo Experiments (ARRIVE); the procedures were evaluated and approved by the Italian Health Ministry (project identification code: 112/2017-PR). Eighty-four male C57 BL/6J mice (25-30 g) were obtained from Charles River Laboratories Italia Srl (Calco, LC, Italy) and stored at the animal house faculty of our university hospital. A standard diet was provided ad libitum and the animals had free access to water; they were kept on a 12-h light/dark cycle. The animals were randomly distributed into twelve groups of seven mice each. Six groups (viz. 42 mice) were considered as controls $(0.9 \% \mathrm{NaCl}$ (vehicle, $1 \mathrm{~mL} / \mathrm{kg})$, seleno-L-methionine (Se) $(0.2 \mathrm{mg} / \mathrm{kg})$, Se $(0.4 \mathrm{mg} / \mathrm{kg})$, MI (360 mg $/ \mathrm{kg})$, MI (360 mg/kg) plus Se $(0.2 \mathrm{mg} / \mathrm{kg})$, MI $(360 \mathrm{mg} / \mathrm{kg})$ plus Se $(0.4 \mathrm{mg} / \mathrm{kg}))$. The other six groups were challenged with $\mathrm{CdCl}_{2}(2 \mathrm{mg} / \mathrm{kg})$ plus a vehicle, $\mathrm{CdCl}_{2}(2 \mathrm{mg} / \mathrm{kg})$ plus MI $(360 \mathrm{mg} / \mathrm{kg})$, $\mathrm{CdCl}_{2}(2 \mathrm{mg} / \mathrm{kg})$ plus Se $(0.2 \mathrm{mg} / \mathrm{kg}), \mathrm{CdCl}_{2}(2 \mathrm{mg} / \mathrm{kg})$ plus Se $(0.4 \mathrm{mg} / \mathrm{kg}), \mathrm{CdCl}_{2}(2 \mathrm{mg} / \mathrm{kg})$ plus MI (360 mg/kg) plus Se $(0.2 \mathrm{mg} / \mathrm{kg})$ and $\mathrm{CdCl}_{2}(2 \mathrm{mg} / \mathrm{kg})$ plus MI $(360 \mathrm{mg} / \mathrm{kg})$ plus Se $(0.4 \mathrm{mg} / \mathrm{kg})$. An additional group of $\mathrm{CdCl}_{2}$-challenged animals $(n=7)$ were given $20 \mathrm{mg} / \mathrm{kg}$ of resveratrol [51,52], a biologically active compound with potent antioxidant properties [53]. $\mathrm{CdCl}_{2}$ and $\mathrm{NaCl}$ were administered intraperitoneally (i.p.), while MI, Se and resveratrol per os. MI was ready for use, while $\mathrm{CdCl}_{2}$ and Se were diluted in $0.9 \% \mathrm{NaCl}$ before use. After 14 days of treatment, mice were sacrificed 
with an overdose of ketamine and xylazine, and their thyroids were collected and processed for histological and immunohistochemical procedures.

\subsection{Histological Evaluation}

The thyroid glands were fixed in $4 \%$ paraformaldehyde in $0.2 \mathrm{M}$ phosphate buffer saline (PBS), dehydrated in ethanol, cleared in xylene and embedded in Paraplast (SPI Supplies, West Chester, PA, USA). Blocks were cut in a microtome (RM2125 RT, Leica Instruments, Nussloch, Germany), and $5 \mu \mathrm{m}$ sections were cleared with xylene, rehydrated in ethanol and stained with hematoxylin and eosin (HE) and Sirius red (SR). All samples were observed with a Nikon Ci-L (Nikon Instruments, Tokyo, Japan) light microscope and the micrographs were obtained using a digital camera (Nikon Ds-Ri2) and saved as Tagged Image Format Files (TIFF) with the Adobe Photoshop CS5 12.1 software.

\subsection{Immunohistochemistry for Monocyte Chemoattractant Protein-1 (MCP-1) and C-X-C Motif Chemokine 10 (CXCL10)}

The same specimens used for histological evaluation were cut at $5 \mu \mathrm{m}$ and the sections were placed on polysine slides (Thermo Fisher Scientific, Waltham, MA, USA), cleared with xylene and rehydrated in ethanol. Antigen retrieval was obtained in buffer citrate $\mathrm{pH}$ 6.0; endogenous peroxidase was blocked with $0.3 \% \mathrm{H}_{2} \mathrm{O}_{2}$ in PBS. Incubation with primary antibodies (MCP-1, 1:150, Santa Cruz, Dallas, TX, USA; CXCL10, 1:100, Biorbyt, Cambridge, UK) was performed overnight at $4{ }^{\circ} \mathrm{C}$ in a moisturized chamber; then, secondary antibodies (anti-mouse and anti-rabbit, Vectastain, Vector, Burlingame, CA, USA) were added, and the reaction was evidenced with 3,3'-diaminobenzidine (DAB) (Sigma-Aldrich, Milan, Italy). Slides were counterstained in Mayer's hematoxylin. For each test, specific positive and negative controls were prepared. Micrographs were taken with a Nikon Ci-L (Nikon Instruments, Tokyo, Japan) light microscope using a digital camera (Nikon Ds-Ri2).

\subsection{Morphometric and Immunohistochemical Evaluation}

All micrographs were printed at the same final magnification $(800 \times)$ and were blindly assessed by two trained observers, without knowledge of the previous treatment. Five microscopic fields (MFs), all including two entire thyroid follicles from ten non-serial sections stained with the HE of each group were considered.

As for the follicular compartment, a Peak Scale Loupe 7× (GWJ Company, Hacienda Heights, CA, USA) micrometer was used as a scale calibration standard to estimate the follicular diameters. The area (A) of each follicle was calculated by measuring the smaller inner diameter (d) and the larger inner diameter $(\mathrm{D})$ of the follicle, both expressed in micrometers $(\mu \mathrm{m})$. The estimated area of the follicular lumen was obtained by the following formula:

$$
\mathrm{A}=\pi \cdot(\mathrm{d} / 2 . \mathrm{D} / 2)
$$

In each thyroid gland, we measured the area of 20 follicles. To calculate the epithelial height, a straight line perpendicular to the epithelium was traced and measured, and the results were expressed in micrometers.

For the evaluation of the stroma, a quantitative study of micrographs from 20 microscopic fields of Sirius Red (SR)-stained not-serial sections for each group was performed with the Adobe Photoshop CS5 12.1 software, acquiring the pink/red color of collagen fibers. Positive areas were automatically calculated based on their pixel number. Values were indicated as the pixel number of the positively stained area/unit area (UA). The area of the entire micrograph was evaluated as the UA.

For an assessment of the immunoreactivity of MCP-1/CCL2 and CXCL10, positive cells were counted from 10 non-serial sections of the thyroid, selecting two unit areas (UA) of $0.1 \mathrm{~mm}^{2}$ $(316 \times 316 \mu \mathrm{m})$. Cells overlapping the right and top borders of the areas were not counted, while the cells overlapping the left and the bottom borders were considered. 


\subsection{Drugs and Chemicals}

$\mathrm{CdCl}_{2}$, Se and resveratrol were bought from Sigma-Aldrich Srl (Milan, Italy). LO.LI. Pharma Srl (Rome, Italy) kindly provided MI. All chemicals not otherwise mentioned were commercially available reagent grade quality.

\subsection{Statistical Analysis}

Values are expressed as the mean \pm standard error (SE). The statistical significance of differences between group mean values was established using Student's t-test. The statistical evaluation of differences among groups was obtained with ANOVA. The statistical analysis of histological scores was done using the Mann-Whitney U test with Bonferroni correction. A $p$ value of $\leq 0.05$ was considered statistically significant.

\section{Results}

\subsection{Histopathological Data}

\subsubsection{Follicular Epithelium}

Images are presented in Figure $1 \mathrm{~A}-\mathrm{G}$, with the quantification of the follicular area and the height of the follicular epithelium (thyrocytes) summarized in Figure 1H-I.

All control animals had thyroids with normal morphologies (results not shown). Therefore, for sake of simplicity, we present a single micrograph as representative of controls (Figure 1A). In the thyroid of mice challenged with $\mathrm{CdCl}_{2}$, compared to controls, the follicular area was smaller and thyrocytes were taller but poorly stained (Figure $1 \mathrm{~B}$ ). In the thyroid of mice treated with $\mathrm{CdCl}_{2}$ plus either dose of Se, compared to controls, the follicular area was also dose-dependently significantly smaller and the follicular epithelium was also dose-dependently significantly taller (Figure 1C,D), though the area and height changed to a lesser degree compared to mice treated with $\mathrm{CdCl}_{2}$ alone (compare Figure 1C,D with Figure 1B, and corresponding points in Figure 1H,I). In the thyroid of mice treated with $\mathrm{CdCl}_{2}$ plus $\mathrm{MI}$, compared to controls, the follicular area was also significantly smaller, and the follicular epithelium was significantly taller (Figure 1E), while both the area and height changed to an even lesser degree compared to mice treated with $\mathrm{CdCl}_{2}$ plus either dose of Se (compare Figure $1 \mathrm{E}$ with Figure $1 \mathrm{~B}$, and corresponding points in Figure $1 \mathrm{H}, \mathrm{I})$. In mice treated with $\mathrm{CdCl}_{2}$ plus both $\mathrm{MI}$ and Se at either 0.2 or $0.4 \mathrm{mg} / \mathrm{kg}$, the follicular area and epithelial height were no longer statistically different from the controls (Figure 1F,G), but both indices were statistically different from their counterparts in the other treated mice (compare Figure 1F,G with Figure 1B,G, and corresponding points in Figure 1H,I). Furthermore, the effect of the combination of MI plus Se on the follicular area and epithelial height was greater than that brought about by resveratrol, used for its potent antioxidant properties (see Supplemental materials Figure S1). 
A

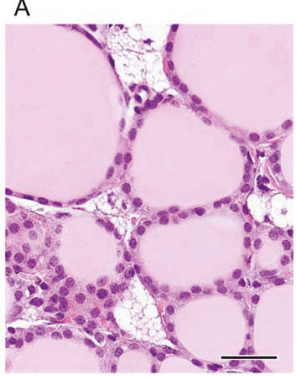

D

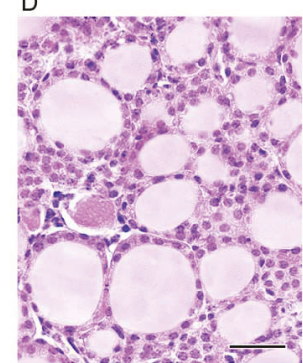

G

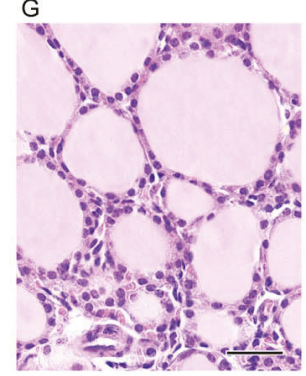

B

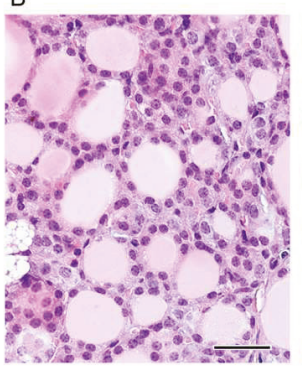

E
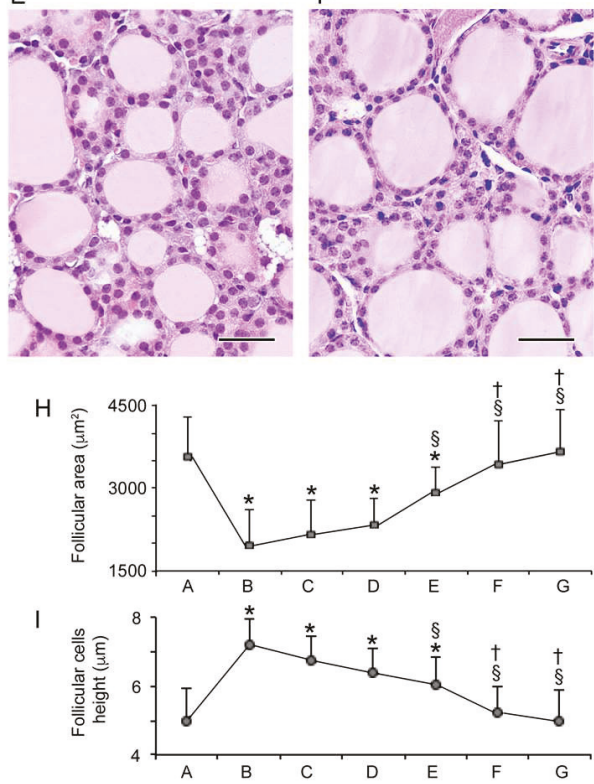

Figure 1. Histological organization of the thyroid (hematoxylin-eosin stain; scale bar: $25 \mu \mathrm{m})$. Mice groups (seven mice/group) are: controls (A), cadmium chloride $\left(\mathrm{CdCl}_{2}\right)$ plus vehicle $(\mathbf{B}), \mathrm{CdCl}_{2}$ plus seleno-L-methionine (Se) $0.2 \mathrm{mg} / \mathrm{kg}(\mathbf{C}), \mathrm{CdCl}_{2}$ plus Se $0.4 \mathrm{mg} / \mathrm{kg}$ (D), $\mathrm{CdCl}_{2}$ plus myo-inositol (MI) (E), $\mathrm{CdCl}_{2}$ plus MI plus Se $0.2 \mathrm{mg} / \mathrm{kg}(\mathbf{F}), \mathrm{CdCl}_{2}$ plus MI plus Se $0.4 \mathrm{mg} / \mathrm{kg}(\mathbf{G})$. A: Control mice have a normal thyroid structure, as demonstrated also by bar A in $\mathrm{H}$ and I. B: $\mathrm{CdCl}_{2}$-treated mice show small follicles and less stainable follicular epithelium (thyrocytes), the height of which is increased, as shown by bar B in (H,I). C-D: In mice treated with $\mathrm{CdCl}_{2}$ plus $0.2 \mathrm{mg} / \mathrm{Kg}$ Se or $\mathrm{CdCl}_{2}$ plus $0.4 \mathrm{mg} / \mathrm{kg} \mathrm{Se}$, small follicles are present with thyrocytes of smaller height, as indicated by bars $\mathrm{C}$ and $\mathrm{D}$ in $\mathrm{H}$ and I. E: In mice treated with $\mathrm{CdCl}_{2}$ plus $\mathrm{MI}$, the follicles and thyrocytes show a tendency to acquire a normal size and height, even though both indices are significantly different from the controls; see also bar $\mathrm{E}$ in $\mathrm{H}$ and I. F-G: In mice treated with $\mathrm{CdCl}_{2}$ plus MI and $0.2 \mathrm{mg} / \mathrm{Kg}$ Se or $\mathrm{CdCl}_{2}$ plus MI and $0.4 \mathrm{mg} / \mathrm{kg} \mathrm{Se}$, follicles and epithelial cells were close to normal, as demonstrated by bars F and $\mathrm{G}$ in $\mathrm{H}$ and I. H: Mean \pm standard error values of follicular area in the different groups of mice. I: Mean \pm standard error values of epithelial cells height in the different groups of mice. ${ }^{*} p<0.05$ versus control; $\S p<0.05$ versus $\mathrm{CdCl}_{2}$ plus vehicle and $\mathrm{CdCl}_{2}$ plus 0.2 or $0.4 \mathrm{mg} / \mathrm{kg} \mathrm{Se} ;+p<0.05$ versus $\mathrm{CdCl}_{2}$ plus MI alone.

\subsubsection{Stroma}

As indicated in the Materials and Methods, Sirius Red staining allowed us to quantify the thyroid stroma, since stromal areas are positive to such staining. Positive areas were quantified by a software 
based on their pixel number. Data were expressed as the pixel number of the positively stained area/unit area (UA), considered to be the entire micrograph area. Matching the illustration of data for the epithelium (see above), images are presented in Figure $2 A-G$, with quantification also summarized in Figure $2 \mathrm{H}$.
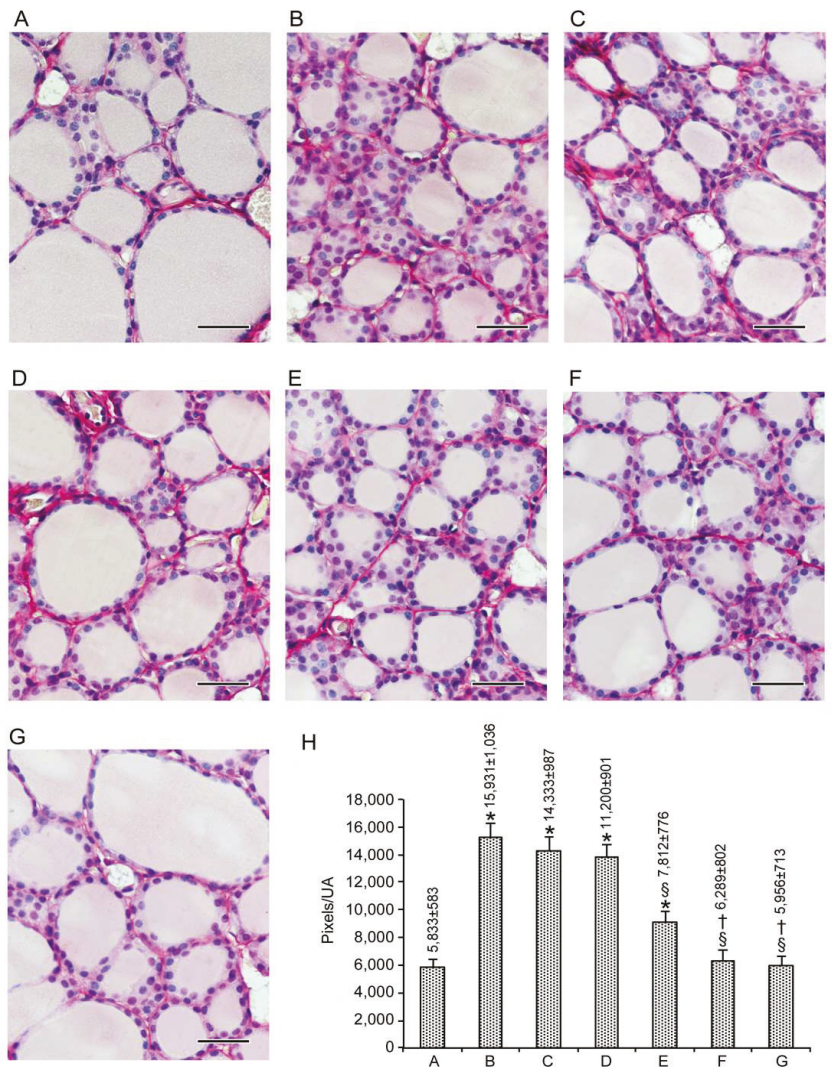

Figure 2. Structural organization of the thyroid stroma based on staining with Sirius Red (scale bar: $25 \mu \mathrm{m})$. Mice groups are as in Figure 1. (A): Control mice have a normal architecture of interstitial collagen, with well-stained fibrillary elements, as indicated by bar A in $\mathrm{H}$. (B): In $\mathrm{CdCl}_{2}$-treated mice, an increased amount of perifollicular connective tissue is present around the follicles, as indicated by bar B in $\mathrm{H}$. (C,D): In mice challenged with $\mathrm{CdCl}_{2}$ and $0.2 \mathrm{mg} / \mathrm{kg}$ Se or $\mathrm{CdCl}_{2}$ and $0.4 \mathrm{mg} / \mathrm{kg}$ Se, stained areas are similar to mice challenged with $\mathrm{CdCl}_{2}$, as shown by bars $\mathrm{C}$ and $\mathrm{D}$ in $\mathrm{H}$. (E): $\mathrm{CdCl}_{2}$ plus MI-treated mice have stained areas with a statistically significant decrease in the pink/red colored collagen fibers, as evident in $\mathrm{H}$, bar E. (F,G): In mice treated with $\mathrm{CdCl}_{2}$ plus $\mathrm{MI}$ and $0.2 \mathrm{mg} / \mathrm{kg}$ Se or $\mathrm{CdCl}_{2}$ plus $\mathrm{MI}$ and $0.4 \mathrm{mg} / \mathrm{kg} \mathrm{Se}$, a significant reduction in the stained areas can be seen, as also demonstrated by bars F and $\mathrm{G}$ in $\mathrm{H}$. (H): Mean \pm standard error values of pixel numbers of Sirius Red (SR)-stained areas/unit areas (UA) in the different groups of challenged mice. ${ }^{*} p<0.05$ versus control; $\S p<0.05$ versus $\mathrm{CdCl}_{2}$ plus vehicle and $\mathrm{CdCl}_{2}$ plus 0.2 or $0.4 \mathrm{mg} / \mathrm{kg} \mathrm{Se} ;+p<0.05$ versus $\mathrm{CdCl}_{2}$ plus MI.

When comparing Figure $2 \mathrm{H}$ with Figure $1 \mathrm{H}, \mathrm{I}$, it is evident that changes in the stroma were parallel to changes in epithelial height and opposite to changes in follicular area. Compared to the amount of stroma in the seven untreated mice (5912 \pm 556 pixels/UA (data not shown)), in the other 42 control mice, the variation was between $-5.0 \%$ (mice treated with only $0.2 \mathrm{mg} / \mathrm{kg} \mathrm{Se}$ ) AND $+2.1 \%$ (mice treated 
with vehicle) (data not shown). Accordingly, the value of $5833 \pm 583$ (mean \pm SE of the 49 control mice; Figure $2 \mathrm{~A}$ and bar $\mathrm{A}$ in Figure $2 \mathrm{H}$ ) was taken as the reference to evaluate the effects of $\mathrm{CdCl}_{2}$ alone or $\mathrm{CdCl}_{2}$ co-administered with $\mathrm{Se}, \mathrm{MI}$, or their association. Exposure to $\mathrm{CdCl}_{2}$ alone increased the amount of perifollicular connective tissue by almost threefold (compare Figure 2A,B, and bars $\mathrm{A}$ and $\mathrm{B}$ in Figure 2H). The co-administration of $\mathrm{CdCl}_{2}$ and Se decreased-even though the $\mathrm{CdCl}_{2}$-induced an insignificant increase in - thyroid connective tissue (compare Figure 2C,D with Figure 2B, and bars $\mathrm{C}$ and D with bar B in Figure $2 \mathrm{H}$ ). MI co-administration was more effective compared to either dose of $\mathrm{Se}$, since the increase in the amount of stroma was of a smaller magnitude (compare Figure 2E with Figure 2C,D, and bar E with bars C-D in Figure 2H) or approximately 1.5-fold higher when compared to controls (compare Figure 2E with Figure 2A, and bar E with bar A in Figure 2H). The association of MI with either dose of Se in mice that were simultaneously treated with $\mathrm{CdCl}_{2}$ was even more effective, resulting in an amount of stroma superimposable to that of the control mice (compare Figure 2F,G with Figure 2A, and bars F-G with bar A in Figure 2H).

In summary, both the follicular epithelium and the connective tissue respond in a similar fashion to the administration of $\mathrm{Se}, \mathrm{MI}$ or their combination in $\mathrm{CdCl}_{2}$ co-treated mice. This response consists of a benefit that is modest in the case of Se, moderate in the case of MI, and high (full protection) in the case of MI combined with either dose of Se.

\subsection{Immunohistochemical Expression of $M C P-1 / C C L 2$}

To maintain the modality of illustrating results, images are presented in Figure 3A-G, with quantification also summarized in Figure $3 \mathrm{H}$ for MCP-1/CCL2, and in Figure 4A-G, with quantification also summarized in Figure 4H for CXCL10.

In the baseline condition represented by untreated mice, there were no cells at all that expressed MCP-1/CCL2 (data not shown), a pattern that was also true for the vehicle-treated mice and the other groups of control mice, except three groups. These three groups, in which only one cell was stained, were those treated with either concentrations of Se alone and the group treated with $0.4 \mathrm{mg} / \mathrm{kg}$ Se plus MI (data not shown). Overall, in the 49 mice from the seven control groups, the number of cells immunostained by the MCP-1/CCL2 averaged $0.35 \pm 0.34 / \mathrm{UA}$ (Figure 3A, and bar A in Figure 3H). In contrast, $\mathrm{CdCl}_{2}$ plus the vehicle induced a marked expression of MCP-1/CCL2, with a 60 -fold increase in the number of thyrocytes immunostained (compare Figure 3B with Figure 3A, and bar $\mathrm{B}$ with bar $\mathrm{A}$ in Figure $3 \mathrm{H}$ ). In the mice from the remaining groups, the over-expression induced by $\mathrm{CdCl}_{2}$ was counteracted significantly by all of the tested compounds (Figure $3 \mathrm{C}-\mathrm{G}$, and bars $\mathrm{C}-\mathrm{G}$ in Figure $3 \mathrm{H}$ ). This antagonism was small with either the dose of Se alone (Figure 3C,D, and bars C-D in Figure $3 \mathrm{H}$ ), moderate with MI alone (Figure $3 \mathrm{E}$, and bar E in Figure $3 \mathrm{H}$ ), and great with the dose of Se and MI (Figure 3F-G, and bars F-G in Figure 3H). Indeed, $0.4 \mathrm{mg} / \mathrm{kg}$ Se plus MI decreased the number of cells to $0.44 \pm 0.39$, which is statistically similar to the above $0.35 \pm 0.34$ for the 49 control mice. 
A

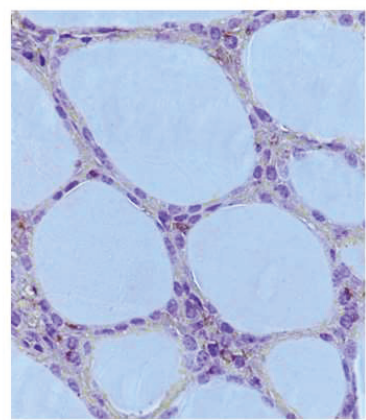

D

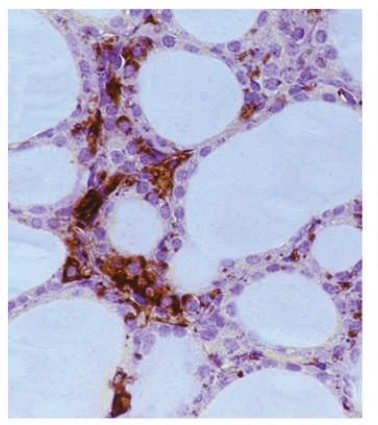

G

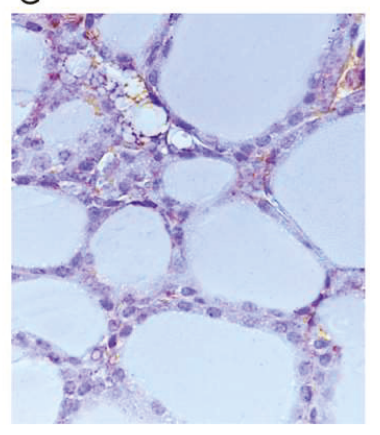

B

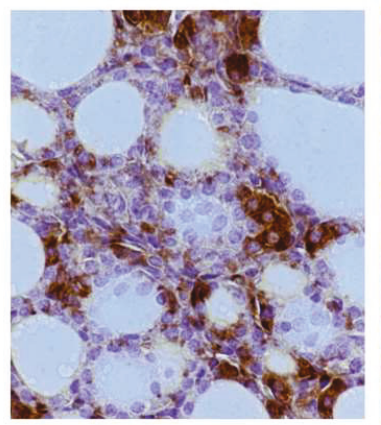

E

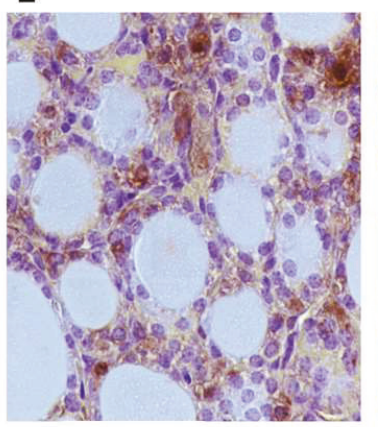

C

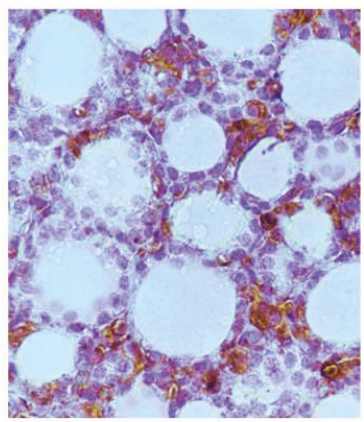

$\mathrm{F}$

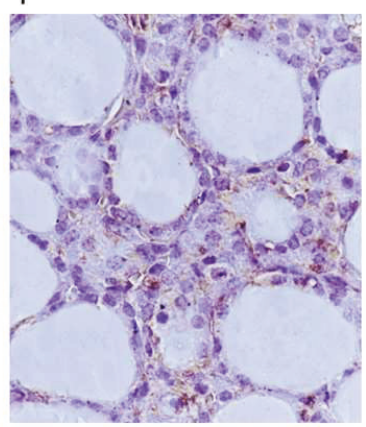

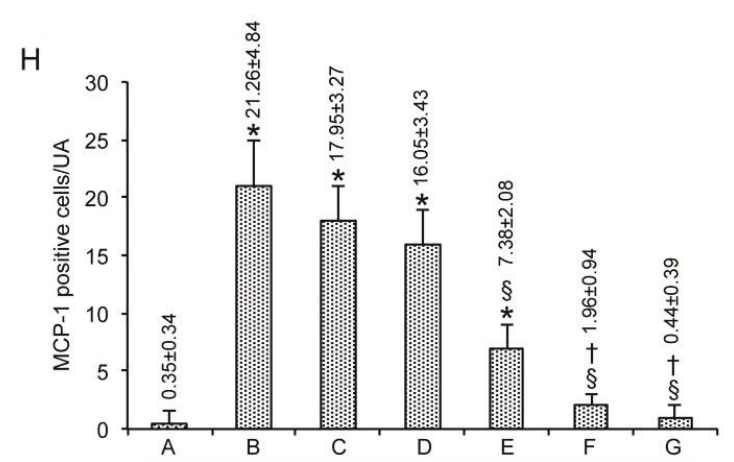

Figure 3. Immunohistochemical expression of monocyte chemoattractant protein-1 (MCP-1) in the thyroid (scale bar: $25 \mu \mathrm{m}$ ). Mice groups are as in Figure 1. (A): In controls, no MCP-1-positive cells are present, as shown by bar $\mathrm{A}$ in $\mathrm{H}$. (B): $\mathrm{CdCl}_{2}$-treated mice show a marked increase in $\mathrm{MCP}-1$ immunoreactivity, as indicated by bar $\mathrm{B}$ in $\mathrm{H}$; positive cells line the follicle wall with strong stains on their cytoplasm. (C,D): In mice treated with $\mathrm{CdCl}_{2}$ plus $0.2 \mathrm{mg} / \mathrm{kg}$ Se or $\mathrm{CdCl}_{2}$ plus $0.4 \mathrm{mg} / \mathrm{kg}$ Se, the number of MCP-1-positive cells is decreased, but still higher than controls, as evidenced by bars $\mathrm{C}$ and $\mathrm{D}$ in $\mathrm{H}$. (E): $\mathrm{CdCl}_{2}$ plus MI-treated mice, $\mathrm{MCP}$-1-positive cells are fewer, as shown by bar E in $\mathrm{H}$, and show reduced cytoplasmic staining. $(\mathrm{F}, \mathrm{G})$ : In the thyroid of mice treated with $\mathrm{CdCl}_{2}$ plus $\mathrm{MI}$ and $0.2 \mathrm{mg} / \mathrm{Kg}$ Se or $\mathrm{CdCl}_{2}$ plus $\mathrm{MI}$ and $0.4 \mathrm{mg} / \mathrm{kg}$ Se, $\mathrm{MCP}-1$ immunoreactivity is significantly decreased, as indicated by bars F-G in $\mathrm{H}$. (H): The number of MCP-1-positive cells per microscopic field in the different groups of mice (mean \pm standard error). ${ }^{*} p<0.05$ versus control; $\S p<0.05$ versus $\mathrm{CdCl}_{2}$ plus vehicle and $\mathrm{CdCl}_{2}$ plus 0.2 or $0.4 \mathrm{mg} / \mathrm{kg} \mathrm{Se} ;+p<0.05$ versus $\mathrm{CdCl}_{2}$ plus MI. 
A

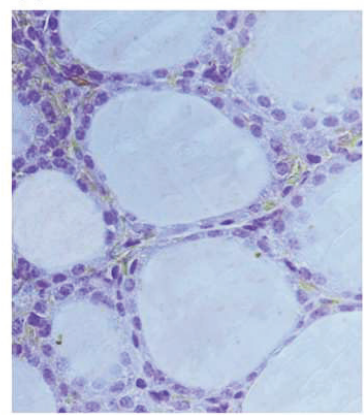

$\mathrm{D}$

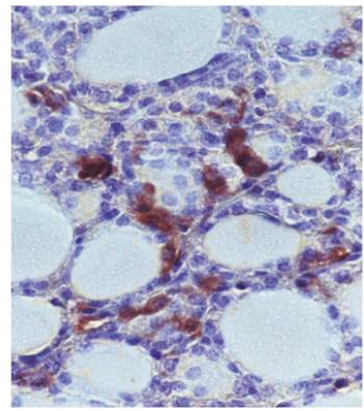

G

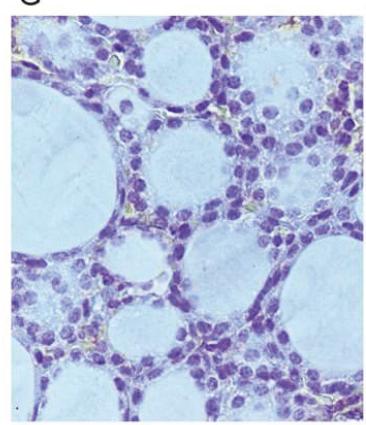

B

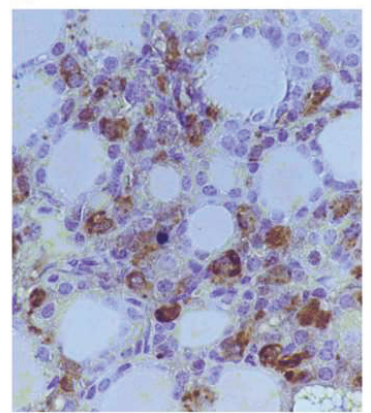

$\mathrm{E}$

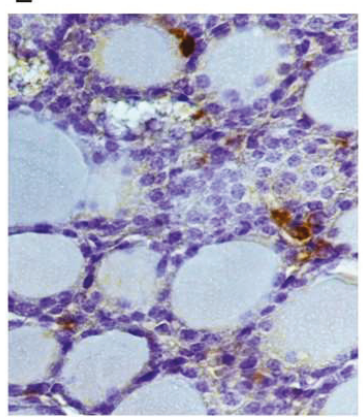

C

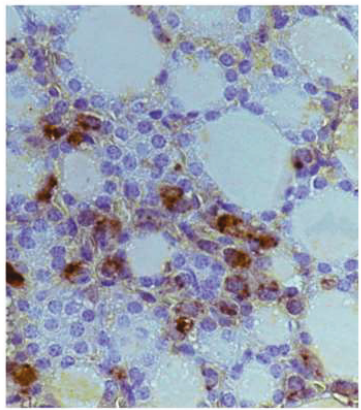

$\mathrm{F}$

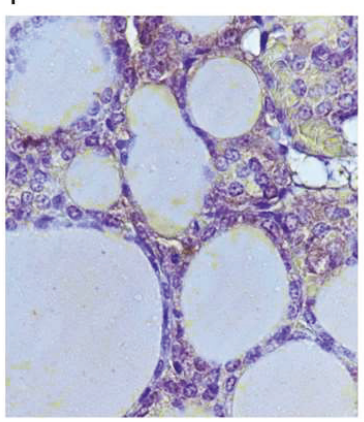

$\mathrm{H}$

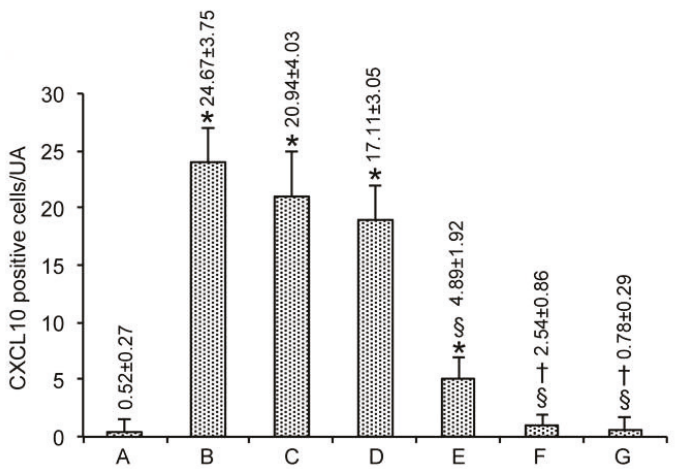

Figure 4. Immunohistochemical expression of C-X-C motif chemokine 10 (CXCL10) in the thyroid (scale bar: $25 \mu \mathrm{m}$ ). Mice groups are as in Figure 1. (A): In controls, no CXCL10-positive cells are evident, as shown by bar A in $\mathrm{H}$. (B): In $\mathrm{CdCl}_{2}$-treated mice, a large number of CXCL10-positive cells is present among the follicle walls, as indicated by bar B in $\mathrm{H}$. (C,D): In mice treated with $\mathrm{CdCl}_{2}$ plus $0.2 \mathrm{mg} / \mathrm{kg}$ Se or $\mathrm{CdCl}_{2}$ plus $0.4 \mathrm{mg} / \mathrm{kg} \mathrm{Se}$, the number of CXCL10-positive cells is decreased, but still high, as evidenced by bars $\mathrm{C}$ and $\mathrm{D}$ in $\mathrm{H}$. (E): $\mathrm{In} \mathrm{CdCl}_{2}$ plus MI-treated mice, only a few CXCL10-positive cells are present, as shown by bar $\mathrm{E}$ in $\mathrm{H}$. (F,G): In the thyroid of $\mathrm{CdCl}_{2}$ plus MI and $0.2 \mathrm{mg} / \mathrm{kg}$ Se or $\mathrm{CdCl}_{2}$ plus MI and $0.4 \mathrm{mg} / \mathrm{kg}$ Se, no CXCL10 immunoreactivity is detectable, as indicated by bars F-G in H. (H): The number of CXCL10-positive cells per microscopic field in the different groups of mice (mean \pm standard error). ${ }^{*} p<0.05$ versus control; $\S p<0.05$ versus $\mathrm{CdCl}_{2}$ plus vehicle and $\mathrm{CdCl}_{2}$ plus Se 0.2 or $0.4 \mathrm{mg} / \mathrm{kg}$ Se; $\uparrow p<0.05$ versus $\mathrm{CdCl}_{2}$ plus MI. 


\subsection{Immunohistochemical Expression of CXCL10}

When CXCL10 immunoreactivity was considered, the results mimicked those described above for MCP-1/CCL2. Thus, in the 49 mice from the seven control groups, the number of cells immunostained by the CXCL10 averaged $0.52 \pm 0.27 / \mathrm{UA}$ (Figure 4A, and bar A in Figure $4 \mathrm{H}$ ). The overexpression of CXLC10 induced by $\mathrm{CdCl}_{2}$ plus the vehicle was fully counteracted by the combination of MI with either dose of Se (Figure 4F,G, and bars F-G in Figure 4H).

\section{Discussion}

In the present work, we have confirmed that $\mathrm{Cd}$ exposure has negative consequences for the murine thyroid. These consist of histologically demonstrable alterations in the follicular epithelium and stroma, and in the induced expression of two chemoattractant chemokines, an expression that is absent prior to Cd exposure.

In fact, after chronic exposure to $\mathrm{Cd}$, desquamated cells into the follicles, mononuclear cell infiltration in the stroma and follicles lined by higher cells with light cytoplasm were observed [25]. Therefore, these Cd-elicited thyroid changes have consequences in terms of both thyroid dysfunction and autoimmunity $[31,32,54]$.

Se is considered to exert an overall protection against toxicity induced by heavy metals such as $\mathrm{Cd}$, $\mathrm{Pb}$, As and $\mathrm{Hg}$ [55], mainly through the sequestration of these elements into biologically inert complexes and/or through the action of Se-dependent antioxidant enzymes [55]. This protection from Cd toxicity occurs regardless of the Se form (as selenite, selenomethionine, nanoSe, or Se from lentils) [56]. Furthermore, it was recently demonstrated that Se alleviated oxidative stress in chicken ovari and rat kidneys, and counteracted the endoplasmic reticulum stress able to induce apoptosis [57,58]. However, in this paper, we found that the trace element Se was less potent than the carbocyclic sugar MI in protecting mice from $\mathrm{CdCl}_{2}$ thyroid toxicity, though the co-administration of Se amplified the protection conferred by MI alone. The complementary activity of the two antioxidants can be related to their distinctive mechanism of action. While Se is a vital constituent of the enzyme glutathione peroxidase that catalyzes the reaction between GSH and hydrogen peroxide, thus protecting against oxidative stress, MI is a hydroxyl radical scavenger, preventing lipid peroxidation. The combined action of the two compounds may enhance the antioxidant effect [39]. Interestingly the efficacy of this combination was greater that that of resveratrol (used for its potent antioxidant properties), at least when using the follicular area and the epithelial height as read-outs for a comparison evaluation.

One limitation of our work is the lack of hormone measurements. However, considering (i) the aforementioned Chinese study on the direct relationship between blood Cd levels with thyroid hypofunction and serum thyroid autoantibody levels [31], (ii) the association of insulin resistance with either decreased thyroid hormone levels or increased serum TSH [59-61], with counteracting effects by insulin-sensitizing agents [62-64], and (iii) the insulin-mimetic action of MI [54,65,66], we expected that Cd-exposed mouse thyroids would display decreased thyroid hormone levels and increased TSH compared to Cd-unexposed mice. We also expected that at least the combination of MI+Se would have fully counteracted these hormone changes induced by $\mathrm{Cd}$.

On the other hand, the strengths of this study are the findings that are consistent with the previous literature concerning the benefits for the thyroid [38] and other endocrine organs, such as the testes [39], including consistency in the hierarchy of benefits (MI+Se $>\mathrm{MI}>>$ Se). In particular, $\mathrm{CdCl}_{2}$ determined significant increase in MCP-1 and CXCL10-positive cell numbers. Our data clearly agree with many in vitro and in vivo experiments by different groups, showing that the production of these chemokines by thyrocytes may play a central role in the recruitment of monocytes and T-lymphocytes at immune inflammatory sites in the thyroid gland from the blood in humans, thus providing a possible mechanism by which thyrocytes themselves may participate in the processes of thyroid autoimmune and inflammatory disease $[45,46]$. After treatment with Se, MCP-1 and CXCL10-positive cell numbers were reduced. These data about the effects of Se on the thyroid gland, from our point of view, are not particularly surprising. In fact, the recent literature indicates that, regarding thyroid pathology, 
selenium intake has been associated with autoimmune disorders [67]. Our experimental data indicate the relative inefficacy of Se when administered alone, probably due to extensive detrimental effects of $\mathrm{Cd}$ on thyroid structure and function, not adequately counterbalanced by micronutrient administration alone. MI treatment significantly lowered MCP-1 and CXCL10-positive cell numbers, particularly in association with Se, thus confirming that this nutraceutical compound could impact different molecular pathways related to oxidative stress and inflammation, involving chemokines such as MCP-1 and CXCL10 [46].

In view of the "prophylactic" benefit reported in the present paper, it will now be interesting to investigate whether Se, MI and their combination (Se+MI) have "therapeutic" benefits. The demonstration of the latter's benefits requires that animals would be first exposed to $\mathrm{CdCl}_{2}$ for a time sufficient to induce thyroid toxicity (14 days, based on the present work), and then administered Se, MI and Se+MI at doses equal to or greater than those used in the present work and for the same or a longer time ( $\geq 14$ days), in order to show the reversal of the alterations induced by prior $\mathrm{Cd}$ exposure. Another translational implication of the data presented in this paper is that, because several pollutants, such as organochlorine compounds, polychlorinated biphenyls, polybrominated diphenylethers, bisphenol A, triclosan, perchlorates, thiocyanates, nitrates and heavy metals different from Cd [3-8] disturb thyroid homeostasis and confer increased environmental susceptibility to thyroid autoimmunity, it would be worthwhile to test whether the said molecules (particularly MI+Se) may have prophylactic and/or therapeutic effects against the thyroid alterations caused by exposure to a number of thyroid-disrupting chemicals.

Supplementary Materials: The following are available online at http:/www.mdpi.com/2072-6643/12/5/1222/s1, Figure S1: Histological organization of the thyroid (hematoxylin-eosin stain; scale bar: $25 \mu \mathrm{m}$ ). Mice groups (7 mice/group) are: (A) controls, (B) cadmium chloride $\left(\mathrm{CdCl}_{2}\right)$ plus vehicle, $(\mathrm{C}) \mathrm{CdCl}_{2}$ plus seleno-L-methionine (Se) $0.2 \mathrm{mg} / \mathrm{kg}$, CdCl 2 plus Se $0.4 \mathrm{mg} / \mathrm{kg}$, (E) $\mathrm{CdCl}_{2}$ plus myo-inositol (MI), (F) $\mathrm{CdCl}_{2}$ plus MI plus Se $0.2 \mathrm{mg} / \mathrm{kg}$, $\mathrm{CdCl}_{2}$ plus MI plus Se $0.4 \mathrm{mg} / \mathrm{kg}$. A: Control mice have normal thyroid structure, as demonstrated also by bar A in $\mathrm{I}$ and L. B: $\mathrm{CdCl}_{2}$-treated mice show small follicles and less stainable follicular epithelium (thyrocytes), the height of which is increased, as shown by bar B in I and L. C-D: In mice treated with $\mathrm{CdCl}_{2}$ plus $0.2 \mathrm{mg} / \mathrm{Kg} \mathrm{Se} \mathrm{or} \mathrm{CdCl}_{2}$ plus $0.4 \mathrm{mg} / \mathrm{kg}$ Se, small follicles are present with thyrocytes of smaller height, as indicated by bars C and D in I and L. E: In mice treated with $\mathrm{CdCl}_{2}$ plus MI, the follicles and thyrocytes show a tendency to acquire the normal size and height, even though both indices are significantly different from controls; see also bar E in I and L. F-G: In mice treated with $\mathrm{CdCl}_{2}+\mathrm{MI}+0.2 \mathrm{mg} / \mathrm{Kg}$ Se or $\mathrm{CdCl}_{2}+\mathrm{MI}+0.4 \mathrm{mg} / \mathrm{kg}$ Se, follicles and the epithelial cells were close to normal, as demonstrated by bars $\mathrm{F}$ and $\mathrm{G}$ in in I and L. H: In mice treated with $\mathrm{CdCl}_{2}$ plus resveratrol, the follicles show an increased size and thyrocytes a reduced height, being both indices significantly different from controls, as shown also by bar H in I and L histograms. I - Mean \pm standard error values of follicular area in the different groups of mice. L - Mean \pm standard error values of epithelial cells height in the different groups of mice. * $p<0.05$ versus control; $\S p<0.05$ versus $\mathrm{CdCl}_{2}$ plus vehicle and $\mathrm{CdCl} 2$ plus 0.2 or $0.4 \mathrm{mg} / \mathrm{kg} \mathrm{Se} ;+p<0.05$ versus $\mathrm{CdCl}_{2}$ plus MI alone; $\neq p<0.05$ versus $\mathrm{CdCl}_{2}+\mathrm{MI}+0.2 \mathrm{mg} / \mathrm{Kg}$ Se and $\mathrm{CdCl}_{2}+\mathrm{MI}+0.4 \mathrm{mg} / \mathrm{kg}$ Se.

Author Contributions: Conceptualization, S.B., H.R.M., A.M., A.A., F.S., L.M.; methodology and software, A.M., J.F.; formal analysis, D.P., N.I., G.P., D.A., S.B., L.M.; data curation, D.P., A.M., L.M.; writing the first draft of the manuscript, D.P., L.M.; writing sections of the manuscript, S.B., S.M.F., P.F.; reviewing the manuscript, H.R.M., S.B., A.M. All authors have read and agreed to the published version of the manuscript.

Funding: This research did not receive any specific grant from funding agencies in the public, commercial, or not-for-profit sectors.

Acknowledgments: The authors thank LO.LI. Pharma S.r.l. (Rome, Italy) for the kind gift of MI.

Conflicts of Interest: S.B. has been an invited speaker for LO.LI. Pharma, which provided us with pure MI, but had no role in the design of the study; in the collection, analyses, or interpretation of data; in the writing of the manuscript, or in the decision to publish the results. All the other authors declare no conflict of interest.

\section{References}

1. Wiersinga, W.M. Hashimoto's Thyroiditis. In Thyroid Diseases. Pathogenesis, Diagnosis, and Treatment; Vitti, P., Hegedus, L., Eds.; Springer: New York, NY, USA, 2018; pp. 205-247. 
2. Davies, L.; Morris, L.G.; Haymart, M.; Chen, A.Y.; Goldenberg, D.; Morris, J.; Ogilvie, J.B.; Terris, D.J.; Netterville, J.; Wong, R.J.; et al. AACE Endocrine Surgery Scientific Committee. American Association of Clinical Endocrinologists and American College of Endocrinology disease state clinical review: The increasing incidence of thyroid cancer. Endocr. Pract. 2015, 21, 686-696. [CrossRef] [PubMed]

3. Köhrle, J. Environment and endocrinology: The case of thyroidology. Ann. Endocrinol. 2008, 69, 116-122. [CrossRef] [PubMed]

4. Bajaj, J.K.; Salwan, P.; Salwan, S. Various possible toxicants involved in thyroid dysfunction: A review. J. Clin. Diagn. Res. 2016, 10, FE01. [CrossRef] [PubMed]

5. Zoeller, T.R. Environmental chemicals targeting thyroid. Hormones 2010, 9, 28-40. [CrossRef]

6. Maqbool, F.; Mostafalou, S.; Bahadar, H.; Abdollahi, M. Review of endocrine disorders associated with environmental toxicants and possible involved mechanisms. Life Sci. 2016, 145, 265-273. [CrossRef]

7. Buha, A.; Matovic, V.; Antonijevic, B.; Bulat, Z.; Curcic, M.; Renieri, E.A.; Tsatsakis, A.M.; Schweitzer, A.; Wallace, D. Overview of Cadmium Thyroid Disrupting Effects and Mechanisms. Int. J. Mol. Sci. 2018, 19, 1501. [CrossRef]

8. Benvenga, S.; Antonelli, A.; Vita, R. Thyroid nodules and thyroid autoimmunity in the context of environmental pollution. Rev. Endocr. Metab. Disord. 2015, 16, 319-340. [CrossRef]

9. Thévenod, F.; Lee, W.K. Toxicology of cadmium and its damage in mammalian organs. Met. Ions Life Sci. 2013, 11, 415-490. [CrossRef]

10. Margoshes, M.; Vallee, B.L. A cadmium protein from equine kidney cortex. J. Am. Chem. Soc. 1957, 79, 4813-4814. [CrossRef]

11. Klaassen, C.D.; Liu, J.; Diwan, B. Metallothionein protection of cadmium toxicity. Toxicol. Appl. Pharmacol. 2009, 238, 215-220. [CrossRef]

12. Matović, V.; Buha, A.; Bulat, Z.; Đukić-Ćosić, D. Cadmium Toxicity Revisited: Focus on Oxidative Stress Induction and Interactions with Zinc and Magnesium. Arch. Ind. Hyg. Toxicol. 2011, 62, 65-76. [CrossRef]

13. Matović, V.; Buha, A.; Dukić-Ćosić, D.; Bulat, Z. Insight into the oxidative stress induced by lead and/or cadmium in blood, liver and kidneys. Food Chem. Toxicol. 2015, 78, 130-140. [CrossRef] [PubMed]

14. Rinaldi, M.; Micali, A.; Marini, H.; Adamo, E.B.; Puzzolo, D.; Pisani, A.; Trichilo, V.; Altavilla, D.; Squadrito, F.; Minutoli, L. Cadmium, organ toxicity and therapeutic approaches: A review on brain, kidney and testis damage. Curr. Med. Chem. 2017, 24, 3879-3893. [CrossRef] [PubMed]

15. Mezynska, M.; Brzóska, M.M. Environmental exposure to cadmium-A risk for health of the general population in industrialized countries and preventive strategies. Environ. Sci. Pollut. Res. 2018, 25, 3211-3232. [CrossRef] [PubMed]

16. Uetani, M.; Kobayashi, E.; Suwazono, Y.; Honda, R.; Nishijo, M.; Nakagawa, H.; Kido, T.; Nogawa, K. Tissue cadmium $(\mathrm{Cd})$ concentrations of people living in a Cd polluted area, Japan. BioMetals 2006, 19, 521-525. [CrossRef]

17. IARC. Personal Habits and Indoor Combustions. In IARC Monographs on the Evaluation of Carcinogenic Risks to Humans; International Agency for Research on Cancer: Lyon, France, 2012; Volume 100.

18. Larsson, S.C.; Orsini, N.; Wolk, A. Urinary cadmium concentration and risk of breast cancer: A systematic review and dose-response meta-analysis. Am. J. Epidemiol. 2015, 182, 375-380. [CrossRef]

19. Buha, A.; Wallace, D.; Matovic, V.; Schweitzer, A.; Oluic, B.; Micic, D.; Djordjevic, V. Cadmium Exposure as a Putative Risk Factor for the Development of Pancreatic Cancer: Three Different Lines of Evidence. Biomed. Res. Int. 2017, 2017, 1-8. [CrossRef]

20. Feki-Tounsi, M.; Hamza-Chaffai, A. Cadmium as a possible cause of bladder cancer: A review of accumulated evidence. Environ. Sci. Pollut. Res. 2014, 21, 10561-10573. [CrossRef]

21. Stojsavljević, A.; Rovčanin, B.; Krstić, Đ.; Jagodić, J.; Borković-Mitić, S.; Paunović, I.; Živaljević, V.; Mitić, B.; Gavrović-Jankulović, M.; Manojlović, D. Cadmium as main endocrine disruptor in papillary thyroid carcinoma and the significance of $\mathrm{Cd} / \mathrm{Se}$ ratio for thyroid tissue pathophysiology. J. Trace Elem. Med. Biol. 2019, 55, 190-195. [CrossRef]

22. Hammouda, F.; Messaoudi, I.; El Hani, J.; Baati, T.; Saïd, K.; Kerkeni, A. Reversal of cadmium-induced thyroid dysfunction by selenium, zinc, or their combination in rat. Biol. Trace Elem. Res. 2008, 126, 194-203. [CrossRef] 
23. Buha, A.; Antonijević, B.; Bulat, Z.; Jaćević, V.; Milovanović, V.; Matović, V. The impact of prolonged cadmium exposure and co-exposure with polychlorinated biphenyls on thyroid function in rats. Toxicol. Lett. 2013, 221, 83-90. [CrossRef] [PubMed]

24. Jancic, S.A.; Stosic, B.Z. Cadmium effects on the thyroid gland. Vitam. Horm. 2014, 94, 391-425. [CrossRef] [PubMed]

25. Piłat-Marcinkiewicz, B.; Brzóska, M.M.; Sawicki, B.; Moniuszko-Jakoniuk, J. Structure and function of thyroid follicular cells in female rats chronically exposed to cadmium. Bull. Vet. Inst. Pulawy 2003, 47, 157-163.

26. Aaseth, J.; Frey, H.; Glattre, E.; Norheim, G.; Ringstad, J.; Thomassen, Y. Selenium concentrations in the human thyroid gland. Biol. Trace Elem. Res. 1990, 24, 147-152. [CrossRef]

27. Köhrle, J.; Jakob, F.; Contempré, B.; Dumont, J.E. Selenium, the thyroid, and the endocrine system. Endocr. Rev. 2005, 26, 944-984. [CrossRef]

28. Köhrle, J. Selenium and the thyroid. Curr. Opin. Endocrinol. Diabetes Obes. 2015, 22, 392-401. [CrossRef]

29. Duntas, L.H.; Benvenga, S. Selenium: An element for life. Endocrine 2015, 48, 756-775. [CrossRef]

30. Ralston, N.V.; Raymond, L.J. Dietary selenium's protective effects against methylmercury toxicity. Toxicology 2010, 278, 112-123. [CrossRef]

31. Nie, X.; Chen, Y.; Chen, Y.; Chen, C.; Han, B.; Li, Q.; Zhu, C.; Xia, F.; Zhai, H.; Wang, N.; et al. Lead and cadmium exposure, higher thyroid antibodies and thyroid dysfunction in Chinese women. Environ. Pollut. 2017, 230, 320-328. [CrossRef]

32. Chung, S.M.; Moon, J.S.; Yoon, J.S.; Won, K.C.; Lee, H.W. Sex-specific effects of blood cadmium on thyroid hormones and thyroid function status: Korean nationwide cross-sectional study. J. Trace Elem. Med. Biol. 2019, 53, 55-61. [CrossRef]

33. Ogawa, Y.; Itoh, M.; Hirai, S.; Suna, S.; Naito, M.; Qu, N.; Terayama, H.; Ikeda, A.; Miyaso, H.; Matsuno, Y.; et al. Cadmium exposure increases susceptibility to testicular autoimmunity in mice. J. Appl. Toxicol. 2013, 33, 652-660. [CrossRef] [PubMed]

34. Monastero, R.N.; Vacchi-Suzzi, C.; Marsit, C.; Demple, B.; Meliker, J.R. Expression of Genes Involved in Stress, Toxicity, Inflammation, and Autoimmunity in Relation to Cadmium, Mercury, and Lead in Human Blood: A Pilot Study. Toxics 2018, 6, 35. [CrossRef] [PubMed]

35. Rani, A.; Kumar, A.; Lal, A.; Pant, M. Cellular mechanisms of cadmium-induced toxicity: A review. Int. J. Environ. Health Res. 2014, 24, 378-399. [CrossRef] [PubMed]

36. Bekheet, S.H. Comparative effects of repeated administration of cadmium chloride during pregnancy and lactation and selenium protection against cadmium toxicity on some organs in immature rats' offsprings. Biol. Trace Elem. Res. 2011, 144, 1008-1023. [CrossRef] [PubMed]

37. Badr, G.M.; Elsawy, H.; Sedky, A.; Eid, R.; Ali, A.; Abdallah, B.M.; Alzahrani, A.M.; Abdel-Moneim, A.M. Protective effects of quercetin supplementation against short-term toxicity of cadmium-induced hematological impairment, hypothyroidism, and testicular disturbances in albino rats. Environ. Sci. Pollut. Res. Int. 2019, 26, 8202-8211. [CrossRef] [PubMed]

38. Benvenga, S.; Feldt-Rasmussen, U.; Bonofiglio, D.; Asamoah, E. Nutraceutical Supplements in the Thyroid Setting: Health Benefits beyond Basic Nutrition. Nutrients 2019, 11, 2214. [CrossRef]

39. Benvenga, S.; Micali, A.; Pallio, G.; Vita, R.; Malta, C.; Puzzolo, D.; Irrera, N.; Squadrito, F.; Altavilla, D.; Minutoli, L. Effects of Myo-inositol Alone and in Combination with Seleno-L-methionine on Cadmium-Induced Testicular Damage in Mice. Curr. Mol. Pharmacol. 2019, 12, 311-323. [CrossRef]

40. Pallio, G.; Micali, A.; Benvenga, S.; Antonelli, A.; Marini, H.R.; Puzzolo, D.; Macaione, V.; Trichilo, V.; Santoro, G.; Irrera, N.; et al. Myo-inositol in the protection from cadmium-induced toxicity in mice kidney: An emerging nutraceutical challenge. Food Chem. Toxicol. 2019, 132, 110675. [CrossRef]

41. Condorelli, R.A.; La Vignera, S.; Di Bari, F.; Unfer, V.; Calogero, A.E. Effects of myoinositol on sperm mitochondrial function in-vitro. Eur. Rev. Med. Pharmacol. Sci. 2011, 15, 129-134.

42. Condorelli, R.A.; La Vignera, S.; Bellanca, S.; Vicari, E.; Calogero, A.E. Myoinositol: Does it improve sperm mitochondrial function and sperm motility? Urology 2012, 79, 1290-1295. [CrossRef]

43. Caprio, F.; D’Eufemia, M.D.; Trotta, C.; Campitiello, M.R.; Ianniello, R.; Mele, D.; Colacurci, N. Myo-inositol therapy for poor-responders during IVF: A prospective controlled observational trial. J. Ovarian Res. 2015, 8, 37. [CrossRef] 
44. Jiang, W.D.; Wu, P.; Kuang, S.Y.; Liu, Y.; Jiang, J.; Hu, K.; Li, S.H.; Tang, L.; Feng, L.; Zhou, X.Q. Myo-inositol prevents copper-induced oxidative damage and changes in antioxidant capacity in various organs and the enterocytes of juvenile Jian carp (Cyprinus carpio var. Jian). Aquat. Toxicol. 2011, 105, 543-551. [CrossRef] [PubMed]

45. Kasai, K.; Banba, N.; Motohashi, S.; Hattori, Y.; Manaka, K.; Shimoda, S.I. Expression of monocyte chemoattractant protein-1 mRNA and protein in cultured human thyrocytes. FEBS Lett. 1996, 394, 137-140. [CrossRef]

46. Fallahi, P.; Ferrari, S.M.; Elia, G.; Ragusa, F.; Paparo, S.R.; Caruso, C.; Guglielmi, G.; Antonelli, A. Myo-inositol in autoimmune thyroiditis, and hypothyroidism. Rev. Endocr. Metab. Disord. 2018, 19, 349-354. [CrossRef]

47. Ferrari, S.M.; Fallahi, P.; Di Bari, F.; Vita, R.; Benvenga, S.; Antonelli, A. Myo-inositol and selenium reduce the risk of developing overt hypothyroidism in patients with autoimmune thyroiditis. Eur. Rev. Med. Pharmacol. Sci. 2017, 21, 36-42. [PubMed]

48. Benvenga, S.; Vicchio, T.; Di Bari, F.; Vita, R.; Fallahi, P.; Ferrari, S.M.; Catania, S.; Costa, C.; Antonelli, A. Favorable effects of myo-inositol, selenomethionine or their combination on the hydrogen peroxide-induced oxidative stress of peripheral mononuclear cells from patients with Hashimoto's thyroiditis: Preliminary in vitro studies. Eur. Rev. Med. Pharmacol. Sci. 2017, 21, 89-101. [PubMed]

49. Nordio, M.; Basciani, S. Treatment with Myo-Inositol and Selenium Ensures Euthyroidism in Patients with Autoimmune Thyroiditis. Int. J. Endocrinol. 2017, 2017, 2549491. [CrossRef]

50. Gupta, P.; Kar, A. Role of ascorbic acid in cadmium-induced thyroid dysfunction and lipid peroxidation. J. Appl. Toxicol. 1998, 18, 317-320. [CrossRef]

51. Eleawa, S.M.; Alkhateeb, M.A.; Alhashem, F.H.; Bin-Jaliah, I.; Sakr, H.F.; Elrefaey, H.M.; Elkarib, A.O.; Alessa, R.M.; Haidara, M.A.; Shatoor, A.S.; et al. Resveratrol reverses cadmium chloride-induced testicular damage and subfertility by downregulating p53 and Bax and upregulating gonadotropins and Bcl-2 gene expression. J. Reprod. Dev. 2014, 60, 115-127. [CrossRef]

52. Rafati, A.; Hoseini, L.; Babai, A.; Noorafshan, A.; Haghbin, H.; Karbalay-Doust, S. Mitigating Effect of Resveratrol on the Structural Changes of Mice Liver and Kidney Induced by Cadmium; A Stereological Study. Prev. Nutr. Food Sci. 2015, 20, 266-275. [CrossRef]

53. Salehi, B.; Mishra, A.P.; Nigam, M.; Sener, B.; Kilic, M.; Sharifi-Rad, M.; Fokou, P.; Martins, N.; Sharifi-Rad, J. Resveratrol: A Double-Edged Sword in Health Benefits. Biomedicines 2018, 6, 91. [CrossRef] [PubMed]

54. Giammanco, M.; Leto, G. Selenium and autoimmune thyroiditis. EC Nutr. 2019, 14, 449-450.

55. Rahman, M.M.; Hossain, K.F.B.; Banik, S.; Sikder, M.T.; Akter, M.; Bondad, S.E.C.; Rahaman, M.S.; Hosokawa, T.; Saito, T.; Kurasaki, M. Selenium and zinc protections against metal-(loids)-induced toxicity and disease manifestations: A review. Ecotoxicol. Environ. Saf. 2019, 168, 146-163. [CrossRef] [PubMed]

56. Zwolak, I. The Role of Selenium in Arsenic and Cadmium Toxicity: An Updated Review of Scientific Literature. Biol. Trace Elem. Res. 2020, 193, 44-63. [CrossRef] [PubMed]

57. Wan, N.; Xu, Z.; Liu, T.; Min, Y.; Li, S. Ameliorative Effects of Selenium on Cadmium-Induced Injury in the Chicken Ovary: Mechanisms of Oxidative Stress and Endoplasmic Reticulum Stress in Cadmium-Induced Apoptosis. Biol. Trace Elem. Res. 2018, 184, 463-473. [CrossRef]

58. Chen, Z.J.; Chen, J.X.; Wu, L.K.; Li, B.Y.; Tian, Y.F.; Xian, M.; Huang, Z.P.; Yu, R.A. Induction of Endoplasmic Reticulum Stress by Cadmium and Its Regulation on Nrf2 Signaling Pathway in Kidneys of Rats. Biomed. Environ. Sci. 2019, 32, 1-10. [CrossRef]

59. Benvenga, S.; Antonelli, A. Inositol(s) in thyroid function, growth and autoimmunity. Rev. Endocr. Metab. Disord. 2016, 17, 471-484. [CrossRef]

60. Brenta, G.; Caballero, A.S.; Nunes, M.T. Case finding for hypothyroidism should include type 2 diabetes and metabolic syndrome patients: A Latin American Thyroid Society (LATS) position statement. Endocr. Pract. 2019, 25, 101-105. [CrossRef]

61. Chang, Y.C.; Hua, S.C.; Chang, C.H.; Kao, W.Y.; Lee, H.L.; Chuang, L.M.; Huang, Y.T.; Lai, M.S. High TSH Level within Normal Range Is Associated with Obesity, Dyslipidemia, Hypertension, Inflammation, Hypercoagulability, and the Metabolic Syndrome: A Novel Cardiometabolic Marker. J. Clin. Med. 2019, 8, 817. [CrossRef]

62. Lupoli, R.; Di Minno, A.; Tortora, A.; Ambrosino, P.; Lupoli, G.A.; Di Minno, M.N. Effects of treatment with metformin on TSH levels: A meta-analysis of literature studies. J. Clin. Endocrinol. Metab. 2014, 99, E143-E148. [CrossRef] 
63. Dimic, D.; Golubovic, M.V.; Radenkovic, S.; Radojkovic, D.; Pesic, M. The effect of metformin on TSH levels in euthyroid and hypothyroid newly diagnosed diabetes mellitus type 2 patients. Bratisl. Med. J. 2016, 117, 433-435. [CrossRef] [PubMed]

64. Wang, J.; Gao, J.; Fan, Q.; Li, H.; Di, Y. The Effect of Metformin on Thyroid-Associated Serum Hormone Levels and Physiological Indexes: A Meta-Analysis. Curr. Pharm. Des. 2019, 25, 3257-3265. [CrossRef] [PubMed]

65. D’Anna, R.; Di Benedetto, A.; Scilipoti, A.; Santamaria, A.; Interdonato, M.L.; Petrella, E.; Neri, I.; Pintaudi, B.; Corrado, F.; Facchinetti, F. Myo-inositol Supplementation for Prevention of Gestational Diabetes in Obese Pregnant Women: A Randomized Controlled Trial. Obstet. Gynecol. 2015, 126, 310-315. [CrossRef] [PubMed]

66. D'Anna, R.; Santamaria, A.; Alibrandi, A.; Corrado, F.; Di Benedetto, A.; Facchinetti, F. Myo-Inositol for the Prevention of Gestational Diabetes Mellitus. A Brief Review. J. Nutr. Sci. Vitaminol. 2019, 65, S59-S61. [CrossRef]

67. Ventura, M.; Melo, M.; Carrilho, F. Selenium and Thyroid Disease: From Pathophysiology to Treatment. Int. J. Endocrinol. 2017, 2017, 1297658. [CrossRef]

(C) 2020 by the authors. Licensee MDPI, Basel, Switzerland. This article is an open access article distributed under the terms and conditions of the Creative Commons Attribution (CC BY) license (http://creativecommons.org/licenses/by/4.0/). 


\title{
Nutraceuticals in Thyroidology: A Review of in Vitro, and in Vivo Animal Studies
}

\author{
Salvatore Benvenga ${ }^{1,2}$, Silvia Martina Ferrari ${ }^{3}$, Giusy Elia ${ }^{3}$, Francesca Ragusa ${ }^{3}$, \\ Armando Patrizio ${ }^{3}$, Sabrina Rosaria Paparo ${ }^{3}$, Stefania Camastra ${ }^{3}$, Daniela Bonofiglio ${ }^{4}$, \\ Alessandro Antonelli ${ }^{3, *}$ and Poupak Fallahi ${ }^{5}$ \\ 1 Master Program on Childhood, Adolescent and Women's Endocrine Health, Department of Clinical and \\ Experimental Medicine, University of Messina, 98125 Messina; s.benvenga@live.it \\ 2 Interdepartmental Program of Molecular \& Clinical Endocrinology, and Women's Endocrine Health, \\ University Hospital, Policlinico Universitario G. Martino, 98125 Messina, Italy \\ 3 Department of Clinical and Experimental Medicine, University of Pisa, 56126 Pisa, Italy; \\ sm.ferrari@int.med.unipi.it (S.M.F.); e.giusy_87@hotmail.it (G.E.); francescaragusa86@gmail.com (F.R.); \\ armandopatrizio125@gmail.com (A.P.); sabrinapaparo@gmail.com (S.R.P.); stefania.camastra@unipi.it (S.C.) \\ 4 Department of Pharmacy, Health and Nutritional Sciences, University of Calabria, \\ 87036 Arcavacata di Rende (CS), Italy; daniela.bonofiglio@unical.it \\ 5 Department of Translational Research and New Technologies in Medicine and Surgery, University of Pisa, \\ 56126 Pisa, Italy; poupak.fallahi@unipi.it \\ * Correspondence: alessandro.antonelli@med.unipi.it; Tel.: +39-050-992318
}

Received: 21 March 2020; Accepted: 6 May 2020; Published: 8 May 2020

\begin{abstract}
Nutraceuticals are defined as a food, or parts of a food, that provide medical or health benefits, including the prevention of different pathological conditions, and thyroid diseases, or the treatment of them. Nutraceuticals have a place in complementary medicines, being positioned in an area among food, food supplements, and pharmaceuticals. The market of certain nutraceuticals such as thyroid supplements has been growing in the last years. In addition, iodine is a fundamental micronutrient for thyroid function, but also other dietary components can have a key role in clinical thyroidology. Here, we have summarized the in vitro, and in vivo animal studies present in literature, focusing on the commonest nutraceuticals generally encountered in the clinical practice (such as carnitine, flavonoids, melatonin, omega-3, resveratrol, selenium, vitamins, zinc, and inositol), highlighting conflicting results. These experimental studies are expected to improve clinicians' knowledge about the main supplements being used, in order to clarify the potential risks or side effects and support patients in their use.
\end{abstract}

Keywords: nutraceuticals; thyroid; carnitine; flavonoids; melatonin; omega-3; resveratrol; selenium; vitamins; zinc

\section{Introduction}

The term "nutraceutical" is placed in an area among food, food supplements, and pharmaceuticals [1]. Nutraceuticals are considered complementary medicines, defined as a "food, or parts of a food, that provide medical or health benefits, including the prevention and treatment of disease" [2]. Most nutraceuticals are normal human metabolites (i.e., dehydroepiandrosterone (DHEA) and S-adenoylmethionine (SAMe), carnitine, creatine, coenzyme Q10, lipoic acid, melatonin), or bioactive plant dietary components [2]. Food categories and supplements are both described in the European regulation (No. 1924/2006 of the European Parliament and of the Council, updated by EU Regulation 2015/2283), even if an official mention or recognition of the term "nutraceutical" does not exist [3]. The European Food Safety Authority (EFSA) does not distinguish clearly the terms 
"food supplements" and "nutraceuticals, while in America "medical foods" and "dietary supplements" are regulatory terms, although "nutraceuticals" and "functional foods" are determined according to consumer trends [1].

In the last years, interest and knowledge in nutraceuticals have been growing. Nutraceuticals can be considered for the prevention of different pathological conditions, including thyroid diseases and associated disorders [4-6].

In addition to iodine, which is a fundamental nutrient for thyroid function, other dietary components (such as carnitine, flavonoids, melatonin, omega-3, resveratrol, selenium, vitamins, zinc, and inositol) were found to have some role in thyroid homeostasis, so that they could have a role in clinical thyroidology. The principal issue about the appropriateness and effectiveness of nutraceuticals in prevention and treatment depends on the lack or scarcity of clinical data [1]. Moreover, there is the problem of the not uncommon discrepancy between the concentration reported in the label and the real one [1]. Conventional medicines are usually submitted to quality control to ensure that they contain the claimed dose of active constituents, and that they have suitable disintegration characteristics and bioavailability, enabling absorption in the gut tract. Composition of nutraceuticals is increasingly being evaluated, the results of the analyses being that composition sometimes fails the relevant standards, or the label claims are not respected [2].

Here, we aim to review various nutraceuticals that can influence human thyroid homeostasis, addressing on the in vitro, and in vivo experimental animal studies reported in literature. We will focus on nutraceuticals, other than iodine, that are more likely to be encountered in the clinical practice.

\section{Search of the Literature}

A PubMed search, run on March 2020, using the word "nutraceuticals" as the entry, yielded 74,935 results, indicating the great interest in general for this emerging class of natural compounds that makes the line between food and drugs to fade. Interestingly, using the entry "nutraceuticals AND thyroid" a total of 6622 published papers were obtained, highlighting that the scientific interest of nutraceutical area covers the thyroid research field. Indeed, different nutraceuticals possibly influence human thyroid function and/or thyroid tumor biology that will be reviewed and commented upon. Particularly, using the filter "humans" to exclude "other animals", and the filter "other animals" in order to exclude "humans", we have meticulously screened the in vitro and in vivo experimental studies on thyroid and carnitine ("carnitine AND thyroid"), flavonoids ("flavonoids AND thyroid"), isoflavonoids ("isoflavonoids AND thyroid"), soy ("soy AND thyroid"), melatonin ("melatonin AND thyroid"), omega-3 polyunsaturated fatty acids ("omega-3 polyunsaturated fatty acids AND thyroid"), resveratrol ("resveratrol AND thyroid"), selenium ("selenium AND thyroid"), vitamins ("vitamins AND thyroid"), zinc ("zinc AND thyroid"), and inositol ("inositol AND thyroid") (Table 1).

Table 1. Summary of number of articles on given nutraceuticals retrievable on PubMed as of 21 March 2020 *.

\begin{tabular}{cccc}
\hline n. of Items. & Entry & Humans & Other Animals \\
\hline 1 & nutraceuticals & 55,737 & 31,391 \\
2 & nutraceuticals AND thyroid & $522(0.9 \%)$ & $224(0.9 \%)$ \\
3 & carnitine & 8134 & 8778 \\
4 & carnitine AND thyroid & $71(0.8 \%)$ & $95(1.1 \%)$ \\
5 & flavonoids & 44,187 & 49,719 \\
6 & flavonoids AND thyroid & $222(0.5 \%)$ & $248(0.5 \%)$ \\
7 & isoflavonoids & 404 & 281 \\
8 & isoflavonoids AND thyroid & $4(0.9 \%)$ & $4(1.4 \%)$ \\
9 & soy & 7965 & 6531 \\
10 & soy AND thyroid & $93(1.2 \%)$ & $75(1.1 \%)$ \\
\hline
\end{tabular}


Table 1. Cont.

\begin{tabular}{cccc}
\hline n. of Items. & Entry & Humans & Other Animals \\
\hline 11 & melatonin & 11,142 & 14,477 \\
12 & melatonin AND thyroid & $200(1.8 \%)$ & $364(2.5 \%)$ \\
13 & omega-3 polyunsaturated fatty acids & 17,168 & 12,783 \\
14 & omega-3 polyunsaturated fatty acids AND thyroid & $37(0.21 \%)$ & $38(0.3 \%)$ \\
15 & resveratrol & 5823 & 5961 \\
16 & resveratrol AND thyroid & $54(0.9 \%)$ & $42(0.7 \%)$ \\
17 & selenium & 13,794 & 13,888 \\
18 & selenium AND thyroid & $600(4.3 \%)$ & $372(2.7 \%)$ \\
19 & vitamin A & 32,637 & 22,296 \\
20 & vitamin A AND thyroid & $495(1.5 \%)$ & $593(2.7 \%)$ \\
21 & vitamin D & 61,418 & 20311 \\
22 & vitamin D AND thyroid & $1280(2.1 \%)$ & $554(2.7 \%)$ \\
23 & vitamin E & 22,004 & 18,811 \\
24 & vitamin E AND thyroid & $96(0.4 \%)$ & $123(0.6 \%)$ \\
25 & zinc & 58,247 & 50,628 \\
26 & zinc AND thyroid & $503(0.86 \%)$ & $401(0.7 \%)$ \\
27 & inositol & 17,144 & 27,226 \\
28 & inositol AND thyroid & $147(0.86 \%)$ & $205(0.75 \%)$ \\
\hline
\end{tabular}

* The PubMed search was run using the filter "humans" to exclude "other animals", and the filter "other animals" in order to exclude "humans". Note how thyroidal studies account for a tiny fraction of total studies for any listed nutraceutical, and with comparable percentages in humans and animals. For instance, "resveratrol AND thyroid" accounted for 54 of 5823 studies in humans $(0.9 \%)$ and 42 of 5961 studies in other animals $(0.7 \%)$.

\section{Carnitine}

The naturally occurring quaternary amine, carnitine, is ubiquitous in mammalian tissues, and according to studies of about 40 years ago, it was considered a peripheral antagonist of thyroid hormone (TH) action [7].

Old studies published in German language showed that carnitine is capable of contrasting $\mathrm{TH}$-induced changes associated with the nitrogen balance in rats and metamorphosis of tadpoles $[8,9]$. In the more recent of such papers, carnitine contrasted the thyroxine (T4)-induced liver and circulating concentration of both alanine aminotransferase (ALT) and aspartate aminotransferase (AST) [9]. Tissue culture experiments on human skin fibroblasts, human hepatoma cells HepG2, and mouse neuroblastoma cells NB 41A3 demonstrated that L-carnitine inhibits cell entry, and overall nuclear entry, of triiodothyronine (T3) and T4 [7]. There was no inhibition on TH efflux from cells, and no inhibition of TH binding to isolated nuclei. These data confirm that carnitine is a peripheral antagonist of TH action, and that one level of inhibition occurs at the nuclear envelope or before it [7].

Four experimental groups were formed starting from 21 male Sprague Dawley rats: hyperthyroidism $(n=5)$, hyperthyroidism plus low dose L-carnitine ( $100 \mathrm{mg} / \mathrm{kg} / \mathrm{d}$ for 10 days; $n=5)$, hyperthyroidism plus high dose L-carnitine $(500 \mathrm{mg} / \mathrm{Kg} / \mathrm{d}$ for 10 days; $n=5)$, and controls $(0.2 \mathrm{~mL} / 100 \mathrm{~g}$ body weight, subcutaneously, of $0.9 \% \mathrm{NaCl}$ solution; $n=6$ ) [10]. The injection of levothyroxine (L-T4) in a dose of $250 \mu \mathrm{g} / \mathrm{kg}$ body weight per day for 20 consecutive days was able to induce hyperthyroidism in rats. The treatment with either dose of L-carnitine was by intraperitoneal injection, and it started on the 10th day of hyperthyroidism continuing for the following 10 days. Activities of one marker of oxidative stress (malondialdehyde (MDA)) and activities of three markers of antioxidant defense (namely, the antioxidant enzymes catalase (CAT), glutathione peroxidase (GPX), and myeloperoxidase (MPO)) were measured in liver homogenates. MDA activity was increased by $59 \%$ in the carnitine-untreated hyperthyroid group, but it decreased significantly and to levels comparable to the control rats in either group of hyperthyroid rats receiving L-carnitine. Activities of the three enzymes were $21 \%$ to $76 \%$ lower in the carnitine-untreated hyperthyroid rats with respect to the control group. Treatment of hyperthyroid rats with either low or high dose of L-carnitine increased strongly the liver activities of the antioxidant enzymes (with dose-dependency absent for CAT, moderate for GPX and great 
for MPO), indicating that even a low dose of L-carnitine was enough to prevent the oxidative stress induced in the rat liver by L-T4 [10].

Some experimental data are available in the neoplastic setting of the thyroid. L-carnitine, the biologically active form of carnitine, transports long-chain acyl groups from fatty acids into the mitochondrial matrix to generate metabolic energy in living cells. Although, it has been reported that treatment with L-carnitine efficiently induced ATP generation in normal cells, it has been found to selectively inhibit cancer cell growth in vitro and in vivo models [11].

Controversially, the expression of the enzyme involved in this transport, the carnitine palmitoyltransferase 1C (Cpt1c), has been detected at higher levels in papillary thyroid tissues compared with normal ones and Cpt1c up-regulation has been found to promote cancer cell growth and metastasis in human papillary thyroid carcinomas cell lines [12].

Recently, carnitine has been reported as a potential candidate biomarker able to discriminate between normal and thyroid cancer cells, however, further studies are needed to confirm carnitine as the thyroid cancer diagnostic oncometabolite [13]. Of interest, a recent Turkish study [14] used 40 guinea pigs to assess the protective effects of amifostine ( $200 \mathrm{mg} / \mathrm{kg}$ ip), L-carnitine ( $200 \mathrm{mg} / \mathrm{kg}$ ip), or vitamin $\mathrm{E}(40 \mathrm{mg} / \mathrm{kg} \mathrm{im})$ against high dose radioactive iodine (131I) treatment-induced salivary gland damage. Control animals received ${ }^{131}$ I was administered intraperitoneally at doses (555-660 MBq) that ablate the thyroid and impair the parenchymal function of the salivary glands. The damage of the salivary glands was evaluated one month after treatment, by salivary gland scintigraphy and histopathology, in 40 guinea pigs. The three molecules gave different levels of protection against radioactive iodine treatment injury in salivary glands; however, none of the agents could provide absolute protection.

\section{Flavonoids, Isoflavonoids, Soy}

Flavonoids are the most common group of polyphenolic compounds in the human diet and are widespread in plants [15], and they can be classified into flavonoids or bioflavonoids; isoflavonoids; and neoflavonoids. It has been reported that flavonoids can interfere with thyroperoxidase (TPO) activity, reducing TH synthesis with subsequent raise of thyroid-stimulating hormone (TSH) levels and potential development of goiter. Goiter occurrence has been described among infants fed with soy formula, while the thyroid profile was normal in post-menopausal women with regular soy diet. Moreover, flavonoids seem to impair the peripheral action of $\mathrm{TH}$, by the inhibition of deiodinase or displacing T4 from transthyretin [16]. Recently, the debate on soy foods and diet has earned attention among the healthcare and general public.

Since isoflavones from soy and other legumes showed to act on estrogen pathway, they are also proposed as nutraceutical products to relieve women from symptoms of menopause [17]. However, data regarding the impact of isoflavones on endogenous estrogens levels in women are still controversial. To date, no health issue on isoflavones has been ratified by EFSA because of insufficient scientific evidence, while the available human studies ruled out the hypothesis of adverse effects of isolated isoflavones on mammary gland, uterus or thyroid health among postmenopausal women. Nevertheless, there are many divergences to consider in term of metabolism of isoflavones, developmental stage at time of consumption and in their temporarily restricted uptake during certain stages of life, that make animal models not reliable for humans. Thus, potential adverse effects cannot be completely ignored, especially among women with unknown diseases status (i.e., undetected precancerous lesions in the mammary gland) [17].

In 2014, a review explored 5 health benefits-relieves of menopausal symptoms and prevention of breast cancer, heart disease, osteoporosis, and prostate cancer, and 5 health risks-increased risk of breast cancer, hypothyroidism, male hormonal and fertility problems, antinutrient content, and harmful processing by-products [18]. The authors considered in their analysis prospective human trials, systematic reviews of human trials, observational human studies, in vitro studies, laboratory analyses of soy components, and animal studies. They noticed that isoflavones and soy foods may wane 
menopausal symptoms and protect from breast cancer and heart disease, but not from osteoporosis. The impact on male fertility and reproduction was controversial. With regard to thyroid activity, data are conflicting and there is uncertainty, demonstrating that soy may have unpredictable effect on thyroid physiology [18].

In a study, adult female cynomolgus monkeys (Macaca fascicularis) were randomized in 2 groups, according to diet: One to consume casein-lactalbumin $(n=44)$ and the other soy protein with isoflavones $(n=41)$ [19]. All animals were ovariectomized after 34 months, and then, for other 34 months, half of the monkeys from each diet treatment group continued to receive their preovariectomy diet. The remaining animals were not considered furtherly. The authors concluded that soy protein and isoflavones do not adversely affect thyroid function in females [19].

Anyway, studies of soy isoflavones in experimental animals suggest possible adverse effects as well (i.e., anti-thyroid effects, modulation of endocrine function, and enhancement of reproductive organ cancer) [20].

A study showed that rats fed with a diet containing soy ( $20 \%$ defatted soy bean) had a severe hypothyroid state (low T4, increased TSH and thyroid weight), with evidence for increased thyroid cell proliferation. This hypothyroidism was induced only when a dietary condition of iodine deficiency was added [21].

Another paper indicated a dramatic synergism between soy intake and iodine deficiency on the induction of thyroid hyperplasia in rats [22]. Female F344 rats were randomized into 8 groups, and for a 5 -week period received a diet containing: 1) $0.2 \%$ soy isoflavone mixture (SI); 2 ) $0.2 \%$ SI + iodine deficiency (ID); 3) $0.04 \%$ SI; 4) $0.04 \%$ SI + ID; 5) $20 \%$ defatted soybean (DS) alone; 6) $20 \%$ DS + ID; 7) ID alone; 8 ) basal diet alone. In the group receiving $20 \%$ DS, serum T4 and TSH levels increased inducing thyroid growth in rats exposed also to the ID diet. In the ID diet groups, proliferating cell nuclear antigen labeling indices (\%) were elevated and increased by DS, but not SI, suggesting that isoflavones may not participate in the mechanisms underlying the synergistic goitrogenic effect of soybean with iodine deficiency [22].

Genistein (4',5,7-trihydroxyflavone) is a phytoestrogen that belongs to the class of soy isoflavones and is effective to treat osteoporosis, menopausal vasomotor symptoms, cardiovascular diseases, as well as a variety of cancers. Little is known about the action of isoflavones on thyroid integrity in humans, even if it seems that genistein does not act negatively on thyroid safety in euthyroid humans [23]. Recently, it has been demonstrated that genistein has antineoplastic effects, but it does not induce genotoxic effects whereas it decreases oxidative-induced DNA damage in human primary thyroid cells from papillary thyroid cancer, supporting its potential use in therapeutic intervention [24].

A study evaluated the biological effects of genistein in rats receiving genistein aglycone in soy-free feed fortified at $0,5,100$, and $500 \mathrm{ppm}$, beginning in utero through 20 weeks [24]. In rat serum, the genistein content was of $8 \mu \mathrm{M}$, and it increases in thyroid tissues up to $1 \mathrm{pmol} / \mathrm{mg}$ both in male and female rats. The activity of TPO was reduced by up to $80 \%$ dose-dependently in rats of both gender. Male and female rats receiving a standard soy-based rodent diet had TPO activity $50 \%$ lower than rats consuming a soy-free diet. Comparing treated and untreated groups, there were no differences in T3, T4, and TSH serum levels, thyroid weights, and histopathology. The reported data suggested that, even if normal rats lose partial activity of TPO when they receive soy isoflavone, thyroid homeostasis is guaranteed by remaining enzymatic activity [25].

Quercetin is the most abundant dietary flavonoid in fruit and vegetables, and it has different therapeutic actions, i.e., the induction of apoptosis in cancer cells, and antioxidant, antiviral, anti-proliferative, and anti-inflammatory effects [26]. Regarding the thyroid, many studies have shown anti-thyroid and goitrogenic effects of flavonoids, different according to each specific flavonoid [16].

As a pretreatment for Wistar rats, quercetin was administered orally at the dose of $10 \mathrm{mg} / \mathrm{kg}$ for 7 days, and it protected them from myocardial infarction induced by subcutaneous injection of isoproterenol. The ST-segment elevation was lowered and levels of lipid peroxidation products were decreased in plasma and heart [27]. Moreover, the pretreatment with quercetin reduced significantly 
the levels of total cholesterol, triglycerides and free fatty acids in serum, heart, and heart mitochondria and serum phospholipids, and it lowered levels of serum LDL and very LDL cholesterol, while raised significantly serum HDL [27].

When quercetin was given $(0.1 \% ; \mathrm{w} / \mathrm{w}$ in diet) to human CRP transgenic mice, a humanized inflammation model, and $\mathrm{ApoE}^{*} 3$ Leiden transgenic mice, a humanized atherosclerosis model, it halted IL-1b-induced CRP expression in the first and lowered the burden of atherosclerosis $(40 \%)$ in the second through a reduction of circulating inflammatory markers, "serum amyloid A proteins" and fibrinogen. The quercetin plasma levels (13-19 $\mathrm{mM}$ ) were similar among both groups and to those measured in rodents treated with the same doses $(0.1 \%, \mathrm{w} / \mathrm{w})$ [28].

In 2008, quercetin was shown to halt the spread in FRTL-5 thyroid cells dose- and time-dependently, by inhibiting insulin-regulated Akt kinase action [29]. Quercetin interferes with TSH-dependent NIS gene expression and I- transport in FRTL-5 cells. These observations may help us to understand the molecular mechanism of the antithyroid effect of quercetin on cell growth and function. Even if collected from an in vitro, hormonally controlled, functioning thyroid cell line, that does not have the characteristics of a transformed cell, these results led to evaluate quercetin as an antithyroid drug in hyperfunctioning states [29].

In recent studies, quercetin seems to reduce the expression of the thyrotropin receptor, TPO and thyroglobulin (Tg) genes [30]. The antithyroid impact of quercetin was further evaluated in vivo: Quercetin was administered $(50 \mathrm{mg} / \mathrm{kg})$ to a Sprague-Dawley rat and after 14 days of treatment, radioiodine uptake decreased significantly demonstrating that quercetin may act as a thyroid disruptor [30].

Apigenin, a plant-derived flavonoid, has been also considered able to increase the iodide influx through Akt inhibition in thyroid cells under acute TSH stimulation [31]. Radioiodide accumulation thanks to apigenin-mediated Akt inhibition was also described in $\mathrm{PCCl} 3$ rat thyroid cells overexpressing $B R A F(V 600 E)$ and in primary thyroid tumor cells from $T R \beta(P V / P V)$ mice. These results suggest that the outcome of radioiodine therapy for thyroid cancer can be improved by apigenin and other Akt inhibitors given as food supplements [31].

Soy extracts suppressed iodine uptake and increased the protein content of a known autoimmunogenic $\mathrm{Tg}$ fragment in Fischer rat thyroid cells (FRTL). These effects might be responsible for the association between higher incidence of Soy consumption with thyroid disorders such as hypothyroidism, goiter, and autoimmune thyroid disease [32].

Among flavonoids, epigallocatechin-3 gallate (EGCG), a catechin abundant in green tea, when administrated to male rats at doses of 25,50 , and $100 \mathrm{mg} / \mathrm{kg}$ body weight showed antithyroidal effects as emerged by decreased activity of thyroid peroxidase and $5^{\prime}$-deiodinase I and increased thyroidal $\mathrm{Na}^{+} / \mathrm{K}^{+}$ATPase activity. In addition, serum T3 and T4 levels were reduced, while serum TSH was elevated in rats, showing in vivo goitrogenic potential [33].

Moreover, the effect of EGCG $(10,40,60 \mu \mathrm{M})$ was also tested on the proliferation and motility of human thyroid papillary (FB-2) and follicular (WRO) carcinoma cell lines. EGCG treatment inhibited thyroid cancer cell growth, reduced cell motility and migration with concomitant loss of epithelial-to-mesenchymal cell transition markers [34].

\section{Melatonin}

Melatonin is an indoleamine with different activities in animals and plants, such as anti-aging, antioxidant, circadian rhythm controlling, antiproliferative, or immunomodulatory [35].

In a paper published in 1991, both in the Results ("As shown in Table 2, in surviving mice at 19 and 23 months, melatonin treatment resulted in a significant decrease in night levels of T3 and T4 after 7 ...") and in the Discussion ("chronic night treatment with melatonin in the drinking water in aging mice significantly lowers night levels of T3 and T4 in peripheral blood (Table 2) and thus affects aging related thyroid dysfunction by a mechanism yet to be elucidated"), the authors stated that both T3 and $\mathrm{T} 4$ decreased after 7 months of melatonin treatment [36]. However, inspection of their Table 2 
(see the following Table 2 that was redrawn by S. Benvenga), shows that only the reduction of T3 was statistically significant. Incidentally, another inaccuracy is that such reductions are lower $(-20 \%$ for T3 and $-23 \%$ for T4) than those shown in their Table $2(-25 \%$ and $-30 \%)$.

Table 2. Table redrawn from reference \#36. In that paper [36], this table was Table 2, and its heading was "Chronic (night) treatment with melatonin modifies night levels of thyroid hormones in serum and maintains the delayed-type hypersensitivity (DTH) response of aging C57BL/6 male mice".

\begin{tabular}{|c|c|c|c|c|}
\hline Groups & $\begin{array}{c}\text { Age } \\
\text { (Months) }\end{array}$ & $\begin{array}{c}\text { Melatonin } \\
\text { (Duration of Treatments, Months) }\end{array}$ & $\begin{array}{c}\text { T3 } \\
\text { (ng/mL) }\end{array}$ & $\begin{array}{c}\mathrm{T} 4 \\
(\mu \mathrm{g} / \mathrm{dL})\end{array}$ \\
\hline $\begin{array}{l}\text { Untreated } \\
(n=10)\end{array}$ & 19 & & $0.854 \pm 0.165$ & $5.48 \pm 1.09$ \\
\hline $\begin{array}{l}\text { Treated } \\
(n=10)\end{array}$ & 19 & 3 & $\begin{array}{c}0.873 \pm 0.160 \\
(+2.2 \%) \\
P>0.05(\mathrm{NS})\end{array}$ & $\begin{array}{c}5.46 \pm 1.51 \\
(-0.36 \%) \\
P>0.05(\mathrm{NS})\end{array}$ \\
\hline $\begin{array}{l}\text { Untreated } \\
(n=4)\end{array}$ & 23 & $\longrightarrow$ & $0.850 \pm 0.028$ & $4.94 \pm 1.10$ \\
\hline $\begin{array}{l}\text { Treated } \\
(n=8)\end{array}$ & 23 & 7 & $\begin{array}{c}0.682 \pm 0.049 \\
(-19.8 \%)^{*} \\
P<0.001\end{array}$ & $\begin{array}{c}3.79 \pm 1.37 \\
(-23.3 \%) \S \\
P>0.05(\mathrm{NS})\end{array}$ \\
\hline
\end{tabular}

* In the original Table, the Authors wrote " $(-25 \%)$ ". Having noted this error, S. Benvenga wished to repeat statistical analysis with the same test used by the Authors (two-tailed Student's $t$ test). He obtained, $t=6.199$, which is significant at a $P<0.001$, confirming the tabulated $P$ value. $\S$ In the original table, the authors wrote " $(-30 \%)$ ". Having noted this error, S. Benvenga wished to repeat statistical analysis with the same test used by the Authors (two-tailed Student's $t$ test). He obtained, $t=1.450$, which is insignificant $(P>0.10)$, thus confirming the tabulated value.

One note of caution comes from preliminary experiments by the same group in $\mathrm{C} 3 \mathrm{H} / \mathrm{He}$ female mice that started to be treated with melatonin $(10 \mu \mathrm{g} / \mathrm{mL}$ in the drinking water) at 1 year of age. "Melatonin not only failed to prolong the life span of the mice, but, on the contrary, induced a high number of tumors primarily affecting the reproductive tract (lympho- or reticulosarcoma, carcinoma of ovarian origin; histology not shown here) and thus adversely affected the health and survival of melatonin-treated mice" [36]. Indeed, as stated in the Discussion "It was not surprising, in this study, that ovarian tumors developed following chronic melatonin administration, as Kikuchi et al. found that melatonin stimulated in vitro proliferation of a human ovarian KF cell line" [36]. Instead, "a remarkable prolongation of life was seen when NZB mice were chronically given melatonin in the drinking water at night, while no effect was seen when melatonin was given during the day. In spite of the effect of melatonin, the common causes of death in all melatonin-treated or control NZB mice were autoimmune hemolytic anemia, nephrosclerosis and development of systemic or localized type A or B reticulum cell neoplasia" [36]. "A repetition of our experiments by night administration of melatonin in older, aging C57BL/6 male mice resulted again in a significant prolongation of their survival" [36].

At the end of a 4-week duration study in adult male rats, pinealectomy was associated with increased levels of serum FT3 and FT4 levels compared to control rats and, to a greater extent, compared to zinc-deficient rats [37]. The same Turkish team [38] showed that, at the end of a 4-week treatment period with $3 \mathrm{mg} / \mathrm{kg} / \mathrm{day}$ of zinc and/or melatonin, melatonin has a thyroid function suppressing action, just the opposite to the effect of zinc. However, when zinc is administered along with melatonin, the thyroid function suppression exerted by melatonin is lowered. Just recently, in rats with experimentally-induced thyroid dysfunction, Baltaci et al. [39] found that both melatonin and zinc levels are increased in hyperthyroidism and decreased in hypothyroidism.

In cultured rat thyroid follicular cells, melatonin increases directly Tg expression, thus regulating TH biosynthetic activity. On the other hand, it has also been reported that thyroid C-cells synthesize melatonin suggesting in the meantime a paracrine role for this molecule in the regulation of thyroid activity [35]. 
Interestingly, melatonin was found to suppress cell viability, migration and to induce apoptosis in thyroid cancer cell lines in vitro and reduce tumor growth in the subcutaneous mouse model in vivo. In addition, melatonin could enhance sensitivity of thyroid cancer cells to irradiation in vitro and in vivo, suggesting that this molecule may have clinical benefits in thyroid cancer [40].

\section{Omega-3 Polyunsaturated Fatty Acids (Or Fish Oil)}

Omega-3 ( $\omega-3)$ polyunsaturated fatty acids (PUFAs) are docosapentaenoic acid (DPA), $\alpha$-linolenic acid (ALA), stearidonic acid (SDA), docosahexaenoic acid (DHA), and eicosapentaenoic acid (EPA). Several clinical trials and animal models have suggested that $\omega-3$ possess multiple effects, such as reduction of lipid levels, direct interactions with cytosolic or membrane bound proteins, metabolic effects, alteration of membrane fluidity (after being incorporated into the phospholipid bilayer) or cardiac tissue remodeling and cell-to-cell communications, even if the data demonstrating improvement remain contradictory [41].

Some Authors demonstrated the anti-apoptotic action of $\omega$-3-fatty acids ( $\omega$-3 FAs) on cerebellar organogenesis in a murine model of hypothyroidism-induced neuronal apoptosis [42]. Pregnant and lactating rats were first made hypothyroid by methimazole (MMI) administration and then received $\omega-3$ FAs as a mixture of DHA and EPA. Serum levels of T3, T4, TSH, and the cerebellum of postnatal pups at 16 days of age were evaluated. Compared with the euthyroid pups, serum T4 and T3 levels were significantly lower in the untreated hypothyroid and $\omega-3$ FA-treated hypothyroid pups. Thus, $\omega-3$ FA-supplementation caused no significant change in serum T4 and T3 levels in the hypothyroid d16 pups. Compared with the euthyroid and untreated hypothyroid pups, the percentages of EPA and DHA in total cerebellar FAs rose significantly in the $\omega$-3 FA-treated hypothyroid pups. The weight of the cerebellum decreased significantly in untreated hypothyroid pups compared to euthyroids, which was totally recovered upon $\omega-3$ FA treatment of hypothyroids. The cerebellar weight in untreated hypothyroids was about $16 \%$ lower than euthyroids and $\omega-3$ FA-treated hypothyroids. The percentage of apoptotic cells in the cerebellum was significantly higher in hypothyroid than in euthyroid pups. However, the apoptotic index of the $\omega-3$ FA-treated hypothyroid pups was not significantly different from that of the euthyroids, but was significantly lower than untreated hypothyroid pups. There was a significantly impaired DNA fragmentation and caspase- 3 activation in the developing cerebellum of hypothyroid pups. Upon $\omega-3$ FA treatment the cleaved caspase- 3 levels attenuated significantly compared to untreated hypothyroids, nearly reaching the levels of euthyroids. The levels of pro-apoptotic basal cell lymphoma protein-2 (Bcl-2)-associated X protein (Bax) were significantly higher and Bcl-2 and Bcl-extra large (Bcl-xL) were significantly lower in the cerebellum of hypothyroids than in euthyroids. In the cerebellum of $\omega-3$ FA-treated hypothyroids, there was significantly lower expression of Bax and significantly higher expression of Bcl-2 and Bcl-xL compared to untreated hypothyroids. Finally, w-3 FA-supplementation restored levels of cerebellar phospho (p)-AKT, phospho-extracellular regulated kinase (p-ERK) and phospho-c-Jun N-terminal kinase (p-JNK), all of these molecules being downregulated in hypothyroidism, with no impact on the expression of myelin basic protein, a TH responsive gene. These findings suggest a protective role of $\omega-3$ FAs against cerebellum and brain injury due to fetal hypothyroidism [42].

Another study investigated in adult male rats the effect of hypothyroidism on spatial learning and memory, the underlying mechanisms and the potential therapeutic role of $\omega-3$ supplementation [43]. A subdivision into 3 groups was done starting from 30 male rats: Control, hypothyroid and $\omega-3$ treated. $\omega-3$ FAs supplementation improved memory deficits, increased serum total antioxidant capacity, and also a diminished expression of Cav1.2 protein (the voltage dependent LTCC alpha 1c subunit), together with reduced structural changes, were observed. The data showed that $\omega-3$ FAs could be a useful neuroprotective agent against the cognitive damage that hypothyroidism can induce [43].

TH also have impact on lipid metabolism. For this reason, it has been explored the effect of $\omega-3$ FAs (at dose of $200 \mathrm{mg} / \mathrm{kg}$ of body weight/day for 6 weeks) on lipid metabolism among euthyroid, hyperthyroid or hypothyroid Lewis male rats [44]. Hyperthyroid rats had higher fasting blood 
glucose and plasma postprandial triglycerides levels compared to euthyroid and hypothyroid animals. In contrast, hypothyroid rats had higher levels of total cholesterol, LDL, and HDL cholesterol [44].

A large body of evidence reveals that $\omega-3$ PUFAs have general anti-inflammatory activities and antineoplastic properties. For instance, they act through different mechanisms including alteration of membrane fluidity and cell surface receptor function, modulation of COX activity and increased cellular oxidative stress. The anti-cancer activities exerted by $\omega-3$ PUFAs are also due to their ability to bind the tumor suppressor Peroxisome Proliferator-Activated Receptor gamma (PPAR $\gamma$ ) $[45,46]$.

Ligand activation of PPAR $\gamma$ induces growth inhibition and apoptosis in different thyroid cell lines, including anaplastic thyroid cancer cells [47-49]. Activation of PPAR $\gamma$ could represent a novel treatment option for anaplastic thyroid cancer in order to extend life duration thus warranting a good quality of life $[50,51]$.

\section{Resveratrol}

Resveratrol (3,5,4'-trihydroxy-trans-stilbene) is a stilbenoid polyphenol that can be found in various vegetables and fruit, including peanuts, peanut sprouts and grapes. As it seems to have a significant role as either a chemo-preventive and therapeutic agent to treat different diseases [52,53], resveratrol has recently obtained more attention among health professionals and other nutrition experts.

Resveratrol has antioxidant, anti-inflammatory, and antidiabetic effects, in particular its cardiovascular protective actions are associated with various molecular targets, including apoptosis, inflammation, oxidative stress, angiogenesis, mitochondrial dysfunction, and platelet aggregation [53].

In a rat model of subclinical hypothyroidism $(\mathrm{SCH})$, in which $\mathrm{SCH}$ is caused by hemi-thyroid electrocauterization, the effect and potential mechanism of resveratrol on memory and spatial learning were studied [54]. The treatment with resveratrol $(15 \mathrm{mg} / \mathrm{kg})$ and L-T4 in SCH rats demonstrated an inversion of learning and memory impairment in behavioral test. Resveratrol treatment of $\mathrm{SCH}$ rats caused reduced expression of the hypothalamic thyrotropin releasing hormone (TRH) mRNA and decreased plasma TSH. This could indicate that resveratrol treatment would reverse the hypothalamic-pituitary-thyroid (HPT) axis imbalance in $\mathrm{SCH}$ rats. Furthermore, resveratrol treatment of SCH rats up-regulated the hippocampal levels of syt- 1 and BDNF. In brief, resveratrol treatment improves spatial learning and memory of SHC rats [54].

In another study, by the same team, the possible antidepressant effect of resveratrol was evaluated, after having previously shown that this rat model develops a depression-like behavior [55]. In SCH rats, the over-expression of the hypothalamic TRH mRNA and the high concentration of TSH were decreased to control levels by resveratrol treatment. Compared to SCH rats, resveratrol-treated SCH rats showed a higher preference for sucrose in the sucrose preference test, an increase in breeding frequency and distance in the open field test and a reduced immobility in the forced swimming test. Resveratrol-treated $\mathrm{SCH}$ rats had lower plasma corticosterone levels, adrenal gland weight in relation to bodyweight, and expression of the hypothalamic corticotrophin release hormone $(\mathrm{CRH})$ mRNA. In addition to this, resveratrol, on the one hand, adjusted negatively the relative ratio of phosphorylated- $\beta$-catenin ( $p$ - $\beta$-catenin)/ $\beta$-catenin and expression of GSK3 $\beta$, and on the other, adjusted positively the relative ratio of phosphorylated-GSK3 $\beta$ (p-GSK3 $\beta$ )/GSK3 $\beta$ and protein levels of $p$-GSK3 $\beta$, cyclin D1, and c-myc, in the hippocampus [55]. Altogether, these results indicate that the canonical Wnt pathway was activated in the hippocampus of the untreated model rats and that activation was ameliorated by the resveratrol treatment [36]. The authors concluded that resveratrol exerts anxiolyticand antidepressant-like effect in $\mathrm{SCH}$ rats by downregulating hyperactivity of the HPA axis and regulating both the HPT axis and the Wnt/ $\beta$-catenin pathway [55].

Fluoride is the most abundant anion in groundwater, creating problems in drinking water and causing metabolic, functional, and structural damage in several organ systems, including structural abnormalities of the thyroid follicles. It was shown that resveratrol supplementation in fluoride-exposed animals prevented metabolic toxicity caused by fluoride, and restored the functional status and the 
ultra-structural organization of the thyroid [56]. Hence, this study shows therapeutic efficacy of resveratrol as a natural antioxidant in thyroprotection against toxic insult caused by fluoride [37].

The antiproliferative effect of resveratrol depends on the induction of ERK1/2- and p53-dependent antiproliferation in tumoral cells, binding to a specific receptor on plasma membrane integrin $\alpha \mathrm{v} \beta 3$, and the accumulation of resveratrol-induced nuclear COX-2; in turn, COX-2 combined with ERK1/2, and ultimately with p53, generates a transcriptionally active complex [57]. To date there are conflicting opinions on the preventive and therapeutic abilities of resveratrol. Physiological concentrations of TH (especially T4) interfere with the antiproliferative/anticancer action of resveratrol. This suggests that the in vivo block of the surface receptor for $\mathrm{TH}$ on cancer cells, as well as the reduction of circulating levels of T4 and the substitution of T3 (to maintain a condition of euthyroidism), could be used as strategies to recover or potentiate the clinical effectiveness of resveratrol in tumor treatment $[57,58]$.

Resveratrol has been reported to inhibit sodium/iodide symporter (NIS) gene expression and function in FRTL-5 cells, decreasing cellular iodide uptake after 48-h treatment and this effect was also confirmed in in vivo Sprague-Dawley rats [59].

Recently, resveratrol has been investigated for its antithyroid effects in vitro and in vivo models. Specifically, in FRTL-5 cells resveratrol has been found to reduce the expression of thyroid-specific genes, such as Tg, TPO, TSHR, NKX2-1, Foxe1, and PAX8 while in rats treated with resveratrol $25 \mathrm{mg} / \mathrm{kg}$ body weight intraperitoneally for 60 days a significant increase in thyroid size along with higher serum TSH levels compared with control rats were found [60].

Regarding the role of resveratrol as antineoplastic agent, it has been recently reported that this compound inhibits cell proliferation through STAT3 signaling involvement [61] and reverses retinoic acid resistance of anaplastic thyroid cancer cells [62].

More importantly, resveratrol sensitizes selectively thyroid cancer cells to 131-iodine toxicity, while it exhibited radioprotective effects on normal cells, thus for these beneficial actions, resveratrol might improve the treatment of patients with thyroid cancer during radioiodine therapy [63].

In the thyroid setting, the proliferation of thyroid tumoral cells can be stopped by resveratrol, due to the resveratrol-induced increases the quantity and phosphorylation of p53 [1]. Resveratrol also has an action on iodine trapping, for which it appears to be a promising anti-thyroid drug. Overall, the in vitro and in vivo data indicate that resveratrol may act as a thyroid disruptor and a goitrogen, which should be taken into account for potential therapeutic use of resveratrol or as a supplement.

\section{Selenium}

The chemical non-metal element selenium is an essential micronutrient necessary for cellular function. Selenium exerts its nutritional functions in the form of the amino acid selenoCysteine (SeCys) inserted into a group of proteins known as selenoproteins, some of which are the antioxidant enzymes, glutathione peroxidase (GSH-Px) and thioredoxin reductase, and the three deiodinases of thyroid hormones [64]. The major sources of selenium intake are meat and meat products (31\%), fish and shellfish $(20 \%)$, pasta and rice $(12 \%)$, and bread and breakfast cereals $(11 \%)$, while the largest selenium concentrations (1 mg/kg) are found in Brazil nuts and offal [64].

One study investigated the improving effects of selenium on cerebrum and cerebellum impairments caused by the MMI-induced hypothyroidism in suckling rats [65]. Pregnant rats were randomized into 4 groups to receive control diet, MMI alone, MMI plus selenium, or selenium alone. Treatments were given from the 14th day of pregnancy until day 14 after delivery. Following the treatment with MMI, a reduction in plasma levels of FT3 and FT4, protein, DNA and RNA contents in cerebrum and cerebellum was observed, in comparison to controls. These parameters improved after cotreatment with selenium. Furthermore, antioxidant enzyme activities (SOD, CAT, GSH-Px) decreased significantly in the group treated with MMI, while malonaldialdehyde (MDA) levels in cerebrum and cerebellum raised. Co-administration of selenium restored these parameters to near normal values. The authors concluded that selenium improved the cerebral and cerebellar damages induced by MMI in suckling 
rats, and because of such neuroprotection selenium could be used as a dietary supplement against brain impairments [65].

Laureano-Melo and colleagues [66] evaluated potential behavioral alterations in offspring of female rats supplemented with sodium selenite during pregnancy and lactation. Selenium supplementation raised T3 and T4 serum levels, decreased tryptophan hydroxylase 2 expression and cholinesterase activity, and increased tyrosine hydroxylase expression in the hippocampus. In childhood, the selenium-supplemented offspring had a decrease in anxiety-like behavior; in adulthood, the locomotor activity and rearing episodes increased in selenium-treated pups. These findings demonstrated that maternal supplementation by sodium selenite induced psychobiological alterations during childhood and adulthood, probably caused by neurochemical changes generated by $\mathrm{TH}$ during the critical period of the central nervous system ontogeny [66].

One study evaluated the effect of selenium on CD4(+)CD25(+)Foxp3(+) regulatory T cells (Treg) by using an iodine-induced AIT model [67]. This study aimed to explain clinical observations concerning decreased serum levels of thyroid autoantibodies in patients with autoimmune thyroiditis (AIT). NOD.H-2(h4) mice received $0.005 \%$ sodium iodine (NaI) water for 8 weeks, and AIT was induced. The group of selenium-treated mice were fed $0.3 \mathrm{mg} / \mathrm{L}$ sodium selenite in drinking water. AIT mice showed fewer Treg cells and lower Foxp3 mRNA expression in splenocytes compared to controls $(P<0.01)$. However, both Treg cells and Foxp3 mRNA expression increased after the treatment with selenium, in comparison to untreated AIT mice $(P<0.05)$. Moreover, selenium-treated AIT mice had lower serum $\mathrm{Tg}$ antibody $(\mathrm{TgAb})$ titers and reduced lymphocytic infiltration in the thyroid than untreated AIT mice. These findings suggested that selenium supplementation, through the up-regulation of the Foxp3 mRNA expression, can restore normal levels of CD4(+)CD25(+) T cells in mice with AIT [67].

In the thyroid oncology setting, data are available for human cell lines of thyroid malignancy ARO (anaplastic), NPA (BRAF positive papillary), WRO (BRAF negative papillary), and FRO (follicular) cells treated with 150 microM seleno-l-methionine (SM) were assessed for viability at 24,48 , and $72 \mathrm{~h}$. Seleno-methionine treatment was found to inhibit thyroid cancer cell proliferation through the overexpression of GADD (growth arrest and DNA damage inducible) family genes and cell cycle arrest in $\mathrm{S}$ and $\mathrm{G} 2 / \mathrm{M}$ phases [68].

Although these data are intriguing, the available evidence on the relationship between selenium and thyroid cancer is yet inconclusive [69].

\section{Vitamins}

\subsection{Vitamin A}

Vitamin A deficiency (VAD) and iodine deficiency (ID) are major global public health problems, affecting more than $30 \%$ of the population worldwide. VAD can adversely affect thyroid metabolism [70]. A study investigated the effect of concurrent vitamin A and ID on the thyroid-pituitary axis in rats [70]. Weaning rats received for 30 days a diet deficient in vitamin $A$ (VAD group), iodine (ID group), vitamin $\mathrm{A}$ and iodine (VAD+ID group), or sufficient in both vitamin A and iodine (control). Serum retinol levels were $\sim 35 \%$ lower in the VAD and VAD+ID groups $(P<0.001)$, in comparison to controls and ID groups. No significant differences in TSH, TSH-beta mRNA, thyroid weight, or TH levels, were observed in the VAD and control groups, while they were higher in the VAD+ID and ID groups, and FT4 and TT4 were lower compared to controls. The authors concluded that moderate VAD alone has no measurable effect on the pituitary-thyroid axis, and that concurrent ID and VAD produce more severe primary hypothyroidism than ID alone [70]. Repletion studies in VAD and ID animals suggested: a) In animals with concurrent moderate VAD and ID, primary hypothyroidism does not reduce the effectiveness of high doses of oral Vitamin A; b) VAD does not lower the effectiveness of dietary iodine to correct pituitary-thyroid axis dysfunction due to ID; c) without iodine repletion, high-dose Vitamin A alone in combined VAD and ID could decrease both thyroid hyperstimulation and the risk for goiter [71]. 
One Chinese study [72] moved from the fact that the interconnections among neural tube defects (NTDs) and TH or vitamin A have been investigated previously but the interaction between the TH and vitamin A pathways were not elucidated. The authors measured the expression levels of TH signaling genes in human fetuses with spinal NTDs associated with maternal hyperthyroidism, and the levels of retinoic acid (RA) signaling genes in mouse fetuses exposed to an overdose of RA on spinal cord tissues [72]. The promoters of cellular retinoic acid-binding protein 1 (CRABP1) and retinoic acid receptor beta (RARB) (both being RA signaling genes) were ectopically occupied by elevated retinoid $X$ receptor gamma ( $R X R G$ ) and retinoid $X$ receptor beta (RXRB), but had lowered levels of inhibitory histone modifications, indicating that elevated TH signaling improperly induces RA signaling genes. On the contrary, the observed decrease in deiodinase type 3 (Dio3) expression in the mouse model could be explained by raised levels of inhibitory histone modifications in the Dio3 promoter region, indicating that overactive RA signaling could ectopically derepress TH signaling. These data led to hypothesize a potential improper cross-promotion in vivo between two different hormonal signals through their common RXRs, and then histone modifications recruitment [72].

In FRTL-5 cells, all-trans retinoic acid (ATRA) exerts protective role attenuating endoplasmic reticulum (ER) stress-induced alteration of NIS by modulating the phosphorylation of p38 MAPK [73].

ATRA has been also known to induce in vitro radioiodine uptake and to inhibit cell proliferation and invasion of human thyroid carcinoma cells [74,75], thus making this molecule a promising drug able to improve the isotope sensitivity of the most aggressive thyroid carcinoma.

\subsection{Vitamin D}

Cholecalciferol (or vitamin D3) is synthetized in the skin upon the exposure to ultraviolet B radiation, and it is also introduced from few dietary sources (such as fatty fish). Ergocalciferol (vitamin D2) is synthesized by plants and fungi. Both forms are hydroxylated to 25 -hydroxyvitamin $\mathrm{D}$ in the liver [76].

Mice, previously sensitized with porcine $\mathrm{Tg}$, and injected intraperitoneally with/without calcitriol $(0.1-0.2 \mu \mathrm{g} / \mathrm{kg}$ body weight/die), showed a minor severity of thyroid inflammation vs mice treated with placebo [77]. This effect was even higher in the case of injection with calcitriol and cyclosporine [78].

In another study, mice were pre-treated with intra-peritoneal injection of calcitriol $(5 \mu \mathrm{g} / \mathrm{kg}$ every $48 \mathrm{~h}$ ) before sensitization with porcine Tg. The thyroid did not show the standard inflammation signs compared to controls, indicating a protective role of vitamin D in preventing thyroiditis [79].

The effect of vitamin D was also investigated in animal models of Graves' disease (GD) [80]. By immunization with adenovirus encoding the A-subunit of thyrotropin receptor, BALB/c mice became model of GD. Hyperthyroid BALB/mice fed with a vitamin D deficient diet showed fewer splenic B cells, decreased interferon-gamma responses to mitogen and lack of memory T-cell responses to A-subunit protein, with respect to mice fed with a regular diet. No differences in TSHR antibody levels were observed. Furthermore, vitamin D deficient BALB/c mice had lower pre-immunization T4 levels and developed persistent hyperthyroidism, indicating that vitamin D is able to modulate thyroid function in this animal model [80].

A study investigated the potential pathophysiological mechanisms for hypocalcaemia in hyperthyroid cats [81]. Hyperthyroid cats had lower ionized calcium levels than healthy geriatric cats, and ionized calcium concentrations were higher in hyperthyroid cats with concomitant or masked chronic kidney disease than non-uremic hyperthyroid cats. Moreover, hyperthyroid cats had higher plasma calcitriol concentrations than control cats. In hyperthyroid cats, hypocalcaemia was not associated with concomitant or masked chronic kidney disease or reduced plasma calcitriol levels. Elevated TH concentrations might influence ionized calcium levels independently from the control by parathyroid hormone and calcitriol [81].

Evidence suggests that vitamin D can negatively regulate the entire process of tumorigenesis, from initiation to metastasis by multiple mechanisms including the regulation of growth factors, cell cycle and signaling pathways [82]. Indeed, it has been largely reported the antineoplastic activities 
of vitamin D alone and/or in combination with other agents on thyroid cancer cells [83-85]. These findings suggest that the activation of vitamin D signaling could be a promising strategy for prevention, as well as treatment of thyroid cancer.

\subsection{Vitamin $E$}

Due to its ability to scavenge free radicals, vitamin $\mathrm{E}$ is considered an antioxidant. Vitamin $\mathrm{E}$ is also very active in the antioxidative protection of thyroid cells membranes, and it is concentrated in the thyroid in control rats, and increased two fold in goiters. Acute and excessive iodine supplementation can cause iodine-induced thyroid cyto-toxicity, that is probably due to an excessive oxidative stress. A study aimed to investigate whether vitamin E could improve iodine-induced thyroid cytotoxicity [86]. Rats received a low-iodine (LI) diet for 12 weeks and developed goiter. A 50-fold vitamin E dose could attenuate two fold iodine-induced thyroid cytotoxicity, even if weight or relative weight of the iodine-induced involuting gland was not diminished by its supplementation, showing that excess iodine can cause thyroid damage and vitamin E can improve in part the iodine-induced thyroid cytotoxicity [86].

In Sprague-Dawley rats, the oxidative stress status of the serum and hippocampus in hypothyroidism, and the effect on cognitive deficit, of L-T4 replacement therapy with vitamin $\mathrm{E}$ supplementation, were evaluated. It was shown that L-T4 replacement therapy with vitamin E can improve cognitive deficit in propylthiouracil (PTU)-induced hypothyroidism by decreasing the oxidative stress status [87]. Another study confirmed that L-T4 replacement therapy in combination with vitamin E reduces hippocampus cellular apoptosis index by ameliorating oxidative stress, suggesting that in a hypothyroid rat model the mechanisms of hippocampus tissue damage are associated with hippocampus apoptosis caused by a marked oxidative stress [88].

The role of vitamin $\mathrm{E}$ and curcumin has been investigated on hyperthyroidism-induced mitochondrial oxygen consumption and oxidative damage to lipids and proteins of rat liver [89]. Adult male rats received $0.0012 \% \mathrm{~L}-\mathrm{T} 4$ in their drinking water and became hyperthyroid, and vitamin $\mathrm{E}$ ( $200 \mathrm{mg} / \mathrm{kg}$ body weight) and curcumin ( $30 \mathrm{mg} / \mathrm{kg}$ body weight) for 30 days. Both vitamin $\mathrm{E}$ and curcumin have differential regulation on complexes I and II mediated-mitochondrial respiration and were protective against hepatic dysfunction and oxidative stress induced by L-T4 [89].

Another study, conducted in Labeo rohita juveniles fed normal or increased levels of vitamin E and tryptophan for 60 days and then exposed to sub-lethal nitrite for another 45 days without changing their diet, reported that the negative impact on steroidogenesis exercised by environmental nitrites could be bypassed by supplementation of high levels of vitamin $\mathrm{E}$ and to a lesser extent of tryptophan [90].

Recently, vitamin $\mathrm{E}$ has been found in combination with curcumine and piperine to exert inhibitory effect on cell proliferation through influencing cell cycle regulators such as $\beta$-catenin, cyclin D1 and p53 in human thyroid papillary carcinoma cells; however, further studies are necessary to candidate vitamin $\mathrm{D}$ as alternative cancer therapy [91].

\section{Zinc}

The negative effect of zinc deficiency and positive effect of zinc supplementation on thyroid function of adult male rats (as measured by serum FT3 and FT4 levels) have been mentioned above [36,37]. In these rats, circulating zinc levels are increased in hyperthyroidism and decreased in hypothyroidism [38].

In adult male rats, thyroid function has been slightly damaged by the oral administration of $3 \mathrm{~mL}$ $30 \%$ ethanol [92]. The moderate decrease in serum T3 and T4 and increase in serum TSH was reversed by the 8 -week administration of zinc (Zinc sulfate, $227 \mathrm{~mL}$ in the drinking water). Of note, serum $\mathrm{Zn}$ levels were low upon ethanol feeding, but they were restored to normal levels after $\mathrm{Zn}$ supplementation. 
In contrast with the above data on adult male rats [36,37], there are findings from obese mice [93] and from small ruminants [94]. Obese mice and lean controls received a basal diet or a zinc-supplemented diet $(200 \mathrm{mg} / \mathrm{kg}$ diet) for 8 weeks. After the basal diet, obese mice had lower serum and hepatic T4 and T3 levels than lean mice $(P<0.05)$. Zinc supplementation diminished significantly circulating T4 levels in both groups [93]. A total of 24 healthy male ruminants (12 lambs and 12 goats) were subdivided in 2 groups: Control or Zn group [94]. Control lambs and goats received basal rations alone ( $40 \mathrm{mg} / \mathrm{kg}$ and $35 \mathrm{mg} / \mathrm{kg}$ in dry matter, respectively). Both species of animals in the Zn group received a basal ration added with zinc sulphate up to a dose of $250 \mathrm{mg} \mathrm{Zn/kg}$. The treatment lasted for 12 weeks in lambs and 8 weeks in goats. Animals receiving Zn showed more elevated plasma $\mathrm{Zn}$ levels than controls during all the experimental period, excluding the 4 th week in goats. Compared to controls, the levels of serum total T4 and total T3 were lower in lambs and goats receiving Zn, except in the 4th week. Furthermore, circulating total TH levels of the goats were higher at the 4th week than at the 8th week. Even if a decrease (vs. controls) in the levels of free T4 and free T3 of both small ruminant species in the Zn groups was present, it was not statistically significant [94].

In another study, adult male rats were supplemented for 45 days with either zinc $(227 \mathrm{mg} / \mathrm{L})$ or magnesium (100 mg/Kg body weight) and then treated with daily intraperitoneal injection of $100 \mathrm{mg} / \mathrm{kg}$ body weight of alloxan for 15 days (days 46 to 60 ) to induce diabetes mellitus. Circulating total cholesterol, triglyceride, and glucose levels were higher while serum T3 and T4 were lower in diabetic rats than controls. Zinc supplementation did not change any parameter in diabetic rats, whereas magnesium decreased the elevated total cholesterol and triglyceride levels of the diabetic rats to the control level [95].

FRTL-5 cell model, derived from a Fischer rat thyroid and displaying follicular cell phenotype, was used to study the effect of zinc depletion, upon the zinc-specific chelator N,N,N0,N0-tetrakis (2-pyridylmethyl) ethylene-diamine, on thyroid function. In this experimental setting which would mimic the in vivo condition, Tg secretion was decreased. Proteomic analyses performed comparing data from zinc depleted/repleted thyroid cells have identified 108 proteins modulated by intracellular zinc status with important physiopathological implications for this endocrine tissue [96].

\section{Inositol}

Inositol is a water-soluble compound strictly related to the vitamin B group (also called vitamin B8). Its most abundant form is myo-inositol [97].

That myo-inositol plays an important role in the thyroid gland can be inferred by the evidence, in male rats, that radioactive myo-inositol is accumulated rapidly (within $1 \mathrm{~h}$ ) by the thyroid [98]. A previous study in primary cultures of sheep and human thyrocytes demonstrated the TSH regulates myo-inositol transport through an increased phospholipase A2-mediated turnover of phosphatidylinositol and a simultaneous increase in arachidonic acid turnover [99]. Biosynthesis of myo-inositol has been investigated in hypophysectomized and thyroidectomized male rats [100]. It was shown that inositol-1-phosphate synthase is controlled by the pituitary in the reproductive organs and by the thyroid in the liver [100].

Myo-inositol is the precursor for the synthesis of phosphoinositides, implicated in the phosphatidylinositol (PtdIns) signal transduction pathway, and it is involved in different cellular processes. In the thyroid cells, PtdIns takes part in the intracellular TSH signaling, via Phosphatidylinositol $(3,4,5)$-trisphosphate (PtdIns(3,4,5)P3) (PIP-3) [101].

In a recent systematic review on metabolite profile alterations of thyroid cells myo-inositol has been suggested as a thyroid cancer oncometabolite [13].

The effects of inositol supplementation on serum levels of thyroid hormones were evaluated in dairy cows [102]. The supplementation decreased circulating T3 and FT3 concentrations, but not T4 and FT4 concentrations [102].

In humans, it has been shown that the increased levels of TSH declined in patients with AIT and subclinical hypothyroidism, treated with myo-inositol and seleno-methionine. The concentration of 
both TPOAb and $\operatorname{Tg} \mathrm{Ab}$ decreased in both groups. The supplementation with seleno-methionine alone was not able to promote the same reduction [103].

Another paper first showed an immune-modulatory effect of myo-inositol in association with seleno-methionine in patients with euthyroid AIT [104].

A paper reported the beneficial effects of myo-inositol, seleno-methionine or their combination on peripheral blood mononuclear cells (PBMC) exposed in vitro to hydrogen peroxide ( $\mathrm{H} 2 \mathrm{O} 2)$-induced oxidative stress in both control and women with Hashimoto's thyroiditis (HT) [105]. PBMC, from 8 HT women and 3 controls, were cultured in the presence of $\mathrm{H} 2 \mathrm{O} 2$ alone, or with subsequent addition of myo-inositol, seleno-methionine, or their combination. $\mathrm{H} 2 \mathrm{O} 2$ alone decreased PBMC proliferation, and it decreased furtherly and dose-dependently in either group. Moreover, $\mathrm{H} 2 \mathrm{O} 2$ alone reduced vitality both in controls and HT women, but vitality was rescued by the three additions, contrasting also genotoxicity. Chemokines levels were increased by $\mathrm{H} 2 \mathrm{O} 2$ alone (more in $\mathrm{HT}$ women than in controls), and each addition dose-dependently decreased these concentrations in either group, particularly with Myo+SelMet [105].

Another study investigated whether myo-inositol alone, or its combination with seleno-methionine, is effective in protecting thyrocytes from the effects given by cytokines, or $\mathrm{H} 2 \mathrm{O} 2$ [106]. $\mathrm{H} 2 \mathrm{O} 2$ had a toxic effect in primary thyrocytes increasing the apoptosis, and decreasing the proliferation, slightly reducing cytokines-induced CXCL10 secretion. The interferon(IFN)- $\gamma+$ tumor necrosis factor alpha(TNF)- $\alpha$ induced secretion of CXCL10 was reduced by myo-inositol+seleno-methionine, in both the presence or absence of $\mathrm{H} 2 \mathrm{O} 2$. Seleno-methionine alone had no effect. These findings suggested a protective effect of myo-inositol on thyroid cells [106].

Finally, the beneficial effects of myo-inositol, either alone $(2.5 \mathrm{~g} / \mathrm{kg} /$ day in the drinking water) or administered in association with T3 (30 micrograms.kg-1.day-1 s.c.), were investigated on the cardiac lipid content and function of streptozocin-induced diabetic (STZ-D) rats [107]. The elevations in both plasma and myocardial lipids associated with diabetes were prevented by myo-inositol treatment. Moreover, a partial improvement in cardiac performance of STZ-D rats was observed in the group treated with myo-inositol alone and the group treated with myo-inositol plus T3 [107].

\section{Conclusions}

Nutraceuticals have a place in complementary medicines, defined as a "food, or parts of a food, that provide medical or health benefits, including the prevention and treatment of disease" [2], for the prevention of different pathological conditions, including thyroid diseases. Thyroid supplements have gained lots of attention in the last years. Iodine is the major nutrient for thyroid function, but also other dietary components can have a key role in clinical thyroidology. In this review, we have summarized the cell cultures and animal studies present in literature, focusing on the commonest nutraceuticals generally encountered in the clinical practice (such as carnitine, flavonoids, melatonin, omega-3, resveratrol, selenium, vitamins, zinc, inositol), highlighting conflicting results (Table 3 and Figure 1). These experimental studies are expected to improve the clinicians' knowledge about the main supplements being used, in order to clarify the potential risks or side effects and support patients in their use. 
Table 3. Summary of the main findings.

\begin{tabular}{|c|c|c|}
\hline Compounds & Main Findings & References \\
\hline carnitine & $\begin{array}{l}\text { antagonism of thyroid hormone action, } \\
\text { thyroid diagnostic oncometabolite }\end{array}$ & $\begin{array}{c}{[9]} \\
{[13]}\end{array}$ \\
\hline $\begin{array}{l}\text { flavonoids, } \\
\text { isoflavonoids, soy }\end{array}$ & $\begin{array}{c}\text { inhibition of deiodinase or displacing T4 from } \\
\text { transthyretin, decreased activity of thyroid peroxidase } \\
\text { anti-thyroid effects } \\
\text { goitrogenic effect } \\
\text { antineoplastic effects }\end{array}$ & $\begin{array}{c}{[16,33]} \\
{[20,29-31]} \\
{[22]} \\
{[24,34]}\end{array}$ \\
\hline melatonin & $\begin{array}{l}\text { regulation of thyroid activity } \\
\text { antineoplastic effects }\end{array}$ & $\begin{array}{c}{[37-39]} \\
{[40]}\end{array}$ \\
\hline $\begin{array}{l}\text { omega-3 } \\
\text { poly-unsaturated } \\
\text { fatty acids }\end{array}$ & $\begin{array}{l}\text { neuroprotection against fetal hypothyroidism } \\
\text { antineoplastic effects }\end{array}$ & $\begin{array}{c}{[42,43]} \\
{[45]}\end{array}$ \\
\hline resveratrol & $\begin{array}{c}\text { improvement of spatial learning and memory } \\
\text { antidepressant effect } \\
\text { inhibition of sodium/iodide symporter expression and } \\
\text { function } \\
\text { antineoplastic effects }\end{array}$ & $\begin{array}{c}{[54]} \\
{[55]} \\
{[59]} \\
{[57,58,61-63]}\end{array}$ \\
\hline selenium & $\begin{array}{c}\text { neuroprotection against fetal hypothyroidism } \\
\text { immunoregulation } \\
\text { antineoplastic effects }\end{array}$ & $\begin{array}{c}{[65,66]} \\
{[67]} \\
{[68]}\end{array}$ \\
\hline vitamin A & $\begin{array}{l}\text { antigoitrogenic effect } \\
\text { regulation thyroid hormone signaling } \\
\text { antineoplastic effects }\end{array}$ & $\begin{array}{c}{[71]} \\
{[72]} \\
{[73-75]}\end{array}$ \\
\hline vitamin D & $\begin{array}{l}\text { immunoregulation } \\
\text { antineoplastic effects }\end{array}$ & $\begin{array}{c}{[77-80]} \\
{[82]}\end{array}$ \\
\hline vitamin $\mathrm{E}$ & $\begin{array}{l}\text { antioxidative protection } \\
\text { antineoplastic effects }\end{array}$ & $\begin{array}{c}{[86-89]} \\
{[91]}\end{array}$ \\
\hline
\end{tabular}

involvement in the intracellular TSH signaling, via PIP-3

inositol supplementation decreased circulating T3 and FT3

concentrations

thyroid diagnostic oncometabolite

the treatment, in combination with seleno-methionine,

declined the elevated levels of TSH in patients with AIT

and subclinical hypothyroidism
immune-modulatory effect of myo-inositol in association

with seleno-methionine in patients with euthyroid AIT

inositol

beneficial effects of myo-inositol, seleno-methionine or

protective effect of myo-inositol on thyroid cells

myo-inositol, either alone or in association with T3

improved cardiac lipid content and function of streptozocin-induced diabetic rats

\footnotetext{
AIT, autoimmune thyroiditis; H2O2, hydrogen peroxide; HT, Hashimoto's thyroiditis; PIP-3, Phosphatidylinositol

(3,4,5)-trisphosphate (PtdIns(3,4,5)P3); PBMC, peripheral blood mononuclear cells.
} 


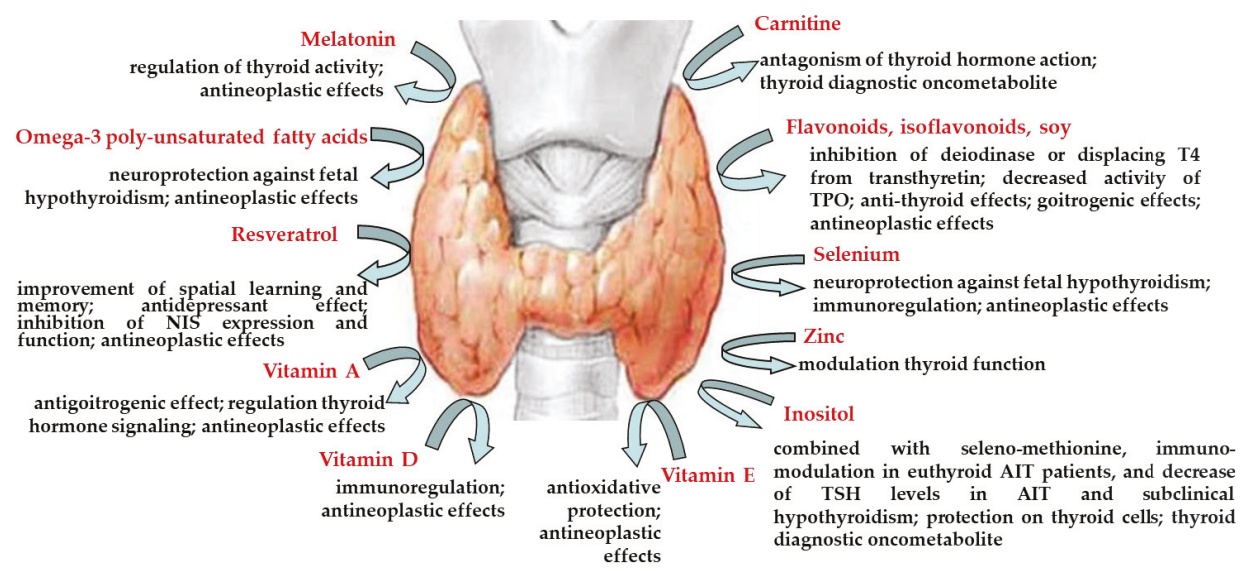

Figure 1. Summary of the main findings. NIS, sodium/iodide symporter; TPO, thyroid peroxidase; AIT, autoimmune thyroiditis.

Author Contributions: Conceptualization, S.B. and A.A.; methodology, G.E., F.R., A.P., S.R.P., S.C.; writingoriginal draft preparation, S.B., A.A., D.B. and S.M.F.; writing-review and editing, S.B., A.A., D.B., and P.F.; supervision, S.B., A.A., D.B. All authors have read and agreed to the published version of the manuscript.

Funding: This research received no external funding.

Acknowledgments: Nothing to declare.

Conflicts of Interest: The authors declare no conflict of interest.

\section{References}

1. Benvenga, S.; Feldt-Rasmussen, U.; Bonofiglio, D.; Asamoah, E. Nutraceutical Supplements in the Thyroid Setting: Health Benefits beyond Basic Nutrition. Nutrients 2019, 11, 2214. [CrossRef] [PubMed]

2. Lockwood, G.B. The quality of commercially available nutraceutical supplements and food sources. J. Pharm. Pharmacol. 2011, 63, 3-10. [CrossRef] [PubMed]

3. European Parliament. Regulation EU 2015/2283 of the European Parliament and of the Council of 25 November 2015 on Novel Foods, Amending Regulation (EU) No 1169/2011 of the European Parliament and of the Council and Repealing Regulation (EC) No 258/97 of the European Parliament and of the Council and Commission Regulation (EC) No 1852/2001. Available online: https://eur-lex.europa.eu/legal-content/en/ TXT/?uri=CELEX\%3A32015R2283 (accessed on 13 March 2020).

4. Galetta, F.; Franzoni, F.; Bernini, G.; Poupak, F.; Carpi, A.; Cini, G.; Tocchini, L.; Antonelli, A.; Santoro, G. Cardiovascular complications in patients with pheochromocytoma: A mini-review. Biomed. Pharmacother. 2010, 64, 505-509. [CrossRef] [PubMed]

5. Galetta, F.; Franzoni, F.; Fallahi, P.; Tocchini, L.; Braccini, L.; Santoro, G.; Antonelli, A. Changes in heart rate variability and QT dispersion in patients with overt hypothyroidism. Eur. J. Endocrinol. 2008, 158, 85-90. [CrossRef]

6. Antonelli, A.; Ferrari, S.M.; Frascerra, S.; Di Domenicantonio, A.; Nicolini, A.; Ferrari, P.; Ferrannini, E.; Fallahi, P. Increase of circulating CXCL9 and CXCL11 associated with euthyroid or subclinically hypothyroid autoimmune thyroiditis. J. Clin. Endocrinol. Metab. 2011, 96, 1859-1863. [CrossRef]

7. Benvenga, S.; Lakshmanan, M.; Trimarchi, F. Carnitine is a naturally occurring inhibitor of thyroid hormone nuclear uptake. Thyroid 2000, 12, 1043-1050. [CrossRef]

8. Rotzsch, W.; Strack, E. Umstaz Und Wirkung des Carnitins im Tierkorper. Int. Abstr. Biol. Sci. 1958, 11, 80.

9. Hellthaler, G.; Wenzel, K.W.; Rotzsch, W. Aminotransferasen unter thyroxin und Karnitin. Acta Biol. German $1967,19,641-652$. 
10. Yildirim, S.; Yildirim, A.; Dane, S.; Aliyev, E.; Yigitoglu, R. Dose-dependent protective effect of L-carnitine on oxidative stress in the livers of hyperthyroid rats. Eurasian J. Med. 2013, 45, 1-6. [CrossRef]

11. Huang, H.; Liu, N.; Guo, H.; Liao, S.; Li, X.; Yang, C.; Liu, S.; Song, W.; Liu, C.; Guan, L.; et al. L-Carnitine Is an Endogenous HDAC Inhibitor Selectively Inhibiting Cancer Cell Growth In Vivo and In Vitro. PLoS ONE 2012, 7, e49062. [CrossRef]

12. Wang, R.; Cheng, Y.; Su, D.; Gong, B.; He, X.; Zhou, X.; Pang, Z.; Cheng, L.; Chen, Y.; Yao, Z. Cpt1c regulated by AMPK promotes papillary thyroid carcinomas cells survival under metabolic stress conditions. J. Cancer 2017, 8, 3675-3681. [CrossRef] [PubMed]

13. Khatami, F.; Payab, M.; Sarvari, M.; Gilany, K.; Larijani, B.; Arjmand, B.; Tavangar, S.M. Oncometabolites as biomarkers in thyroid cancer: A systematic review. Cancer Manag. Res. 2019, 11, 1829-1841. [CrossRef] [PubMed]

14. Torun, N.; Muratli, A.; Serim, B.D.; Ergulen, A.; Altun, G.D. Radioprotective Effects of Amifostine, L-Carnitine and Vitamin E in Preventing Early Salivary Gland Injury due to Radioactive Iodine Treatment. Curr. Med. Imag. Rev. 2019, 15, 395-404. [CrossRef]

15. Spencer, J.P. Flavonoids: Modulators of brain function? Br. J. Nutr. 2008, 99, ES60-ES77. [CrossRef]

16. de Souza Dos Santos, M.C.; Gonçalves, C.F.; Vaisman, M.; Ferreira, A.C.; de Carvalho, D.P. Impact of flavonoids on thyroid function. Food Chem. Toxicol. 2011, 49, 2495-2502. [CrossRef]

17. Lehmann, L.; Soukup, S.T.; Gerhäuser, C.; Vollmer, G.; Kulling, S.E. [Isoflavone-containing dietary supplements]. Bundesgesundheitsblatt Gesundheitsforschung Gesundheitsschutz 2017, 60, 305-313. [CrossRef]

18. D'Adamo, C.R.; Sahin, A. Soy foods and supplementation: A review of commonly perceived health benefits and risks. Altern. Ther. Health Med. 2014, 20, 39-51.

19. Silverstein, M.G.; Kaplan, J.R.; Appt, S.E.; Register, T.C.; Shively, C.A. Effect of soy isoflavones on thyroid hormones in intact and ovariectomized cynomolgus monkeys (Macaca fascicularis). Menopause 2014, 21, 1136-1142. [CrossRef]

20. Doerge, D.R.; Chang, H.C. Inactivation of thyroid peroxidase by soy isoflavones, in vitro and in vivo. J. Chromatogr. B 2002, 777, 269-279. [CrossRef]

21. Ikeda, T.; Nishikawa, A.; Imazawa, T.; Kimura, S.; Hirose, M. Dramatic synergism between excess soybean intake and iodine deficiency on the development of rat thyroid hyperplasia. Carcinogenesis 2000, 21, 707-713. [CrossRef]

22. Son, H.Y.; Nishikawa, A.; Ikeda, T.; Imazawa, T.; Kimura, S.; Hirose, M. Lack of effect of soy isoflavone on thyroid hyperplasia in rats receiving an iodine-deficient diet. Jpn. J. Cancer Res. 2001, 92, 103-108. [CrossRef] [PubMed]

23. Marini, H.; Polito, F.; Adamo, E.B.; Bitto, A.; Squadrito, F.; Benvenga, S. Update on genistein and thyroid: An overall message of safety. Front. Endocrinol. 2012, 3, 94. [CrossRef] [PubMed]

24. Ferrari, S.M.; Antonelli, A.; Guidi, P.; Bernardeschi, M.; Scarcelli, V.; Fallahi, P.; Frenzilli, G. Genotoxicity Evaluation of the Soybean Isoflavone Genistein in Human Papillary Thyroid Cancer Cells. Study of Its Potential Use in Thyroid Cancer Therapy. Nutr. Cancer 2019, 71, 1335-1344. [CrossRef] [PubMed]

25. Chang, H.C.; Doerge, D.R. Dietary genistein inactivates rat thyroid peroxidase in vivo without an apparent hypothyroid effect. Toxicol. Appl. Pharmacol. 2000, 168, 244-252. [CrossRef] [PubMed]

26. Russo, M.; Spagnuolo, C.; Tedesco, I.; Bilotto, S.; Russo, G.L. The flavonoid quercetin in disease prevention and therapy: Facts and fancies. Biochem. Pharmacol. 2012, 83, 6-15. [CrossRef]

27. Prince, P.S.; Sathya, B. Pretreatment with quercetin ameliorates lipids, lipoproteins and marker enzymes of lipid metabolism in isoproterenol treated cardiotoxic male Wistar rats. Eur. J. Pharmacol. 2010, 635, 142-148. [CrossRef]

28. Kleemann, R.; Verschuren, L.; Morrison, M.; Zadelaar, S.; van Erk, M.J.; Wielinga, P.Y.; Kooistra, T. Antiinflammatory, anti-proliferative and anti-atherosclerotic effects of quercetin in human in vitro and in vivo models. Atherosclerosis 2011, 218, 44-52. [CrossRef]

29. Giuliani, C.; Noguchi, Y.; Harii, N.; Napolitano, G.; Tatone, D.; Bucci, I.; Piantelli, M.; Monaco, F.; Kohn, L.D. The flavonoid quercetin regulates growth and gene expression in rat FRTL-5 thyroid cells. Endocrinology 2008, 149, 84-92. [CrossRef]

30. Giuliani, C.; Bucci, I.; Di Santo, S.; Rossi, C.; Grassadonia, A.; Piantelli, M.; Monaco, F.; Napolitano, G. The flavonoid quercetin inhibits thyroid-restricted genes expression and thyroid function. Food Chem. Toxicol. 2014, 66, 23-29. [CrossRef] 
31. Lakshmanan, A.; Doseff, A.I.; Ringel, M.D.; Saji, M.; Rousset, B.; Zhang, X.; Jhiang, S.M. Apigenin in combination with Akt inhibition significantly enhances thyrotropin-stimulated radioiodide accumulation in thyroid cells. Thyroid 2014, 24, 878-887. [CrossRef]

32. Tran, L.; Hammuda, M.; Wood, C.; Xiao, C.W. Soy extracts suppressed iodine uptake and stimulated the production of autoimmunogen in rat thyrocytes. Exp. Biol. Med. 2013, 238, 623-630. [CrossRef] [PubMed]

33. Chandra, A.K.; De, N. Goitrogenic/antithyroidal potential of green tea extract in relation to catechin in rats. Food Chem. Toxicol. 2010, 48, 2304-2311. [CrossRef] [PubMed]

34. De Amicis, F.; Perri, A.; Vizza, D.; Russo, A.; Panno, M.L.; Bonofiglio, D.; Giordano, C.; Mauro, L.; Aquila, S.; Tramontano, D.; et al. Epigallocatechin gallate inhibits growth and epithelial-to-mesenchymal transition in human thyroid carcinoma cell lines. J. Cell Physiol. 2013, 228, 2054-2062. [CrossRef]

35. Garcia-Marin, R.; Fernandez-Santos, J.M.; Morillo-Bernal, J.; Gordillo-Martinez, F.; Vazquez-Roman, V.; Utrilla, J.C.; Carrillo-Vico, A.; Guerrero, J.M.; Martin-Lacave, I. Melatonin in the thyroid gland: Regulation by thyroid-stimulating hormone and role in thyroglobulin gene expression. J. Physiol. Pharmacol. 2015, 66, 643-652. [PubMed]

36. Pierpaoli, G.; Dall'Ara, A.; Pedrinis, E.; Regelson, W. The pineal control of aging: The effects of melatonin and pineal grafting on the survival of older mice. Ann. N. Y. Acad. Sci. 1991, 621, 291-313. [CrossRef]

37. Baltaci, A.K.; Mogulkoc, R.; Bediz, C.S.; Kul, A.; Ugur, A. Pinealectomy and zinc deficiency have opposite effects on thyroid hormones in rats. Endocr. Res. 2003, 29, 473-481. [CrossRef]

38. Baltaci, A.K.; Mogulkoc, R.; Kul, A.; Bediz, C.S.; Ugur, A. Opposite effects of zinc and melatonin on thyroid hormones in rats. Toxicology 2004, 195, 65-75. [CrossRef]

39. Baltaci, A.K.; Mogulkoc, R.; Leptin, N.P.Y. Melatonin and Zinc Levels in Experimental Hypothyroidism and Hyperthyroidism: The Relation to Zinc. Biochem. Genet. 2017, 55, 223-233. [CrossRef]

40. Zou, Z.W.; Liu, T.; Li, Y.; Chen, P.; Peng, X.; Ma, C.; Zhang, W.J.; Li, P.D. Melatonin suppresses thyroid cancer growth and overcomes radioresistance via inhibition of p65 phosphorylation and induction of ROS. Redox Biol. 2018, 16, 226-236. [CrossRef]

41. Soukup, T. Effects of long-term thyroid hormone level alterations, n-3 polyunsaturated fatty acid supplementation and statin administration in rats. Physiol. Res. 2014, 63, S119-S131.

42. Sinha, R.A.; Khare, P.; Rai, A.; Maurya, S.K.; Pathak, A.; Mohan, V.; Nagar, G.K.; Mudiam, M.K.; Godbole, M.M.; Bandyopadhyay, S. Anti-apoptotic role of omega-3-fatty acids in developing brain: Perinatal hypothyroid rat cerebellum as apoptotic model. Int. J. Dev. Neurosci. 2009, 27, 377-383. [CrossRef] [PubMed]

43. Abd Allah, E.S.; Gomaa, A.M.; Sayed, M.M. The effect of omega-3 on cognition in hypothyroid adult male rats. Acta Physiol. Hung. 2014, 101, 362-376. [CrossRef] [PubMed]

44. Rauchová, H.; Vokurková, M.; Pavelka, S.; Behuliak, M.; Tribulová, N.; Soukup, T. N-3 polyunsaturated fatty acids supplementation does not affect changes of lipid metabolism induced in rats by altered thyroid status. Horm. Metab. Res. 2013, 45, 507-512. [CrossRef] [PubMed]

45. Gani, O.A. Are fish oil omega-3 long-chain fatty acids and their derivatives peroxisome proliferator-activated receptor agonists? Cardiovasc. Diabetol. 2008, 20,1-6. [CrossRef] [PubMed]

46. Yousefnia, S.; Momenzadeh, S.; Seyed Forootan, F.; Ghaedi, K.; Nasr Esfahani, M.H. The influence of peroxisome proliferator-activated receptor $\gamma(\operatorname{PPAR} \gamma)$ ligands on cancer cell tumorigenicity. Gene 2018, 649, 14-22. [CrossRef] [PubMed]

47. Ohta, K.; Endo, T.; Haraguchi, K.; Hershman, J.M.; Onaya, T. Ligands for peroxisome proliferator-activated receptor gamma inhibit growth and induce apoptosis of human papillary thyroid carcinoma cells. J. Clin. Endocrinol. Metab. 2001, 86, 2170-2177. [CrossRef]

48. Hayashi, N.; Nakamori, S.; Hiraoka, N.; Tsujie, M.; Xundi, X.; Takano, T.; Amino, N.; Sakon, M.; Monden, M. Antitumor effects of peroxisome proliferator activate receptor gamma ligands on anaplastic thyroid carcinoma. Int. J. Oncol. 2004, 24, 89-95.

49. Bonofiglio, D.; Qi, H.; Gabriele, S.; Catalano, S.; Aquila, S.; Belmonte, M.; Andò, S. Peroxisome proliferatoractivated receptor gamma inhibits follicular and anaplastic thyroid carcinoma cells growth by upregulating p21Cip1/WAF1 gene in a Sp1-dependent manner. Endocr. Relat. Cancer 2008, 15, 545-557. [CrossRef]

50. Antonelli, A.; Fallahi, P.; Ferrari, S.M.; Ruffilli, I.; Santini, F.; Minuto, M.; Galleri, D.; Miccoli, P. New targeted therapies for thyroid cancer. Curr. Genom. 2011, 12, 626-631. [CrossRef] 
51. Antonelli, A.; Miccoli, P.; Derzhitski, V.E.; Panasiuk, G.; Solovieva, N.; Baschieri, L. Epidemiologic and clinical evaluation of thyroid cancer in children from the Gomel region (Belarus). World J. Surg. 1996, 20, 867-871. [CrossRef]

52. Rauf, A.; Imran, M.; Suleria, H.A.R.; Ahmad, B.; Peters, D.G.; Mubarak, M.S. A comprehensive review of the health perspectives of resveratrol. Food Funct. 2017, 8, 4284-4305. [CrossRef] [PubMed]

53. Limmongkon, A.; Janhom, P.; Amthong, A.; Kawpanuk, M.; Nopprang, P.; Poohadsuan, J.; Somboon, T.; Saijeen, S.; Surangkul, D.; Srikummool, M.; et al. Antioxidant activity, total phenolic, and resveratrol content in five cultivars of peanut sprouts. Asian Pac. J. Trop. Biomed. 2017, 7, 332-338. [CrossRef]

54. Ge, J.F.; Xu, Y.Y.; Li, N.; Zhang, Y.; Qiu, G.L.; Chu, C.H.; Wang, C.Y.; Qin, G.; Chen, F.H. Resveratrol improved the spatial learning and memory in subclinical hypothyroidism rat induced by hemi-thyroid electrocauterization. Endocr. J. 2015, 62, 927-938. [CrossRef]

55. Ge, J.F.; Xu, Y.Y.; Qin, G.; Cheng, J.Q.; Chen, F.H. Resveratrol Ameliorates the Anxiety- and Depression-Like Behavior of Subclinical Hypothyroidism Rat: Possible Involvement of the HPT Axis, HPA Axis, and Wnt/ $\beta$-Catenin Pathway. Front. Endocrinol. 2016, 7, 44. [CrossRef]

56. Sarkar, C.; Pal, S. Ameliorative effect of resveratrol against fluoride-induced alteration of thyroid function in male wistar rats. Biol. Trace Elem. Res. 2014, 162, 278-287. [CrossRef]

57. Ho, Y.; Lin, Y.S.; Liu, H.L.; Shih, Y.J.; Lin, S.Y.; Shih, A.; Chin, Y.T.; Chen, Y.R.; Lin, H.Y.; Davis, P.J. Biological Mechanisms by Which Antiproliferative Actions of Resveratrol Are Minimized. Nutrients 2017, 9, 1046. [CrossRef]

58. Hercbergs, A.; Johnson, R.E.; Ashur-Fabian, O.; Garfield, D.H.; Davis, P.J. Medically induced euthyroid hypothyroxinemia may extend survival in compassionate need cancer patients: An observational study. Oncologist 2015, 20, 72-76. [CrossRef]

59. Giuliani, C.; Bucci, I.; Di Santo, S.; Rossi, C.; Grassadonia, A.; Mariotti, M.; Piantelli, M.; Monaco, F.; Napolitano, G. Resveratrol inhibits sodium/iodide symporter gene expression and function in rat thyroid cells. PLoS ONE 2014, 9, e107936. [CrossRef]

60. Giuliani, C.; Iezzi, M.; Ciolli, L.; Hysi, A.; Bucci, I.; Di Santo, S.; Rossi, C.; Zucchelli, M.; Napolitano, G. Resveratrol has anti-thyroid effects both in vitro and in vivo. Food Chem. Toxicol. 2017, 107, 237-247. [CrossRef]

61. Wu, J.; Li, Y.T.; Tian, X.T.; Liu, Y.S.; Wu, M.L.; Li, P.N.; Liu, J. STAT3 signaling statuses determine the fate of resveratrol-treated anaplastic thyroid cancer cells. Cancer Biomark. 2020, 27, 461-469. [CrossRef]

62. Liu, X.; Li, H.; Wu, M.L.; Wu, J.; Sun, Y.; Zhang, K.L.; Liu, J. Resveratrol Reverses Retinoic Acid Resistance of Anaplastic Thyroid Cancer Cells via Demethylating CRABP2 Gene. Front. Endocrinol. 2019, 10, 734. [CrossRef] [PubMed]

63. Hosseinimehr, S.J.; Hossein, S.A.H. Resveratrol Sensitizes Selectively Thyroid Cancer Cell to 131-Iodine Toxicity. J. Toxicol. 2014, 2014, 839597. [CrossRef] [PubMed]

64. Duntas, L.H.; Benvenga, S. Selenium: An element for life. Endocrine 2015, 48, 756-775. [CrossRef] [PubMed]

65. Ben Amara, I.; Fetoui, H.; Guermazi, F.; Zeghal, N. Dietary selenium addition improves cerebrum and cerebellum impairments induced by methimazole in suckling rats. Int. J. Dev. Neurosci. 2009, 27, 719-726. [CrossRef]

66. Laureano-Melo, R.; Império, G.E.; da Silva-Almeida, C.; Kluck, G.E.; Cruz Seara Fde, A.; da Rocha, F.F.; da Silveira, A.L.; Reis, L.C.; Ortiga-Carvalho, T.M.; da Silva Côrtes, W. Sodium selenite supplementation during pregnancy and lactation promotes anxiolysis and improves mnemonic performance in wistar rats' offspring. Pharmacol. Biochem. Behav. 2015, 138, 123-132. [CrossRef]

67. Xue, H.; Wang, W.; Li, Y.; Shan, Z.; Li, Y.; Teng, X.; Gao, Y.; Fan, C.; Teng, W. Selenium upregulates $\mathrm{CD} 4(+) \mathrm{CD} 25(+)$ regulatory T cells in iodine-induced autoimmune thyroiditis model of NOD.H-2(h4) mice. Endocr. J. 2010, 57, 595-601. [CrossRef]

68. Kato, M.A.; Finley, D.J.; Lubitz, C.C.; Zhu, B.; Moo, T.A.; Loeven, M.R.; Ricci, J.A.; Zarnegar, R.; Katdare, M.; Fahey, T.J. 3rd. Selenium decreases thyroid cancer cell growth by increasing expression of GADD153 and GADD34. Nutr. Cancer 2010, 62, 66-73. [CrossRef]

69. de Oliveira Maia, M.; Batista, B.A.M.; Sousa, M.P.; de Souza, L.M.; Maia, C.S.C. Selenium and thyroid cancer: A systematic review. Nutr. Cancer 2019, 22,1-9. [CrossRef]

70. Biebinger, R.; Arnold, M.; Koss, M.; Kloeckener-Gruissem, B.; Langhans, W.; Hurrell, R.F.; Zimmermann, M.B. Effect of concurrent vitamin A and iodine deficiencies on the thyroid-pituitary axis in rats. Thyroid 2006, 16, 961-965. [CrossRef] 
71. Zimmermann, M.B. Interactions of vitamin A and iodine deficiencies: Effects on the pituitary-thyroid axis. Int. J. Vitam. Nutr. Res. 2007, 77, 236-240. [CrossRef]

72. Li, H.; Bai, B.; Zhang, Q.; Bao, Y.; Guo, J.; Chen, S.; Miao, C.; Liu, X.; Zhang, T. Ectopic cross-talk between thyroid and retinoic acid signaling: A possible etiology for spinal neural tube defects. Gene 2015, 573, 254-260. [CrossRef] [PubMed]

73. Lee, S.J.; Kim, S.H.; Kang, J.G.; Kim, C.S.; Ihm, S.H.; Choi, M.G.; Yoo, H.J. Effects of all-trans retinoic acid on sodium/iodide symporter and CCAAT/enhancer-binding protein-homologous protein under condition of endoplasmic reticulum stress in FRTL5 thyroid cells. Horm. Metab. Res. 2011, 43, 331-336. [CrossRef] [PubMed]

74. Lan, L.; Basourakos, S.; Cui, D.; Zuo, X.; Deng, W.; Huo, L.; Chen, H.; Zhang, G.; Deng, L.; Shi, B.; et al. ATRA increases iodine uptake and inhibits the proliferation and invasiveness of human anaplastic thyroid carcinoma SW1736 cells: Involvement of $\beta$-catenin phosphorylation inhibition. Oncol. Lett. 2017, 14, 7733-7738. [CrossRef] [PubMed]

75. Zhang, M.; Guo, R.; Xu, H.; Zhang, M.; Li, B. Retinoic acid and tributyrin induce in-vitro radioiodine uptake and inhibition of cell proliferation in a poorly differentiated follicular thyroid carcinoma. Nucl. Med. Commun. 2011, 32, 605-610. [CrossRef] [PubMed]

76. Nettore, I.C.; Albano, L.; Ungaro, P.; Colao, A.; Macchia, P.E. Sunshine vitamin and thyroid. Rev. Endocr. Metab. Disord. 2017, 18, 347-354. [CrossRef]

77. Fournier, C.; Gepner, P.; Sadouk, M.; Charreire, J. In vivo beneficial effects of cyclosporin A and 1,25-dihydroxyvitamin D3 on the induction of experimental autoimmune thyroiditis. Clin. Immunol. Immunopathol. 1990, 54, 53-63. [CrossRef]

78. Chen, W.; Lin, H.; Wang, M. Immune intervention effects on the induction of experimental autoimmune thyroiditis. J. Huazhong Univ. Sci. Technol. Med. Sci. 2002, 22, 343-345. [CrossRef]

79. Liu, S.; Xiong, F.; Liu, E.M.; Zhu, M.; Lei, P.Y. [Effects of 1,25- dihydroxyvitamin D3 in rats with experimental autoimmune thyroiditis]. Nan Fang Yi Кe Da Хие Хие Вao 2010, 30, 1573-1576.

80. Misharin, A.; Hewison, M.; Chen, C.R.; Lagishetty, V.; Aliesky, H.A.; Mizutori, Y.; Rapaport, B.; McLachlan, S.M. Vitamin D deficiency modulates Graves' hyperthyroidism induced in BALB/c mice by thyrotropin receptor immunization. Endocrinology 2009, 150, 1051-1060. [CrossRef]

81. Williams, T.L.; Elliott, J.; Berry, J.; Syme, H.M. Investigation of the pathophysiological mechanism for altered calcium homeostasis in hyperthyroid cats. J. Small Anim. Pract. 2013, 54, 367-373. [CrossRef]

82. Jeon, S.M.; Shin, E.A. Exploring vitamin D metabolism and function in cancer. Exp. Mol. Med. 2018, 50, 20. [CrossRef] [PubMed]

83. Clinckspoor, I.; Hauben, E.; Verlinden, L.; Van den Bruel, A.; Vanwalleghem, L.; Vander Poorten, V.; Delaere, P.; Mathieu, C.; Verstuyf, A.; Decallonne, B. Altered expression of key players in vitamin D metabolism and signaling in malignant and benign thyroid tumors. J. Histochem. Cytochem. 2012, 60, 502-511. [CrossRef] [PubMed]

84. Zhang, T.; He, L.; Sun, W.; Qin, Y.; Zhang, P.; Zhang, H. 1,25-Dihydroxyvitamin D3 enhances the susceptibility of anaplastic thyroid cancer cells to adriamycin-induced apoptosis by increasing the generation of reactive oxygen species. Mol. Med. Rep. 2019, 20, 2641-2648. [CrossRef] [PubMed]

85. Peng, W.; Wang, K.; Zheng, R.; Derwahl, M. 1,25 dihydroxyvitamin D3 inhibits the proliferation of thyroid cancer stem-like cells via cell cycle arrest. Endocr. Res. 2016, 41, 71-80. [CrossRef]

86. Yu, J.; Shan, Z.; Chong, W.; Mao, J.; Geng, Y.; Zhang, C.; Xing, Q.; Wang, W.; Li, N.; Fan, C.; et al. Vitamin E ameliorates iodine-induced cytotoxicity in thyroid. J. Endocrinol. 2011, 209, 299-306. [CrossRef]

87. Pan, T.; Zhong, M.; Zhong, X.; Zhang, Y.; Zhu, D. Levothyroxine replacement therapy with vitamin E supplementation prevents oxidative stress and cognitive deficit in experimental hypothyroidism. Endocrine 2013, 43, 434-439. [CrossRef]

88. Guo, Y.; Wan, S.Y.; Zhong, X.; Zhong, M.K.; Pan, T.R. Levothyroxine replacement therapy with vitamin E supplementation prevents the oxidative stress and apoptosis in hippocampus of hypothyroid rats. Neuroendocrinol. Lett. 2014, 35, 684-690.

89. Subudhi, U.; Das, K.; Paital, B.; Bhanja, S.; Chainy, G.B. Alleviation of enhanced oxidative stress and oxygen consumption of L-thyroxine induced hyperthyroid rat liver mitochondria by vitamin E and curcumin. Chem. Biol. Interact. 2008, 173, 105-114. [CrossRef] 
90. Ciji, A.; Sahu, N.P.; Pal, A.K.; Akhtar, M.S. Nitrite-induced alterations in sex steroids and thyroid hormones of Labeo rohita juveniles: Effects of dietary vitamin E and L-tryptophan. Fish Physiol. Biochem. 2013, 39, 1297-1307. [CrossRef]

91. Esposito, T.; Lucariello, A.; Hay, E.; Contieri, M.; Tammaro, P.; Varriale, B.; Guerra, G.; De Luca, A.; Perna, A. Effects of curcumin and its adjuvant on TPC1 thyroid cell line. Chem. Biol. Interact. 2019, 305, 112-118. [CrossRef]

92. Pathak, R.; Dhawan, D.; Pathak, A. Effect of zinc supplementation on the status of thyroid hormones and $\mathrm{Na}$, $\mathrm{K}$, and Ca levels in blood following ethanol feeding. Biol. Trace Elem. Res. 2011, 140, 208-214. [CrossRef] [PubMed]

93. Chen, M.D.; Lin, P.Y.; Lin, W.H. Zinc supplementation on serum levels and hepatic conversion of thyroid hormones in obese (ob/ob) mice. Biol. Trace Elem. Res. 1998, 61, 89-96. [CrossRef] [PubMed]

94. Keçeci, T.; Keskin, E. Zinc supplementation decreases total thyroid hormone concentration in small ruminants. Acta Vet. Hung. 2002, 50, 93-100. [CrossRef] [PubMed]

95. Baydas, B.; Karagoz, S.; Meral, I. Effects of oral zinc and magnesium supplementation on serum thyroid hormone and lipid levels in experimentally induced diabetic rats. Biol. Trace Elem. Res. 2002, 88, 247-253. [CrossRef]

96. Guantario, B.; Capolupo, A.; Monti, M.C.; Leoni, G.; Ranaldi, G.; Tosco, A.; Marzullo, L.; Murgia, C.; Perozzi, G. Proteomic Analysis of Zn Depletion/Repletion in the Hormone-Secreting Thyroid Follicular Cell Line FRTL-5. Nutrients 2018, 10, 1981. [CrossRef]

97. Benvenga, S.; Antonelli, A. Inositol(s) in thyroid function, growth and autoimmunity. Rev. Endocr. Metab. Disord. 2016, 17, 471-484. [CrossRef]

98. Lewin, L.M.; Yannai, Y.; Sulimovici, S.; Kraicer, P.F. Studies on the Metabolic Role of Myo-Inositol. Distribution of Radioactive Myo-Inositol in the Male Rat. Biochem. J. 1976, 156, 375-380. [CrossRef]

99. Grafton, G.; Baxter, M.A.; Sheppard, M.C.; Eggo, M.C. Regulation of Myo-Inositol Transport During the Growth and Differentiation of Thyrocytes: A Link With Thyroid-Stimulating Hormone-Induced Phospholipase A2 Activity. Biochem. J. 1995, 309, 667-675. [CrossRef]

100. Hasegawa, R.; Eisenberg, F., Jr. Selective Hormonal Control of Myo-Inositol Biosynthesis in Reproductive Organs and Liver of the Male Rat. Proc. Natl. Acad. Sci. USA 1981, 78, 4863-4866. [CrossRef]

101. Fallahi, P.; Ferrari, S.M.; Elia, G.; Ragusa, F.; Paparo, S.R.; Caruso, C.; Guglielmi, G.; Antonelli, A. Myo-inositol in autoimmune thyroiditis, and hypothyroidism. Rev. Endocr. Metab. Disord. 2018, 19, 349-354. [CrossRef]

102. Gerloff, B.J.; Herdt, T.H.; Wells, W.W.; Nachreiner, R.F.; Emery, R.S. Inositol and Hepatic Lipidosis. II. Effect of Inositol Supplementation and Time from Parturition on Serum Insulin, Thyroxine and Triiodothyronine and Their Relationship to Serum and Liver Lipids in Dairy Cows. J. Anim. Sci. 1986, 62, 1693-1702. [CrossRef] [PubMed]

103. Nordio, M.; Pajalich, R. Combined treatment with Myo-inositol and selenium ensures euthyroidism in subclinical hypothyroidism patients with autoimmune thyroiditis. J. Thyroid. Res. 2013, 2013, 424163. [CrossRef] [PubMed]

104. Ferrari, S.M.; Fallahi, P.; Di Bari, F.; Vita, R.; Benvenga, S.; Antonelli, A. Myo-inositol and selenium reduce the risk of developing overt hypothyroidism in patients with autoimmune thyroiditis. Eur. Rev. Med. Pharmacol. Sci. 2017, 21, 36-42.

105. Benvenga, S.; Vicchio, T.; Di Bari, F.; Vita, R.; Fallahi, P.; Ferrari, S.M.; Catania, S.; Costa, C.; Antonelli, A. Favorable effects of myo-inositol, selenomethionine or their combination on the hydrogen peroxide-induced oxidative stress of peripheral mononuclear cells from patients with Hashimoto's thyroiditis: Preliminary in vitro studies. Eur. Rev. Med. Pharmacol. Sci. 2017, 21, 89-101. [PubMed]

106. Ferrari, S.M.; Elia, G.; Ragusa, F.; Paparo, S.R.; Caruso, C.; Benvenga, S.; Fallahi, P.; Antonelli, A. The protective effect of myo-inositol on human thyrocytes. Rev. Endocr. Metab. Disord. 2018, 19, 355-362. [CrossRef] [PubMed]

107. Xiang, H.; Heyliger, C.E.; McNeill, J.H. Effect of Myo-Inositol and T3 on Myocardial Lipids and Cardiac Function in Streptozocin-Induced Diabetic Rats. Diabetes 1988, 37, 1542-1548. [CrossRef]

(C) 2020 by the authors. Licensee MDPI, Basel, Switzerland. This article is an open access article distributed under the terms and conditions of the Creative Commons Attribution (CC BY) license (http://creativecommons.org/licenses/by/4.0/). 


\title{
Nutraceutical Supplements in the Thyroid Setting: Health Benefits beyond Basic Nutrition
}

\author{
Salvatore Benvenga ${ }^{1,2,3}$, Ulla Feldt-Rasmussen ${ }^{4}$, Daniela Bonofiglio ${ }^{5}$ and Ernest Asamoah ${ }^{6, *}$ \\ 1 Department of Clinical and Experimental Medicine-Endocrinology, University of Messina, \\ via Consolare Valeria-Gazzi, 98125 Messina, Italy; s.benvenga@live.it \\ 2 Master Program on Childhood, Adolescent and Women's Endocrine Health, University of Messina, \\ via Consolare Valeria-Gazzi, 98125 Messina, Italy \\ 3 Interdepartmental Program on Molecular and Clinical Endocrinology and Women's Endocrine Health, \\ AOU Policlinico G. Martino, via Consolare Valeria-Gazzi, 98125 Messina, Italy \\ 4 Medical Endocrinology and Metabolism PE 2132, Rigshospitalet, Copenhagen University Hospital, \\ Blegdamsvej 9, DK-2100 Copenhagen, Denmark; ufeldt@rh.dk \\ 5 Department of Pharmacy, Health and Nutritional Sciences, University of Calabria, \\ 87036 Arcavacata di Rende (CS), Italy; daniela.bonofiglio@unical.it \\ 6 Community Physicians Network, Diabetes \& Endocrinology Care, 8435 Clearvista Place, Suite 101, \\ Indianapolis, IN 46256, USA \\ * Correspondence: eoasamoah@mac.com
}

Received: 29 July 2019; Accepted: 9 September 2019; Published: 13 September 2019

\begin{abstract}
In recent years, there has been a growing interest in nutraceuticals, which may be considered as an efficient, preventive, and therapeutic tool in facing different pathological conditions, including thyroid diseases. Although iodine remains the major nutrient required for the functioning of the thyroid gland, other dietary components play important roles in clinical thyroidology—these include selenium, L-carnitine, myo-inositol, melatonin, and resveratrol—some of which have antioxidant properties. The main concern regarding the appropriate and effective use of nutraceuticals in prevention and treatment is due to the lack of clinical data supporting their efficacy. Another limitation is the discrepancy between the concentration claimed by the label and the real concentration. This paper provides a detailed critical review on the health benefits, beyond basic nutrition, of some popular nutraceutical supplements, with a special focus on their effects on thyroid pathophysiology and aims to distinguish between the truths and myths surrounding the clinical use of such nutraceuticals.
\end{abstract}

Keywords: nutraceuticals; thyroid function; dietary supplements

\section{Introduction}

\subsection{Definition of Nutraceutical}

The definition of nutraceuticals is still in the grey area between food, food supplements, and pharmaceuticals. Some definitions [1-5] of nutraceuticals are provided in Table 1. The term "nutraceutical" was coined in 1989 by Stephen De Felice, founder and chairman of the Foundation for Innovation in Medicine, an American organization which encourages medical health research. He defined a nutraceutical as a "food, or parts of a food, that provide medical or health benefits, including the prevention and treatment of disease" [4]. Japan was among the first countries to face the issue of regulating food supplements and foodstuffs. This legislation, originally set in 1991, evolved into the 2003 Health Promotion Law [5]. The current European regulation (Regulation No. 1924/2006 of the European Parliament and of the Council, recently updated by EU Regulation 2015/2283) defines food categories and includes a definition of food supplements, although there is no official mention or recognition the term "nutraceutical" [6]. Accordingly, the European Food Safety Authority (EFSA) 
does not make any distinction between "food supplements" and "nutraceuticals" for beneficial health claim applications for new products. In a similar way, the Dietary Supplement Health and Education Act (DSHEA, 1994) [7] defined dietary supplements as a category of food, as did the US Food and Drug Administration (FDA) [8]. Indeed, in America "medical foods" and "dietary supplements" are regulatory terms, however "nutraceuticals", "functional foods", and other such terms are determined by consultants and marketers, based on consumer trends. Further information on the dietary supplements given by the Food and Drug Administration (FDA) on its website [9] is summarized in Appendix Table A1.

Table 1. Some definitions of "nutraceutical".

\begin{tabular}{cl}
\hline Reference & \multicolumn{1}{c}{ Definition } \\
\hline$[1]$ & $\begin{array}{l}\text { "A foodstuff (such as a fortified food or dietary supplement) that provides health benefits in } \\
\text { addition to its basic nutritional value. (First known use: 1990)". }\end{array}$ \\
\hline$[2]$ & "A food to which vitamins, minerals, or drugs have been added to make it healthier." \\
\hline "Nutraceuticals, which have also been called medical foods, designer foods, phytochemicals, \\
functional foods and nutritional supplements, include such everyday products as "bio" \\
yoghurts and fortified breakfast cereals, as well as vitamins, herbal remedies and even \\
genetically modified foods and supplements. Many different terms and definitions are used in \\
different countries, which can result in confusion."
\end{tabular}

\subsection{Search of the Literature}

A PubMed search, run on 14 July 2017, using the word "nutraceutical" as the entry, yielded 67,344 results. Results fell to 4820 using the entry "nutraceuticals AND hormones" and to 553 using the entry "nutraceuticals AND thyroid". Approximately 18 months later (5 February 2019), the corresponding numbers were 78,919 (+17\%), $5538(+15 \%)$ and $642(+16 \%)$, indicating that the interest in the thyroid proceeds with the same pace as that for nutraceuticals in general and hormones in general. Confirmation of these data came from a final search that was run on 9 July 2019 (Table 2).

In the following text, different nutraceuticals possibly influencing human thyroid function and/or immunity will be reviewed and commented upon.

A general effect of the nutraceuticals beyond the thyroid effect is not within the scope of this review, nor is a meticulous review of animal or other experimental studies. We were guided by our clinical practices, particularly those for which patients were most curious. As mentioned in the following section, there is indeed a growing market for such nutraceuticals.

There was relatively scant literature on the topic, and most research focused on thyroid cancer and was experimental in nature, concerning the nutraceuticals illustratively mentioned by the Food and Drug Administration, as shown in Appendix Table A1. 
Table 2. Summary of number of articles on given nutraceuticals retrievable on PubMed as of 9 July 2019.

\begin{tabular}{ccccccc}
\hline & \multirow{2}{*}{ Entry } & \multicolumn{2}{c}{ No. of Items } & \multicolumn{3}{c}{ Proportions } \\
\cline { 3 - 7 } & & Total & Human & Human/Total & Thyroid/Total & Thyroid/Human \\
\hline 1 & & 81,422 & 52,406 & $64.4 \%$ & N/A & N/A \\
2 & nutraceuticals AND hormones & 5698 & 3664 & $61.4 \%$ & N/A & N/A \\
3 & nutraceuticals AND thyroid & 656 & 487 & $74.2 \%$ & $0.8 \%$ & $0.9 \%$ \\
4 & carnitine & 16,737 & 7831 & $46.8 \%$ & N/A & N/A \\
5 & carnitine AND thyroid & 145 & 68 & $46.9 \%$ & $0.9 \%$ & $0.9 \%$ \\
6 & inositol & 44,801 & 16,700 & $37.3 \%$ & N/A & N/A \\
7 & inositol AND thyroid & 295 & 141 & $47.8 \%$ & $0.6 \%$ & $0.8 \%$ \\
8 & melatonin & 24,921 & 10,740 & $43.1 \%$ & N/A & N/A \\
9 & melatonin AND thyroid & 514 & 195 & $37.9 \%$ & $2.1 \%$ & $1.8 \%$ \\
10 & resveratrol & 11,983 & 5447 & $45.4 \%$ & N/A & N/A \\
11 & resveratrol AND thyroid & 78 & 47 & $60.2 \%$ & $0.6 \%$ & $0.9 \%$ \\
12 & selenium & 33,980 & 13,333 & $39.2 \%$ & N/A & N/A \\
13 & selenium AND thyroid & 938 & 576 & $61.4 \%$ & $2.8 \%$ & $4.3 \%$ \\
\hline
\end{tabular}

Note that the number of items under the keyword "nutraceuticals" underestimates the bulk of the literature. Indeed, by adding items \#4, 6, 10,12, 14 and 16 the sum is 164,513 , which is greater than 81,422 for item \#1. Similar considerations apply for the corresponding human studies (67,565 vs. 52,406), and for the thyroid studies (total studies $=2305$ vs. 656 ; human studies $=1269$ vs. 487 ).

\subsection{Market and Sales}

Based on data from a decade ago, annual supplement sales were $\$ 23$ billion, and about 40,000 supplement products were on the market in the United States [10]. In 2015, the American market for dietary supplements was valued at \$37 billion, with the economic impact in the United States for 2016 estimated at $\$ 122$ billion, including employment wages and taxes [11]. One 2016 analysis estimated the total market for dietary supplements could reach $\$ 278$ billion worldwide by 2024 [11]. Table 3 summarizes the details for the nutraceuticals reviewed here [12-16].

Table 3. Economic issues for the reviewed nutraceuticals.

\begin{tabular}{cl}
\hline Nutraceutical & \multicolumn{1}{c}{ Market and Sales ^ } \\
\hline \multirow{2}{*}{ L-carnitine } & $\begin{array}{l}\text { L-carnitine market is expected to be worth USD } 127 \text { million by 2017, with the United States } \\
\text { being the largest market, and the Asia-Pacific region, particularly China, expected to } \\
\text { experience a 5.5\% annual growth rate through 2017 [12]. } \\
\text { No. of items on sale-Amazon: 53; Walgreens: No match; CVS Pharmacy:13. }\end{array}$ \\
\hline & $\begin{array}{l}\text { In the consumption market, the global consumption value of inositol increases with the } \\
\text { 2.01\% average growth rate. Europe and China are the mainly consumption regions [11]. }\end{array}$ \\
& $\begin{array}{l}\text { With myo-inositol being the most common form of inositols, over the next five years the } \\
\text { inositol market, will register a 6.8\% compound annual growth rate in terms of revenue, the } \\
\text { global market size will reach US \$140 million by 2024, from US \$94 million in 2019 [13]. }\end{array}$ \\
& No. of items on sale-Amazon: 3; Walgreens: No match; CVS Pharmacy: No match. \\
\hline \multirow{2}{*}{ Melatonin } & $\begin{array}{l}\text { The North America region is the largest supplier of melatonin, with a production market } \\
\text { share nearly 54\% in 2016, Europe coming next with 27\% [14]. The global market size will } \\
\text { reach US \$2080 million by 2024, from US \$700 million in 2019 [14]. }\end{array}$ \\
& No. of items on sale-Amazon: 122; Walgreens: 11; CVS Pharmacy: 91. \\
\hline \multirow{2}{*}{ Resveratrol } & $\begin{array}{l}\text { Resveratrol supplements, with annual sales of \$30 million in the United States [15] } \\
\text { No. of items on sale-Amazon: 45; Walgreens: No match; CVS Pharmacy: 19. }\end{array}$ \\
\hline \multirow{2}{*}{ Selenium } & $\begin{array}{l}\text { Selenium market reached \$87 million U.S. in 2017 [16]. } \\
\text { No. of items on sale-Amazon: 91; Walgreens: No match; CVS Pharmacy: 84. }\end{array}$ \\
\hline
\end{tabular}

^ Numbers in brackets are references. Internet sales by Amazon, Walgreens and CVS Pharmacy are reported. Search was performed for the pure nutraceutical, such as entering "pure melatonin". Search performed on the Amazon website by omitting the word "pure", yielded a greater number of results ( 973 for L-carnitine, 48 for myo-inositol, 178 for resveratrol, over 1000 for selenium, and over 1000 for biotin). Search on the Walgreens website by omitting the word "pure", yielded a greater number of results (12 for L-carnitine, 1 for myo-inositol, 107 for melatonin, 10 for resveratrol, 21 for selenium, and 71 for biotin). 


\subsection{The Issue of Purity}

"The biggest problem with supplements is that many of them do not actually contain what the label claims. As many as 70\% of the supplements on the market either don't have ingredients that match their labels or contain contaminants of some kind" [17]. In his review, Lockwood aimed to investigate the extent of substandard formulated and raw material nutraceuticals [17]. The key findings were that "published evaluations of over 70 formulations of 25 different nutraceuticals revealed variable quality; no nutraceutical showed consistent high quality, but a number revealed consistent low quality, thereby making the case for closer regulation of manufacturers. Whole food sources have also been shown to be widely variable in constituent levels." [17]. Concerning the issue of purity, the illegal presence of thyroid hormones in the majority of dietary health supplements marketed for "thyroid support" potentially exposes patients to the risk of developing iatrogenic thyrotoxicosis [18].

In the following text, we now give some data concerning the nutraceuticals dealt upon in our paper. Concerning carnitine, of 12 over-the-counter carnitine formulations, the actual mean content was only $52 \%$ of that indicated on the label [19]. Furthermore, of the same 12 preparations, five had unsatisfactory pharmaceutical dissolution characteristics.

Concerning myo-inositol, one study evaluated label accuracy of four myo-inositol products, designed for polycystic ovary syndrome (PCOS) treatment and available on the Italian market, and performed a cost comparison based on myo-inositol content in milligrams for products analyzed [20]. A significant difference in the myo-inositol content, compared with the labeling was found for the products. Only one product contained more than $95 \%$ of the myo-inositol content claimed on the label, and there was a product with less than $75 \%$ of the labeling amount. Based on a 2-g myo-inositol per day dose, the cost of a 30-day supply ranged from Euro 20.77 and Euro 71.86, after correction by the actual amount of myo-inositol.

One recent study aimed to determine the dose of melatonin in food supplements marketed in Europe (pharmacies of Spain) and the United States (supermarkets of San Francisco, CA, USA) by validating a liquid chromatography method with diode array detection (LC-DAD) [21]. The authors tentatively identified eight tryptophan-related contaminants in melatonin supplements, with only one supplement declaring its addition on the label. Label melatonin doses varied from 1-1.95 mg/unit and 0.3-5 mg/unit for supplements marketed in Europe (Spain) and the US, respectively. Four out of 17 supplements showed significant deviations from melatonin content declared on the label (from $-60 \%$ to $-20 \%$ ). Only five out of the eight supplements purchased in Spain actually met the qualifications needed to claim to reduce the time to fall asleep. Another study analyzed the actual melatonin content (and presence of contaminants) in 31 melatonin supplements purchased from groceries and pharmacies in one city in Canada [22]. Melatonin content varied from $-83 \%$ to $+478 \%$ of labeled melatonin and approximately three-fourths had melatonin concentration $\leq 10 \%$ of what was claimed. Worse yet, the content of melatonin between lots of the same product varied by as much as $465 \%$. An additional $26 \%$ of the 31 melatonin supplements were found to contain serotonin.

Concerning resveratrol, 14 brands of resveratrol-containing nutraceuticals were evaluated [23]. The 14 preparations were purchased directly from online stores during 2010 and were analysed before their expiry dates. Only five out of 14 brands had near label values, compliant with Good Manufacturing Practices (GMP) requirements (95\%-105\% content of active constituent), four products were slightly out of this range $(83 \%-111 \%)$ and three were in the $8 \%-64 \%$ range. Two samples were below the limit of detection. The greater the difference between actual and labeled resveratrol content, the lower the antioxidant and antiproliferative activity strength.

With regard to selenium, one study analysed six different brands of yeast-based selenium food supplements that were obtained from local stores [24]. These supplements were treated with milder extraction and hydrolysis conditions to analyse for the expected selenomethionine content. Only two brands had high levels of selenomethionine, one brand appeared to contain all inorganic selenium, and one brand appeared to contain greater than half inorganic selenium despite label claims of content being only selenomethionine. 


\section{Carnitine: Compound and Physiology}

Carnitine is a quaternary ammonium compound (3-Hydroxy-4-(trimethylazaniumyl) butanoate) that is ubiquitous in tissues and biological fluids of mammals [25]. The natural enantiomer is L-carnitine, which acts as an obligatory cofactor for $\beta$-oxidation of fatty acids by facilitating the transport of the long-chain fatty acids across the mitochondrial inner membrane as acyl-carnitine esters. This oxidation liberates energy via the production of ATP in the respiratory chain, thus playing a role in cell's energy metabolism. Particularly, L-carnitine exerted a physiological benefit with a positive impact on cardiac function through reduced oxidative stress, inflammation and necrosis of cardiac myocytes. [26]. Only $25 \%$ of the body stores of carnitine come from biosynthesis and $75 \%$ comes from the diet. The main source is red meat and dairy products. Muscles are the most prominent carnitine depository since they store about $95 \%$ of the $120 \mathrm{mmol}$ total amount contained in the adult human body, and the concentration in skeletal muscle $(3.5 \mathrm{mmol} / \mathrm{L})$ is 70 -fold greater than that in plasma.

The main interest in carnitine supplementation comes from athletes and other physical exercise performers [27]. Thus, repeated-dose carnitine supplements may increase skeletal muscle content. For instance, long-distance runners given a daily dose of $2 \mathrm{~g}$ carnitine for 28 days and subjected to a four-week training period [28] increased skeletal muscle carnitine by approximately $13 \%$ as compared to a decrease of about $10 \%$ in placebo-treated athletes. In other athletes, supplementation with 1 $\mathrm{g}$ /day carnitine for 120 days of training increased carnitine concentrations in skeletal muscle by an average of $9 \%$ compared to a decrease of $5 \%$ in the placebo-treated athletes [29]. Carnitine is critical for normal skeletal muscle bioenergetics [30-32], and skeletal muscles suffer seriously in states of carnitine deficiency. A relative carnitine deficiency can occur in athletes as a result of increased energy metabolism, unbalanced nutrition, decreased skeletal muscle content and increased renal excretion of carnitine. The important energetic role of carnitine, the relative deficiency associated with sustained physical exercise, and the fact that carnitine is a natural compound, has led healthy subjects aiming to improve their exercise performance to conclude that "more carnitine should be better [30-32], but basically this was proven to be without any beneficial effect.

\section{Carnitine and Thyroid Function}

A German group of authors conducted pivotal clinical studies as early as 1959 in a very limited number of patients with Graves' disease, using a mixture of the two isomers (L-and D-carnitine) [33]. The first patient was a 53-year-old bedridden woman with very severe Graves' disease and nervousness, insomnia, weight loss, sweating, tachycardia and Graves' orbitopathy. Basal metabolic rate (BMR) was $+82 \%$, and she was administered $1 \mathrm{~g} / \mathrm{d} \mathrm{D}, \mathrm{L}$-carnitine. After 10 days, BMR was unchanged but one week later it fell to $+59 \%$. Five weeks after starting D,L-carnitine, BMR was still $+50 \%$ and the authors switched to the naturally occurring L-carnitine. After only 10 days BMR dropped more rapidly to $+8 \%$ with associate improvement in general well-being and heart rate. Atrial fibrillation disappeared and heart rate was $80-90$ beats $/ \mathrm{min}$. To prove that the improvement was due to L-carnitine, it was withdrawn in the 7 th week from admission. BMR rose to $+39 \%$, but after rechallenge with L-carnitine it fell again to $+18 \%$ [33].

In the English-language literature, the first three monotherapy carnitine-treated hyperthyroid patients were reported in the mid-1960s [34]. The authors found that patients became clinically euthyroid without any consistent changes in the thyroid function tests, thus supporting the notion that the antithyroid effect of carnitine is one of peripheral antagonism of thyroid hormone, rather than a direct inhibition of thyroid gland function [35]. This was consistent with human tissue culture experiments where L-carnitine inhibited both cell entry and, to a greater extent, nuclear entry of both T3 and T4 [36]. These data are consistent with carnitine being a peripheral antagonist of thyroid hormone action, with a site of inhibition at or before the nuclear envelope [36].

The first controlled clinical trial addressing the value of L-carnitine in antagonizing elevated circulating levels of thyroid hormones was conducted in 50 women under Thyroid stimulating hormone (TSH)-suppressive L-T4 therapy for cytologically benign thyroid nodules who received 
a simultaneous treatment for six months with placebo $(n=10)$, or for given periods of time with L-carnitine ( $2 \mathrm{~g} / \mathrm{d}$ or $4 \mathrm{~g} / \mathrm{d}$ to test dose-dependence) [37]. Evaluation by both extensive clinical and biochemical assessment demonstrated positive effects with the exception of osteocalcin, which increased further during L-carnitine administration and partial exception of total cholesterol (minimal or no increase during L-carnitine administration). Serum FT3, FT4 and TSH remained unchanged throughout the 180 day-duration of the trial. Thus, there was no antagonism from L-carnitine on the negative feedback that thyroid hormones exert on thyrotropin releasing hormone (TRH)/TSH. In addition to the hypothalamic TRH-producing neurons and the pituitary thyrotropin, also osteoblasts were refractory to the thyroid-hormone antagonizing effect of L-carnitine (see above). Thus, L-carnitine synergized with thyroid hormone on the osteoblasts to increase osteocalcin serum concentrations. The favorable effect on the osteoblasts was supported by measuring femur and lumbar bone density by dual-energy-X-ray absorptiometry [37].

More recent cases of severe forms of Graves' disease-related hyperthyroidism, including thyroid storms, were treated successfully with L-carnitine [38-40]. Recently, a pilot study indicated the beneficial effects of a combination of L-carnitine and selenium supplementation in subclinical hyperthyroidism [41]. A rationale for a beneficial effect of L-carnitine supplementation in hyperthyroid patients seems likely because increased levels of thyroid hormones deprive the tissue deposits of L-carnitine itself [42], which is further substantiated by the finding of decreased concentrations of carnitine in the skeletal muscles of hyperthyroid patients. Interestingly, trendwise decreased concentrations of carnitine were found in skeletal muscles of hypothyroid patients [43], which were restored upon regaining euthyroidism. Therefore, decreased concentrations of carnitine in skeletal muscles may contribute to myopathy associated with either hypothyroidism or hyperthyroidism.

Sixty thyroid-hormone adequately replaced hypothyroid Korean patients (age $50.0 \pm 9.2$ years, 57 females) continued to complain of fatigue [44]. These patients were given L-carnitine $(990 \mathrm{mg}$ L-carnitine twice daily; $n=30)$ or placebo $(n=30)$ for 12 weeks. After 12 weeks, although neither the fatigue severity score nor the physical fatigue score changed significantly after 12 weeks, but the mental fatigue score was significantly improved by treatment with L-carnitine compared with placebo $(p<0.01)$. In subgroups, both the physical and mental fatigue scores improved significantly in patients younger than 50 years and those with free $\mathrm{T} 3 \geq 4.0 \mathrm{pg} / \mathrm{mL}$ by treatment with $\mathrm{L}$-carnitine compared with placebo. Other case-based studies have indicated a benefit from L-carnitine on hypothyroid symptoms, but all of them have been case-based [45], while other studies may support benefits in the corticosteroid hormone setting [46].

\section{Inositol: Compound and Physiology}

Inositol is a water-soluble compound closely associated with the vitamin B group (also known as vitamin B8) [47]. Inositol is a carbohydrate which has a taste half as sweet as that of sucrose. Inositol has long been known for its metabolic effects in humans, where it plays a part in the synthesis of secondary messengers within cells. It is an essential component of the phospholipids that makes up cellular membranes and is found in virtually all cells. The most abundant form of the nutrient is myo-inositol. It assists in the transmission of nerve signals, helps to transport lipids within the body, and is also critical for the proper action of insulin and maintenance of cellular calcium balance. Foods containing the highest concentrations of myo-inositol include fruits, beans, grains and nuts. However, in grains, it is in a non-available form called phytate. The more bioavailable form of inositol comes from lecithin. Inositol is a necessary component of all cellular membranes. It is a member of the B-vitamin family that contributes to muscular and nerve function and participates in the metabolism of fats in the liver. Myo-inositol is the most abundant form of this nutrient, with its highest concentrations being found in the brain and central nervous system. Myo-inositol in particular is a versatile nutrient for the promotion of emotional and mental wellness, healthy eating patterns, and restful sleep through its critical role in neurotransmitter messaging systems. In addition, it is an important nutritional element for the maintenance of ovarian health and normal blood sugar maintenance, especially in women. 
Inositol is a non-essential member of the B-complex family with dietary sources from both animal and plant foods. The form of inositol used in this product is myo-inositol, the most abundant form of this nutrient. Inositol is found in all cell membranes, with the highest concentrations in the brain and central nervous system, where it plays an important role in neurotransmitter signaling. Inositol is also critical for the proper action of insulin, lipid metabolism, and for the maintenance of cellular calcium balance. Inositol is a necessary component of all cellular membranes. It is a member of the inositols are marketed as beneficial nutraceutics for improving mood and for the treatment of polycystic ovary syndrome [20]. A significant difference in the myo-inositol content of available products, and there are no regulations to ensure homogenous quality and accuracy [20].

\section{Inositol and Thyroid Function/Autoimmunity}

Inositols are essential for the signaling of hormones such as insulin, gonadotropins (follicle stimulating hormone $[\mathrm{FSH}]$ and luteinizing hormone [LH]), and TSH. In the thyroid, imbalances in the inositol metabolism can impair thyroidal hormone biosynthesis, storage and secretion [47]. TSH signaling is rather complex involving two different signal cascades. One branch of the signal cascade involves as second messenger cyclic AMP (cAMP), while another branch is inositol-dependent [48]. In a controlled trial, 48 women with autoimmune subclinical hypothyroidism were randomized to treatment with either selenomethionine alone or selenomethionine plus myo-inositol. The authors demonstrated that patients with autoimmune thyroiditis and subclinical hypothyroidism, treated with myo-inositol and selenomethionine, had a reduction of the increased TSH, which selenomethionine supplementation alone was not able to promote. However, the concentration of both thyroperoxidase and thyroglobulin autoantibodies (TPOAb and $\mathrm{TgAb}$ ) declined in both groups [48]. In a subsequent study of 86 patients with Hashimoto's thyroiditis and subclinical hypothyroidism, the same authors found that the administration of myo-inositol and selenomethionine for six months significantly decreased TSH, TPOAb, and TgAb concentrations, while at the same time enhancing thyroid hormones and personal wellbeing, thereby restoring euthyroidism in patients diagnosed with autoimmune thyroiditis [49]. This was confirmed in a larger study of 168 patients with Hashimoto's thyroiditis and subclinical hypothyroidism (TSH 3-6 mU/L) [50].

The mechanism of this effect might be through immune modulation rather than through thyroid function per se [51]. Using the afore-mentioned combined treatment in 22 patients with autoimmune thyroiditis, the initial TSH levels in the high normal range $(2.1<\mathrm{TSH}<4.0)$ significantly declined, suggesting that the combined treatment can reduce the risk of progression to hypothyroidism in subjects with autoimmune thyroid diseases. Antithyroid autoantibody levels also declined and, moreover, the suspected immune-modulatory effect was confirmed by the finding that the concentration of the chemokine CXCL10 also declined. Studies are, however, awaited to extend the observations in a larger population, to evaluate the effect on the quality of life, and to study the mechanism of the effect on chemokines.

Very recently, thyroid nodular disease also seemed to improve after the combined treatment with myo-inositol and selenomethionine [52], but this also needs confirmation. Final data in this study was analyzed from 34 patients with subclinical hypothyroidism: in 76\% of mixed thyroid nodules a significant reduction of their size was observed and $56 \%$ of them significantly regressed nodule stiffness following oral supplementation with the combined nutraceutics for six months. The mean number of mixed thyroid nodules shifted from $1.4 \pm 0.2$ to $1.1 \pm 0.2(p \leq 0.05)$ and the TSH concentrations dropped from $4.2 \pm 0.2 \mathrm{mIU} / \mathrm{L}$ at baseline to $2.1 \pm 0.2 \mathrm{mIU} / \mathrm{L}$ post-treatment $(p<0.001)$. In the control group, $38 \%$ of the thyroid nodules reduced their diameter but TSH concentrations significantly increased up to the threshold after six months (from $4.0 \pm 0.2 \mathrm{mIU} / \mathrm{L}$ to $4.3 \pm 0.2 \mathrm{mIU} / \mathrm{L}, p \leq 0.05$ ). However, further studies are required, both in vitro and in vivo, in order to investigate the mechanism of this effect on the one hand, and a possible clinical treatment use of myo-inositol plus selenomethionine for the general management of thyroid nodules on the other. 


\section{Melatonin: Compound and Physiology}

The isolation of melatonin was first reported in 1958 [53]. Since the demonstration that pineal melatonin synthesis reflects both daily and seasonal time, melatonin has become a key element of chronobiology research. In mammals, pineal melatonin is essential for transducing day-length information into seasonal physiological responses. Due to its lipophilic nature, melatonin is able to cross the placenta and is believed to regulate multiple aspects of perinatal physiology. The endogenous daily melatonin rhythm is also likely to play a role in the maintenance of synchrony between circadian clocks throughout the adult body. Pharmacological doses of melatonin are effective in resetting circadian rhythms if taken at an appropriate time of day and can acutely regulate factors such as body temperature and alertness, especially when taken during the day. Despite the extensive literature on melatonin physiology, several key questions remain unanswered. Particularly the amplitude of melatonin rhythms has recently been associated with diseases such as type 2 diabetes mellitus but the physiological significance of melatonin rhythm amplitude remains poorly understood.

As a nutraceutical, melatonin is easily available over the counter and is marketed to regulate the sleep pattern and adaptation to time zone differences among numerous other conditions.

\section{Melatonin and Thyroid Function}

Melatonin has antioxidant properties, which is one of the reasons why it is assumed to be beneficial for many disease conditions. However, very few human studies exist, and they are primarily of a physiological nature. One such study considers several endocrine and immune interactions in healthy persons at different ages [54] and found statistically significant time-qualified correlations among lymphocyte subset percentages and hormone serum levels in the young and middle aged and one could speculate that the phenomenon of lymphocyte subpopulation redistribution may be more complex, and may involve other hormones such as TRH, TSH, GH (growth hormone), IGF1 (insulin-like growth factor 1), monoamines such as melatonin, cytokines such as IL2 (Interleukin 2), and chemokines. The aging of immune system function may be related to the alteration of circadian rhythmicity, with a loss of interaction among key lymphocyte subsets, immunomodulating hormones, as well as cytokines/chemokines.

Thirty-six perimenopausal and 18 postmenopausal women between 42 and 62 years of age with no pathology or medication were selected for a randomized study of melatonin or placebo at bedtime (22:00-00:00). The melatonin concentration was measured in saliva to divide the participants into low, medium, and high-melatonin subjects [55]. Three- and six-months later, blood was taken for the determination of pituitary (LH and FSH), ovarian, and thyroid hormones (T3 and T4). The results showed that women low in melatonin after treatment with melatonin significantly increased thyroid hormones levels and improved gonadal functions [55]. These results were confirmed by the same authors in another study where peri- and menopausal women $(N=139)$ took a daily dose of $3 \mathrm{mg}$ synthetic melatonin or placebo for 6 months. Melatonin concentrations were determined from five daily saliva samples at fixed times while other hormone levels were determined from blood samples three times over the six-month period [56]. The conclusion was that the six-months treatment with melatonin produced a remarkable and highly significant improvement of thyroid function, positive changes of gonadotropins towards more juvenile levels, and the abrogation of menopause-related depression.

In 40 menopausal women the combination of myo-inositol plus melatonin seemed to positively affect glucose metabolism. Myo-inositol alone seemed to improve thyroid function, while addition of melatonin increased the serum TSH concentration [57]. The reason for this is unknown, but all melatonin products warn against worsening of autoimmune diseases on basis of its potential effect on the immune system. Recently, SNPs related to melatonin receptor gene polymorphism haplotypes were associated with susceptibility to Graves' disease in an ethnic Chinese population and thus support the involvement of the melatonin pathway in the pathogenesis of this autoimmune thyroid disease [58].

In conclusion, there is to date no controlled trials to substantiate a use of melatonin for general thyroid health improvement. 


\section{Resveratrol: Compound and Physiology}

Resveratrol (3,4',5-trihydroxy-trans-stilbene) belongs to the flavonoids family and is a major natural polyphenolic compound found in several fruit and vegetables such as grapes, peanuts, and peanut sprouts. It seems to play an important role as a therapeutic and chemopreventive agent used in the treatment of various illnesses $[59,60]$ and has therefore recently gained much attention among health professionals as well as other nutrition experts. Resveratrol exhibits effects against several cancers $[61,62]$ through different pathways and, furthermore, it has antidiabetic, anti-inflammatory, and antioxidant effects. The cardiovascular protective capacities of resveratrol are believed to be associated with multiple molecular targets such as inflammation, oxidative stress, apoptosis, mitochondrial dysfunction, angiogenesis and platelet aggregation [59].

Similarly, resveratrol is a potent scavenger for free radicals. The high efficiency of resveratrol might be due to the three hydroxyl groups in its structure. Thus, the use of resveratrol as a health-promoting dietary supplement is rapidly increasing in today's market. Many reports have shown that resveratrol offers a wide range of preventive and therapeutic alternatives against various diseases including different types of cancer.

Resveratrol is a member of a family of enzymes, under the general name of stilbene synthase, which makes up part of a larger family of proteins with numerous functions. Notably, its chemical structure resembles that of $\mathrm{L}-\mathrm{T} 4$, however it is not clear if this has any functional implications [63]. Resveratrol synthase is developed from chalcone synthase via gene duplication and mutations. The absorption in humans is approximately $75 \%$ (delayed by food) by trans-epithelial diffusion, while tissue accumulation enhances efficacy at target sites.

\section{Resveratrol and Thyroid Function}

Resveratrol may arrest the proliferation of thyroid cancer cells by increasing the abundance and phosphorylation of p53 [64-66]. Moreover, resveratrol mediates the regulation of TSH while, due to its effects on iodine trapping, it shows promise as a prospective anti-thyroid drug. On the other hand, these effects also resulted in a pronounced proliferative action on thyrocytes and resveratrol may therefore be a thyroid disrupting compound [67]. No clinical studies on the compound's effect on the thyroid has been performed in humans, so all available evidence is based on animal and in vitro cellular studies.

Finally, resveratrol as an antioxidant agent is a free radical scavenger and this property can be of interest in thyroid disease states that are accompanied by increased production of hydrogen peroxide and radical oxygen species, such as autoimmune thyroiditis and hyperthyroidism [68]. Proper randomized clinical trials would, however, be required before implementing any use.

Resveratrol supplements can be easily purchased over the counter but they are not regulated by the FDA or any other health authority. Most resveratrol capsules sold in the U.S. contain extracts from an Asian plant called Polygonum cuspidatum. Other resveratrol supplements are made from red wine or red grape extracts. The dosages in most resveratrol supplements typically contain 250 to 500 milligrams, which is much lower than the amounts that have been shown beneficial in research (2000 milligrams of resveratrol or more a day).

\section{Selenium: Compound and Physiology}

Selenium is a non-metal chemical element that is an essential micronutrient. Selenium salts are toxic in large amounts, but trace amounts are necessary for cellular function in many organisms, including all animals. Dietary selenium comes from nuts, cereals, and mushrooms. Brazil nuts are the richest dietary source (though this is soil-dependent since the Brazil nut does not require high levels of the element for its own needs). Selenium is an ingredient in many multivitamins and other dietary supplements. It is a component of the antioxidant enzymes glutathione peroxidase and thioredoxin reductase, which indirectly reduce certain oxidized molecules in animals and some plants. It is also 
found in three deiodinase enzymes, which convert one thyroid hormone to another. In living systems, selenium is found in the amino acids selenomethionine, selenocysteine, and methylselenocysteine.

The U.S. recommended dietary allowance (RDA) for teenagers and adults is $55 \mu \mathrm{g} /$ day. Selenium as a dietary supplement is available in many forms, including multi-vitamins/mineral supplements, which typically contain 55 or $70 \mu \mathrm{g} / \mathrm{serving}$. Selenium-specific supplements typically contain either 100 or $200 \mu \mathrm{g} / \mathrm{serving}$. In June 2015, the U.S. FDA published its final rule establishing the requirement of minimum and maximum levels of selenium in infant formula. The reference values of EFSA for selenium range from $15 \mu \mathrm{g} /$ day for children aged one to three years to $70 \mu \mathrm{g} /$ day for adolescents aged 15-17 years [69]. The selenium content in the human body is believed to be in the range of 13-20 milligram [70].

Selenium food supplements are most efficient as yeast-based selenomethionine, but the contents are not standardized or under any control. For instance, six different brands of yeast-based selenium food supplements were analysed for the expected selenomethionine content [23]. Only two brands had high levels of selenomethionine; one brand appeared to contain only inorganic selenium, and one brand appeared to contain more than half inorganic selenium despite label claims of content being only selenomethionine. Nevertheless, selenium supplementation is increasingly prescribed by endocrinologists as recently documented for Italian endocrinologists [70]. In detail, approximately one in four respondents use selenium often/always, with only one in either use never. Rates were approximately one-fourth of respondents prescribing selenium often/always in Hashimoto's thyroiditis, and one-fifth prescribing selenium in the case presented. In patients with autoimmune thyroiditis (AIT) who are planning pregnancy or are already pregnant, approximately $40 \%$ of respondents suggest selenium use [71]. It is worth underlining that the American Thyroid Association (ATA) pregnancy guideline reported that "selenium supplementation is not recommended for the treatment of TPOAb-positive women during pregnancy" [72].

\section{Selenium and Thyroid Function/Autoimmunity}

Among all tissues, the thyroid gland has the highest concentration of selenium, of which much is stored in the thyrocytes as the selenoproteins [73,74]: deiodinases (DI1, DI2), glutathion peroxidase (GPx1, GPx3, GPx4), and thioredoxin reductases (TR1, TR2). Both the thyroid gland and all other cells that are dependent of thyroid hormone for proper function use selenium as a cofactor for three of the four known types of thyroid hormone deiodinases, which can both activate and deactivate thyroid hormones and their metabolites-the iodothyronine deiodinases are the subfamily of deiodinase enzymes that use selenium, as does the otherwise rare amino acid selenocysteine. Only iodotyrosine deiodinase does not use selenium.

Adequate selenium intake is required for normal function of thyrocytes and the angiofollicular units in thyroid hormone biosynthesis and storage. Inadequate selenium intake has been associated with increased thyroid volume in females, but not males in one study [75], and in a larger Danish population, this negative correlation between selenium status and thyroid volume was confirmed, and there was, furthermore, a trend toward increased numbers of thyroid nodules with inadequate selenium status [74,76]. Adequate selenium intake, with respect to proper thyroid function, can be monitored by the analysis of serum or plasma selenoproteins such as selenoprotein P or plasma GPx3 $[74,77,78]$. Intoxication has been reported in several places in China from dietary intake and soil contamination $[79,80]$. Measurement of these variables is becoming more important in the view of the increased interest in selenium supplementation in various patient groups particularly with autoimmune thyroid diseases (see below) and since there is a risk of overdosing by general too high doses on the one hand and supplementation of selenium sufficient individuals on the other. The U-shaped curve of beneficial effects from selenium concentrations, i.e., exhibiting major advantages in selenium-deficient individuals but specific health risks in those with selenium excess should be seriously considered [81]. 
Selenium status has been shown to affect immune functions, e.g., $\mathrm{T}$ cell differentiation, and selenium deficiency has been associated with Th2 cells/markers, while higher selenium concentrations seem to favor an increased Th1 and Treg response [82]. These observations are thus in keeping with the suggestion of beneficial effects of selenium supplementation in autoimmune diseases of the thyroid $[73,83]$. Newly diagnosed autoimmune hyperthyroidism, Graves' disease, has been associated with low selenium concentrations [84], an observation which has fuelled several interventional treatment studies of selenium supplementation as adjunctive to antithyroid drugs in Graves' disease [85-88]. A very recent systematic review and meta-analysis of 10 randomized clinical trials could not substantiate a systematic effect of selenium supplementation as an adjunctive treatment in Graves' disease [89]. Generally, the studies were all underpowered, of too short a duration, and with too broad clinical characteristics of the patients, and the issue is therefore yet to be resolved-results from larger ongoing prospective studies are awaited [90].

Concerning the subpopulations of Graves' disease, however, a prospective case-control study demonstrated lower serum selenium concentrations in patients with Graves' orbitopathy compared to Graves' patients without orbitopathy in an Australian study population with marginal selenium status [91]. Against this background, relative selenium deficiency may be an independent risk factor for orbitopathy in patients with Graves' diseases. This has been further substantiated by one major multicentric prospective, placebo and serum-controlled study of Graves' patients with orbitopathy, with demonstration of improved quality of life and disease activity scores [92].

Several placebo-controlled and double-blind studies, both observational and prospective, have been performed to demonstrate the improved quality of life, wellbeing, thyroid hormone status, and disease symptoms of chronic autoimmune thyroiditis of the Hashimoto type with or without hypothyroidism. Although many studies have consistently demonstrated a reduction in thyroid autoantibody concentrations by selenium supplementation, including some compared with control/placebo [93-96], recent meta-analyses found insufficient evidence for the clinical efficacy of selenium supplementation in chronic autoimmune thyroiditis [97,98]. Hopefully, future trials can ultimately provide reliable evidence to help inform clinical decision making. Results were less optimistic than the individual study results, many of which were, however, underpowered, and therefore, in this autoimmune patient group, results are unclear and further ongoing study results are awaited [99].

In women at risk of postpartum thyroiditis, adequate selenium status prevents its development. In a prospective placebo-controlled double-blind prevention study [100], there were fewer cases of postpartum thyroiditis-these results, however, have not been confirmed in other studies [73,101].

Finally, there has been no indication of an increased risk of thyroid cancer in either selenium deficiency or with supplementation of selenium [74].

In conclusion, selenium status has a high impact on normal thyroid development and function, and it is still a potential candidate for improvement of clinical markers and quality of life in some situations of autoimmune thyroid diseases by supplementation, e.g., Graves' orbitopathy and possibly postpartum thyroiditis. However, more solid evidence is awaited until firm conclusions can be made concerning recommendations for global routine clinical use.

\section{Perspective and Conclusions}

As clinicians, we often see patients who are taking all sorts of supplements with the hope of improving their health and medical conditions, as well as simply feeling better.

Thyroid supplements attract a disproportionately large amount of attention, just as the thyroid gland gets "blamed" for multiple symptoms. There are truths and myths that this review had tried to clarify. Of the numerous nutraceuticals out there for thyroid disease management, we focused on the common or popular ones we encounter in the clinical practice.

Clinicians should acknowledge that over $30 \%$ of our patients are using supplements and thus should inquire about them during our office encounters. Apart from improving their general health, 
patients are using these alleged thyroid supplements to help "improve their metabolism, have more energy, and to lose weight".

It is important that we do not just dismiss these patients, but rather have honest discussions about the claimed benefits and potential risks. Physicians would do well to familiarize themselves with the main supplements being used, and also to know the scientific evidence available to support or refute these claims. More importantly, physicians should understand the potential risks or side effects in order to properly counsel patients about their use.

Based on the literature reviewed in the preceding sections, the evidence for the clinical use and potential benefit of the nutraceuticals addressed in this paper is summarized in Table 4. It is, however, worth noting that very few studies have been randomized clinical trials and generally all the studies have lacked proper power and even attempts to perform power calculations including the few randomized clinical trials. For selenium, two randomized, properly powered, placebo controlled clinical trials are ongoing and results are awaited $[89,98]$. Similar studies are required also for the most relevant nutraceuticals with a possible influence on the thyroid, in order to provide proper guidance both to patients and clinicians.

Table 4. Summary of evidence for clinical use of the nutraceuticals reviewed here in the thyroid setting *.

Question: Is There
Evidence for

Clinical Use of ....?

Currently available evidence supports the usefulness of L-carnitine in hyperthyroid patients. Carnitine ameliorates a number of symptoms and signs, including cardiac arrhythmia. Case reports have shown benefits even in the setting of thyroid storm.

Carnitine However, no changes in thyroid function tests were reported. One practical setting for the use of L-carnitine (two grams per day) is the control of hyperthyroidism symptomatology when the patients need to take low doses of antithyroid drugs. Only one Korean study is currently available for hypothyroidism, thus precluding conclusions.

Only in one study, MI alone ( $2 \mathrm{~g}$ twice a day) or MI plus melatonin ( $2 \mathrm{~g} / \mathrm{d}$ MI plus $3 \mathrm{~g} / \mathrm{d}$ melatonin) were given in two groups of euthyroid postmenopausal women, and serum FT4 and TSH evaluated. MI alone caused an almost 3.5\% increase in serum FT4 and a $10 \%$ decrease in serum TSH. This contrasted with the opposite changes $(3.5 \%$ decrease in serum FT4 and almost 10\% increase in serum TSH) observed in the group under MI

Inositols plus melatonin.

Few studies have been conducted only in one Western country (Italy), and with the combination of MI plus selenium or MI plus carnitine. Supplementation with the first combination has been used in the setting of patients with Hashimoto's thyroiditis related SCHypo, and it decreased both serum thyroid autoantibodies and TSH. The combination of MI plus carnitine was only investigated in one study of patients with SCHyper, thus precluding conclusions.

SCHyper, thus precluding conclusions.

There has been interest in melatonin and autoimmunity and the thyroid gland has been implicated in the discussion. It is thought that melatonin may have a paracrine role

Melatonin and in thyroid disease under a condition of oxidative stress may reduce the processes involved in thyroid antoimmunity. However, there are no controlled trials or definite data to show conclusively that melatonin can be beneficial in thyroid disease.

\begin{tabular}{ll}
\hline Resveratrol & No answer can be given, simply for lack of studies. \\
\hline & $\begin{array}{l}\text { Benefits have been demonstrated for mild forms of Graves' ophthalmopathy. Benefits } \\
\text { for the clinical course of GD itself are controversial. In the setting of HT, a benefit has } \\
\text { been shown more on serum thyroid autoantibodies than on thyroid function. There is } \\
\text { only one study on the benefit given by selenium supplementation, both in terms of } \\
\text { serum thyroid autoantibodies and thyroid dysfunction, in the setting of PPT. For the } \\
\text { combinations of selenium with MI see above. }\end{array}$ \\
\hline
\end{tabular}

Abbreviations, in alphabetical order: GD = Graves' disease; HT = Hashimotos' thyroiditis; MI = myo-inositol; $\mathrm{PPT}=$ postpartum thyroiditis. SCHyper = subclinical hyperthyroidism; SCHypo = subclinical hypothyroidism 
Author Contributions: S.B., U.F.-R. and E.A. conceptualized, searched literature and wrote the first versions of the manuscript. D.B. took care of the final update, revision and editing.

Funding: This work received no external funding.

Acknowledgments: UF-R's research salary is sponsored by an unrestricted research grant from the NovoNordisk Foundation. This paper received no administrative or technical support.

Conflicts of Interest: The authors declare no conflict of interest.

\section{Appendix A}

Table A1. Information on the dietary supplements provided by the Food and Drug Administration *.

\begin{tabular}{|c|c|}
\hline Questions & Answers \\
\hline $\begin{array}{l}\text { What is a dietary } \\
\text { supplement? } \S\end{array}$ & $\begin{array}{l}\text { Congress defined the term "dietary supplement" in the Dietary Supplement Health and } \\
\text { Education Act (DSHEA) of 1994. A dietary supplement is a product taken by mouth that } \\
\text { contains a "dietary ingredient" intended to supplement the diet. The "dietary ingredients" } \\
\text { in these products may include vitamins, minerals, herbs or other botanicals, amino acids, } \\
\text { and substances such as enzymes, organ tissues, glandulars, and metabolites. Dietary } \\
\text { supplements can also be extracts or concentrates and may be found in many forms such as } \\
\text { tablets, capsules, softgels, gelcaps, liquids, or powders. They can also be in other forms, } \\
\text { such as a bar, but if they are, information on their label must not represent the product as a } \\
\text { conventional food or a sole item of a meal or diet. Whatever their form may be, DSHEA } \\
\text { places dietary supplements in a special category under the general umbrella of "foods", } \\
\text { not drugs, and requires that every supplement be labeled a dietary supplement. }\end{array}$ \\
\hline $\begin{array}{l}\text { What is a "new dietary } \\
\text { ingredient" in a dietary } \\
\text { supplement? } \S\end{array}$ & $\begin{array}{l}\text { The Dietary Supplement Health and Education Act (DSHEA) of } 1994 \text { defined both of the } \\
\text { terms "dietary ingredient" and "new dietary ingredient" as components of dietary } \\
\text { supplements. In order for an ingredient of a dietary supplement to be a "dietary } \\
\text { ingredient," it must be one or any combination of the following substances: } \\
\text { a vitamin, } \\
\text { a mineral, } \\
\text { an herb or other botanical, } \\
\text { an amino acid, } \\
\text { a dietary substance for use by man to supplement the diet by increasing the total dietary } \\
\text { intake (e.g., enzymes or tissues from organs or glands), or a concentrate, metabolite, } \\
\text { constituent or extract. } \\
\text { A "new dietary ingredient" is one that meets the above definition for a "dietary ingredient" } \\
\text { and was not sold in the U.S. in a dietary supplement before } 15 \text { October } 1994 \text {. }\end{array}$ \\
\hline $\begin{array}{l}\text { What are the benefits of } \\
\text { dietary supplements? }\end{array}$ & $\begin{array}{l}\text { Some supplements can help assure that you get enough of the vital substances the body } \\
\text { needs to function; others may help reduce the risk of disease. But supplements should not } \\
\text { replace complete meals which are necessary for a healthful diet-so, be sure you eat a } \\
\text { variety of foods as well. } \\
\text { Unlike drugs, supplements are not permitted to be marketed for the purpose of treating, } \\
\text { diagnosing, preventing, or curing diseases. That means supplements should not make } \\
\text { disease claims, such as "lowers high cholesterol" or "treats heart disease." Claims like } \\
\text { these cannot be legitimately made for dietary supplements. }\end{array}$ \\
\hline $\begin{array}{l}\text { Are there any risks in } \\
\text { taking supplements? }\end{array}$ & $\begin{array}{l}\text { Yes. Many supplements contain active ingredients that have strong biological effects in the } \\
\text { body. This could make them unsafe in some situations and hurt or complicate your health. } \\
\text { For example, the following actions could lead to harmful-even } \\
\text { life-threatening-consequences. } \\
\text { Combining supplements } \\
\text { Using supplements with medicines (whether prescription or over the counter) } \\
\text { Substituting supplements for prescription medicines } \\
\text { Taking too much of some supplements, such as vitamin A, vitamin D, or iron } \\
\text { Some supplements can also have unwanted effects before, during, and after surgery. So, be } \\
\text { sure to inform your healthcare provider, including your pharmacist about any } \\
\text { supplements you are taking. }\end{array}$ \\
\hline
\end{tabular}


Table A1. Cont.

\begin{tabular}{|c|c|}
\hline Questions & Answers \\
\hline $\begin{array}{c}\text { Some Common Dietary } \\
\text { Supplements }\end{array}$ & $\begin{array}{l}\text { Calcium } \\
\text { Echinacea } \\
\text { Fish Oil } \\
\text { Glucosamine and/or } \\
\text { Chondroitin Sulphate } \\
\text { Garlic } \\
\text { Vitamin D } \\
\text { St. John's Wort } \\
\text { Saw Palmetto } \\
\text { Ginkgo } \\
\text { Green Tea } \\
\text { Note: These examples do not represent either an endorsement or approval by FDA. }\end{array}$ \\
\hline $\begin{array}{c}\text { How can I find out } \\
\text { more about the dietary } \\
\text { supplement I'm taking? }\end{array}$ & $\begin{array}{l}\text { Dietary supplement labels must include name and location information for the } \\
\text { manufacturer or distributor. } \\
\text { If you want to know more about the product that you are taking, check with the } \\
\text { manufacturer or distributor about: } \\
\text { Information to support the claims of the product. } \\
\text { Information on the safety and effectiveness of the ingredients in the product. }\end{array}$ \\
\hline $\begin{array}{c}\text { Report Problems to } \\
\text { FDA }\end{array}$ & $\begin{array}{l}\text { Notify the FDA if the use of a dietary supplement caused you or a family member to have } \\
\text { a serious reaction or illness (even if you are not certain that the product was the cause, or } \\
\text { you did not visit a doctor or clinic). } \\
\text { Follow these steps: } \\
\text { - Stop using the product. } \\
\text { - Contact your healthcare provider to find out how to take care of the problem. } \\
\text { - } \quad \text { Report problems to FDA in either of these ways: } \\
\text { - Contact the Consumer Complaint Coordinator in your area. } \\
\text { - File a safety report online through the Safety Reporting Portal. }\end{array}$ \\
\hline
\end{tabular}
$\S$ Source is [7]. * Source is [8].

\section{References}

1. Merriam-Webster Dictionary. Available online: https://www.merriam-webster.com/dictionary/nutraceutical (accessed on 3 September 2019).

2. Cambridge Dictionary. Available online: http://dictionary.cambridge.org/dictionary/english/nutraceutical (accessed on 3 September 2019).

3. Bull, E.; Rapport, L.; Lockwood, B. What is a nutraceutical? Pharm. J. 2000, 265, 57-58. Available online: https://www.pharmaceutical-journal.com/download?ac=1064856 (accessed on 3 September 2019).

4. Kalra, E.K. Nutraceutical-definition and introduction. AAPS Pharm. Sci. 2003, 5, E25. [CrossRef] [PubMed]

5. Available online: https://www.eu-japan.eu/sites/default/files/publications/docs/2016-03-nutraceuticals-japanmin.pdf (accessed on 3 September 2019).

6. European Parliament. Regulation EU 2015/2283 of the European Parliament and of the Council of 25 November 2015 on novel foods, amending Regulation (EU) No 1169/2011 of the European Parliament and of the Council and repealing Regulation (EC) No 258/97 of the European Parliament and of the Council and Commission Regulation (EC) No 1852/2001. Available online: https://eur-lex.europa.eu/legal-content/en/ TXT/?uri=CELEX\%3A32015R2283 (accessed on 3 September 2019).

7. DSHEA 1994. United States Food and Drug Administration (FDA). Dietary Supplement Health and Education Act (DSHEA). U.S. Department of Health and Human Services. United States. Public Law 103-417. Available online: https://ods.od.nih.gov/About/DSHEA_Wording.aspx (accessed on 3 September 2019).

8. Dietary Supplements: What You Need to Know. Available online: https://www.fda.gov/Food/ DietarySupplements/UsingDietarySupplements/ucm109760.htm (accessed on 3 September 2019).

9. Questions and Answers on Dietary Supplements. Available online: https://www.fda.gov/Food/ DietarySupplements/UsingDietarySupplements/ucm480069.htm\#what_is (accessed on 3 September 2019).

10. Wootan, G.D.; Brittain, P.M. Detox Diets for Dummies; Wiley Publishing, Inc.: Hoboken, NJ, USA, $2010 ;$ p. 88.

11. Available online: https://en.wikipedia.org/wiki/Dietary_supplement (accessed on 3 September 2019). 
12. Daniells, S. L-carnitin market to hit \$ 130 million by 2017, predicts report. 2011. Available online: https://www.nutraingredients-usa.com/Article/2011/04/22/L-carnitine-market-to-hit-130-millionby-2017-predicts-report (accessed on 3 September 2019).

13. Inositol Market Worth 140 Million USD Industry Making 6.8\% of CAGR by 2024. Inositol Market Report. 2019. Available online: https://pmrpressrelease.com/inositol-market-worth-140-million-usd-industry-making-6-8of-cagr-by-2024/ (accessed on 3 September 2019).

14. Global Melatonin Market Growth 2019-2024. 2019. Available online: https://www.lpinformationdata.com/ reports/154866/global-melatonin-market (accessed on 3 September 2019).

15. Yoshino, J.; Conte, C.; Fontana, L.; Mittendorfer, B.; Imai, S.; Schechtman, K.B.; Gu, C.; Kunz, I.; Rossi Fanelli, F.; Patterson, B.W.; et al. Resveratrol supplementation does not improve metabolic function in nonobese women with normal glucose tolerance. Cell Metab. 2012, 16, 658-664. [CrossRef] [PubMed]

16. National Business Journal Reports: \$87 Million U.S. Selenium Sales by Channel in 2017. Supplement Business Report 2018 Informa. Available online: https://www.nutritionbusinessjournal.com/reports/2018nbj-supplement-business-report/ (accessed on 3 September 2019).

17. Lockwood, G.B. The quality of commercially available nutraceutical supplements and food sources. J. Pharm. Pharmacol. 2011, 63, 3-10. [CrossRef] [PubMed]

18. Kang, G.Y.; Parks, J.R.; Fileta, B.; Chang, A.; Abdel-Rahim, M.M.; Burch, H.B.; Bernet, V.J. Thyroxine and triiodothyronine content in commercially available thyroid health supplements. Thyroid 2013, 23, 1233-1237. [CrossRef] [PubMed]

19. Millington, D.S.; Dubag, G. Dietary supplement L-carnitine: Analysis of different brands to determine bioavailability and content. Clin. Res. Reg. Affairs 1993, 10, 71-80.

20. Papaleo, V.; Molgora, M.; Quaranta, L.; Pellegrino, M.; De Michele, F. Myo-inositol products in polycystic ovary syndrome (PCOS) treatment: Quality, labeling accuracy, and cost comparison. Eur. Rev. Med. Pharmacol. Sci. 2011, 15, 165-174. [PubMed]

21. Cerezo, A.B.; Leal, A.; Alvarez-Fernandez, M.A.; Hornedo-Ortega, R.; Troncoso, A.M.; Garcia-Parrilla, M.C. Quality control and determination of melatonin in food supplements. J. Food Compos. Anal. 2016, 45, 80-86. [CrossRef]

22. Erland, L.A.; Sazena, P.K. Melatonin Natural Health Products and Supplements: Presence of Serotonin and Significant Variability of Melatonin Content. J. Clin. Sleep. Med. 2017, 13, 275-281. [CrossRef]

23. Rossi, D.; Guerrini, A.; Bruni, R.; Brognara, E.; Borgatti, M.; Gambari, R.; Maietti, S.; Sacchetti, G. trans-Resveratrol in nutraceuticals: Issues in retail quality and effectiveness. Molecules 2012, 17, 12393-12405. [CrossRef]

24. B'Hymer, C.; Caruso, J.A. Evaluation of yeast-based selenium food supplements using high-performance liquid chromatography and inductively coupled plasma mass spectrometry. J. Anal. At. Spectrom. 2000, 15, 1531-1539. [CrossRef]

25. Hoppel, C. The physiologic role of carnitine. In L-Carnitine and its Role in Medicine: From Function to Therapy; Ferrari, R., Di Mauro, S., Sherwood, G., Eds.; Academic Press: San Diego, CA, USA, 1990; pp. 5-19.

26. Wang, Z.Y.; Liu, Y.Y.; Liu, G.H.; Lu, H.B.; Mao, C.Y. L-Carnitine and heart disease. Life Sci. 2018, 194, 88-97. [CrossRef] [PubMed]

27. Benvenga, S. Effects of L-carnitine on thyroid hormone metabolism and on physical exercise tolerance. Horm. Metab. Res. 2005, 37, 566-571. [CrossRef] [PubMed]

28. Arenas, J.; Huertas, R.; Campos, Y.; Diaz, A.E.; Villalon, J.M.; Vilas, E. Effects of L-carnitine on the pyruvate dehydrogenase complex and carnitine palmitoyl transferase in muscle athletes. FEBS Lett. 1994, 341, 91-93. [CrossRef]

29. Arenas, J.; Ricoy, J.R.; Encinas, A.R.; Pola, P.; D’Iddio, S.; Zeviani, M.; Di Donato, S.; Corsi, M. Carnitine in muscle, serum and urine of non-professional athletes; effects of physical exercise, training, and L-carnitine administration. Muscle Nerve 1991, 14, 598-604. [CrossRef]

30. Brass, E.P.; Hiatt, W.R. The role of carnitine and carnitine supplementation during excercise in man and in individuals with special needs. J. Am. Coll. Nutr. 1998, 17, 207-215. [CrossRef]

31. Brass, E.P. Supplemental carnitine and exercise. Am. J. Clin. Nutr. 2000, 72, 618S-623S. [CrossRef]

32. Brass, E.P. Carnitine and sports medicine: Use or abuse? Ann. NY Acad. Sci. 2004, 1033, 67-78. [CrossRef]

33. Strack, E.; Wortz, G.; Rotzsch, W. Wirkungen von Carnitin bei Uberfunktion der Schildruse (Effects of Carnitine in cases of Thyroid Hyperfunction). Endocrinologie 1959, 38, 218-225. 
34. Gilgore, S.G.; De Felice, S.L. Evaluation of carnitine-An antagonist of thyroid hormone. J. N. Drugs 1966, 6, 349-350. [CrossRef]

35. De Felice, S.L.; Gilgore, S.G. The antagonistic effect of carnitine in hyperthyroidism. Preliminary report. J. N. Drugs 1966, 6, 351-353. [CrossRef]

36. Benvenga, S.; Lakshmanan, M.; Trimarchi, F. Carnitine is a naturally occurring inhibitor of thyroid hormone nuclear uptake. Thyroid 2000, 12, 1043-1050. [CrossRef] [PubMed]

37. Benvenga, S.; Ruggeri, R.M.; Russo, A.; Lapa, D.; Campenni, A.; Trimarchi, F. Usefulness of L-carnitine, a naturally occurring peripheral antagonist of thyroid hormone action, in iatrogenic hyperthyroidism: A randomized, double-blind, placebo-controlled clinical trial. J. Clin. Endocrinol. Metab. 2001, 86, 3579-3594. [CrossRef] [PubMed]

38. Benvenga, S.; Lapa, D.; Cannavò, S.; Trimarchi, F. Successive thyroid storms treated with L-carnitine and low doses of methimazole. Am. J. Med. 2003, 115, 417-418. [CrossRef]

39. Chee, R.; Agah, R.; Vita, R.; Benvenga, S. Severe hyperthyroidism treated with L-carnitine, propranolol, and finally with thyroidectomy in a seriously ill cancer patient. Hormones 2014, 13, 407-412. [PubMed]

40. Kimmoun, A.; Munagamage, G.; Dessalles, N.; Gerard, A.; Feillet, F.; Levy, B. Unexpected awakening from comatose thyroid storm after a single intravenous injection of L-carnitine. Intensive Care Med. 2011, 37, 1716-1717. [CrossRef] [PubMed]

41. Nordio, M. A novel treatment for subclinical hyperthyroidism: A pilot study on the beneficial effects of L-carnitine and selenium. Eur. Rev. Med. Pharmacol. Sci. 2017, 21, 2268-2273.

42. Maebashi, M.; Kawamura, N.; Sato, N.; Imamura, A.; Yoshinaga, K. Urinary excretion of carnitine in patients with hyperthyroidism and hypothyroidism: Augmentation by thyroid hormone. Metabolism 1977, 26, 351-356. [CrossRef]

43. Sinclair, C.; Gilchrist, J.M.; Hennessey, J.V.; Kandula, M. Muscle carnitine in hypo- and hyperthyroidism. Muscle Nerve 2005, 32, 357-359. [CrossRef]

44. An, J.H.; Kim, Y.J.; Kim, K.J.; Kim, S.H.; Kim, N.H.; Kim, H.Y.; Kim, N.H.; Choi, K.M.; Baik, S.H.; Choi, D.S.; et al. L-carnitine supplementation for the management of fatigue in patients with hypothyroidism on levothyroxine treatment: A randomized, double-blind, placebo-controlled trial. Endocr. J. 2016, 63, 885-895. [CrossRef]

45. Benvenga, S.; Sindoni, A. L-carnitine supplementation for the management of fatigue in patients with hypothyroidism on levothyroxine treatment. Endocr. J. 2016, 63, 937-938. [CrossRef] [PubMed]

46. Alesci, S.; De Martino, M.U.; Mirani, M.; Benvenga, S.; Trimarchi, F.; Kino, T.; Chrousos, G.P. L carnitine: A nutritional modulator of glucocorticoid receptor functions. FASEB J. 2003, 17, 1553-1555. [CrossRef] [PubMed]

47. Benvenga, S.; Antonelli, A. Inositol(s) in thyroid function, growth and autoimmunity. Rev. Endocr. Metab. Disord. 2016, 17, 471-484. [CrossRef] [PubMed]

48. Nordio, M.; Pajalich, R. Combined treatment with Myo-inositol and selenium ensures euthyroidism in subclinical hypothyroidism patients with autoimmune thyroiditis. J. Thyroid Res. 2013, 2013, 424163. [CrossRef] [PubMed]

49. Nordio, M.; Basciani, S. Treatment with Myo-Inositol and Selenium Ensures Euthyroidism in Patients with Autoimmune Thyroiditis. Int. J. Endocrinol. 2017. [CrossRef]

50. Nordio, M.; Basciani, S. Myo-inositol plus selenium supplementation restores euthyroid state in Hashimoto's patients with subclinical hypothyroidism. Eur. Rev. Med. Pharmacol. Sci. 2017, 21 (Suppl. 2), 51-59.

51. Ferrari, S.M.; Fallahi, P.; Di Bari, F.; Vita, R.; Benvenga, S.; Antonelli, A. Myo-inositol and selenium reduce the risk of developing overt hypothyroidism in patients with autoimmune thyroiditis. Eur. Rev. Med. Pharmacol. Sci. 2017, 21 (Suppl. 2), 36-42.

52. Nordio, M.; Basciani, S. Evaluation of thyroid nodule characteristics in subclinical hypothyroid patients under a myo-inositol plus selenium treatment. Eur. Rev. Med. Pharmacol. Sci. 2018, 22, 2153-2159.

53. Johnston, J.D. 60 Years of neuroendocrinology: Regulation of mammalian neuroendocrine physiology and rhythms by melatonin. J. Endocrinol. 2015, 226, T187-T198. [CrossRef]

54. Mazzoccoli, G.; De Cata, A.; Carughi, S.; Greco, A.; Inglese, M.; Perfetto, F.; Tarquini, R. A possible mechanism for altered immune response in the elderly. In Vivo 2010, 24, 471-487. 
55. Bellipanni, G.; Bianchi, P.; Pierpaoli, W.; Bulian, D.; Ilyia, E. Effects of melatonin in perimenopausal and menopausal women: A randomized and placebo controlled study. Exp. Gerontol. 2001, 36, 297-310. [CrossRef]

56. Bellipanni, G.; Di Marzo, F.; Blasi, F.; Di Marzo, A. Effects of melatonin in perimenopausal and menopausal women: Our personal experience. Ann. N. Y. Acad. Sci. 2005, 1057, 393-402. [CrossRef] [PubMed]

57. D'Anna, R.; Santamaria, A.; Giorgianni, G.; Vaiarelli, A.; Gullo, G.; Di Bari, F.; Benvenga, S. Myo-inositol and melatonin in the menopausal transition. Gynecol. Endocrinol. 2017, 33, 279-282. [CrossRef] [PubMed]

58. Lin, J.D.; Yang, S.F.; Wang, Y.H.; Fang, W.F.; Lin, Y.C.; Liou, B.C.; Lin, Y.F.; Tang, K.T.; Cheng, C.W. Association of melatonin receptor gene polymorphisms with Graves' disease. PLoS ONE 2017, 12, e0185529. [CrossRef]

59. Rauf, A.; Imran, M.; Suleria, H.A.R.; Ahmad, B.; Peters, D.G.; Mubarak, M.S. A comprehensive review of the health perspectives of resveratrol. Food Funct. 2017, 8, 4284-4305. [CrossRef] [PubMed]

60. Limmongkon, A.; Janhom, P.; Amthong, A.; Kawpanuk, M.; Nopprang, P.; Poohadsuan, J.; Somboon, T.; Saijeen, S.; Surangkul, D.; Metawee, S.; et al. Antioxidant activity, total phenolic, and resveratrol content in five cultivars of peanut sprouts. Asian Pac. J. Trop. Biomed. 2017, 7, 332-338. [CrossRef]

61. Rauf, A.; Imran, M.; Butt, M.S.; Nadeem, M.; Peters, D.G.; Mubarak, M.S. Resveratrol as an anti-cancer agent: A review. Crit. Rev. Food Sci. Nutr. 2016. [CrossRef]

62. Aggarwal, B.B.; Bhardwaj, A.; Aggarwal, R.S.; Seeram, N.P.; Shishodia, S.; Takada, Y. Role of resveratrol in prevention and therapy of cancer: Preclinical and clinical studies. Anticancer Res. 2004, 24, 2783-2840.

63. Duntas, L.H. Resveratrol and its impact on aging and thyroid function. J. Endocrinol. Investig. 2011, 34, 788-792.

64. Yu, X.M.; Jaskula-Sztul, R.; Ahmed, K.; Harrison, A.D.; Kunnimalaiyaan, M.; Chen, H. differentiation markers expression in anaplastic thyroid carcinoma via activation of Notch1 signaling and suppresses cell growth. Mol. Cancer Ther. 2013, 12, 1276-1287. [CrossRef]

65. Shih, A.; Davis, F.B.; Lin, H.Y.; Davis, P.J. Resveratrol induces apoptosis in thyroid cancer cell lines via a MAPK- and p53-dependent mechanism. J. Clin. Endocrinol. Metab. 2002, 87, 1223-1232. [CrossRef] [PubMed]

66. Truong, M.; Cook, M.R.; Pinchot, S.N.; Kunnimalaiyaan, M.; Chen, H. Resveratrol induces Notch2-mediated apoptosis and suppression of neuroendocrine markers in medullary thyroid cancer. Ann. Surg. Oncol. 2011, 18, 1506-1511. [CrossRef] [PubMed]

67. Giuliani, C.; Iezzi, M.; Ciolli, L.; Hysi, A.; Bucci, I.; Di Santo, S.; Rossi, C.; Zucchelli, M.; Napolitano, G. Resveratrol has anti-thyroid effects both in vitro and in vivo. Food Chem. Toxicol. 2017, 107, 237-247. [CrossRef] [PubMed]

68. Sebai, H.; Hovsepian, S.; Ristorcelli, E.; Aouani, E.; Lombardo, D.; Fayet, G. Resveratrol increases iodide trapping in the rat thyroid cell line FRTL-5. Thyroid 2010, 20, 195-203. [CrossRef] [PubMed]

69. Available online: https://efsa.onlinelibrary.wiley.com/doi/epdf/10.2903/j.efsa.2014.3846 (accessed on 3 September 2019).

70. GB Health Watch. Available online: https://www.gbhealthwatch.com/Nutrient-Selenium-Overview.php (accessed on 3 September 2019).

71. Negro, R.; Attanasio, R.; Grimaldi, F.; Marcocci, C.; Guglielmi, R.; Papini, E. A 2016 Italian Survey about the Clinical Use of Selenium in Thyroid Disease. Eur. Thyr. J. 2016, 5, 164-170. [CrossRef] [PubMed]

72. Alexander, E.K.; Pearce, E.N.; Brent, G.A.; Brown, R.S.; Chen, H.; Dosiou, C.; Grobman, W.A.; Laurberg, P.; Lazarus, J.H.; Mandel, S.J.; et al. 2017 Guidelines of the American Thyroid Association for the Diagnosis and Management of Thyroid Disease During Pregnancy and the Postpartum. Thyroid 2017, 27, 315-389. [CrossRef] [PubMed]

73. Drutel, A.; Archambeaud, F.; Caron, P. Selenium and the thyroid gland: More good news for clinicians. Clin. Endocrinol. (Oxf) 2013, 78, 155-164. [CrossRef] [PubMed]

74. Köhrle, J. Selenium and the thyroid. Curr. Opin. Endocrinol. Diabetes Obes. 2013, 20, 441-448. [CrossRef]

75. Derumeaux, H.; Valeix, P.; Castetbon, K.; Bensimon, M.; Boutron-Ruault, M.C.; Arnaud, J.; Hercberg, S. Association of selenium with thyroid volume and echostructure in 35- to 60-year-old French adults. Eur. J. Endocrinol. 2003, 148, 309-315. [CrossRef]

76. Rasmussen, L.B.; Schomburg, L.; Köhrle, J.; Pedersen, I.B.; Hollenbach, B.; Hög, A.; Ovesen, L.; Perrild, H.; Laurberg, P. Selenium status, thyroid volume, and multiple nodule formation in an area with mild iodine deficiency. Eur. J. Endocrinol. 2011, 164, 585-590. [CrossRef] 
77. Burk, R.F.; Hill, K.E. Selenoprotein P: An extracellular protein with unique physical characteristics and a role in selenium homeostasis. Ann. Rev. Nutr. 2005, 25, 215-235. [CrossRef] [PubMed]

78. Burk, R.F.; Norsworthy, B.K.; Hill, K.E.; Motley, A.K.; Byrne, D.W. Effects of chemical form of selenium on plasma biomarkers in a high-dose human supplementation trial. Cancer Epidemiol. Biomarkers Prev. 2006, 15, 804-810. [CrossRef] [PubMed]

79. Cui, Z.; Huang, J.; Peng, Q.; Yu, D.; Wang, S.; Liang, D. Risk assessment for human health in a seleniferous area, Shuang'an, China. Environ. Sci. Pollut. Res. Int. 2017, 24, 17701-17710. [CrossRef] [PubMed]

80. Dinh, Q.T.; Cui, Z.; Huang, J.; Tran, T.A.T.; Wang, D.; Yang, W.; Zhou, F.; Wang, M.; Yu, D.; Liang, D. Selenium distribution in the Chinese environment and its relationship with human health: A review. Environ. Int. 2018, 112, 294-309. [CrossRef] [PubMed]

81. Duntas, L.; Benvenga, S. Selenium: An element for life. Endocrine 2015, 48, 756-775. [CrossRef] [PubMed]

82. Huang, Z.; Rose, A.H.; Hoffmann, P.R. The role of selenium in inflammation and immunity: From molecular mechanisms to therapeutic opportunities. Antioxid. Redox Signal. 2012, 16, 705-743. [CrossRef] [PubMed]

83. Toulis, K.A.; Anastasilakis, A.D.; Tzellos, T.G.; Goulis, D.G.; Kouvelas, D. Selenium supplementation in the treatment of Hashimoto's thyroiditis: A systematic review and a metaanalysis. Thyroid 2010, 20, 1163-1173. [CrossRef]

84. Bülow Pedersen, I.; Knudsen, N.; Carlé, A.; Schomburg, L.; Köhrle, J.; Jørgensen, T.; Rasmussen, L.B.; Ovesen, L.; Laurberg, P. Serum selenium is low in newly diagnosed Graves' disease: A population-based study. Clin. Endocrinol. (Oxf) 2013, 79, 584-590. [CrossRef]

85. Leo, M.; Bartalena, L.; Rotondo Dottore, G.; Piantanida, E.; Premoli, P.; Ionni, I.; Di Cera, M.; Masiello, E.; Sassi, L.; Tanda, M.L. Effects of selenium on short-term control of hyperthyroidism due to Graves' disease treated with methimazole: Results of a randomized clinical trial. J. Endocrinol. Investig. 2017, 40, 281-287. [CrossRef]

86. Calissendorff, J.; Mikulski, E.; Larsen, E.H.; Möller, M. A Prospective Investigation of Graves' Disease and Selenium: Thyroid Hormones, Autoantibodies and Self-Rated Symptoms. Eur. Thyroid J. 2015, 4, 93-98. [CrossRef]

87. Wang, L.; Wang, B.; Chen, S.R.; Hou, X.; Wang, X.F.; Zhao, S.H.; Song, J.Q.; Wang, Y.G. Effect of Selenium Supplementation on Recurrent Hyperthyroidism Caused by Graves' Disease: A Prospective Pilot Study. Horm. Metab. Res. 2016, 48, 559-564. [CrossRef]

88. Kahaly, G.J.; Riedl, M.; König, J.; Diana, T.; Schomburg, L. Double-blind, placebo-controlled, randomized trial of selenium in graves hyperthyroidism. J. Clin. Endocrinol. Metab. 2017, 102, 4333-4341. [CrossRef] [PubMed]

89. Zheng, H.; Wei, J.; Wang, L.; Wang, Q.; Zhao, J.; Chen, S.; Wei, F. Effects of Selenium Supplementation on Graves' disease: A Systematic Review and Meta-Analysis. Evid. Based Complement. Alternat. Med. 2018, 2018, 3763565. [CrossRef] [PubMed]

90. Watt, T.; Cramon, P.; Bjorner, J.B.; Bonnema, S.J.; Feldt-Rasmussen, U.; Gluud, C.; Gram, J.; Hansen, J.L.; Hegedüs, L.; Knudsen, N. Selenium supplementation for patients with Graves' hyperthyroidism (the GRASS trial): Study protocol for a randomized controlled trial. Trials 2013, 14, 119. [CrossRef] [PubMed]

91. Khong, J.J.; Goldstein, R.F.; Sanders, K.M.; Schneider, H.; Pope, J.; Burdon, K.P.; Craig, J.E.; Ebeling, P.R. Serum selenium status in Graves' disease with and without orbitopathy: A case-control study. Clin. Endocrinol. (Oxf) 2014, 80, 905-910. [CrossRef] [PubMed]

92. Marcocci, C.; Kahaly, G.J.; Krassas, G.E.; Bartalena, L.; Prummel, M.; Stahl, M.; Altea, M.A.; Nardi, M.; Pitz, S.; Boboridis, K. European Group on Graves' Orbitopathy. Selenium and the course of mild Graves' orbitopathy. N. Engl. J. Med. 2011, 364, 1920-1931. [CrossRef] [PubMed]

93. Gärtner, R.; Gasnier, B.C.H.; Dietrich, J.W.; Krebs, B.; Angstwurm, M.W. Selenium supplementation in patients with autoimmune thyroiditis decreases thyroid peroxidase antibodies concentrations. J. Clin. Endocrinol. Metab. 2002, 87, 1687-1691. [CrossRef] [PubMed]

94. Duntas, L.H.; Mantzou, E.; Koutras, D.A. Effects of a six month treatment with selenomethionine in patients with autoimmune thyroiditis. Eur. J. Endocrinol. 2003, 148, 389-393. [CrossRef]

95. Turker, O.; Kumanlioglu, K.; Karapolat, I.; Dogan, I. Selenium treatment in autoimmune thyroiditis: 9-month follow-up with variable doses. J. Endocrinol. 2006, 190, 151-156. [CrossRef] 
96. Winther, K.H.; Bonnema, S.J.; Cold, F.; Debrabant, B.; Nybo, M.; Cold, S.; Hegedüs, L. Does selenium supplementation affect thyroid function? Results from a randomized, controlled, double-blinded trial in a Danish population. Eur. J. Endocrinol. 2015, 172, 657-667. [CrossRef]

97. Van Zuuren, E.J.; Albusta, A.Y.; Fedorowicz, Z.; Carter, B.; Pijl, H. Selenium supplementation for Hashimoto's thyroiditis. Cochrane Database Syst. Rev. 2013, 6, CD010223. [CrossRef] [PubMed]

98. Winther, K.H.; Wichman, J.E.; Bonnema, S.J.; Hegedüs, L. Insufficient documentation for clinical efficacy of selenium supplementation in chronic autoimmune thyroiditis, based on a systematic review and meta-analysis. Endocrine 2017, 55, 376-385. [CrossRef] [PubMed]

99. Winther, K.H.; Watt, T.; Bjørner, J.B.; Cramon, P.; Feldt-Rasmussen, U.; Gluud, C.; Gram, J.; Groenvold, M.; Hegedüs, L.; Knudsen, N. The chronic autoimmune thyroiditis quality of life selenium trial (CATALYST): Study protocol for a randomized controlled trial. Trials 2014, 15. [CrossRef] [PubMed]

100. Negro, R.; Greco, G.; Mangieri, T.; Pezzarossa, A.; Dazzi, D.; Hassan, H. The influence of selenium supplementation on postpartum thyroid status in pregnant women with thyroid peroxidase autoantibodies. J. Clin. Endocrinol. Metab. 2007, 92, 1263-1268. [CrossRef] [PubMed]

101. Mao, J.; Pop, V.J.; Bath, S.C.; Vader, H.L.; Redman, C.W.; Rayman, M.P. Effect of low-dose selenium on thyroid autoimmunity and thyroid function in UK pregnant women with mild-to-moderate iodine deficiency. Eur. J. Nutr. 2016, 55, 55-61. [CrossRef] [PubMed]

(C) 2019 by the authors. Licensee MDPI, Basel, Switzerland. This article is an open access article distributed under the terms and conditions of the Creative Commons Attribution (CC BY) license (http://creativecommons.org/licenses/by/4.0/). 

MDPI

St. Alban-Anlage 66

4052 Basel

Switzerland

Tel. +41 616837734

Fax +41 613028918

www.mdpi.com

Nutrients Editorial Office

E-mail: nutrients@mdpi.com

www.mdpi.com/journal/nutrients

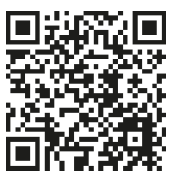



MDPI

St. Alban-Anlage 66

4052 Basel

Switzerland

Tel: +41 616837734

Fax: +41 613028918

www.mdpi.com 